Operações de consulta por similaridade em grandes bases de dados complexos 


\title{
Operações de consulta por similaridade em grandes bases de dados complexos
}

\author{
Maria Camila Nardini Barioni
}

Orientador: Prof. Dr. Caetano Traina Júnior

Tese apresentada ao Instituto de Ciências Matemáticas e de Computação - ICMC-USP, como parte dos requisitos para obtenção do título de Doutor em Ciências - Ciências de Computação e Matemática Computacional.

USP - São Carlos

Agosto de 2006 

Ao meu querido marido, Humberto. 



\section{Agradecimentos}

A meu orientador, Prof. Dr. Caetano Traina Júnior, agradeço o apoio, o incentivo e a confiança que dispensou durante a elaboração deste trabalho.

Ao Humberto, meu querido marido e companheiro de todos os momentos, agradeço pelo incentivo, pelo carinho, pela paciência e, principalmente, pela colaboração em vários trabalhos desenvolvidos durante a realização desta tese.

A minha mãe, Juliana, sempre dedicada e atenciosa, agradeço pelo incentivo, amor e carinho. Sem seu apoio fundamental eu não teria chegado até aqui.

Ao meu pai, Carlos Alberto, por ter me mostrado que é preciso lutar por aquilo que se almeja.

Aos meus queridos avós Idalina e Dito que, apesar de não entenderem muito bem o que se faz em um programa de doutorado, sempre me incentivaram a continuar "estudando".

Aos meus tios mineiros, Laura e Roberto, por vibrarem com cada uma de minhas conquistas.

Ao José Rubens, aos meus irmãos, Guilherme, Gabriel, Rebecca, Levy e Natan, ao meu querido afilhado, Ruan, e demais familiares, pela atenção e carinho.

Aos estimados amigos Thaty e Enzo pelo companheirismo e pelos bons momentos compartilhados.

Gostaria também de agradecer à Profa. Dra. Agma J. M. Traina, pela atenção e pelas sugestões críticas que muito contribuíram para o aprimoramento deste trabalho.

Aos colegas do Grupo de Bases de dados e Imagens, com os quais compartilhei todos esses anos.

Aos funcionários do ICMC, especialmente às secretárias da Seção de Pós-Graduação, Beth, Laura e Ana Paula, pelo apoio técnico e administrativo.

À CAPES, Coordenação de Aperfeiçoamento de Pessoal de Nível Superior, pelo apoio financeiro. 

Os Sistemas de Gerenciamento de Bases de Dados (SGBD) foram desenvolvidos para armazenar e recuperar de maneira eficiente dados formados apenas por números ou cadeias de caracteres. Entretanto, nas últimas décadas houve um aumento expressivo, não só da quantidade, mas da complexidade dos dados manipulados em bases de dados, dentre eles os de natureza multimídia (como imagens, áudio e vídeo), informações geo-referenciadas, séries temporais, entre outros. Assim, surgiu a necessidade do desenvolvimento de novas técnicas que permitam a manipulação eficiente de tipos de dados complexos. Para atender às buscas necessárias às aplicações de base de dados modernas é preciso que os SGBD ofereçam suporte para buscas por similaridade - consultas que realizam busca por objetos da base similares a um objeto de consulta, de acordo com uma certa medida de similaridade. Outro fator importante que veio contribuir para a necessidade de suportar a realização de consultas por similaridade em SGBD está relacionado à integração de técnicas de mineração de dados. É fundamental para essa integração o fornecimento de recursos pelos SGBD que permitam a realização de operações básicas para as diversas técnicas de mineração de dados existentes. Uma operação básica para várias dessas técnicas, tais como a técnica de detecção de agrupamentos de dados, é justamente o cálculo de medidas de similaridade entre pares de objetos de um conjunto de dados. Embora haja necessidade de fornecer suporte para a realização desse tipo de consultas em SGBD, o atual padrão da linguagem SQL não prevê a realização de consultas por similaridade. Esta tese pretende contribuir para o fornecimento desse suporte, incorporando ao SQL recursos capazes de permitir a realização de operações de consulta por similaridade sobre grandes bases de dados complexos de maneira totalmente integrada com os demais recursos da linguagem.

BARIONI, M. C. N. Operações de consulta por similaridade em grandes bases de dados complexos. São Carlos, 2006. 145 p. Tese de Doutorado - Instituto de Ciências Matemáticas e de Computação - ICMC, USP. 



\section{Abstract}

Database Management Systems (DBMS) were developed to store and efficiently retrieve only data composed by numbers and small strings. However, over the last decades, there was an expressive increase in the volume and complexity of the data being managed, such as multimedia data (images, audio tracks and video), geo-referenced information and time series. Thus, the need to develop new techniques that allow the efficient handling of complex data types also increased. In order to support these data and the corresponding applications, the DBMS needs to support similarity queries, i.e., queries that search for objects similar to a query object according to a similarity measure. The need to support similarity queries in DBMS is also related to the integration of data mining techniques, which requires the DBMS acting as the provider for resources that allow the execution of basic operations for several existing data mining techniques. A basic operation for several of these techniques, such as clustering detection, is again the computation of similarity measures among pairs of objects of a data set. Although there is a need to execute these kind of queries in DBMS, the SQL standard does not allow the specification of similarity queries. Hence, this thesis aims at contributing to support such queries, integrating to the SQL the resources capable to execute similarity query operations over large sets of complex data. 

1 Introdução 1

1.1 Motivação . . . . . . . . . . . . . . . . . . . . . . 1

1.2 Definição do Problema . . . . . . . . . . . . . . . . . . . 3

1.3 Objetivos do Trabalho . . . . . . . . . . . . . . . . . . . . . 4

1.4 Principais Contribuições . . . . . . . . . . . . . . . 5 5

1.5 Organização do Trabalho . . . . . . . . . . . . . . . . 5 5

2 Recuperação por Conteúdo $\quad 7$

2.1 Principais Conceitos . . . . . . . . . . . . . . . . . . . 8

2.1.1 Extração de Características . . . . . . . . . . . . . . . 9 9

2.1.2 Medidas de Similaridade . . . . . . . . . . . . . . 15

2.1 .3 Estruturas de Indexação . . . . . . . . . . . . . . . . . . 18

2.2 Linguagens e Sistemas para a Recuperação por Conteúdo . . . . . . . . . . 22

2.2 .1 Linguagens . . . . . . . . . . . . . . . . . . . 22

2.2 .2 Sistemas . . . . . . . . . . . . . . . . 23

2.3 Considerações Finais . . . . . . . . . . . . . . . . . . . 25

3 Descoberta de Conhecimento em Bases de Dados 27

3.1 Processo de Descoberta de Conhecimento em Bases de Dados . . . . . . . . 28

3.2 Tarefas de Mineração de Dados . . . . . . . . . . . . . . . . . . . . 30 
3.3 A Integração de Algoritmos de Mineração de Dados com SGBDR . . . . . 31

3.3.1 Principais Componentes dos Algoritmos de Mineração de Dados . . 33

3.4 Detecção de Agrupamentos de Dados . . . . . . . . . . . . . . . . . . . 34

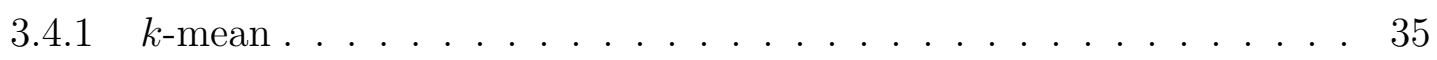

$3.4 .2 k$-medoid . . . . . . . . . . . . . . . . . 37

3.4.3 Estratégias de Otimização . . . . . . . . . . . . . . . . . . . . . . 42

3.5 Considerações Finais . . . . . . . . . . . . . . . . . . . . . . . . 43

4 Operações de Consulta por Similaridade em SGBDR 45

4.1 Conceitos Fundamentais . . . . . . . . . . . . . . . . . . . . 46

4.2 Extensão da Linguagem SQL . . . . . . . . . . . . . . . . . . . . . . . 52

4.2.1 Extensão dos Comandos da DDL . . . . . . . . . . . . . 53

4.2 .2 Extensão dos Comandos da DML . . . . . . . . . . . . . . . . . . 58

4.2.3 Extensão de Comandos SQL para a Especificação de Operações de Detecção de Agrupamentos de Dados . . . . . . . . . . . . . . . . . 63

4.2.4 Outras Construções para a Recuperação dos Valores de Atributos das Métricas . . . . . . . . . . . . . . . . . . . . . . . . . . . . . . 68

4.2.5 Precedência dos Operadores por Similaridade . . . . . . . . . . 69

4.3 Considerações Finais . . . . . . . . . . . . . . . . . . . . . . . . . 72

5 SIREN - Um Mecanismo para Consultas por Similaridade $\quad 73$

5.1 Arquitetura do SIREN . . . . . . . . . . . . . . . . . 73

5.1 .1 Interpretação dos Comandos . . . . . . . . . . . . . . . . 74

5.1 .2 Outros Aspectos Relacionados à Implementação . . . . . . . . . . . 76

5.1.3 Processamento de Consultas por Similaridade . . . . . . . . . . . . 77

5.2 Exemplos de Utilização . . . . . . . . . . . . . . . . . . . . . . . . . . . . . 79

5.3 Considerações Finais . . . . . . . . . . . . . . . . . . . . . . . . 88

6 Algoritmos Desenvolvidos $\quad 89$

6.1 Operações por Similaridade de Grupo . . . . . . . . . . . . . . . . . . . . . 90

6.2 Operações de Junção por Similaridade . . . . . . . . . . . . . . . . . . 93

6.3 Operações de Detecção de Agrupamentos . . . . . . . . . . . . . . . . . 95

6.3.1 Abordagem do Problema . . . . . . . . . . . . . . . . . . 96

6.3 .2 Descrição do Algoritmo . . . . . . . . . . . . . . . . . . . . 96

6.3 .3 Experimentos . . . . . . . . . . . . . . . . . . 98

6.4 Considerações Finais . . . . . . . . . . . . . . . . . . 106

$\begin{array}{lll}7 \text { Conclusão } & 109\end{array}$

7.1 Considerações Finais . . . . . . . . . . . . . . . . . . . . . 109

7.2 Principais Contribuições . . . . . . . . . . . . . . . . . . . . 110 
7.3 Propostas para Trabalhos Futuros . . . . . . . . . . . . . . . 112

$\begin{array}{ll}\text { A Extensão da Linguagem SQL } & 115\end{array}$

A.1 O Comando CREATE METRIC . . . . . . . . . . . . . . . . . 115

A.1.1 Especificando Métricas como Restrições de Coluna no Comando CREATE TABLE . . . . . . . . . . . . . . . . . . 116

A.1.2 Especificando Métricas como Restrições de Tabela no Comando CREATE TABLE . . . . . . . . . . . . . . . . 117

A.2 CREATE INDEX para Dados Complexos . . . . . . . . . . . . 118

A.3 Especificando Consultas por Similaridade no Comando SELECT . . . . . . . 119

A.3.1 Predicados por Similaridade na Cláusula WHERE . . . . . . . . . . . 119

A.3.2 Junções por Similaridade na Cláusula FROM . . . . . . . . . . . . . . 121

A.4 Especificando Operações de Detecção de Agrupamentos de Dados em SQL 122

A.5 Outras Construções . . . . . . . . . . . . . . . . . . . . . . . . . 123

B Conjuntos de Dados $\quad 125$

B.1 CidadeBR . . . . . . . . . . . . . . . . . . . . . 125

B.2 Autos . . . . . . . . . . . . . . . . . 125

B.3 Exame . . . . . . . . . . . . . . . . . . . 126

B.4 BRPolitico e OrientacaoPartido . . . . . . . . . . . . . . . . 126

B.5 Musica . . . . . . . . . . . . . . . . . . . 127

C Dicionário de Dados do SIREN $\quad 129$

C.1 Diagrama Entidade-Relacionamento . . . . . . . . . . . . . . . . . . 129

C.2 Modelo Relacional . . . . . . . . . . . . . . . . . . . . . 131

Referências Bibliográficas $\quad 135$ 



\section{Lista de Figuras}

2.1 Ilustração do fluxo de dados pelos módulos de um sistema de recuperação de imagens por conteúdo. Adaptada de [Smeulders et al., 2000]. . . . . . . 9

2.2 Exemplo de um histograma de cor de uma imagem quantizada em 256 níveis de cinza. . . . . . . . . . . . . . . . . . . . . 11

2.3 Exemplos de textura. . . . . . . . . . . . . . . . . . 12

2.4 Exemplos de consultas por similaridade em um conjunto de objetos. (a) Consulta por abrangência, considerando as funções de distância $L_{1}, L_{2}$ e $L_{\infty}$. (b) Consulta aos $k$-vizinhos mais próximos considerando $k=4$, para a distância euclidiana. . . . . . . . . . . . . . . . . . . 17

2.5 Diferenças entre os três operadores de junção por similaridade. (a) Junção por Abrangência. (b) Junção pelos $k$-Vizinhos mais Próximos considerando $k=2$. (c) Junção dos $k$ Pares de Vizinhos mais Próximos considerando $k$ $=3$.

2.6 A representação de uma Slim-tree com 15 objetos (a) e sua estrutura lógica (b). Os objetos estão organizados em três níveis e a capacidade máxima dos nós é igual a $3 . \ldots \ldots$. . . . . . . . . . . . . . . . . .

3.1 Uma visão geral dos passos que compõem o processo de KDD. Adaptada de [Han \& Kamber, 2001]. . . . . . . . . . . . . . . . . . . . . . 29

3.2 Exemplos dos quatro casos da função de custo para o algoritmo PAM. (a) Caso 1. (b) Caso 2. (c) Caso 3. (d) Caso 4. Adaptada de [Han \& Kamber, 2001]. . . . . . . . . . . . . . . . . . . . .

4.1 Exemplos de consultas $k$-GNNq com $k=1$ e 3 centros de consulta. Ilustração da aplicação da função de distância Euclidiana na Equação 4.1 considerando $p=1$ (a), $p=2$ (b) e $p=\infty$ (c) . . . . . . . . . . . . 
4.2 Exemplo de consulta por similaridade. Ilustração do resultado de uma consulta $k$-NNq das 5 cidades mais próximas de São Carlos-SP. . . . . . . 59

4.3 Exemplos de consultas por similaridade de grupo. (a) Com o método de agregação SUM. (b) Com o método de agregação ALL. (c) Com o método de agregação MAX.

4.4 Exemplo de consulta por similaridade. Ilustração do resultado de uma junção por abrangência entre as capitais da Região Sudeste com as cidades brasileiras. . . . . . . . . . . . . . . . . . . . . 62

4.5 Ilustração da execução de seleções considerando a tabela CidadeBR e os Predicados P4.1 e P4.2 apresentados na Tabela 4.2. (a) Resultado parcial após a execução do predicado P4.1 sobre a tabela CidadeBR. (b) Resposta final após a execução do predicado P4.2 sobre o resultado exibido em (a). 70

4.6 Ilustração da execução de seleções considerando a tabela CidadeBR e os Predicados P4.1 e P4.2 apresentados na Tabela 4.2. (a) Resultado parcial após a execução do predicado P4.2 sobre a tabela CidadeBR. (b) Resposta final após a execução do predicado P4.1 sobre o resultado exibido em (a). . 70

5.1 Arquitetura do SIREN. . . . . . . . . . . . . . . . . . . . . . . . 74

5.2 Esquema de armazenamento dos novos tipos de dados complexos. (a) STILLIMAGE e AUDIO. (b) PARTICULATE. . . . . . . . . . . . . . . . . . . 76

5.3 Ilustração do processo de execução do Comando [C5.1] . . . . . . . . . . . 79

5.4 Exemplos de consultas por similaridade sobre a tabela Exame. (a) Rq usando a métrica Histograma. (b) $k$-NNq usando a métrica Textura. . . . 80

5.5 Exemplos de consultas por similaridade sobre a tabela Autos. (a) "Quais são os 5 carros que apresentam as características mais próximas de $70 \mathrm{cv}$ de potência, $250 \mathrm{l}$ de volume de porta malas e $13 \mathrm{~km} / \mathrm{l}$ de consumo urbano?". (b) "Retorne os 5 carros mais próximos de um determinado carro e que não sejam do mesmo fabricante deste". . . . . . . . . . . . . . . . . . . 81

5.6 Exemplo de consulta por similaridade sobre a tabela Autos: "Quais são os 5 carros que possuem as características mais parecidas com as de 3 carros de interesse?". . . . . . . . . . . . . . . . . . . . . . . . . . . 82

5.7 Exemplo de consulta por similaridade sobre a tabela BRPolitico. $k$-NNq utilizando o Deputado 'José Carlos Aleluia' como objeto de consulta. . . . 83

5.8 Exemplos de consultas por similaridade sobre as tabelas BRPolitico e OrientacaoPartido. (a) $k$-NNq utilizando a orientação do Partido PT como objeto de consulta. (b) Exemplo da execução de uma junção pelos $k$-vizinhos mais próximos.

5.9 Exemplo de consulta por similaridade que envolve a realização de uma junção por abrangência entre as tabelas OrientacaoPartido e BRPolitico. 85 
5.10 Exemplos de consultas por similaridade sobre a tabela Musica. (a) $k$ NNq utilizando uma música do gênero NewAge como objeto de consulta e a métrica AudioMFCC. (b) $k$-NNq utilizando uma música do gênero MPB como objeto de consulta e a métrica padrão definida na criação da tabela (AudioSTFT). . . . . . . . . . . . . . . . . 86

5.11 Exemplos de consultas por similaridade sobre a tabela Musica. (a) $k$-NNq utilizando uma música do gênero PianoClassico como objeto de consulta e a métrica AudioMFCC. (b) $k$-NNq utilizando uma música do gênero PunkRock como objeto de consulta e a métrica AudioMFCC. . . . . . . . . . . . 86

6.1 Exemplo da execução de uma consulta $k$-NNq considerando 3 centros de consulta e os métodos de agregação SUM, ALL e MAX. . . . . . . . . . . . . . 93

6.2 Comparação de eficiência computacional ((a), (b), (c) e (d)) e qualidade de agrupamento ((e), (f), (g) e (h)) entre PAM, CLARANS, CLARA, PAM-SLIM-MD e PAM-SLIM-MO para os conjuntos de dados Synt10_5k, Sint10_10k, Sint10_15k e Sint10_20k. . . . . . . . . . . . . . . . 102

6.3 Comparação de eficiência computacional ((a), (b), (c) e (d)) e qualidade de agrupamento ((e), (f), (g) e (h)) entre PAM, CLARANS, CLARA, PAM-SLIM-MD e PAM-SLIM-MO para os conjuntos de dados Sint30_10k, Sint60_10k, Sint90_10k e Sint120_10k. . . . . . . . . . . . . . . . 104

6.4 Comparação de eficiência computacional ((a), (b) e (c)) e qualidade de agrupamento ((d), (e) e (f)) entre PAM, CLARANS, CLARA, PAM-SLIMMD e PAM-SLIM-MO para o conjunto de dados MedHisto. . . . . . . . . . 106

C.1 Diagrama Entidade-Relacionamento dos extratores de características disponíveis no SIREN. . . . . . . . . . . . . . . . . . . . . . . . . . . . . . . 129

C.2 Diagrama Entidade-Relacionamento da definição dos dados complexos no SIREN . . . . . . . . . . . . . . . . . . 130

C.3 Modelo Relacional do dicionário de dados do SIREN. . . . . . . . . . . . . 131 



\section{Lista de Tabelas}

4.1 Descrição dos predicados por similaridade tratados nesta tese. . . . . . . . 52

4.2 Descrição dos predicados utilizados na realização de seleções sobre a tabela CidadeBR . . . . . . . . . . . . . . . . . . 69

5.1 Tempo para o processamento de comandos que utilizam operadores por similaridade no SIREN. . . . . . . . . . . . . . . . . . . . . . . 87

6.1 Operações implementadas nos métodos de acesso seqüencial e Slim-tree. (*) Previamente existente. (\#) Implementada neste trabalho. (-) Não disponível ainda. . . . . . . . . . . . . . . . . . . . . 9 90

6.2 Descrição dos conjuntos de dados, sintéticos e reais, utilizados nos experimentos. . . . . . . . . . . . . . . . . . 100

6.3 Comparação de tempo entre os algoritmos PAM, CLARANS, PAM-SLIMMD e PAM-SLIM-MO para os conjuntos de dados Synt10_5k, Synt10_10k, Synt10_15k e Synt10_20k. Considerando a execução dos algoritmos PAMSLIM-MD e PAM-SLIM-MO com tamanho de página de 2.048 bytes. Tempo medido em horas:minutos:segundos. . . . . . . . . . . . . . . . . . 103

B.1 Descrição dos atributos do conjunto de dados CidadeBR. . . . . . . . . . . . 125

B.2 Descrição dos atributos do conjunto de dados Autos. . . . . . . . . . . . . . 126

B.3 Descrição dos atributos do conjunto de dados Exame. . . . . . . . . . . . 126

B.4 Descrição dos atributos do conjunto de dados BRPolitico. . . . . . . . . . 127

B.5 Descrição dos atributos do conjunto de dados OrientacaoPartido. . . . . 127

B.6 Descrição dos atributos do conjunto de dados Musica. . . . . . . . . . . . 128 



\section{Lista de Abreviaturas}

$\begin{array}{ll}\text { BIRCH } & \text { Balanced Iterative Reducing and Clustering using Hierarchies. } \\ \text { BK-trees } & \text { Burkhard-Keller-trees. } \\ \text { BLOB } & \text { Binary Large OBject. } \\ \text { CBAR } & \text { Content Based Audio Retrieval. } \\ \text { CBIR } & \text { Content Based Image Retrieval. } \\ \text { CIRCE } & \text { Content-based Image Retrieval Core Engine. } \\ \text { CLARA } & \text { Clustering LARge Applications. } \\ \text { CLARANS } & \text { Clustering Large Applications based upon RANdomized Search. } \\ \text { CF } & \text { Clustering Feature. } \\ \text { CT } & \text { Tomografia Computadorizada. } \\ \text { CURE } & \text { Clustering Using REpresentatives. } \\ \text { DDL } & \text { Linguagem de Definição de Dados. } \\ \text { DM } & \text { Data Mining. } \\ \text { DML } & \text { Linguagem de Manipulação de Dados. } \\ \text { GIS } & \text { Geographic Information Systems. } \\ \text { GNAT } & \text { Geometric Near-neighbor Access Tree. } \\ \text { GRq } & \text { Consultas por Abrangência de Grupo. } \\ \text { HSI } & \text { Hue, Saturation, Intensity. } \\ \text { IAV Extenders } & \text { Image, Audio and Video Extenders. } \\ \text { IR } & \text { Information Retrieval. } \\ \text { KDD } & \text { Knowledge Discovery in Databases. } \\ k \text {-GNNq } & \text { Consultas aos } k \text {-Vizinhos mais Próximos de Grupo. } \\ k \text {-NN } & \text { Métodos de classificação pelos vizinhos mais próximos. } \\ k \text {-NNq } & k \text {-Nearest Neighbor Query. } \\ \bowtie & \end{array}$




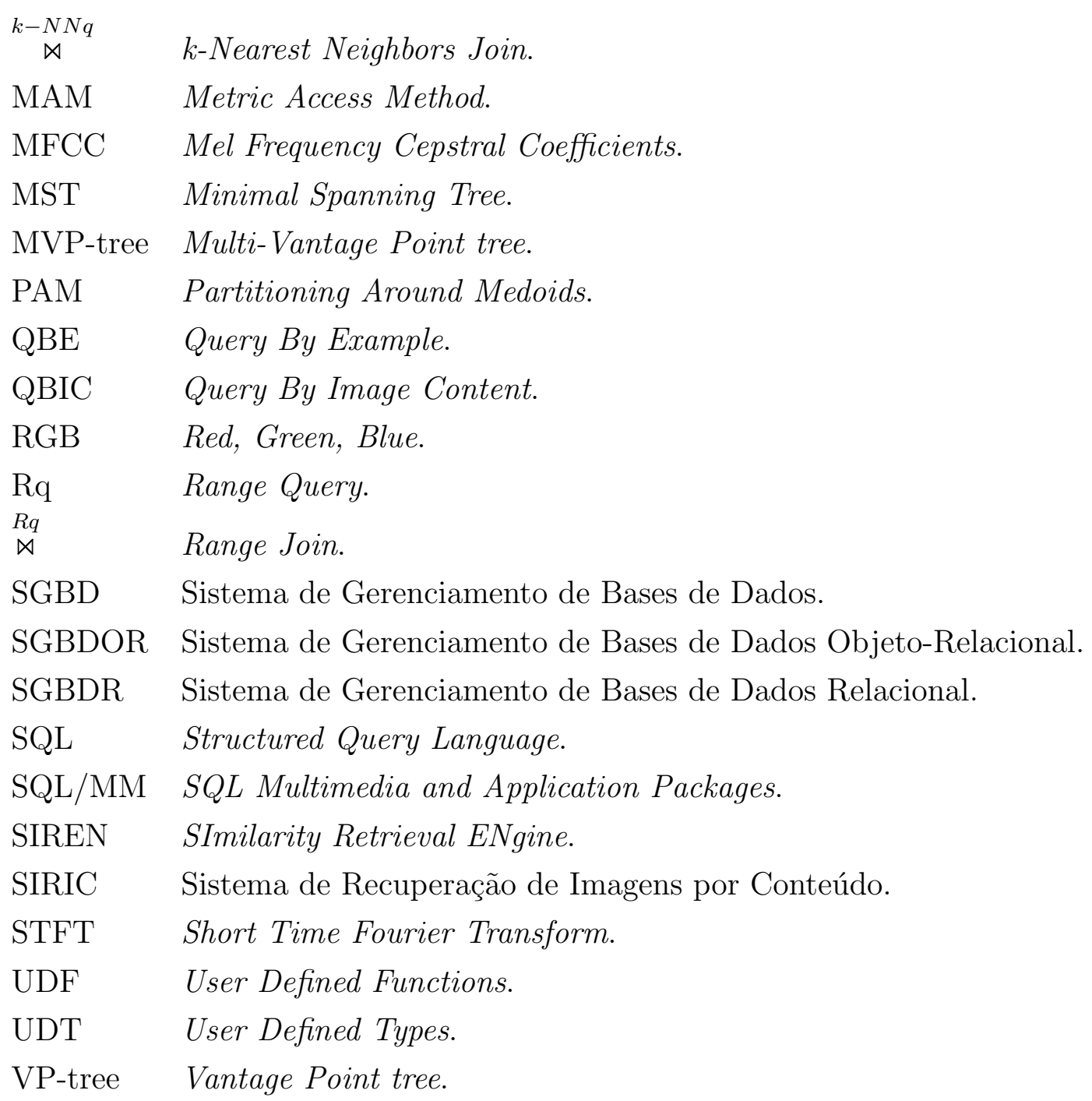




\section{Lista de Símbolos}

$\mathbb{S} \quad$ Conjunto de todos os elementos válidos no domínio de objetos.

$Q \quad$ Conjunto de objetos de consulta (objetos de referência). $Q \in \mathbb{S}$

$s_{q} \quad$ Objeto de consulta (objeto de referência). $s_{q} \in Q$.

$d\left(s_{1}, s_{2}\right)$ Função de distância ou função de dissimilaridade.

$L_{p} \quad$ Função de distância Minkowski. $L_{1}$ é a função de distância Manhattan, $L_{2}$ é a Euclidiana e $L_{\infty}$ é a Chebychev.

$\xi \quad$ Distância máxima de busca (raio) .

$k \quad$ Número inteiro que indica a quantidade de respostas esperadas. Para as operações de seleção e junção por similaridade, indica respectivamente o número de objetos e o número de pares de objetos esperados. Para as operações de detecção de agrupamentos de dados, indica o número de agrupamentos esperados.

$p \quad$ Padrão de agregação. Quando $p=1$, corresponde ao SUM. Quando $p=2$, corresponde ao ALL. Quando $p=\infty$, corresponde ao MAX.

$\hat{\sigma} \quad$ Operador de seleção por similaridade.

$\bowtie \quad$ Operador de junção por similaridade.

$\hat{\mu} \quad$ Operador de análise de agrupamento por similaridade. 



\section{Capítulo \\ 1 \\ Introdução}

\subsection{Motivação}

Atualmente, os Sistemas de Gerenciamento de Bases de Dados (SGBD) são componentes essenciais para qualquer tipo de aplicação, tanto comercial quanto científica. $\mathrm{O}$ seu poder advém de todo o conhecimento e tecnologia que vêm sendo desenvolvidos e incorporados há várias décadas. Os SGBD foram tradicionalmente desenvolvidos para suportar o armazenamento e a recuperação eficientes de grandes volumes de dados compostos apenas por números e pequenas cadeias de caracteres. No entanto, os avanços tecnológicos ocorridos nos últimos anos proporcionaram o surgimento de novas aplicações que passaram a manipular dados mais complexos do que se convencionou chamar de dados tradicionais, ou dados convencionais (números e pequenas cadeias de caracteres). Assim, a organização de novos tipos de dados em bases de dados passou a ser um objetivo importante.

Dentre os novos tipos de dados, denominados dados $\operatorname{complexos}^{1}$, é possível mencionar: fotografias, documentos (como livros e artigos), filmes e arquivos MP3 armazenados por aplicações multimídia; imagens de satélite, informações geo-referenciadas e dados metereológicos armazenados e analisados por sistemas de informação geográfica (Geographic Information Systems - GIS); imagens de exames médicos, dados genômicos e seqüências de proteínas utilizados por sistemas de apoio à medicina, entre outros.

Hoje em dia, a maioria das aplicações utilizam SGBD baseados no Modelo Relacional

\footnotetext{
${ }^{1}$ Nesta tese o termo "dados complexos" se refere a toda informação que não é formada por apenas um tipo simples de dados (ex.: inteiro, ponto flutuante, cadeia de caracteres, etc.).
} 
de Dados [Codd, 1970], os Sistemas de Gerenciamento de Bases de Dados Relacionais (SGBDR) e seus variantes denominados Sistemas de Gerenciamento de Bases de Dados Objeto-Relacionais (SGBDOR). As consultas suportadas por esses SGBD são baseadas na propriedade de relação de ordem total, que permite que números e cadeias de caracteres sejam comparados por meio da utilização dos operadores relacionais $<, \leq,>, \geq \mathrm{e}=$. Entretanto, a maioria dos domínios de dados complexos não requer a realização de consultas baseadas em relação de ordem. A utilização do operador de igualdade $(=)$ também não é significativa para esses domínios de dados, uma vez que é rara a ocorrência de dois elementos idênticos (ex.: duas imagens idênticas) nos conjuntos de dados pertencentes a esses domínios.

As consultas requeridas pelas aplicações que manipulam dados complexos são normalmente baseadas em uma noção de similaridade, específica para cada domínio. Esse tipo de consulta, denominado consulta por similaridade, retorna objetos do conjunto de dados que sejam similares a um objeto de referência (ou objeto de consulta) de acordo com um certo critério de similaridade. Como as comparações por similaridade executadas por esse tipo de consulta necessitam de um meio para mensurar o quão similares são os diferentes pares de objetos de domínios complexos, esses domínios de dados são geralmente representados em um espaço métrico.

Um espaço métrico $M$ é definido pelo par $\{\mathbb{S}, d()\}$, no qual $\mathbb{S}$ define o domínio dos dados e $d()$ é uma função de distância que atende às propriedades de simetria, não-negatividade e desigualdade triangular [Bozkaya \& Ozsoyoglu, 1999, Ciaccia \& Patella, 2002]. São as funções de distância que fornecem as medidas que expressam a dissimilaridade (ou similaridade) existente entre dois objetos e, assim, permitem a realização de consultas por similaridade como a descrita a seguir: "Selecione as $k$ imagens mais similares a uma dada imagem de referência".

Objetos de domínios complexos podem ser armazenados em uma base de dados tanto como um conjunto de atributos de domínios tradicionais (ex.: uma posição geográfica pode ser identificada pela sua latitude e longitude) quanto como um único objeto binário BLOB (ex.: como no caso das imagens). Os objetos complexos armazenados da primeira forma podem ser comparados por similaridade por meio da aplicação de uma função de distância sobre os valores dos atributos que os compõem. Já para os objetos armazenados da segunda forma geralmente é necessário extrair um conjunto prédefinido de características inerentes a seus dados, que são utilizadas no lugar dos objetos propriamente ditos no momento da realização das comparações por similaridade. Essa abordagem de busca é denominada Recuperação por Conteúdo, como a Recuperação de Imagens por Conteúdo (Content Based Image Retrieval - CBIR) [Smeulders et al., 2000, Datta et al., 2005].

O aumento da quantidade de dados de domínios complexos armazenados em bases de dados relacionais impõe a necessidade de criar um suporte para a realização de consultas 
por similaridade em SGBDR. Outro fator que contribui para essa necessidade está relacionado à tendência para a implementação de algoritmos de mineração de dados (Data Mining - DM) que aborda questões relacionadas à integração de métodos de DM com SGBDR [Sattler \& Dunemann, 2001]. Um ponto fundamental para essa integração está relacionado ao fornecimento de recursos nos SGBDR que permitam a realização de operações básicas para as diversas técnicas de mineração de dados existentes. Uma operação básica para várias técnicas de mineração, tais como a técnica de detecção de agrupamentos de dados, é justamente o cálculo de medidas de similaridade entre os pares de objetos de um conjunto de dados.

Embora se constate que existe a necessidade de fornecer suporte para a realização desse tipo de operação em SGBDR, o atual padrão da linguagem SQL (Structured Query Language) não prevê a realização de consultas por similaridade. Esta tese pretende contribuir para o fornecimento desse suporte, incorporando na linguagem SQL recursos capazes de permitir a realização de operações de consulta por similaridade sobre grandes bases de dados complexos de maneira totalmente integrada com os demais recursos da linguagem.

\subsection{Definição do Problema}

Os SGBD são caracterizados pela habilidade de suportar a armazenagem e a recuperação de grandes volumes de dados, garantindo que eles sejam acessados de maneira segura e concorrente entre as diversas aplicações. Eles também se caracterizam por suportar linguagens eficientes que permitem tanto a definição das estruturas dos dados (Linguagem de Definição de Dados - DDL) quanto a consulta e a modificação dos mesmos (Linguagem de Manipulação de Dados - DML), de maneira que o usuário se preocupe apenas em especificar quais dados ele quer, e não em como obtê-los, ou seja, suportam linguagens que seguem o paradigma declarativo, não o imperativo usualmente adotado por linguagens de programação.

A linguagem mais amplamente utilizada nos SGBDR, a SQL, não dispõe de construções sintáticas que permitam a especificação de consultas por similaridade. Para permitir a manipulação de dados complexos em SGBDR é necessário incorporar à linguagem SQL construções que possibilitem:

- Na DDL:

- Definir medidas de similaridade que especifiquem a função de distância a ser utilizada e a estrutura que representa os dados a serem comparados por similaridade. Cada estrutura depende do domínio dos dados complexos a que esteja associada e deve ser definida pelos tipos dos atributos tradicionais que compõem os dados complexos, ou pelo conjunto de características inerentes a esses dados; 
- Especificar tipos de dados complexos na definição de tabelas;

- Associar atributos de domínios complexos a medidas de similaridade disponíveis para seus domínios.

- Definir índices sobre atributos de domínios complexos.

- Na DML:

- Inserir e/ou atualizar os dados em uma base de dados complexos;

- Permitir a especificação de consultas por similaridade de maneira integrada com os outros recursos da linguagem SQL, incluindo operações de seleção, junção e também outras operações que auxiliem a análise de grandes conjuntos de dados complexos.

\subsection{Objetivos do Trabalho}

O trabalho apresentado nesta tese foi desenvolvido com o objetivo de responder às seguintes questões principais:

- Como expressar consultas por similaridade em SQL de maneira flexível, que resulte em um baixo impacto sobre a sintaxe já existente da linguagem?

- Como incorporar a representação de consultas por similaridade na linguagem SQL de maneira declarativa, permitindo que seja possível otimizar essas consultas, seguindo o mesmo processo de otimização utilizado para as consultas tradicionalmente expressas nessa linguagem?

- Como especificar a definição de medidas de similaridade sobre domínios complexos, de maneira que qualquer atributo definido nesses domínios possa utilizar essas medidas?

- Como especificar consultas por similaridade sobre os diferentes domínios de dados complexos por meio da utilização de construções sintáticas equivalentes?

Além disso, como a realização de cálculos de similaridade corresponde a uma operação básica para diversas técnicas de mineração de dados, com o intuito de explorar aspectos relacionados à integração dessas técnicas com SGBDR, o trabalho apresentado nesta tese também teve como objetivos: permitir a especificação de consultas sobre o resultado de processos de detecção de agrupamentos de dados baseados no método $k$-medoid e explorar estratégias para a otimização de algoritmos baseados nesse método de maneira a torná-los exeqüíveis em SGBD. 


\subsection{Principais Contribuições}

As principais contribuições desta tese correspondem a:

- Incorporação de consultas por similaridade na linguagem SQL: Para permitir a incorporação de consultas por similaridade em SGBDR foram definidas várias construções sintáticas que estenderam a sintaxe padrão da linguagem SQL, considerando diferentes domínios de dados complexos e os vários tipos de consulta requeridas por aplicações que manipulam dados pertencentes a esses domínios. Além disso, como contribuição adicional, este trabalho também explorou aspectos relacionados ao processamento necessário em um SGBDR para a realização dessas consultas, implementando um protótipo de ferramenta denominado SIREN (SImilarity Retrieval ENgine);

- Otimização de algoritmos de detecção de agrupamentos de dados e a incorporação dos mesmos em SGBD: A aplicação de conceitos relativos às estruturas de indexação, apropriadas para indexar dados em domínios métricos, para a otimização de algoritmos de agrupamento baseados no método $k$-medoid apresenta resultados iniciais significativos. A abordagem desenvolvida possibilitou a obtenção de uma notável relação custo benefício entre eficiência computacional e qualidade de agrupamento, tornando possível a execução desse tipo de algoritmo em SGBD, em que as restrições para a manipulação de grandes volumes de dados impõem condições muito rígidas de tempo de resposta.

\subsection{Organização do Trabalho}

Esta tese está organizada da seguinte maneira:

- O Capítulo 1 descreve a motivação, a definição do problema e os principais objetivos e contribuições do trabalho desenvolvido.

- O Capítulo 2 apresenta definições e conceitos relacionados à recuperação de objetos complexos por conteúdo abordando, particularmente, aspectos relativos à recuperação de dados multimídia como imagens e áudio. Também são apresentados nesse capítulo alguns exemplos representativos de linguagens e sistemas desenvolvidos para a recuperação de dados complexos por conteúdo.

- No Capítulo 3 são apresentados conceitos de descoberta de conhecimento em bases de dados e mineração de dados, enfatizando os principais aspectos relacionados à integração de algoritmos de mineração de dados com SGBD relacionais. Esse 
capítulo também descreve, em detalhes, uma das principais técnicas de mineração de dados, a técnica de detecção de agrupamentos de dados.

- O Capítulo 4 apresenta os conceitos que fundamentaram a definição da extensão da linguagem SQL proposta nesta tese, para o suporte de consultas por similaridade sobre dados complexos em SGBD relacionais. A sintaxe da extensão da linguagem, propriamente dita, também é descrita nesse capítulo juntamente com vários exemplos de comandos que ilustram a semântica das novas construções adicionadas à linguagem SQL. Além disso, esse capítulo apresenta uma sintaxe para a especificação de consultas sobre o resultado de processos de detecção de agrupamentos de dados, como um passo inicial para a integração de técnicas de DM que envolvam operações por similaridade em SGBD.

- No Capítulo 5 são descritos os conceitos e técnicas empregados na implementação de um protótipo, denominado SIREN, desenvolvido com o intuito de validar a extensão da linguagem SQL apresentada nesta tese. Também são apresentados nesse capítulo vários exemplos de execuções de consultas por similaridade realizadas por meio da utilização dessa ferramenta.

- O Capítulo 6 apresenta vários algoritmos que foram implementados com o objetivo de validar os conceitos apresentados nesta tese, destacando a abordagem e a descrição da técnica desenvolvida para a otimização de algoritmos de detecção de agrupamentos baseados no método $k$-medoid.

- No Capítulo 7 são apresentadas as considerações finais, as principais contribuições deste trabalho e as propostas para trabalhos futuros.

- O Apêndice A apresenta, em detalhes, a sintaxe da extensão da linguagem SQL para o suporte de consultas por similaridade.

- No Apêndice B são descritas as bases de dados reais empregadas na especificação dos comandos SQL.

- O Apêndice $\mathbf{C}$ apresenta o dicionário de dados do SIREN. 


\section{Capítulo \\ 2 \\ Recuperação por Conteúdo}

Tradicionalmente, os Sistemas de Gerenciamento de Bases de Dados (SGBD) foram desenvolvidos para suportar o armazenamento e a recuperação de dados apenas de tipos numéricos ou textuais curtos. Entretanto, nas últimas décadas houve um aumento expressivo não só da quantidade, mas também da complexidade dos dados gerados, armazenados e analisados, sendo uma grande parte deles formada por dados de natureza multimídia, como imagens, vídeo, áudio e textos longos (como documentos html, xml, e etc.) [Mehrotra et al., 1997]. Sendo assim, surgiu a necessidade do desenvolvimento de novas técnicas que pudessem permitir o armazenamento e a recuperação desses tipos de dados de maneira eficiente.

Atualmente, os SGBD mais amplamente utilizados são os construídos segundo o Modelo Relacional [Codd, 1970], os quais tratam todos os elementos de uma modelagem por meio da utilização de apenas dois construtores semânticos: atributos e relações, sendo os atributos definidos por tipos de dados textuais ou numéricos. Dados mais complexos são usualmente armazenados em um atributo de tipo BLOB (Binary Large Object) que consiste em um grande bloco de memória não interpretável, sendo sua recuperação feita por outros atributos de tipos numéricos ou textuais armazenados na mesma relação. Por exemplo, o suporte a imagens nos sistemas de gerenciamento de bases de dados atuais restringe-se à armazenagem das mesmas em atributos BLOB, sendo que muito esforço vem sendo dispendido para viabilizar operações de recuperação eficientes.

Uma estratégia comumente utilizada para comparar dados multimídia requer a extração de características inerentes a esses dados, que são utilizadas no lugar dos dados, propriamente ditos, durante a realização de operações de busca/comparação. Essa abor- 
dagem de busca é denominada Recuperação por Conteúdo. Este capítulo trata dos aspectos relacionados à recuperação por conteúdo de dados multimídia, como imagem e áudio.

\subsection{Principais Conceitos}

A recuperação de dados complexos por conteúdo aplica-se a vários tipos de dados, como imagens e áudio, sendo que as primeiras técnicas utilizadas em recuperação por conteúdo foram desenvolvidas para o domínio de imagens (Content Based Image Retrieval-CBIR) [Smeulders et al., 2000, Datta et al., 2005]. Assim, existem vários trabalhos na área de CBIR que foram desenvolvidos considerando diferentes abordagens, como distribuição de cor, forma e textura das imagens.

Com o aumento da disponibilização de coleções de áudio digitais, especialmente música, também se tornou importante permitir o gerenciamento automático desse tipo de dados por meio da utilização de características intrínsecas ao áudio (Content Based Audio Retrieval-CBAR). Assim, várias técnicas de extração de características foram desenvolvidas para esse domínio de dados, sendo algumas delas especialmente adequadas para a recuperação de música por conteúdo [Tzanetakis, 2002].

As técnicas baseadas em busca por conteúdo utilizam características extraídas automaticamente dos dados complexos para representar e indexar as informações embutidas nesses dados. Cada característica é usualmente um valor ou conjunto de valores numéricos e o conjunto de características extraídas é chamado vetor de características. Nos sistemas de recuperação por conteúdo, as operações de comparação entre dados complexos utilizam os vetores de características para medir a similaridade do conteúdo presente nos dados que eles representam. A Figura 2.1 ilustra o funcionamento de um sistema de recuperação por conteúdo considerando o domínio de imagens.

Um sistema de recuperação de dados complexos por conteúdo possui basicamente quatro componentes principais:

- Um módulo responsável pela extração automática de características que representem o conteúdo presente nos dados complexos;

- Um conjunto definido de métricas capazes de avaliar a similaridade entre os objetos complexos;

- Uma interface de usuário que suporte tanto a definição dos parâmetros para a solicitação da consulta aos dados complexos, quanto a visualização dos resultados obtidos;

- Um mecanismo de busca, que realiza as operações de busca sobre o conjunto de dados armazenados. 


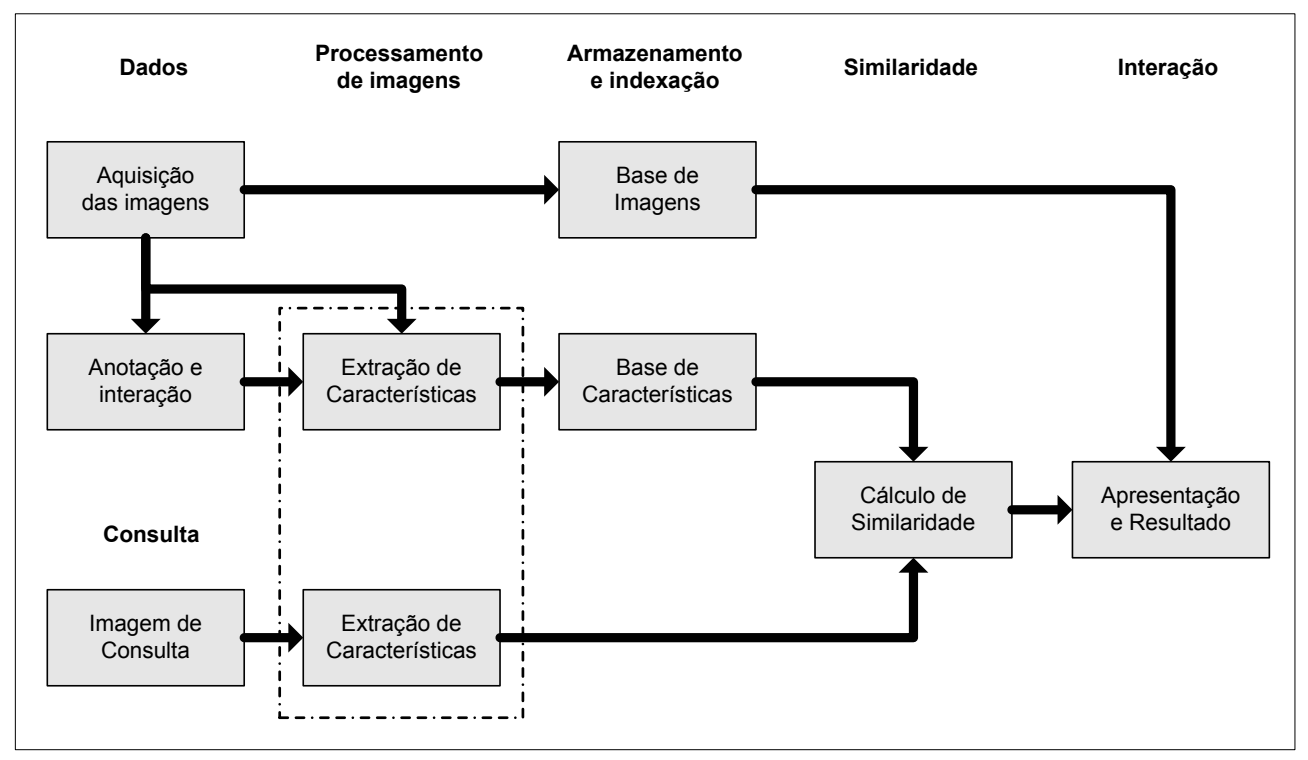

Figura 2.1: Ilustração do fluxo de dados pelos módulos de um sistema de recuperação de imagens por conteúdo. Adaptada de [Smeulders et al., 2000].

Várias áreas de pesquisa têm contribuído para o desenvolvimento de técnicas relacionadas a um ou mais dos componentes descritos acima, como Visão Computacional, Gerenciamento de Bases de Dados, Interface Usuário-Computador, Processamento de Sinais Digitais e Recuperação de Informação. Dentre essas estão as técnicas para a extração automática de características de dados complexos; para a organização, indexação e consulta de dados complexos; e para o gerenciamento de bases de dados complexos. As próximas seções apresentam os principais conceitos e técnicas relacionados à extração de características, às métricas para a avaliação de similaridade entre dados complexos, aos tipos de consulta por similaridade e às estruturas de indexação desenvolvidas para lidar com a recuperação de dados complexos.

\subsubsection{Extração de Características}

O módulo de extração de características é uma das bases fundamentais dos sistemas de recuperação de dados complexos por conteúdo. A sua importância está relacionada ao fato de que são as características extraídas por esse módulo que são utilizadas para a realização da indexação e da recuperação de dados complexos, como imagens e áudio.

O processo de extração de características consiste no cálculo de representações numéricas que podem ser utilizadas para caracterizar um determinado dado complexo. De maneira geral, existem duas abordagens para a extração dessas representações numéricas: a extração de características a partir de dados brutos ( raw data), ou a extração de características a partir de dados transformados, ou seja, as representações numéricas são obtidas a partir de um domínio de transformação comprimido [Traina \& Traina-Jr., 2003]. Considerando o domínio de dados de imagens, por exemplo, é comum extrair características 
a partir dos dados brutos, i.e., diretamente a partir dos pixels da imagem. Dentre as técnicas que utilizam esse tipo de características estão os histogramas de cor. Já no domínio de dados de áudio, muitos dos processos de extração de características baseiam-se em técnicas de transformação de dados, como a Transformada de Fourier de Curta Duração (Short Time Fourier Transform - STFT).

Cada domínio de dados complexos possui propriedades específicas que são utilizadas na representação dos dados. Para discutir essas propriedades é necessário considerar um domínio de dados específico. Assim, são apresentados nas próximas subseções os conceitos relacionados aos dois domínios de dados complexos considerados neste trabalho: imagens e áudio.

\section{Domínio de Dados de Imagem}

Segundo [Gudivada \& Raghavan, 1995], considerando o domínio de imagens, as características normalmente utilizadas pelos Sistemas de Recuperação de Imagens por Conteúdo (SIRIC) podem diferir com relação a três aspectos:

- Tipo da característica. As características das imagens podem ser divididas em primitivas e lógicas. O primeiro tipo é formado por características de baixo nível (como borda e cor) que podem ser extraídas automaticamente a partir de uma imagem. Já o segundo tipo é constituído por representações abstratas que podem apresentar elementos de uma imagem em diferentes níveis de detalhes. Algumas características lógicas são derivadas de características primitivas, outras correspondem a inferências realizadas por usuários a partir do conteúdo da imagem.

- Nível de abstração presente nas características. Segundo [Aslandogan \& Yu, 1999], o conteúdo visual das imagens pode ser classificado hierarquicamente em 4 níveis de abstração. O primeiro nível corresponde aos pixels da imagem, com informações referentes a cor ou brilho. No segundo estão características como bordas, cantos, linhas, curvas e regiões de cores. No terceiro, as características do nível anterior são combinadas e interpretadas como objetos e seus atributos. E o último e mais alto nível de abstração envolve os conceitos relacionados à percepção humana dos relacionamentos existentes entre um ou mais objetos de uma imagem.

- Grau desejado de independência de domínio. As características extraídas de uma imagem podem representar o conteúdo visual geral ou o conteúdo visual específico de um domínio. Dentre as características visuais gerais estão cor, textura e forma. Já as características específicas de um domínio dependem da aplicação e podem incluir, por exemplo, faces humanas e impressões digitais [Long et al., 2002].

No restante desta subseção são apresentadas as características visuais mais comumente utilizadas pelos SIRICs. 
Cor

A cor é uma das características visuais mais amplamente utilizadas na recuperação de imagens. Essa característica é normalmente representada por um descritor de cor definido em um sistema de cores específico. Existem diferentes sistemas de cores, como o RGB (Red, Green, Blue) mais comumente utilizado em dispositivos de exibição, o HSI (Hue, Saturation, Intensity) largamente utilizado em computação gráfica, e outros. O HSI é o sistema que apresenta a descrição de cor de maneira mais intuitiva para o ser humano [Long et al., 2002].

Dentre os descritores de cor utilizados na recuperação de imagens, o histograma de cor é o mais comum (Figura 2.2). Um histograma de cor registra a distribuição da quantidade de pixels de uma imagem para cada cor e pode ser comparado a outro histograma de cor pela soma das diferenças absolutas ou quadráticas do número de pixels de cada cor [Aslandogan \& Yu, 1999]. Embora esse descritor seja simples de ser calculado e tolerante a pequenas alterações da imagem, ele apresenta alguns problemas. Um deles está relacionado ao fato de que um histograma de cor pode conter um grande número de cores, o que não só faz com que o custo computacional se eleve, mas também que ele se torne inadequado para ser utilizado na indexação de uma base de dados de imagens [Long et al., 2002]. Além disso, existe o problema relacionado à baixa capacidade de discriminação do histograma de cor, porque os histogramas de cores não levam em consideração as informações espaciais dos pixels, fazendo com que imagens muito diferentes tenham distribuições de cores semelhantes [Traina, 2001].
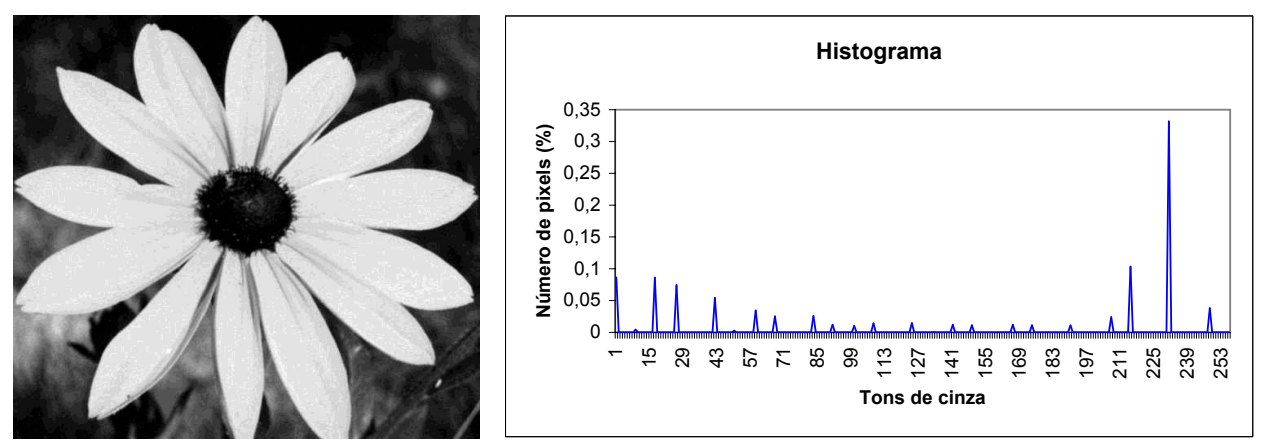

Figura 2.2: Exemplo de um histograma de cor de uma imagem quantizada em 256 níveis de cinza.

Além do histograma de cor existem outros descritores de cores como Color Coherence Vector [Pass \& Zabith, 1996], Color Correlogram [Huang et al., 1997], Histograma Métrico [Traina et al., 2002a], Cell Histograms [Stehling et al., 2003] e outros. Uma visão geral sobre alguns desses descritores pode ser encontrada em [Long et al., 2002]. 


\section{$\underline{\text { Textura }}$}

Embora a textura seja de fácil percepção para o ser humano, não é fácil defini-la. Existem várias definições para essa característica, mas nenhuma definição formal. Segundo [Traina, 2001], uma textura pode ser definida como sendo "um padrão visual em que há um grande número de elementos visíveis arranjados de forma equânime com densidades variadas", no qual um elemento corresponde a "uma região de intensidade uniforme de formas simples que se repete dentro de um intervalo" (a Figura 2.3 apresenta alguns exemplos de textura). Vários métodos de representação de textura têm sido desenvolvidos nas áreas de Reconhecimento de Padrões e Visão Computacional [Tuceryan \& Jain, 1998]. Essas áreas de pesquisa também têm contribuído com o desenvolvimento de vários estudos comparativos de diversos métodos [Ma \& Manjunath, 1995, Ohanian \& Dubes, 1992, Randen \& Hus $\phi y$, 1999, Singh \& Singh, 2002].

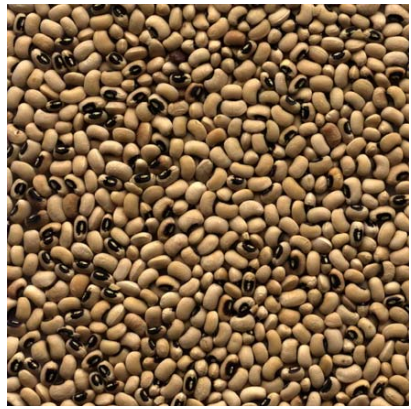

Feijão

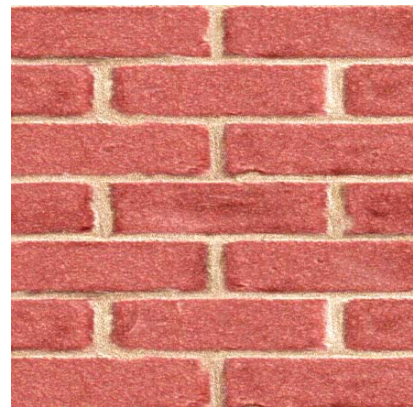

Tijolo

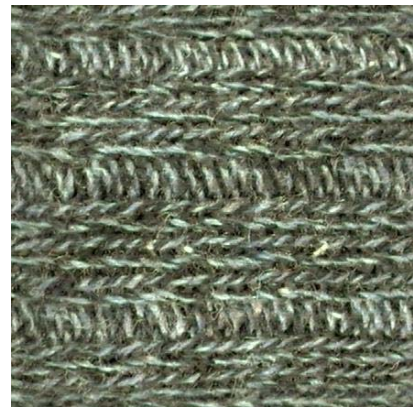

Tecido de lã

Figura 2.3: Exemplos de textura.

Os métodos de representação de textura podem ser classificados basicamente em duas categorias [Sonka et al., 1999]:

- Estatísticos. Os métodos estatísticos caracterizam as texturas por meio do cálculo de diferentes propriedades como granularidade, contraste, periodicidade e outras. Esse tipo de método tende a ser mais adequado para descrever texturas pequenas. Alguns exemplos de métodos estatísticos incluem Matrizes de Coocorrência [Haralick et al., 1973], Transformadas de Gabor [Daugman, 1998] e Wavelets [Daubechies, 1990].

- Sintáticos (ou Estruturais) e Híbridos. Os métodos puramente sintáticos baseiamse na identificação de elementos e na determinação da disposição espacial desses elementos. Já os métodos híbridos são compostos pela combinação dos métodos estatísticos e sintáticos. Nesse tipo de método, os elementos são exatamente definidos e o relacionamento espacial entre eles é baseado em probabilidades. Tanto os métodos sintáticos quanto os híbridos não são tão utilizados quanto os métodos estatísticos e são mais adequados para texturas regulares. Alguns exemplos de métodos sintáticos são apresentados em [Sonka et al., 1999]. 
Embora os descritores de textura diferenciem-se dos descritores de cor, uma vez que são definidos sobre janelas ou regiões e não sobre pixels individuais, eles apresentam os mesmos tipos de problemas relacionados à alta dimensionalidade e à baixa capacidade de discriminação [Aslandogan \& Yu, 1999].

\section{Forma}

A recuperação por forma ainda é considerada um dos aspectos com o maior custo computacional da busca baseada em conteúdo. Segundo [Aslandogan \& Yu, 1999], isso ocorre, principalmente, devido à dificuldade em se obter uma segmentação precisa dos objetos de interesse em uma imagem. Assim, como pode ser observado em [Pentland et al., 1994], a utilização de descritores de forma para a recuperação de imagens tem sido tipicamente limitada a aplicações especiais cujos objetos presentes nas imagens são bem distintos.

Os métodos de representação de forma podem ser caracterizados sob diferentes pontos de vista [Pavlidis, 1978].

- Tipo de representação: Segundo esse critério os métodos de representação de forma podem ser divididos em baseados em borda e baseados em regiões. O primeiro tipo utiliza apenas a borda externa da forma para representa-la, enquanto o segundo utiliza a região inteira da forma.

- Forma de representação: Os métodos de representação podem ser numéricos ou categóricos.

- Habilidade de preservar informação: Considerando esse critério, os métodos são classificados de acordo com a possibilidade ou não de reconstruir os objetos de uma imagem, a partir dos descritores, em métodos que preservam informação e que não preservam informação, sendo que os métodos que preservam informação podem diferir quanto ao grau de precisão na reconstrução dos objetos.

Dentre os métodos mais simples para a representação de forma estão: os métodos geométricos para detecção de borda como comprimento de borda, curvatura (uma medida da velocidade de alteração de inclinação do contorno da borda) e assinatura (uma seqüência de distâncias entre pontos da borda); e os métodos escalares para a detecção de região como área, excentricidade (obtida, por exemplo, pela razão entre o maior e o menor eixo) e retangularidade (uma medida que representa a proximidade da forma do objeto a um retângulo de mesma área). Uma descrição mais detalhada desses e vários outros métodos para a representação de forma pode ser encontrada em [Sonka et al., 1999], e um estudo comparativo de vários descritores de forma em [Zhang \& Lu, 2001].

Outro aspecto importante relacionado à recuperação por forma consiste na escolha de qual é a característica que deve ser usada para delimitar as formas contidas em uma imagem. Em geral é utilizada a cor, mas em imagens médicas, por exemplo, é interessante utilizar a textura. 


\section{Domínio de Dados de Áudio}

Existem basicamente duas abordagens para a utilização de vetores de características na representação de sinais de áudio. Na primeira abordagem, o arquivo de áudio é dividido em pequenos segmentos no tempo e um vetor de características é calculado para cada segmento. Nesse caso, a representação resultante é uma série temporal de vetores de características, que pode ser vista como uma trajetória de pontos no espaço de características.

Na segunda abordagem é utilizado um único vetor de características, compreendendo a informação de todo um arquivo de áudio. Cada uma dessas abordagens é adequada para um tipo específico de análise. A abordagem que utiliza vários vetores de características é apropriada quando a informação precisa ser atualizada em tempo real (ex.: classificação de sinais de rádio), enquanto a abordagem que utiliza um único vetor de características é adequada para situações em que a informação geral de todo o arquivo de áudio é necessária (ex.: classificação de gênero musical de arquivos .mp3). As aplicações que realizam recuperação de áudio por conteúdo utilizam a segunda abordagem [Tzanetakis, 2002].

As primeiras técnicas de extração de características de áudio foram desenvolvidas para a representação e o processamento da fala. Em muitas das técnicas desenvolvidas com esse objetivo, as características são calculadas a partir da análise do formato espectral geral de um sinal de áudio, ou seja, a partir do resultado da aplicação de algum tipo de método de análise de "Tempo-Freqüência", como a Transformada de Fourier de Curta Duração (Short Time Fourier Transform - STFT) [Rabiner \& Schafer, 1978]. Esse tipo de método representa basicamente a distribuição de energia de um sinal de áudio no plano tempo-freqüência, diferindo apenas na maneira como esse plano é subdividido em regiões.

Dentre os exemplos de características extraídas a partir do resultado da aplicação desses métodos estão as características baseadas na transformada STFT, descritas em [Wold et al., 1996, Tzanetakis, 2002], e os Mel Frequency Cepstral Coefficients (MFCC) [Hunt et al., 1980]. Esse tipo de características pode ser utilizado para capturar aspectos relacionados ao timbre de um sinal de áudio e pode ser empregado tanto em aplicações de análise da fala como em aplicações de análise de músicas [Tzanetakis, 2002].

Além dos conjuntos de características mencionados anteriormente, outros tipos de técnicas de extração de características também foram propostos, especificamente, para a representação de sinais de áudio referentes a música. Além de informações relativas ao timbre, o conteúdo musical de um sinal de áudio também pode ser caracterizado quanto ao ritmo e à harmonia. Exemplos de representações para cada um desses tipos de características incluem Beat Histograms, para informações relativas ao ritmo [Tzanetakis, 2001] e Pitch Histograms, para informações relativas a harmonia [Tzanetakis et al., 2002]. 


\subsubsection{Medidas de Similaridade}

Para que um sistema de recuperação por conteúdo possa responder a consultas por similaridade e retornar os objetos que mais se assemelham a um dado objeto de consulta, é necessário que ele seja capaz de mensurar o quão similar são os diferentes pares de objetos armazenados na base de dados bem como com o objeto de consulta. A quantificação do valor dessa similaridade é obtida por meio da aplicação de uma função que calcula a distância (ou dissimilaridade) entre dois objetos e retorna um valor real positivo que indica o grau de semelhança entre eles. Quanto maior o valor retornado, menor a similaridade entre os objetos comparados, sendo que uma distância igual a zero indica identidade ou similaridade total.

As funções de distância empregadas pelas técnicas de recuperação por conteúdo são definidas dentro de um espaço métrico e podem ser formalmente descritas da seguinte maneira [Bozkaya \& Ozsoyoglu, 1999, Ciaccia \& Patella, 2002]: Considerando os objetos $s_{1}, s_{2}$ e $s_{3}$ pertencentes ao domínio $\mathbb{S}$, uma função de distância $d\left(s_{1}, s_{2}\right)$ para o espaço métrico $M\{\mathbb{S}, d()\}$ deve satisfazer às seguintes propriedades:

- Simetria: $d\left(s_{1}, s_{2}\right)=d\left(s_{2}, s_{1}\right)$

- Não-negatividade: $0 \leq d\left(s_{1}, s_{2}\right)<\infty$

- Desigualdade triangular: $d\left(s_{1}, s_{2}\right) \leq d\left(s_{1}, s_{3}\right)+d\left(s_{3}, s_{2}\right)$

É importante notar que, quando os objetos a serem comparados são vetores de coordenadas numéricas em um espaço $n$-dimensional com uma distância métrica definida, tem-se um caso particular do espaço métrico denominado espaço vetorial (ou espaço vetorial de dimensão finita).

Existem muitas funções de distância que podem ser aplicadas para medir a similaridade entre dois objetos. Uma das mais amplamente utilizadas é a função de distância $L_{p}$ (ou Minkowski) que pode ser aplicada a domínios vetoriais. Essa função pode ser definida matematicamente da seguinte maneira:

$$
d(x, y)=\sqrt[p]{\sum_{i=1}^{n}\left|x_{i}-y_{i}\right|^{p}}
$$

na qual $n$ é a dimensão do espaço vetorial e quando $p=1,2$, e $\infty$, têm-se as funções $L_{1}$ (Manhattan), $L_{2}$ (Euclidiana) e $L_{\infty}$ (Chebychev) respectivamente. Em alguns casos, a utilização dessas funções de distância requer a normalização dos vetores de características para fazer com que os valores de todas as dimensões dos vetores variem na mesma faixa. Isso assegura que cada dimensão dos vetores de características influencie igualmente na determinação da similaridade entre dois vetores. Segundo [Wilson \& Martinez, 1997], uma maneira de se fazer isso é por meio da atribuição de diferentes pesos para cada uma 
das dimensões dos vetores. Outros exemplos de funções de distância, como Mahalanobis, Camberra e Kullback-Leibler, utilizadas em domínios vetoriais podem ser encontrados em [Long et al., 2002, Wilson \& Martinez, 1997].

Exemplos de funções de distância para os domínios de objetos complexos em espaços não-vetoriais em que não é possível extrair a mesma quantidade de características para todos os objetos (i.e., domínios puramente métricos) incluem a função de distância $L_{E D I T}$ [Levenshtein, 1966] e a função de distância $M_{H}()$ (Metric Histogram Distance) [Bueno, 2001, Traina et al., 2002a].

Variações da função de distância $L_{E D I T}$ podem ser empregadas, por exemplo, na comparação de cadeias de DNA e palavras de uma língua. Utilizando a função de distância $L_{E D I T}$, a comparação de duas cadeias de caracteres $x$ e $y$ resulta na quantidade mínima de caracteres que precisam ser substituídos, removidos ou inseridos em $x$, para que ela se torne igual a $y$. Por exemplo, $L_{E D I T}$ ('amora', 'aroma') $=2$ (duas substituições) e $L_{E D I T}$ ('amora', 'amor') $=1$ (uma remoção).

Já a função de distância $M_{H}()$ foi desenvolvida para ser aplicada no domínio de Histogramas Métricos. Esse extrator de características de imagens considera a correlação existente entre os elementos (chamados bins) adjacentes de histogramas de níveis de cinza na comparação de duas imagens. O número de elementos do histograma métrico é variável, dependendo da imagem a qual ele representa. Assim, dados dois histogramas métricos $x$ e $y$, a distância $M_{H}(x, y)$ é dada pela área não sobreposta entre as duas curvas que representam cada um dos histogramas métricos.

Embora exista uma grande variedade de funções de distância disponível na literatura, não existe um método que determine, de um modo geral, qual deve ser a melhor função de distância a ser utilizada em cada caso, ou seja, aquela que fornece a noção mais significativa de proximidade ou semelhança entre dois objetos. A escolha ou definição de uma função de distância é uma tarefa que depende muito da análise das características específicas do domínio dos dados a serem manipulados. Dois exemplos de trabalhos que apresentam estudos comparativos, extensões e definições de novas funções de distância, considerando diferentes aspectos dos dados a serem comparados, são descritos em [Wilson \& Martinez, 1997], para dados nominais (discretos), e em [Aggarwal et al., 2001], para dados em altas dimensões.

\section{Tipos de Consultas por Similaridade}

Ao contrário das aplicações tradicionais de bases de dados que manipulam dados numéricos e textuais por meio da realização de consultas por igualdade e ordem, as aplicações que lidam com dados complexos, como dados de natureza multimídia, requerem a realização de consultas por similaridade, ou seja, consultas que realizem busca por objetos da base que sejam similares a um objeto de consulta, de acordo com uma certa medida de similaridade (baseada em uma função de distância). 
Existem basicamente dois tipos de consultas por similaridade: as consultas por abrangência (Range query - Rq), cujo foco de interesse está centrado em todos os objetos da base de dados que sejam dissimilares do objeto de consulta até no máximo um certo limiar; e as consultas aos $k$-vizinhos mais próximos ( $k$-Nearest neighbor query $-k$-NNq), cujo interesse está relacionado à recuperação dos $k$ objetos mais similares ao objeto de consulta. Adotando como base os trabalhos de [Böhm et al., 2001, Chávez et al., 2001], uma definição formal para cada um desses tipos de consulta é apresentada abaixo:

- Consulta por Abrangência: Dado um objeto de consulta $s_{q} \in \mathbb{S}$, um conjunto de objetos $S \subseteq \mathbb{S}$, uma função de distância $d()$ e uma distância máxima de busca $\xi$, a consulta $R_{q}\left(s_{q}, \xi\right)$ recupera todos os objetos de $S$ que estejam a uma distância de $s_{q}$ de no máximo $\xi$. O subconjunto resposta resultante $S^{\prime} \subseteq S$ é $\left\{s_{i} \in S \mid d\left(s_{q}, s_{i}\right) \leq \xi\right\}$.

A Figura 2.4 (a) apresenta um exemplo de consulta por abrangência em um conjunto de objetos, considerando diferentes funções de distância $L_{p}$ para uma dada distância máxima de busca $\xi$.

- Consulta aos $k$-Vizinhos mais Próximos: Dado um objeto de consulta $s_{q} \in \mathbb{S}$, um conjunto de objetos $S \subseteq \mathbb{S}$, uma função de distância $d()$ e um número inteiro $k$, a consulta $k$ - $N N q\left(s_{q}, k\right)$ recupera os $k$ objetos mais próximos de $s_{q}$ em $S$. O subconjunto resposta resultante $S^{\prime} \subseteq S$ é $\left\{s_{i} \in S|| S^{\prime} \mid=k e \forall s_{r} \in S^{\prime}, \forall s_{j} \in\left[S-S^{\prime}\right], d\left(s_{q}, s_{r}\right) \leq d\left(s_{q}, s_{j}\right)\right\}$.

Um exemplo de uma consulta aos $k$-vizinhos mais próximos, com $k=4$, pode ser visto na Figura $2.4(\mathrm{~b})$.

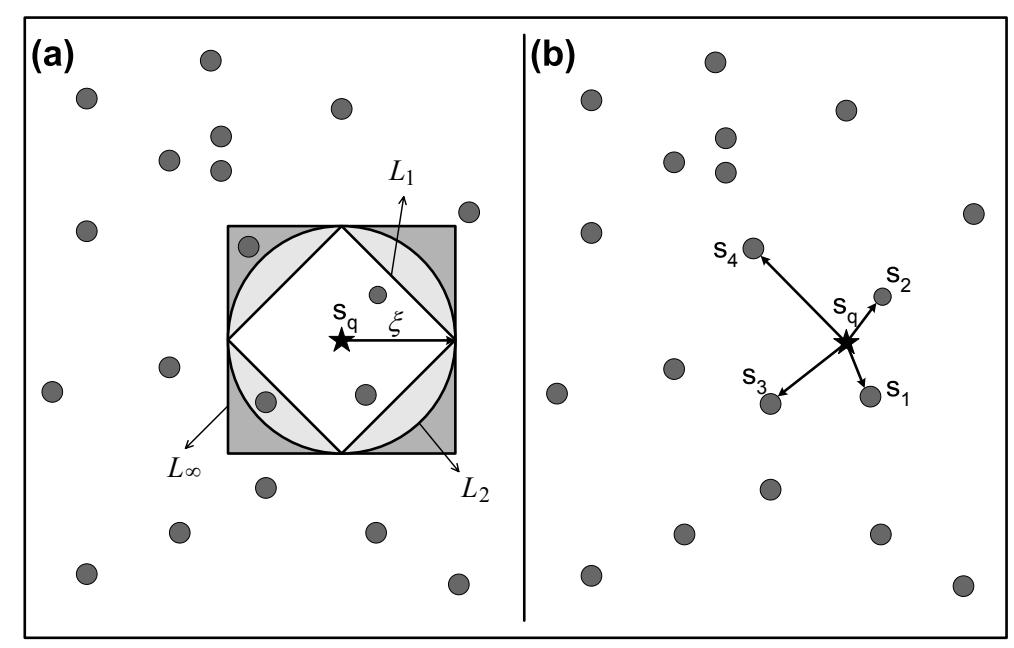

Figura 2.4: Exemplos de consultas por similaridade em um conjunto de objetos. (a) Consulta por abrangência, considerando as funções de distância $L_{1}, L_{2}$ e $L_{\infty}$. (b) Consulta aos $k$-vizinhos mais próximos considerando $k=4$, para a distância euclidiana. 
Além dos dois tipos básicos de consultas por similaridade mencionados anteriormente, também foram propostas operações de junção por similaridade. Esse tipo de operação compara os objetos de dois conjuntos de dados $S, R \subseteq \mathbb{S}$ ordenando pares de objetos $<s_{i}, r_{i}>\mid s_{i} \in S, r_{i} \in R$ de acordo com suas distâncias. Existem basicamente três tipos de junções por similaridade: junção por abrangência (Range Join $-\stackrel{R q}{\bowtie}$ ), junção pelos $k$ vizinhos mais próximos ( $k$-Nearest Neighbors Join $-\underset{k}{k-N q}$ ) e a junção dos $k$-pares de vizinhos mais próximos (k-Closest Neighbors Join $-\stackrel{k-C N q}{\bowtie}$ ) [Böhm \& Krebs, 2002].

- Junção por Abrangência: Dados dois conjuntos de objetos $S, R \subseteq \mathbb{S}$, uma função de distância $d()$ e uma distância máxima de busca $\xi$, a consulta $\stackrel{R q}{\bowtie}(\xi)$ recupera os pares de objetos pertencentes a $S$ e $R$ que estejam a uma distância de no máximo $\xi$ entre si. O subconjunto resposta resultante $S^{\prime} \subseteq S \times R$ é $\left\{<s_{i}, r_{j}>\in S \times R \mid d\left(s_{i}, r_{j}\right) \leq \xi\right\}$.

- Junção pelos k-Vizinhos mais Próximos: Dados dois conjuntos de objetos $S, R \subseteq \mathbb{S}$, uma função de distância $d()$ e um número inteiro $k$, a consulta $\stackrel{k-N N q}{\bowtie}(k)$ recupera pares de objetos pertencentes a $S$ e $R$ de maneira que existam $k$ pares para cada objeto pertencente a $S$, juntamente com os objetos de $R$ mais próximos. O subconjunto resposta resultante $S^{\prime} \subseteq S \times R$ é $\left\{<s_{i}, r_{j}>\in S \times R|| S^{\prime} \mid=[|S| * k]\right.$ e $\left.\forall<s_{i}, r_{j}>\in S^{\prime}, \forall<s_{i}, r_{n}>\in\left[S \times R \backslash S^{\prime}\right], d\left(s_{i}, r_{j}\right) \leq d\left(s_{i}, r_{n}\right)\right\}$.

- Junção dos k-Pares de Vizinhos mais Próximos: Dados dois conjuntos de objetos $S, R \subseteq \mathbb{S}$, uma função de distância $d()$ e um número inteiro $k$, a consulta ${ }_{\bowtie}^{k-C N q}(k)$ recupera os $k$ pares de objetos de $S$ e $R$ mais próximos entre si. O subconjunto resposta resultante $S^{\prime} \subseteq S \times R$ é $\left\{<s_{i}, r_{j}>\in S \times R|| S^{\prime} \mid=k\right.$ e $\left.\forall<s_{i}, r_{j}>\in S^{\prime}, \forall<s_{m}, r_{n}>\in\left[S \times R \backslash S^{\prime}\right], d\left(s_{i}, r_{j}\right) \leq d\left(s_{m}, r_{n}\right)\right\}$.

A Figura 2.5 apresenta uma ilustração dos três tipos de junção por similaridade descritos anteriormente. Nessa figura, os círculos pretos representam objetos do conjunto $S$ e os de cor cinza representam objetos do conjunto $R$.

\subsubsection{Estruturas de Indexação}

Embora as consultas descritas na Seção 2.1.2 possam ser respondidas por meio de uma busca seqüencial na base de dados, essa estratégia não é a mais adequada para ser utilizada em grandes conjuntos de dados, uma vez que o custo computacional envolvido é muito alto. Assim, outro aspecto importante na recuperação de dados complexos por conteúdo está relacionado à utilização de estruturas de indexação apropriadas para espaços métricos que possam agilizar a realização de consultas por similaridade, ou seja, minimizar o número de cálculos de distância necessários para executar uma consulta. 


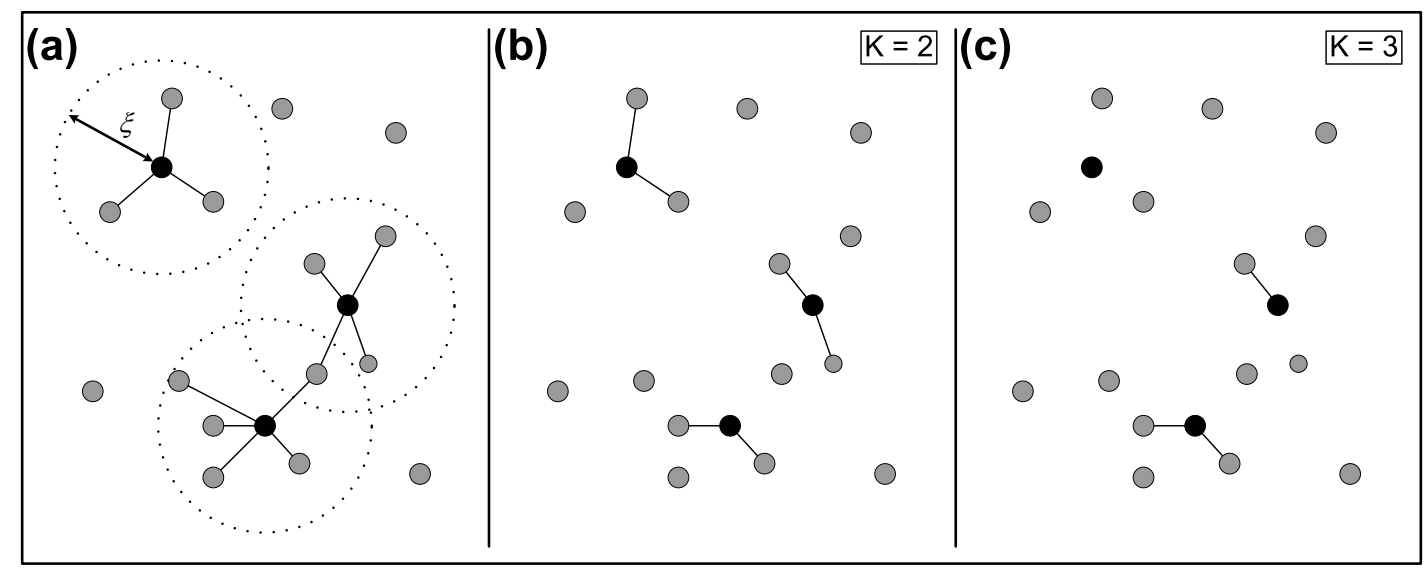

Figura 2.5: Diferenças entre os três operadores de junção por similaridade. (a) Junção por Abrangência. (b) Junção pelos $k$-Vizinhos mais Próximos considerando $k=2$. (c) Junção dos $k$ Pares de Vizinhos mais Próximos considerando $k=3$.

Estruturas de indexação, como a B-tree e suas variantes, e estruturas de hashing (uma descrição sobre essas estruturas pode ser encontrada em [Garcia-Molina et al., 2002]) são normalmente fornecidas pelos SGBD. Entretanto, embora essas estruturas de indexação sejam suficientes para suprir as necessidades dos usuários de aplicações que lidam com dados tradicionais, elas não são adequadas para os sistemas de recuperação de dados complexos por conteúdo, que lidam com dados que apresentam alta dimensionalidade e não apresentam relação de ordem.

Para consultas por similaridade em espaços métricos genéricos (que englobam tanto dados espaciais com dimensão definida quanto dados adimensionais) os Métodos de Acesso Métricos (Metric Access Methods - MAM) são os mais adequados. Os MAM são estruturas de indexação baseadas em distância que utilizam exclusivamente funções de distância (como as definidas na Seção 2.1.2) para organizar os objetos na base de dados. Vários trabalhos têm apresentado propostas de MAM na literatura. Dentre as primeiras estruturas a serem propostas estão as chamadas BK-trees (BurkhardKeller-trees). A idéia básica dessas estruturas consiste na escolha de um objeto arbitrário central e na aplicação de uma função de distância para dividir os demais objetos em vários subconjuntos. Dessa maneira, a estrutura de indexação é construída executando-se esse mesmo procedimento, recursivamente, para cada subconjunto não vazio. Para obter uma visão geral sobre essas e outras estruturas de indexação comumente citadas na literatura, como a VP-tree (Vantage Point tree) [Yianilos, 1993], a MVP-tree (Multi-Vantage Point tree) [Bozkaya \& Özsoyoglu, 1997], a GNAT (Geometric Near-neighbor Access Tree) [Brin, 1995] e a M-tree [Ciaccia et al., 1997] veja [Bozkaya \& Ozsoyoglu, 1999, Chávez et al., 2001]; e para a Slim-tree, a Família-Omni e a DBM-tree veja [Traina et al., 2000, Filho et al., 2001, Vieira et al., 2004] respectivamente. 


\section{Slim-tree}

A Slim-tree é uma árvore dinâmica e balanceada que cresce a partir das folhas em direção a raiz (bottom-up). Assim como outros MAM (ex.: M-tree e DBM-tree), ela agrupa os objetos de um conjunto de dados em páginas de tamanho fixo, sendo que cada página corresponde a um nó da árvore.

A Slim-tree armazena todos os objetos nas folhas, organizando-os hierarquicamente na árvore. Essa hierarquia é construída a partir da seleção de objetos, denominados objetos representantes, que definem centros de regiões no espaço de dados. Cada região possui um raio de cobertura, e apenas os objetos que forem cobertos pelo raio de cobertura de uma determinada região podem ser armazenados nesse nó. Desta forma, cada nó da árvore (exceto o nó raiz) possui, basicamente, um objeto representante, um raio de cobertura e os objetos do conjunto de dados que estão cobertos pela região do nó. A Slim-tree possui dois tipos de nós: nós de dados (ou folhas); e nós índice. Cada tipo de nó armazena um número máximo pré-definido de objetos. A Figura 2.6(a) ilustra a organização de nós, com capacidade máxima igual a 3 objetos, em um espaço bi-dimensional utilizando a função de distância Euclidiana $\left(L_{2}\right)$. Nessa figura são ilustrados o objeto representante (em preto), o raio de cobertura do nó e os objetos abrangidos pela região do nó.

Assim como outras estruturas bottom-up (ex.: B-tree), a construção da Slim-tree é realizada da seguinte maneira: para cada novo objeto a ser inserido, o algoritmo de inserção percorre a árvore a partir da raiz para encontrar um nó folha cujo raio de cobertura possa abranger o novo objeto; se mais de um nó se qualificar, o algoritmo de inserção utiliza uma política de escolha para selecionar a sub-árvore mais apropriada para armazenar o novo objeto (ChooseSubtree); caso nenhum nó se qualifique, seleciona-se o nó que possui o representante mais próximo do novo objeto. Esse processo é aplicado recursivamente para todos os níveis da árvore até chegar a um nó folha, no qual o novo objeto é realmente inserido. As políticas de escolha de sub-árvore da Slim-tree são:

1. Aleatório (Random): seleciona aleatoriamente um dos nós qualificados;

2. Distância mínima (MinDist): escolhe o nó cujo representante esteja o mais próximo possível do novo objeto, i.e., o nó que resulte na menor distância entre o novo objeto e o seu representante;

3. Ocupação mínima (MinOccup): seleciona entre os nós qualificados aquele que possui a menor taxa de ocupação. Essa é a política padrão.

Segundo [Traina-Jr. et al., 2002], a política de ChooseSubtree utilizada na construção da Slim-tree afeta bastante as características da árvore resultante. Por exemplo, a opção MinOccup tende a gerar árvores com maior taxa de ocupação dos nós, o que resulta em um menor número de acessos a disco nas consultas. Entretanto, essa opção também leva 
a maiores taxas de sobreposição entre os nós. Por outro lado, a opção MinDist tende a gerar árvores mais altas com menor taxa de ocupação e menor grau de sobreposição dos nós.

À medida que os objetos são inseridos na árvore novos nós são criados quando os nós atingem suas capacidades máximas de armazenamento. Os objetos são redistribuídos entre os nós (antigos e novos) de acordo com uma política de divisão de nós. Um objeto de cada nó dividido (antigo e novo) é selecionado como representante e inserido, juntamente com seus respectivos raios de cobertura, no nó pai. A Slim-tree possui três políticas para a redistribuição de objetos entre nós. São elas:

1. Aleatório (Random): os dois novos representantes são selecionados aleatoriamente e os objetos existentes são distribuídos entre eles;

2. Mínimo dos maiores raios (MinMax): todas as combinações de pares de objetos possíveis são considerados como potenciais representantes. Para cada par, atribuemse todos os objetos a um dos representantes. O par que minimizar o raio de cobertura é o escolhido;

3. Minimal Spanning Tree (MST): essa estratégia baseia-se na construção de uma MST sobre os objetos [Kruskal, 1956]. Após a construção da MST, sua aresta mais longa é removida e o objeto mais central de cada um dos dois agrupamentos resultantes é selecionado como representante do nó. Essa opção produz Slim-trees tão boas quanto as criadas utilizando a opção MinMax, em uma fração do tempo. Assim, essa é a política padrão de quebra de nós.

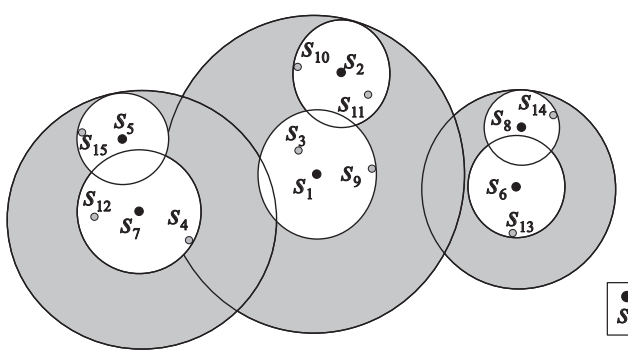

(a)

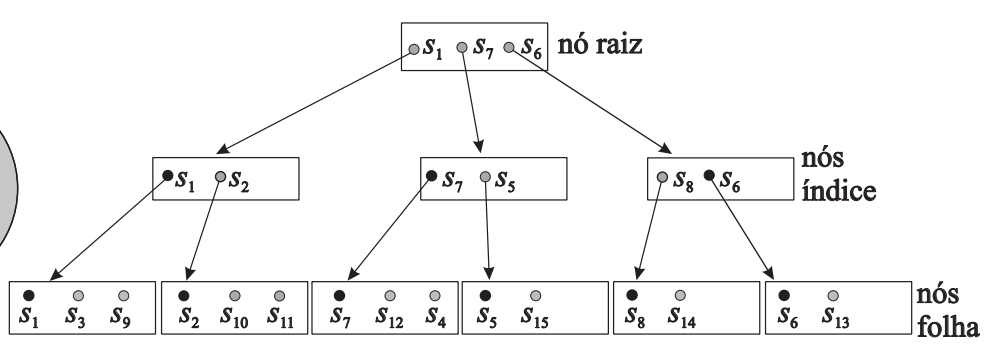

(b)

Figura 2.6: A representação de uma Slim-tree com 15 objetos (a) e sua estrutura lógica (b). Os objetos estão organizados em três níveis e a capacidade máxima dos nós é igual a 3 .

A Figura 2.6 apresenta um exemplo de uma Slim-tree contendo 15 objetos $\left\{s_{1}, s_{2}, \ldots, s_{15}\right\}$ armazenados em nós com capacidade máxima igual a 3. Na Figura 2.6(a), os círculos brancos representam os nós folha; os círculos cinza, os nós índice. Os objetos representantes dos nós são ilustrados em preto. Note que nesse exemplo existe sobreposição entre as regiões determinadas pelos nós da árvore. 
Um problema comum a todos os MAM mencionados nessa seção está relacionado à sobreposição dos nós. À medida que essa sobreposição aumenta, a eficiência das estruturas diminui, uma vez que todos os nós cobertos por uma região de consulta têm que ser processados durante a operação de busca. A Slim-tree foi desenvolvida com o objetivo de minimizar a sobreposição entre os nós, provendo mecanismos para mensurar o grau de sobreposição entre os nós da árvore (ex.: FatFactor) e para reorganizar a árvore (Slimdown). Utilizando esses conceitos, a Slim-tree permite realizar consultas por similaridade de maneira eficiente, minimizando tanto o número de cálculos de distâncias quanto o de acessos a disco.

\subsection{Linguagens e Sistemas para a Recuperação por Conteúdo}

A crescente necessidade de fornecer suporte para a recuperação de dados complexos por conteúdo levou ao surgimento de vários sistemas. Muitos deles foram desenvolvidos focalizando aspectos específicos da manipulação desses tipos de dados, como a utilização de novas estruturas de indexação; a disponibilização de diferentes representações de características inerentes a esses tipos de dados; a integração de técnicas de recuperação baseadas em texto e conteúdo; e também, a implementação de diferentes interfaces de consulta. Além disso, algumas linguagens de consulta para SGBD também têm sido propostas. As próximas seções apresentam alguns exemplos representativos de linguagens e sistemas desenvolvidos para a recuperação de dados complexos por conteúdo.

\subsubsection{Linguagens}

Atualmente, a maioria das aplicações utilizam SGBD relacionais, nos quais a linguagem mais amplamente usada para a manipulação de dados é a SQL. Até o momento, poucas propostas de extensão da linguagem SQL para o suporte de consultas por similaridade foram feitas. Uma extensão simples da linguagem SQL é apresentada em [Carey \& Kossmann, 1997, Carey \& Kossmann, 1998]. O trabalho apresentado nesses artigos estuda a adição da construção STOP AFTER no comando SELECT, como um sufixo opcional, com o objetivo de fornecer suporte para a declaração de consultas que necessitem de ordenação nas respostas. Outra extensão, denominada SQL/sim [Gao et al., 2004], oferece a capacidade de expressar consultas $k$-NNq por meio da utilização de predicados definidos por usuários (user-defined predicate), denominados NN-UDP.

Outro trabalho inicial nesse sentido, desenvolvido por um membro do GBDI (Grupo de Bases de Dados e Imagens do ICMC/USP), foi apresentado em [Araújo, 2003]. Esse trabalho descreve uma extensão da linguagem SQL e uma proposta de sistema, CIRCE (Content-based Image Retrieval Core Engine), específicas para a recuperação de imagens 
por conteúdo. Embora esse trabalho tenha sido desenvolvido utilizando uma abordagem totalmente relacional, ele não abrange todos os tipos de consultas por similaridade descritos na Seção 2.1.2 e, além disso, a estratégia utilizada para a definição de medidas de similaridade restringe a utilização das mesmas por associar a criação da métrica à definição de um atributo complexo. A utilização dessa abordagem acaba impedindo que uma métrica definida para um determinado atributo complexo possa ser utilizada por outros atributos complexos do mesmo domínio.

Também existe um padrão proposto pela ISO (International Standards Organization) conhecido como SQL/MM (SQL Multimedia and Application Packages - ISO/IEC 13249) [Melton \& Eisenberg, 2001]. Esse padrão é composto de várias partes que prevêem o suporte para o armazenamento e a manipulação de vários tipos de dados multimídia (imagens, áudio, vídeo, textos longos e etc.) por meio da utilização de tipos (User Defined Types - UDT) e funções (User Defined Functions - UDF) definidos pelos usuários. Apesar da abordagem adotada pelo padrão SQL/MM permitir que se possam utilizar algoritmos altamente otimizados para cada operação de busca específica, ela não permite a realização de otimizações entre esses operadores ou entre a integração desses operadores com os operadores utilizados em consultas tradicionais.

Embora os trabalhos descritos acima apresentem maneiras de disponibilizar o suporte para a realização de consultas por similaridade em SQL, nenhum deles é capaz de fornecer um suporte robusto, abrangente e totalmente integrado às outras características da linguagem.

\subsubsection{Sistemas}

Atualmente existem vários sistemas disponíveis para a manipulação de dados complexos, tanto acadêmicos quanto comerciais. Sistemas de gerenciamento de bases de dados comerciais, como o Oracle InterMedia [OracleCorporation, 2005] e os módulos opcionais IAV Extenders (Image, Audio and Video Extenders) fornecidos pelo IBM DB2 [IBMCorporation, 2003], por exemplo, permitem o armazenamento, a manipulação e a recuperação de imagens, vídeo e áudio seguindo a abordagem do padrão SQL/MM.

O suporte à recuperação por conteúdo é fornecido apenas para dados do tipo imagem, tanto no Oracle InterMedia quanto nos IAV Extenders do IBM DB2, sendo que os outros tipos de dados - áudio e vídeo - podem ser recuperados por meio da realização de consultas sobre atributos que armazenam meta-dados (como tipo de compressão, formato da mídia, duração, entre outros) ou outros dados (como textos descritivos) associados ao objeto complexo em questão. Esse suporte foi adicionado aos SGBD Oracle e IBM DB2 por meio da integração de sistemas especialmente desenvolvidos para a recuperação de imagens por conteúdo, o Virage e o QBIC respectivamente.

O QBIC (Query By Image Content) [Flickner et al., 1995] foi o primeiro sistema co- 
mercial desenvolvido para a recuperação de imagens baseada em conteúdo. Esse sistema permite a realização de consultas baseadas em características de cor, textura e forma. Essas consultas podem ser efetuadas a partir de uma imagem de consulta, de um esboço desenhado por um usuário e também a partir da seleção de padrões de cor e textura. Outra característica importante do QBIC está relacionada à utilização de uma estrutura de indexação multi-dimensional, variante da R-tree, chamada $\mathrm{R}^{*}$-tree [Beckmann et al., 1990].

Assim como o QBIC, o Virage [Bach et al., 1996] é um mecanismo de busca que permite a realização de consultas baseadas no conteúdo das imagens considerando características de cor (local e global), textura e forma. Além disso, ele permite a realização de combinações arbitrárias dessas características e o ajuste de pesos associados a cada uma delas.

Outros exemplos de sistemas especificamente desenvolvidos para a recuperação de imagens por conteúdo incluem o VisualSEEK e o Photobook. O VisualSEEK [Smith \& Chang, 1996] é um sistema híbrido que suporta a recuperação de imagens baseada na especificação de características visuais de cor e do relacionamento espacial entre elas. Resumidamente, a estratégia adotada por esse sistema funciona da seguinte maneira: quando as imagens são inseridas na base de dados, cada imagem é decomposta em regiões com propriedades descritivas, como cor, e propriedades espaciais, como tamanho, localização e relacionamento com outras regiões. Assim, a recuperação de imagens nesse sistema consiste na realização de comparações entre as regiões das imagens.

O sistema Photobook [Pentland et al., 1994] utiliza três tipos diferentes de descritores para representar as características de forma, textura e face. Cada um deles foi implementado para um domínio de imagens diferente. A característica principal desse sistema está relacionada à estratégia de recuperação de imagens que possibilita a combinação de anotações textuais com um ou mais descritores de características. Mais exemplos de sistemas de recuperação de imagens podem ser encontrados em [Aslandogan \& Yu, 1999, Rui et al., 1997, Veltkamp \& Tanase, 2000].

Embora a área de recuperação por conteúdo tenha sido desenvolvida inicialmente considerando o domínio de imagens, outros domínios de dados também têm sido abordados nessa área. Com o aumento da disponibilização de áudio em formato digital, especialmente músicas, também se tornou necessário prover meios de manipulação eficientes para o gerenciamento de grandes coleções de áudio. Conseqüentemente, vários sistemas também têm sido desenvolvidos para a recuperação de áudio por conteúdo.

Um exemplo de sistema de recuperação por conteúdo que pode ser utilizado para a recuperação de diversos tipos de áudio é apresentado em [Wold et al., 1996]. Esse sistema permite que um usuário possa: consultar ou recuperar sons por meio da utilização de características acústicas e perceptivas; especificar classes com base nessas características; e solicitar a recuperação de sons similares ou dissimilares a um determinado exemplo.

Já a recuperação por similaridade de músicas baseada em conteúdo é explorada pelo 
sistema descrito em [Ghias et al., 1995]. Esse sistema propõe uma variação da abordagem de consulta por exemplo (Query by Example - QBE), denominada Query by Humming. Nessa abordagem, o exemplo de consulta fornecido ao sistema é gerado pelo usuário, que cantarola a melodia da música desejada, e o sistema recupera as músicas cujas melodias se assemelhem ao exemplo dado. Outros exemplos de sistemas de recuperação de áudio por conteúdo voltados para a recuperação de música podem ser encontrados em [Foote, 2000, Tzanetakis \& Cook, 2000, Typke et al., 2005].

\subsection{Considerações Finais}

As áreas de aplicação para os sistemas de recuperação de dados complexos por conteúdo são diversas e podem incluir: bibliotecas, publicidade, medicina, engenharia, sistemas de informações geográficas, educação, entretenimento, vendas de áudio e vídeo pela web, entre outras.

Nem todas essas áreas de aplicação compartilham os mesmos requisitos. Embora alguns requisitos importantes para muitas aplicações, como o tempo de resposta de uma consulta e fácil acessibilidade, estejam sendo bastante explorados em vários trabalhos que tratam de aspectos relacionados à representação, indexação e consulta de dados complexos, ainda existem problemas em aberto.

Um dos problemas está relacionado à falta de flexibilidade das arquiteturas dos sistemas disponíveis para a recuperação de dados complexos por conteúdo. A maioria dos sistemas existentes foi desenvolvida para um domínio de dados específico, apresentando uma arquitetura fechada, que não permite a aplicações que já acessam dados tradicionais serem ampliadas para permitir o acesso a outros tipos de dados, como imagem e áudio. Isso pode representar um grande problema, por exemplo, para a extensão de aplicações típicas de um sistema de informação hospitalar, como o prontuário médico eletrônico, os sistemas de cadastro de paciente e os sistemas administrativos, de maneira que elas também suportem a recuperação de imagens. Assim, seria interessante considerar a utilização de arquiteturas que permitissem a implementação de sistemas com suporte a dados complexos que fossem capazes de se adequar aos requisitos particulares de cada domínio de aplicação.

Embora SGBD, como o Oracle e o IBM DB2, forneçam suporte para a manipulação e recuperação de vários tipos de dados complexos por meio da utilização de UDF e UDT (permitindo a recuperação por conteúdo apenas de imagens), a abordagem adotada por eles não permite que otimizações entre esses operadores, ou entre a integração desses operadores com os operadores utilizados em consultas sobre dados tradicionais, possam ser realizadas. O suporte à realização de consultas por similaridade de conteúdo em SQL de maneira nativa é importante para permitir a otimização de todo o conjunto de operações de busca envolvidas em cada consulta. Assim, a integração de consultas por similaridade 
em uma abordagem totalmente relacional é um passo fundamental para permitir que objetos complexos sejam suportados como "cidadãos de primeira classe" nos sistemas de gerenciamento de bases de dados modernos.

A necessidade de solucionar esses problemas motivou o desenvolvimento de grande parte do trabalho apresentado nesta tese, que consistiu na proposta de uma extensão da linguagem SQL e na implementação de um mecanismo de recuperação por similaridade que permitem a realização de consultas por similaridade em SGBD relacionais de maneira totalmente integrada com os outros recursos da linguagem. Os conceitos relacionados a essa extensão são descritos no Capítulo 4 e o mecanismo de recuperação por similaridade desenvolvido é apresentado no Capítulo 5. 
Capítulo

3

\section{Descoberta de Conhecimento em Bases de Dados}

O processo de descoberta de conhecimento em bases de dados (Knowledge Discovery in Databases - KDD) tem como objetivo extrair conhecimento de alto nível a partir de dados de baixo nível dentro do contexto de grandes conjuntos de dados. Freqüentemente a expressão "mineração de dados" é usada como sinônimo para tal processo, mas tipicamente KDD engloba mais do que mineração de dados. KDD se refere ao processo de descoberta de conhecimento como um todo, enquanto a mineração de dados refere-se a um passo particular desse processo, sendo responsável pela aplicação de algoritmos específicos para a extração de padrões dos dados [Fayyad, 1997].

Nas últimas décadas, uma grande variedade de técnicas de mineração de dados foram desenvolvidas para atender aos objetivos de diversas aplicações de KDD. Inicialmente, o foco principal das pesquisas nessa área estava voltado para a definição de novas operações e o desenvolvimento de novos algoritmos de mineração. A maioria dos algoritmos tratavam a base de dados como sendo apenas um repositório a partir do qual os dados eram extraídos para serem inseridos em estruturas em memória antes de serem enviados aos processos de análise específicos de cada algoritmo de mineração de dados. Esse fato limitava a quantidade de dados que podiam ser manipulados eficientemente por esses algoritmos.

Com o objetivo de tornar o processo de KDD uma ferramenta para aplicações reais que armazenam seus dados em SGBD relacionais, vários pesquisadores começaram a considerar uma mudança de estratégia, abordando questões relacionadas à integração das técnicas de mineração de dados com SGBD relacionais. É nesse contexto que reside uma das principais aplicações desta tese de doutorado. 
Neste capítulo, os conceitos gerais relacionados ao processo de descoberta de conhecimento em bases de dados e uma breve descrição das tarefas de mineração de dados são apresentados nas Seções 3.1 e 3.2, respectivamente. Os principais aspectos relacionados à integração de técnicas de mineração de dados com SGBD relacionais são abordados na Seção 3.3. A Seção 3.4 detalha alguns dos principais algoritmos empregados pela técnica de detecção de agrupamentos de dados. As considerações finais são apresentadas na Seção 3.5 .

\subsection{Processo de Descoberta de Conhecimento em Ba- ses de Dados}

O processo de descoberta de conhecimento em bases de dados pode ser definido como sendo "O processo de identificação de padrões válidos, inéditos, potencialmente úteis e essencialmente compreensiveis embutidos nos dados" [Fayyad et al., 1996]. Cada termo usado nessa definição possui um significado específico dentro do contexto do processo de KDD [Fayyad et al., 1996, Rezende, 2003]:

- Dados: Conjunto de fatos. No contexto de base de dados relacionais, por exemplo, cada item de dado (objeto) armazenado em uma tabela corresponde a uma tupla composta por um conjunto de valores de atributos;

- Padrões: Correspondem a abstrações de um subconjunto dos dados que representam uma tendência dos dados repetirem propriedades;

- Processo: Indica que o processo de KDD envolve a realização de várias etapas;

- Válidos: Os padrões encontrados devem ser válidos para novos dados, com algum grau de certeza;

- Inéditos: Os padrões descobertos devem fornecer informações previamente desconhecidas sobre os dados;

- Úteis: Os padrões descobertos devem trazer algum benefício para a tarefa que apoiam, como, por exemplo, o processo de tomada de decisão, e devem ser entendidos para serem utilizados;

- Compreensíveis: Os padrões encontrados devem permitir uma análise mais profunda dos dados;

- Conhecimento: É determinado por meio de medidas de utilidade, originalidade e compreensão definidas de acordo com um domínio específico. 
O processo de KDD é interativo e iterativo, envolvendo a realização de várias etapas. Embora diferentes autores descrevam esse processo como sendo composto por um número variável de etapas, é possível identificar pelo menos três etapas básicas [Rezende, 2003]:

1. Pré-processamento: Etapa na qual os dados disponíveis são preparados para análise, por meio da realização de operações como limpeza, integração, seleção e transformação dos dados;

2. Descoberta de Padrões: Principal etapa do processo de KDD, é nela que os dados preparados na etapa anterior são enviados a algoritmos de mineração de dados específicos, de acordo com o tipo de tarefa de mineração a ser realizada. Alguns exemplos de tarefas de mineração de dados incluem Deteç̧ão de Agrupamentos, Classificação e Associação. Formalmente, a etapa de Mineração de Dados (Data Mining - DM) pode ser definida como: "A etapa do processo de KDD que consiste na aplicação de algoritmos específicos para enumerar padrões dos dados, dentro de limitações aceitáveis de eficiência computacional" [Fayyad et al., 1996].

3. Avaliação dos Resultados: Etapa final na qual o resultado obtido pelos algoritmos de DM são avaliados quanto a sua utilidade e apresentados por meio de técnicas de representação de conhecimento e visualização (gráficos, tabelas, regras, etc), para que possam ser entendidos.

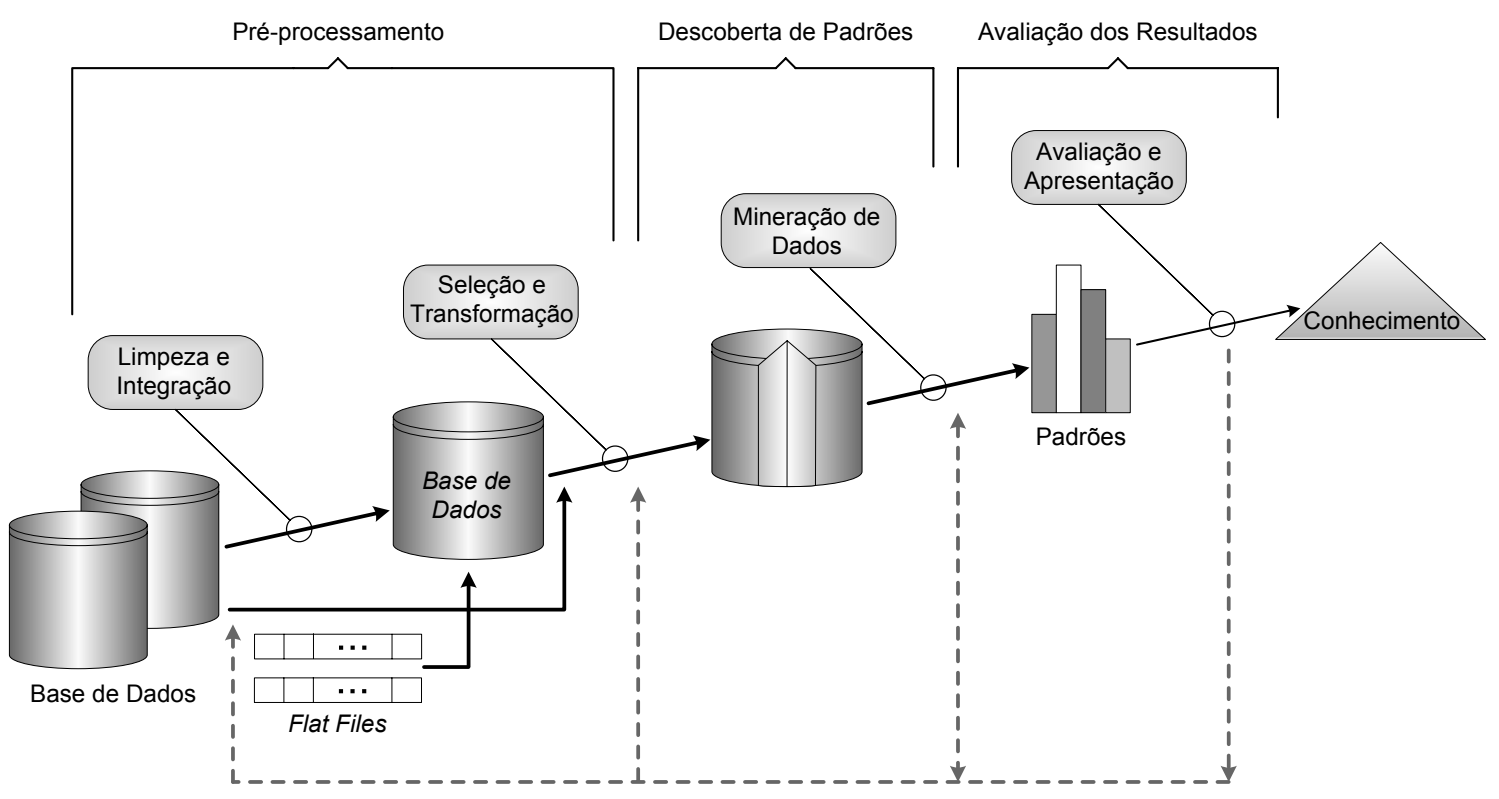

Figura 3.1: Uma visão geral dos passos que compõem o processo de KDD. Adaptada de [Han \& Kamber, 2001].

O fluxo básico das etapas do processo de KDD é ilustrado na Figura 3.1. Embora na prática todas as etapas sejam importantes para o sucesso da aplicação do processo de KDD, a maioria dos trabalhos realizados têm como foco a etapa de mineração de dados. 
Assim, nas próximas seções serão apresentados os principais conceitos relacionados às tarefas de mineração de dados.

\subsection{Tarefas de Mineração de Dados}

De maneira geral, as tarefas de mineração de dados envolvem o ajuste de modelos ou a determinação de padrões em um conjunto de dados [Fayyad et al., 1996]. Dentro desse contexto, o termo modelo refere-se a uma descrição abstrata de um conjunto de dados como um todo, enquanto o termo padrão representa a caracterização de apenas alguns aspectos locais do conjunto de dados [Hand et al., 2001].

Por exemplo, um modelo simples que represente o relacionamento existente entre uma variável $Z$ e outras duas variáveis $X$ e $Y$ em um conjunto de dados pode tomar a seguinte forma (ou representação) funcional: $Z=a X+b Y$, na qual $a$ e $b$ são parâmetros do modelo determinados durante a execução do processo de mineração de dados. Já um padrão pode ser especificado, por exemplo, por meio do estabelecimento de restrições para os valores das variáveis $X$ e $Y$ em uma regra probabilística da forma: se $X>x_{1}$ então $\operatorname{prob}\left(Y>y_{1}\right)=p_{1}$.

Segundo [Han \& Kamber, 2001], as tarefas de mineração de dados podem ser divididas em cinco categorias de acordo com os objetivos desejáveis para a solução a ser encontrada:

1. Análise Exploratória de Dados: O objetivo dessa tarefa é explorar os dados sem que haja qualquer idéia clara sobre o que se espera descobrir. Essa tarefa pode ser descrita como sendo a "geração de hipóteses guiada pelos dados" [Hand et al., 2001], ou seja, os padrões presentes nos dados levam à geração de hipóteses. Essa tarefa explora métodos interativos e visuais para a descoberta de padrões presentes nos dados. Exemplos de técnicas empregadas na realização dessa tarefa incluem: técnicas simples de sumarização, como a definição da média e desvio padrão de todos os campos; e técnicas de visualização de dados multidimensionais [Fayyad et al., 1996].

2. Modelagem Descritiva: O objetivo de um modelo descritivo consiste em apresentar, de maneira adequada, uma descrição das principais características dos dados (ou do processo que os gera). Alguns exemplos de descrições são: modelos que descrevem a distribuição de probabilidade dos dados (estimativa de densidade); o particionamento de um espaço multi-dimensional em grupos (detecção de agrupamentos e segmentação); e modelos que descrevem as dependências mais significativas entre variáveis (modelagem de dependências).

3. Modelagem Preditiva: O objetivo dessa tarefa é a construção de um modelo que permita prever o valor de um atributo de interesse a partir de valores conhecidos de outros atributos. Exemplos de tarefas preditivas incluem a classificação e a 
regressão, sendo que o atributo a ser predito na tarefa de classificação é categórico, e na tarefa de regressão, é quantitativo.

4. Descoberta de Padrões e Regras: Como o nome sugere, o objetivo dessa tarefa é a detecção de padrões em conjuntos de dados. Esse objetivo pode ser alcançado, por exemplo, por meio da utilização de técnicas de descoberta de regras de associação.

5. Recuperação por Conteúdo: Nessa tarefa, o objetivo consiste em, dado um padrão de interesse, encontrar padrões similares no conjunto de dados. O ponto crítico da realização dessa tarefa está relacionado à definição da noção de similaridade. Essa tarefa é comumente utilizada para a realização de buscas em conjuntos de dados de imagens (Content-Based Image Retrieval - CBIR) [Smeulders et al., 2000] e textos (Information Retrieval - IR) [Salton \& McGill, 1983, Baeza-Yates \& Ribeiro-Neto, 1999].

Várias técnicas de mineração de dados foram desenvolvidas para atender aos objetivos específicos de cada tarefa descrita acima. Uma das técnicas que tem se destacado em várias aplicações de mineração de dados (ex.: exploração de dados científicos, IR e mineração de textos, aplicações de base de dados espaciais, marketing, auxílio ao diagnóstico médico e biologia computacional) é a detecção de agrupamentos. Essa técnica será descrita em detalhes na Seção 3.4. Mais detalhes a respeito de outras técnicas de mineração citadas anteriormente podem ser obtidos em [Han \& Kamber, 2001, Hand et al., 2001].

\subsection{A Integração de Algoritmos de Mineração de Da- dos com SGBDR}

As técnicas de KDD evoluiram a partir da integração de técnicas e conceitos de diversas áreas de pesquisa como Base de Dados, Aprendizado de Máquina, Reconhecimento de Padrões, Estatística, Inteligência Artificial e Visualização de Dados.

Áreas como Aprendizado de Máquina, Reconhecimento de Padrões e Estatística têm fornecido muitos dos métodos empregados na etapa de mineração. A maioria dos métodos desenvolvidos nessas áreas assume que todo o conjunto de dados a ser analisado pode ser acessado a partir da memória principal.

Nas últimas décadas, o aumento explosivo do volume de dados disponível para análise gerou a necessidade do desenvolvimento de algoritmos de mineração de dados escaláveis. Com esse objetivo, alguns pesquisadores concentraram seus esforços no desenvolvimento de algoritmos de mineração rápidos, porém para dados armazenados em disco. Esses trabalhos têm levado a uma situação em que, para a realização de um projeto de mineração de dados, é necessária a criação de um ambiente totalmente separado, o que tem gerado um novo problema de gerenciamento de dados fora do SGBD [Netz et al., 2001]. 
Além disso, essa abordagem ignora o fato de que a maioria dos conjuntos de dados que são considerados para análise já estão armazenados em SGBD, e que os SGBD fornecem recursos sofisticados - como técnicas de acesso eficientes aos dados, operações de agrupamento e ordenação dos dados usados internamente para a realização de consultas e técnicas de otimização de consultas - que constituem a base para o desenvolvimento de algoritmos de mineração de dados escaláveis para grandes conjuntos de dados [Fayyad et al., 1996, Sattler \& Dunemann, 2001].

Assim, uma nova abordagem, que explora a questão da integração de métodos de mineração de dados com SGBD relacionais, tem sido adotada em vários trabalhos que propõem a implementação desses métodos considerando pelo menos três níveis de suporte para mineração de dados em SGBD [Sattler \& Dunemann, 2001]:

1. A inclusão de novas construções na linguagem SQL, como descrita em [Meo et al., 1996] para regras de associação;

2. A exploração de funcionalidades de mineração de dados implementadas internamente por meio de uma API especial, como a OLE DB para mineração de dados apresentada em [Netz et al., 2000], ou por meio da especificação de métodos e tipos definidos pelos usuários, como proposto pelo SQL/MM Parte 6;

3. A disponibilização de um conjunto especial de operadores (ou primitivas) que sejam básicos para qualquer tarefa de mineração de dados, como os conjuntos AVC propostos em [Gehrke et al., 1998].

Por exemplo, a integração de técnicas de mineração de regras de associação com SGBD relacionais foi considerada em vários trabalhos como: [Sarawagi et al., 1998] e [Jamil, 2001] que exploram as alternativas e as implicações relacionadas a essa integração; [Imielinski \& Virmani, 1999] que apresenta uma extensão da linguagem SQL, chamada MSQL, que permite consultar um conjunto de regras de associação descobertas; e [Meo et al., 1998] que propõe o operador MINE RULE com o propósito de permitir que uma ampla classe de tarefas relacionadas à mineração de regras de associação possa ser expressa em SQL.

Outros exemplos, relacionados à definição de primitivas básicas para técnicas de mineração de dados de uma maneira geral, como sampling, são apresentados em [Clear et al., 1999] e a especificação de extensões do SQL para a definição de funções de agregação não triviais, que consideram tabelas como parâmetros, é descrita em [Wang et al., 2003].

Questões como a definição de primitivas para a mineração de árvores de decisão [Graefe et al., 1998, Sattler \& Dunemann, 2001] e a implementação de algoritmos de detecção de agrupamentos de dados utilizando SQL [Ordonez \& Cereghini, 2000, Ordonez, 2006] também foram exploradas em trabalhos recentes. 


\subsubsection{Principais Componentes dos Algoritmos de Mineração de Dados}

Um ponto fundamental para a integração dos algoritmos de mineração de dados com os SGBD relacionais é a identificação de componentes básicos para qualquer algoritmo de mineração de dados. Embora cada uma das tarefas descritas na Seção 3.2 apresente objetivos diferentes, é possível identificar pelo menos quatro componentes principais em qualquer algoritmo de mineração de dados desenvolvido para realizar essas tarefas [Hand et al., 2001]. São eles:

1. Representação do modelo ou padrão: Determina o tipo de estrutura básica ou forma funcional do modelo ou padrão que se espera obter a partir dos dados. Entre os tipos mais freqüentes de representação de modelos e padrões, estão: árvores de decisão, regras de associação probabilísticas, modelos lineares e modelos não-lineares (Redes Neurais Artificiais);

2. Critério de avaliação: Utiliza uma função de pontuação (score funtion) para avaliar o quão bem os modelos ou padrões se ajustam a um conjunto de dados. Usualmente, os modelos ou padrões são representados de uma forma estrutural que algumas vezes pode ser composta por parâmetros com valores desconhecidos. Assim, a função de pontuação é utilizada para selecionar um bom conjunto (ou até mesmo o melhor conjunto) de valores para os parâmetros de um determinado modelo ou padrão. Existem várias funções de pontuação que podem ser empregadas com esse objetivo, entre elas a soma dos erros quadrados e a taxa de erro de classificação (empregada em processos de classificação supervisionada). É importante destacar que, para muitas técnicas de mineração de dados (ex.: detecção de agrupamento de dados e métodos de classificação pelos vizinhos mais próximos $-k$-NN), a definição da função de pontuação baseia-se na especificação de medidas de similaridade (funções de distância) entre pares de objetos. Os conceitos referentes à definição de medidas de similaridade, bem como exemplos de diferentes tipos de funções de distância, foram apresentados na Seção 2.1.2;

3. Método de busca e Otimização: O objetivo dos métodos de busca e otimização é determinar os valores dos parâmetros de um determinado modelo ou padrão que permitam alcançar o valor mínimo (ou máximo, dependendo do contexto) de uma função de pontuação. Se o modelo (ou padrão) é representado por uma estrutura fixa, a otimização da função de pontuação é realizada por meio da busca de valores dos parâmetros relacionados a essa forma estrutural fixa. Entretanto, se o modelo (ou padrão) é representado por um conjunto de estruturas diferentes, então é necessário realizar uma busca por ambos: estruturas e parâmetros associados; 
4. Estratégia de gerenciamento de dados: Definição das técnicas a serem utilizadas para garantir o armazenamento, indexação e recuperação dos dados de maneira eficiente durante o processo de busca/otimização. Embora os algoritmos de análise de dados desenvolvidos sem levar em consideração qualquer estratégia de gerenciamento de dados tenham obtido bons resultados para pequenos conjuntos de dados, a eficiência computacional de vários deles (como algoritmos de classificação e detecção de agrupamento de dados) tende a degradar muito quando aplicados a grandes conjuntos de dados. Assim, a contribuição da área de Base de Dados tem sido especialmente vital no que se refere à disponibilização de algoritmos e técnicas escaláveis para grandes volumes de dados, especialmente quando eles não cabem em memória principal, para dar suporte às demais áreas envolvidas na etapa de mineração de dados.

Por exemplo, considerando a tarefa de recuperação por conteúdo (apresentada em detalhes no Capítulo 2), dentro do contexto de recuperação de imagens, uma tarefa simples pode ser descrita a partir dos componentes mencionados acima da seguinte maneira:

- Tarefa: dada uma imagem de consulta e uma grande base de dados de imagens, recuperar as $k$ imagens da base de dados que sejam as mais similares à imagem de consulta, levando em consideração as cores presentes nas imagens.

1. Representação: vetor de coordenadas numéricas armazenando a distribuição da quantidade de pixels para cada cor (vetor de histograma de cor);

2. Função de pontuação: soma das diferenças absolutas do número de pixels de cada cor;

3. Método de busca: comparação do vetor de características da imagem de consulta com uma base pré-calculada de vetores de características de imagens;

4. Técnica de gerenciamento de dados: estruturas de indexação métrica.

\subsection{Detecção de Agrupamentos de Dados}

A detecção de agrupamentos de dados é uma das principais técnicas empregadas no processo de KDD. Geralmente, essa técnica pode ser aplicada de duas maneiras:

- Como ferramenta isolada que tem como objetivos explorar a distribuição dos conjuntos de dados, as características inerentes de cada agrupamento ou, ainda, direcionar análises futuras sobre determinados conjuntos de agrupamentos; 
- Como ferramenta de pré-processamento para outras técnicas, como classificação, que utilizam os agrupamentos detectados como ponto de partida para a execução de seus processos de análise.

Segundo Han e Kamber [Han \& Kamber, 2001], o processo de detecção de agrupamentos de dados pode ser definido como: "O processo de divisão de objetos em classes (ou grupos) de maneira que, os objetos dentro de uma mesma classe apresentem alta similaridade entre si, e ao mesmo tempo, baixa similaridade em relação aos objetos das outras classes". A medida de similaridade é obtida a partir dos valores dos atributos que descrevem os objetos de um conjunto de dados, normalmente, por meio da aplicação de uma função de distância.

Nas últimas décadas, vários algoritmos de detecção de agrupamentos foram desenvolvidos para uma grande variedade de aplicações. Esses algoritmos podem ser divididos em duas categorias principais:

- Algoritmos de particionamento: a idéia básica do método empregado por esse tipo de algoritmos é tentar encontrar o melhor conjunto de $k$ partições de um conjunto de dados, por meio da construção de um único nível de partição que divide os dados em $k$ agrupamentos. Cada agrupamento pode ser representado de duas maneiras: pelo valor médio dos objetos que compõem o agrupamento (centróide), ou pelo objeto que esteja localizado o mais perto possível do centro do agrupamento (medóide);

- Algoritmos hierárquicos: a idéia principal desses algoritmos é a criação de uma hierarquia de agrupamentos, formada por vários níveis de partições aninhadas de um conjunto de dados. De acordo com o modo como a hierarquia de agrupamentos é construída, os métodos empregados por esse tipo de algoritmos podem ser divididos em: aglomerativos (bottom-up) ou divisivos (top-down).

São exemplos de algoritmos de particionamento os métodos $k$-means e $k$-medoids. Dentre os algoritmos hierárquicos estão os métodos Single-Link e CURE (Clustering Using Representatives). Uma boa descrição desses e outros algoritmos de agrupamento pode ser encontrada em [Jain et al., 1999, Berkhin, 2002].

Nesta tese foram abordados apenas os algoritmos de agrupamento baseados no particionamento do conjunto de dados. Assim, são apresentados a seguir alguns dos principais algoritmos de particionamento existentes.

\subsection{1 k-mean}

O $k$-mean é um dos algoritmos de agrupamento mais simples e mais amplamente utilizados tanto em aplicações científicas como comerciais. O seu nome provém da forma como 
os agrupamentos de dados são representados. Nesse algoritmo, cada agrupamento é representado pelo seu ponto central, ou seja, pela média (ou média ponderada) dos objetos que o compõe (pelos centróides) [Berkhin, 2002].

O funcionamento geral do algoritmo $k$-mean pode ser descrito da seguinte maneira. Primeiro, ele seleciona aleatoriamente $k$ objetos do conjunto de dados para compor o conjunto inicial de centróides que representam os centros de cada agrupamento. Cada objeto restante no conjunto de dados é, então, atribuído ao agrupamento com o centróide mais próximo, i.e., a escolha do agrupamento é baseada no cálculo da distância entre um objeto e os centróides que representam cada agrupamento. Em seguida é calculada a nova média para cada agrupamento. Esse processo se repete até que a função de pontuação convirja. A função de pontuação tipicamente empregada pelo $k$-mean é a soma dos erros quadrados, definida como:

$$
E=\sum_{i=1}^{k} \sum_{s_{j} \in C_{i}}\left|s_{j}-m_{i}\right|^{2}
$$

em que $E$ é a soma dos erros quadrados para todos os objetos de um conjunto de dados, $s_{j}$ é o ponto no espaço representando um dado objeto, e $m_{i}$ é o centróide do agrupamento $C_{i}$ [Han \& Kamber, 2001]. Todos os passos empregados pelo $k$-mean são resumidos no Algoritmo 3.1.

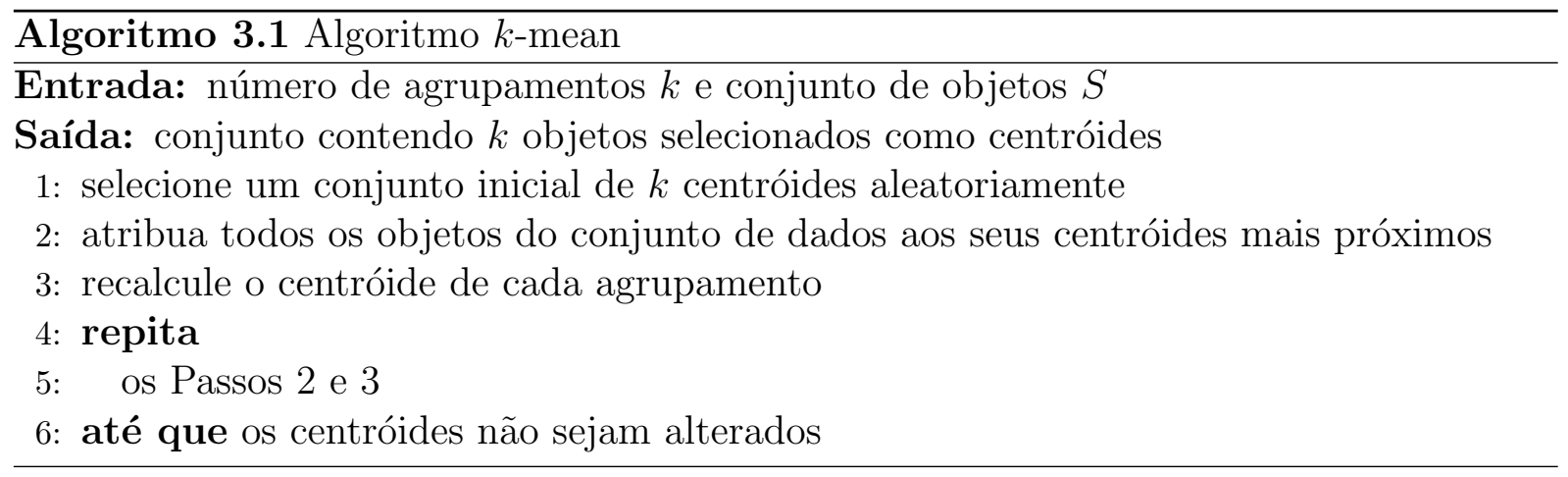

Embora esse algoritmo seja muito popular - devido principalmente à sua complexidade computacional, que é de $\mathrm{O}(N)$ no número de objetos - ele apresenta algumas desvantagens importantes quando aplicado a bases de dados [Ester et al., 1995]:

- O processo de agrupamento empregado pelo $k$ - mean é sensível quanto à presença de outliers (i.e., objetos que estão muito distantes do restante dos objetos), uma vez que um pequeno número de tais objetos pode influenciar substancialmente no cálculo da média dos agrupamentos;

- Os centros dos agrupamentos não representam objetos da base de dados, o que faz com que eles possam não ter nenhum significado no domínio da aplicação;

- Apenas atributos numéricos são permitidos, ou seja, o $k$-mean só pode ser aplicado quando é possível definir a média de um agrupamento; 
Uma alternativa para evitar essas desvantagens é a utilização dos algoritmos de agrupamento baseados no $k$-medoid.

\subsection{2 k-medoid}

De maneira geral, o objetivo dos algoritmos de detecção de agrupamentos baseados no algoritmo $k$-medoid consiste em encontrar um conjunto de agrupamentos não sobrepostos, de modo que cada agrupamento possua um objeto representante (denominado medóide), i.e., um objeto que esteja o mais próximo possível do centro do agrupamento. Para tanto, esses algoritmos executam dois passos principais:

- Inicialização: no qual um conjunto inicial de $k$ objetos (medóides) é selecionado;

- Avaliação: no qual uma função de pontuação, baseada na soma da distância total entre os objetos não selecionados e seus medóides (ou outra medida de similaridade), é minimizada. Quanto menor a soma das distâncias entre os medóides e todos os outros objetos de seus agrupamentos, melhor o resultado do agrupamento.

Os três algoritmos baseados em $k$ medóides mais conhecidos são: PAM (Partitioning Around Medoids), CLARA (Clustering LARge Applications) e CLARANS (Clustering Large Applications based upon RANdomized Search) [Kaufman \& Rousseeuw, 2005]. Os principais aspectos relacionados a cada um desses algoritmos são descritos a seguir.

\section{O algoritmo PAM}

O algoritmo PAM foi um dos primeiros algoritmos desenvolvidos tendo como base o algoritmo $k$-medoid. A estratégia adotada por esse algoritmo baseia-se em um processo de otimização iterativo, que avalia o efeito da troca de um objeto medóide por um objeto não-medóide na qualidade do agrupamento resultante. Essa qualidade é estimada por meio da utilização de uma função de custo total (função de pontuação), $T_{m i}$, que pode ser definida da seguinte maneira. Seja $S$ um conjunto contendo $n$ objetos e $R$ um conjunto inicial contendo $k$ objetos de $S$ selecionados como medóides. Para determinar se um objeto não-medóide $s_{i} \in S$ é uma boa opção de troca para um medóide corrente $r_{m} \in R$ é necessário calcular o custo $C_{j m i}$ para cada não-medóide $s_{j} \in S$ considerando quatro situações possíveis [Kaufman \& Rousseeuw, 2005]:

- Caso 1: $s_{j}$ pertence ao agrupamento representado por $r_{m}$. Se $d\left(s_{j}, s_{i}\right) \geq d\left(s_{j}, r_{n}\right)$, sendo $r_{n}$ o segundo medóide mais similar a $s_{j}$ então, se $r_{m}$ for substituído por $s_{i}$ como medóide, $s_{j}$ deverá pertencer ao agrupamento representado por $r_{n}$ (Figura 3.2 (a)). Assim, o custo da troca de $r_{m}$ por $s_{i}$ é:

$$
C_{j m i}=d\left(s_{j}, r_{n}\right)-d\left(s_{j}, r_{m}\right)
$$


(a)

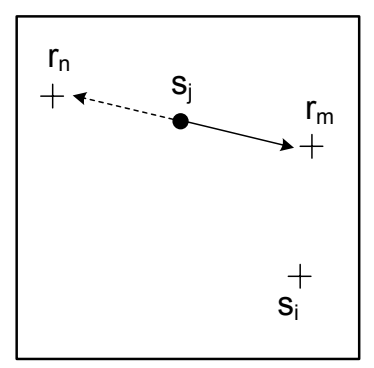

objeto de dados (b)

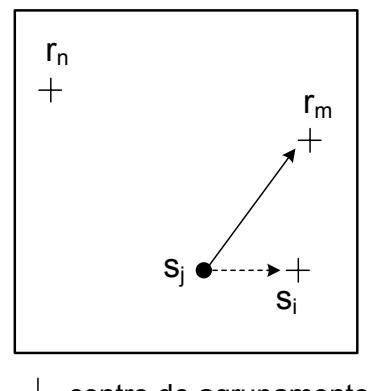

(c)

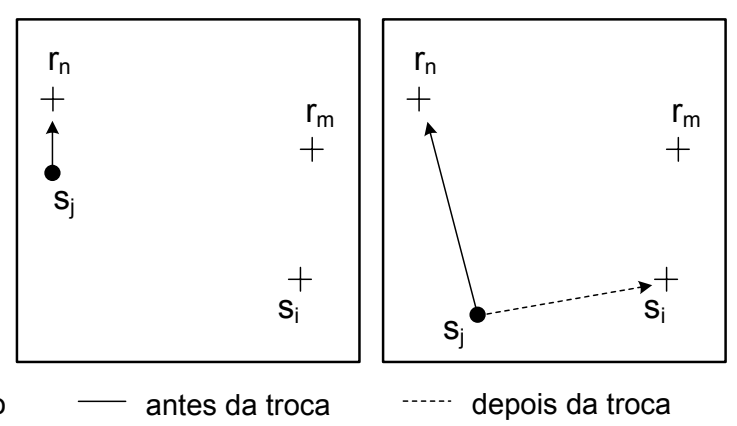

Figura 3.2: Exemplos dos quatro casos da função de custo para o algoritmo PAM. (a) Caso 1. (b) Caso 2. (c) Caso 3. (d) Caso 4. Adaptada de [Han \& Kamber, 2001].

- Caso 2: $s_{j}$ pertence ao agrupamento representado por $r_{m}$. Se $d\left(s_{j}, s_{i}\right)<d\left(s_{j}, r_{n}\right)$, sendo $r_{n}$ o segundo medóide mais similar a $s_{j}$ então, se $r_{m}$ for substituído por $s_{i}$ como medóide, $s_{j}$ deverá pertencer ao agrupamento representado por $s_{i}$ (Figura 3.2 (b)). Nesse caso o custo é:

$$
C_{j m i}=d\left(s_{j}, s_{i}\right)-d\left(s_{j}, r_{m}\right)
$$

- Caso 3: $s_{j}$ pertence ao agrupamento representado por $r_{n}, n \neq m$. Se $d\left(s_{j}, s_{i}\right) \geq$ $d\left(s_{j}, r_{n}\right)$ então, mesmo que $r_{m}$ seja substituído por $s_{i}$ como medóide, $s_{j}$ deverá permanecer no agrupamento representado por $r_{n}$ (Figura 3.2 (c)). Então, o custo é:

$$
C_{j m i}=0
$$

- Caso 4: $s_{j}$ pertence ao agrupamento representado por $r_{n}, n \neq m$. Se $d\left(s_{j}, s_{i}\right)<$ $d\left(s_{j}, r_{n}\right)$ então, se $r_{m}$ for substituído por $s_{i}$ como medóide, isso fará com que $s_{j}$ seja realocado do agrupamento representado por $r_{n}$ para o agrupamento representado por $s_{i}$ (Figura $3.2(\mathrm{~d})$ ). E o custo nesse caso é:

$$
C_{j m i}=d\left(s_{j}, s_{i}\right)-d\left(s_{j}, r_{n}\right)
$$

Combinando os quatro casos descritos acima, o custo total relacionado à troca de $r_{m}$ por $s_{i}$ pode ser expresso pela seguinte equação:

$$
T_{m i}=\sum_{i=1}^{n} C_{j m i}
$$

O conjunto inicial de medóides $R$ utilizado nessa fase de troca é previamente selecionado em uma fase anterior, denominada fase de construção. Nessa fase, um agrupamento inicial dos dados é obtido por meio da realização de seleções sucessivas de objetos representativos até que $k$ objetos tenham sido selecionados como medóides. O primeiro 
medóide selecionado é o objeto que tem a menor soma possível das distâncias para todos os demais objetos do conjunto. Esse medóide é o objeto mais central do conjunto de dados. Em seguida, os outros $(k-1)$ medóides são selecionados, um de cada vez, considerando os objetos que minimizem uma função de custo. Para encontrar esses objetos, são realizados os seguintes passos [Kaufman \& Rousseeuw, 2005]:

- Passo 1: Considere um objeto não-medóide $s_{i}$.

- Passo 2: Considere um objeto não-medóide $s_{j}$ e sua distância, $D_{j}$, ao medóide previamente selecionado mais próximo. Calcule a diferença entre $D_{j}$ e $d\left(s_{j}, s_{i}\right)$.

- Passo 3: Se essa diferença é positiva, então o objeto $s_{j}$ irá contribuir para a seleção do objeto $s_{i}$ como medóide. Então, calcule:

$$
C_{j i}=\max \left(D_{j}-d\left(s_{j}, s_{i}\right), 0\right)
$$

- Passo 4: Calcule o ganho total obtido pela seleção do objeto $s_{i}$ :

$$
\sum_{j=1}^{n} C_{j i}
$$

- Passo 5: Selecione o objeto não-medóide $s_{i}$ que maximize a Equação 3.3.

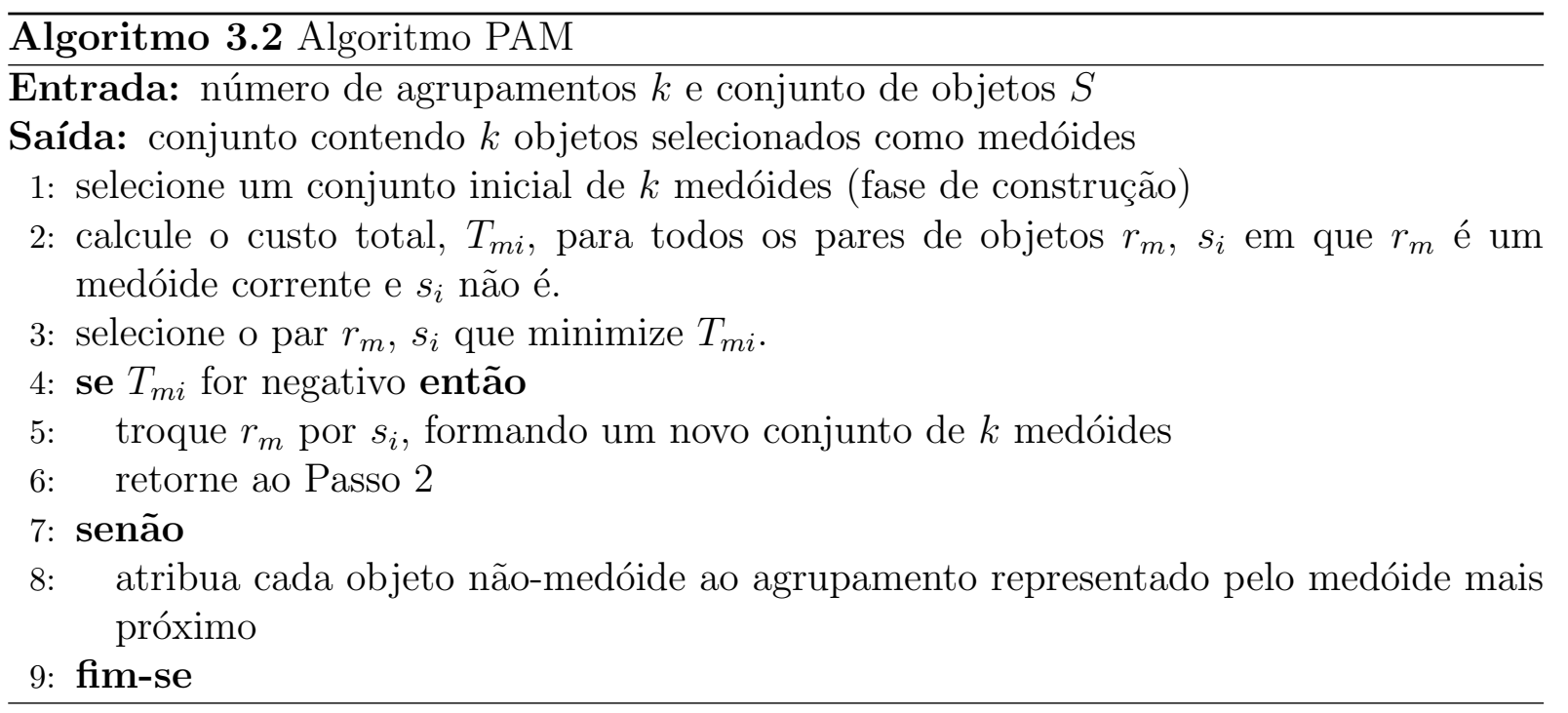

Todos os passos empregados pelo algoritmo PAM para a escolha do melhor conjunto de $k$ medóides são descritos no Algoritmo 3.2. Nesse algoritmo, os passos responsáveis por guiar o processo de agrupamento (Passos 2 a 6) também são os passos que mais contribuem para o elevado custo computacional apresentado pelo PAM. Nos passos de 2 a 6 são considerados, ao todo, $k(n-k)$ pares de objetos $\left[s_{i}, r_{m}\right]$ sendo que, para cada par, o cálculo do custo total $T_{m i}$ requer o teste de todos os objetos não selecionados como 
medóides, o que resulta em um custo computacional de $\mathrm{O}\left(k(n-k)^{2}\right)$ em cada iteração [Ng \& Han, 1994]. Isso explica porque o algoritmo PAM, embora gere agrupamentos de boa qualidade, não é adequado para ser utilizado no agrupamento de grandes conjuntos de dados. Resultados experimentais mostraram que o PAM pode ser aplicado eficientemente apenas para pequenos conjuntos de dados (ex.: 100 objetos em 5 agrupamentos) [Kaufman \& Rousseeuw, 2005].

\section{O algoritmo CLARA}

A complexidade computacional do algoritmo PAM motivou Kaufman e Rousseeuw a desenvolver CLARA, um algoritmo de agrupamento baseado em amostragem (sampling) [Kaufman \& Rousseeuw, 2005]. A idéia fundamental desse algoritmo consiste em selecionar $k$ medóides de um conjunto de dados a partir da análise de apenas uma pequena amostragem desses dados. CLARA seleciona várias amostras de um conjunto de dados, aplica o PAM em cada amostra e retorna como saída o melhor conjunto de medóides obtido a partir dessas amostras.

Nesse algoritmo, a qualidade do agrupamento obtido está relacionada ao tamanho das amostras utilizadas em sua execução. Outro ponto importante a ser destacado é que o CLARA não consegue encontrar o melhor agrupamento dos dados se os melhores $k$ medóides do conjunto de dados não estiverem selecionados entre os objetos amostrados. Experimentos descritos em [Kaufman \& Rousseeuw, 2005] indicaram que 5 amostras contendo $40+2 k$ objetos são suficientes para a obtenção de resultados satisfatórios.

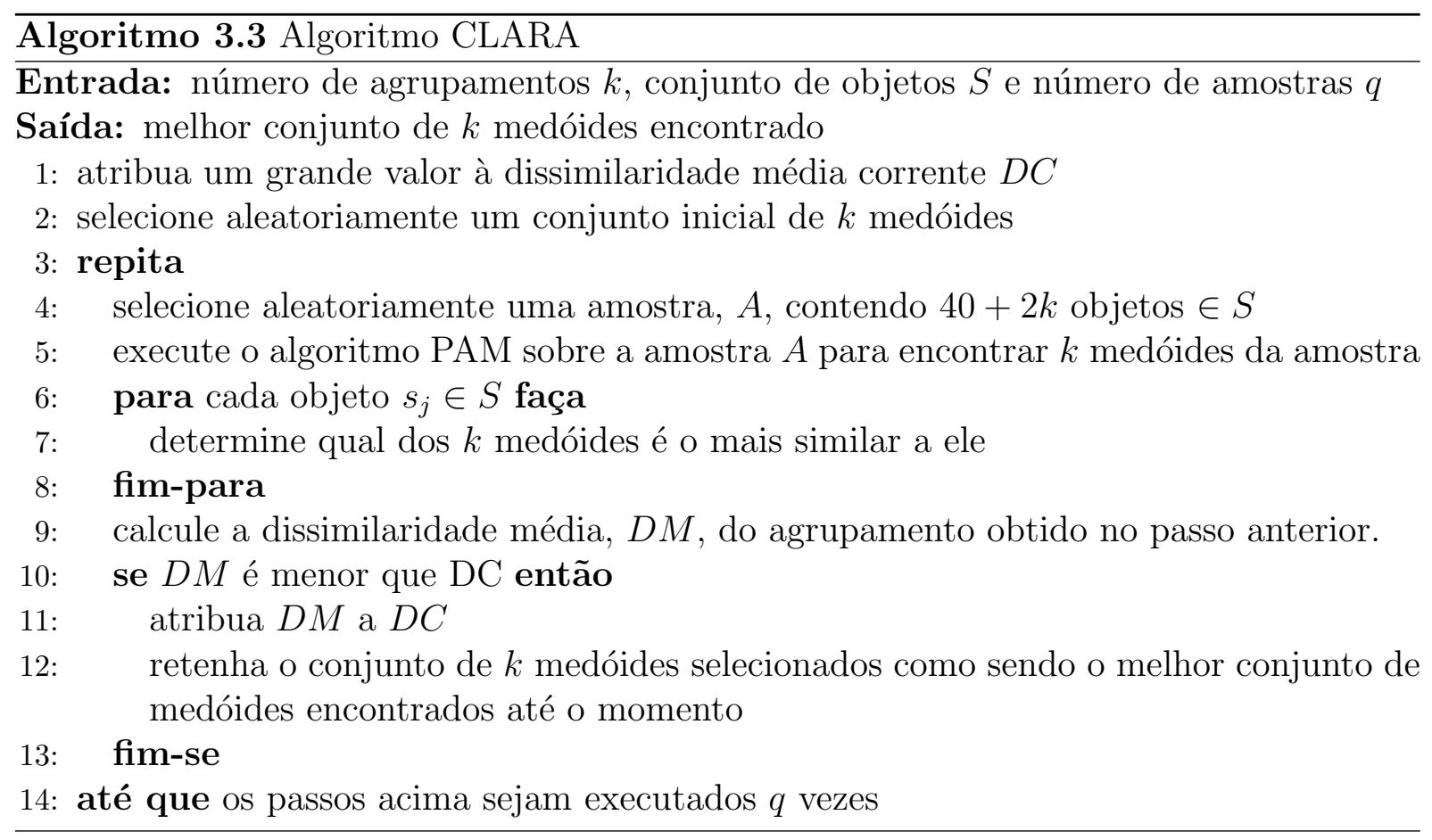

O Algoritmo 3.3 apresenta os passos empregados pelo algoritmo CLARA. A complexidade computacional de cada iteração desse algoritmo é de $\mathrm{O}\left(k s^{2}+k(n-k)\right)$, sendo $s$ o 
tamanho da amostra.

\section{O algoritmo CLARANS}

O algoritmo CLARANS foi desenvolvido para a mineração de dados espaciais [Ng \& Han, 1994]. Ele utiliza uma estratégia baseada em busca aleatória com o objetivo de superar ambos PAM e CLARA em relação à eficiência computacional (complexidade computacional ou tempo de processamento) e à qualidade do agrupamento resultante (distorção média ou distância entre os objetos e seus medóides), respectivamente.

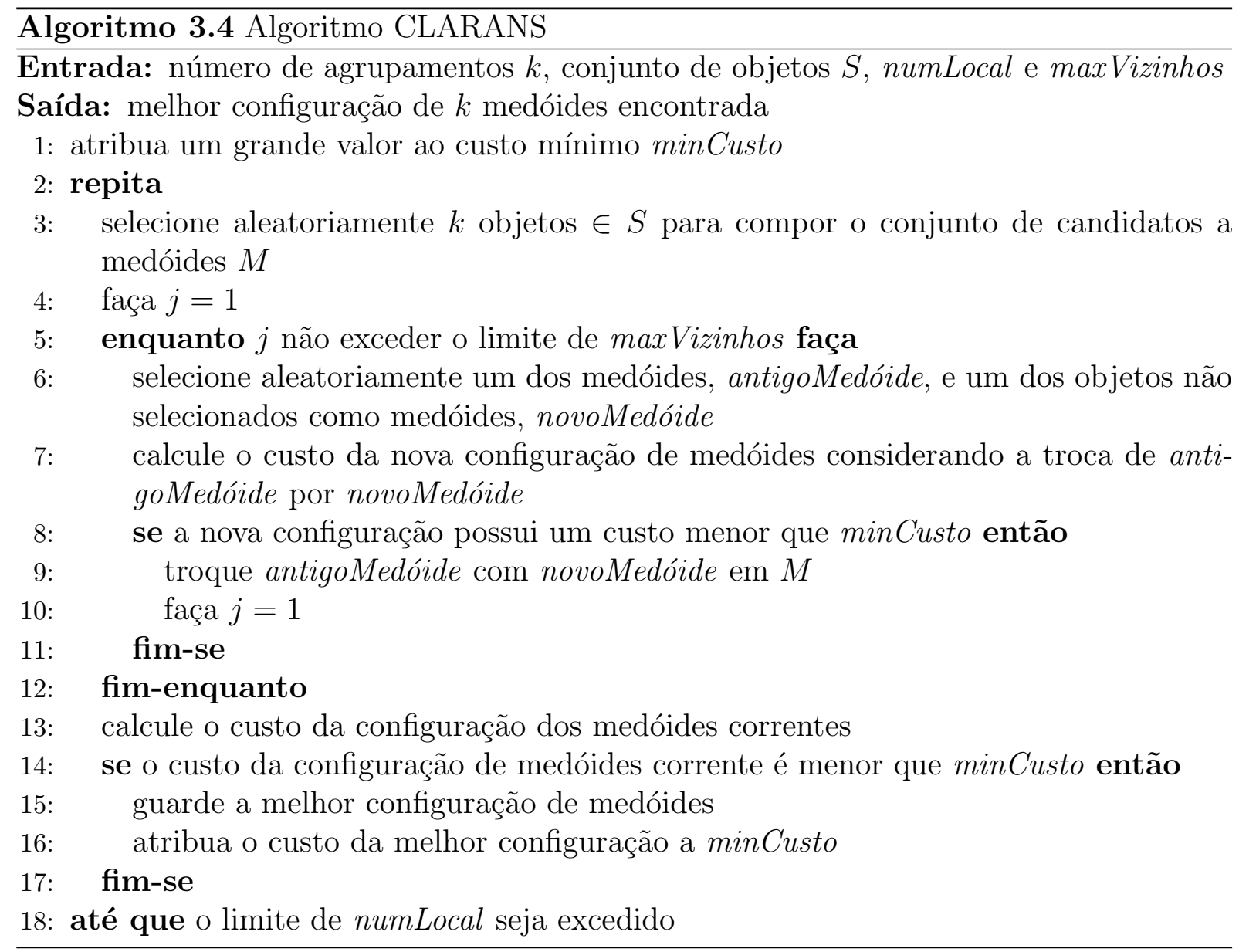

Em sua etapa de avaliação, quando o CLARANS está a procura de um melhor medóide, ele tenta encontrar uma solução melhor selecionando, aleatoriamente, objetos entre os outros $(n-k)$ objetos do conjunto de dados. O número de objetos testados nesse passo é restringido por um parâmetro fornecido pelo usuário (maxVizinhos). Se nenhuma solução melhor é encontrada após maxVizinhos tentativas, assume-se que o máximo local foi atingido. O procedimento continua até que numLocal máximos locais sejam encontrados. Em [Ng \& Han, 2002] recomenda-se que os parâmetros maxVizinhos e numLocal sejam inicializados com os valores 2 e $\max (250,1.25 \%$ de $k *(n-k))$, respectivamente. Os principais passos do algoritmo CLARANS são apresentados no Algoritmo 3.4. A complexidade computacional do algoritmo CLARANS é de $\mathrm{O}\left(N^{2}\right)$ no número de objetos. 


\subsubsection{Estratégias de Otimização}

Com o aumento explosivo do volume de dados acumulados nas últimas décadas e da necessidade de que estes sejam analisados, vários pesquisadores concentraram seus esforços na tentativa de tornar o processo de detecção de agrupamentos exeqüível para grandes bases de dados [Ester et al., 1995, Chu et al., 2002, Zhang \& Couloigner, 2005].

Uma estratégia comumente utilizada para melhorar a eficiência dos algoritmos de detecção de agrupamentos, é a redução do número de objetos empregados na execução desses algoritmos por meio da realização de uma amostragem (sampling) do conjunto de dados, ou da aplicação de técnicas de compressão de dados. A utilização de técnicas de amostragem mostrou-se especialmente útil para os métodos que realizam várias iterações considerando diferentes inicializações, como o algoritmo CLARANS [Ng \& Han, 1994] que, dentre os algoritmos de agrupamento baseados no método $k$-medoid é o algoritmo que apresenta o melhor custo benefício entre tempo de processamento e qualidade de agrupamento, embora a sua complexidade computacional ainda seja de $\mathrm{O}\left(N^{2}\right)$ no número de instâncias no conjunto de dados.

Com o intuito de tornar o algoritmo CLARANS escalável para grandes conjuntos de dados multi-dimensionais, técnicas baseadas na $\mathrm{R}^{*}$-tree [Beckmann et al., 1990] foram propostas em [Ester et al., 1995]. De maneira geral, essas técnicas (chamadas de "focusing techniques") permitem que: o processo de análise do algoritmo focalize apenas as partes relevantes de um conjunto de dados para a realização de atualizações de distância e da qualidade do agrupamento; e que o processo de agrupamento seja realizado sobre uma amostragem do conjunto de dados, obtida a partir de cada página de dados da $\mathrm{R}^{*}$-tree.

As técnicas de compressão de dados examinam o conjunto de dados para computar certas medidas estatísticas que resumem todo o conjunto. Essas medidas estatísticas são então utilizadas no lugar do conjunto de dados, nas etapas de agrupamento posteriores. As medidas estatísticas utilizadas com o objetivo de suportar a realização de algoritmos de agrupamento são basicamente as mesmas para todas as técnicas de compressão de dados.

Como exemplo, um dos mais importantes algoritmos de detecção de agrupamentos que utilizam essa técnica é o algoritmo BIRCH (Balanced Iterative Reducing and Clustering using Hierarchies) [Zhang et al., 1996]. Esse algoritmo utiliza uma estrutura em árvore especializada para realizar o agrupamento de grandes conjuntos de dados multidimensionais. Para tanto, ele calcula incrementalmente descrições compactas de subagrupamentos dos dados, chamadas de características do agrupamento (Clustering Feature - CF). As CFs são organizadas em uma árvore balanceada que é construída por meio da realização de uma busca seqüencial sobre todos os dados do conjunto, de maneira similar à construção da $B^{+}$-tree. Os valores das CFs são suficientes para obter informações sobre todo o conjunto de dados o qual representam, como centróides, raio e diâmetro. Outros exemplos de algoritmos que utilizam o conceito de compressão de dados para otimizar algo- 
ritmos de detecção de agrupamentos de dados (tanto baseados em particionamento quanto hierárquicos) podem ser encontrados em [Bradley et al., 1998, Breunig et al., 2001].

\subsection{Considerações Finais}

Neste capítulo foram apresentados os principais conceitos e técnicas relacionados ao processo de descoberta de conhecimento em bases de dados. Além disso, também foram abordados os principais aspectos relacionados à integração de técnicas de mineração de dados em SGBD.

É importante notar que um ponto fundamental para a integração da mineração de dados em SGBD está relacionado ao fornecimento de recursos para a realização de operações básicas para as diversas técnicas de mineração de dados existentes. Uma operação básica para várias técnicas de mineração de dados, tais como técnicas de recuperação por conteúdo e de detecção de agrupamentos de dados, é o cálculo de medidas de similaridade entre os pares de objetos de um conjunto de dados. Como um passo inicial para a realização dessa integração, o trabalho de doutorado apresentado nesta tese desenvolveu uma extensão da linguagem SQL para permitir a realização de consultas por similaridade em SGBD relacionais, que é apresentada no Capítulo 4, e explorou estratégias para a otimização de algoritmos de detecção de agrupamentos baseados no método $k$-medoid, trabalho apresentado no Capítulo 6. 


\section{Capítulo \\ 4 \\ Operações de Consulta por Similaridade em SGBDR}

No Capítulo 2 foi mostrado que o conceito de busca por similaridade é um paradigma fundamental para a realização de operações de consulta em grandes coleções de dados complexos. As operações de consulta por similaridade realizam operações de comparação sobre os objetos armazenados em uma base de dados para encontrar aqueles que, de acordo com uma medida de similaridade (ou função de distância), atendem mais adequadamente aos critérios de busca definidos para a consulta. Nos últimos anos, muitos trabalhos têm sido desenvolvidos com o intuito de melhorar a eficiência dos algoritmos de consulta por similaridade, como as estruturas de indexação especialmente desenvolvidas para responder a esse tipo de consulta, mas poucas propostas de extensão da linguagem SQL para o suporte de consultas por similaridade foram feitas, e não existe nenhuma extensão que tenha tratado o suporte de consultas por similaridade de uma maneira geral em SQL.

Embora esses trabalhos apresentem maneiras de disponibilizar o suporte a consultas por similaridade em SQL, nenhum deles é capaz de fornecer um suporte robusto, abrangente e totalmente integrado às outras características da linguagem. Com o intuito de suprir essa necessidade, este capítulo apresenta os conceitos, desenvolvidos como parte do trabalho de doutorado, que fundamentaram a extensão da linguagem SQL para o suporte de consultas por similaridade sobre dados complexos em SGBD relacionais. Além disso, este capítulo também apresenta uma sintaxe para a especificação de consultas sobre o resultado de processos de detecção de agrupamentos de dados e exemplifica toda a extensão da linguagem SQL proposta. 


\subsection{Conceitos Fundamentais}

O trabalho apresentado nesta tese procurou uniformizar a representação das consultas por similaridade. Na literatura normalmente apresentam-se:

- Duas operações que comparam um objeto de referência com aqueles armazenados em uma coleção de objetos. Este trabalho considera que essas operações são equivalentes às operações de seleção da álgebra relacional para dados tradicionais (as buscas por vizinhos mais próximos e por abrangência);

- Três operações que comparam pares de objetos armazenados em duas coleções de objetos. Este trabalho considera que essas operações são equivalentes às operações de junção da álgebra relacional para dados tradicionais (as buscas de junção por abrangência, pelos $k$-vizinhos mais próximos e dos $k$-pares de vizinhos mais próximos).

Além dessas, identificou-se a necessidade de generalizar as operações de seleção, para que seja possível obter objetos de uma coleção de dados que se assemelhem não apenas a um objeto de referência, mas possivelmente a diversos deles. A esse tipo de operações denominou-se "seleção por similaridade de grupo". Assim, foi definido, como parte desta tese de doutorado, o arcabouço conceitual para expressar as consultas por similaridade apresentado a seguir.

Uma consulta por similaridade é expressa por meio da utilização de predicados por similaridade. Um predicado por similaridade $P<d(), \mathbb{S}, \lim >$ utiliza uma função de distância $d()$, definida sobre o domínio complexo $\mathbb{S}$, para retornar uma determinada quantidade de objetos definida por um certo limiar lim. Existem basicamente duas maneiras de limitar o número de objetos retornados. A primeira é baseada em uma distância máxima de busca (raio) $\xi$ e a segunda é baseada em um número de objetos $k$. A função de distância $d()$ compara um par de objetos de um domínio $\mathbb{S}$, retornando um valor real positivo que indica o grau de semelhança entre os objetos que compõem o par.

Uma instância de um atributo de tipo complexo é um objeto cujo valor é um elemento $s_{i}$, pertencente ao domínio complexo correspondente $\mathbb{S}$. O conjunto de valores dos objetos complexos armazenados em uma base de dados forma o conjunto de dados $S$, que é examinado pelos operadores ${ }^{1}$ indicados nos predicados por similaridade para responder as consultas. Os predicados empregados nas consultas por similaridade podem ser tanto unários quanto binários.

Os predicados unários correspondem às seleções por similaridade. Os operadores indicados nesse tipo de predicado comparam os objetos de um conjunto de dados $S \subseteq \mathbb{S}$ com

\footnotetext{
${ }^{1}$ Por operador entenda-se o método que implementa a operação por similaridade indicada em um predicado por similaridade (ex.: consulta por abrangência, consulta aos $k$-vizinhos mais próximos, etc.).
} 
um ou mais objetos de referência (chamados de objetos de consulta) $s_{q} \in Q$, informados como parte do predicado. Uma seleção por similaridade sobre o atributo $S$ da relação $T_{1}$ pode ser representada como $\hat{\sigma}_{(S: P<d(), Q, l i m>)} T_{1}$, na qual $Q$ é um conjunto não nulo de centros de consulta e $Q \subseteq \mathbb{S}$. A resposta de uma seleção por similaridade é composta pelo subconjunto de objetos $s_{i} \in S$ que satisfaz a condição expressa no predicado da seleção.

Quando o conjunto de centros de consulta $Q$ possui apenas um objeto $s_{q}$, a seleção por similaridade corresponde ao caso particular dos dois tipos de consultas por similaridade descritos na Seção 2.1.2, ou seja, as consultas por abrangência (Range query - Rq) e as consultas aos $k$-vizinhos mais próximos ( $k$-Nearest neighbor query $-k$-NNq). Esses dois tipos de seleção por similaridade podem ser representados da maneira descrita a seguir:

- Consulta por Abrangência: Dada uma distância máxima de busca $\xi$ como sendo o limite lim, uma função de distância $d()$ e um objeto de consulta $s_{q}$, a consulta $R q$, que recupera todos os objetos $s_{i} \in S$ tal que a $d\left(s_{i}, s_{q}\right) \leq \xi$, pode ser representada como $\hat{\sigma}_{\left(S: R q<d(),\left\{s_{q}\right\}, \xi>\right)} T_{1}$. Um exemplo de consulta que pode ser respondida com a utilização desse tipo de operação seria: "Selecione as imagens que sejam similares à imagem $I_{c}$ até no máximo 5 unidades de distância, considerando a função de distância $L_{2}()$ ", representada como $\hat{\sigma}_{\left(S: R q<L_{2}(),\left\{I_{c}\right\}, 5>\right)}$ Imagens.

- Consulta aos $k$-Vizinhos mais Próximos: Dado um número inteiro $k \geq 1$ como sendo o limite lim, a consulta $k-N N q$, que recupera os $k$ objetos mais próximos do objeto de consulta $s_{q}$ em $S$ de acordo com uma função de distância $d()$, pode ser representada como $\hat{\sigma}_{\left(S: k-N N q<d(),\left\{s_{q}\right\}, k>\right)} T_{1}$. Um exemplo de uma consulta que pode ser respondida com a utilização desse tipo de operação seria: "Selecione as 3 imagens mais similares à imagem $I_{c}$, considerando a função de distância $L_{1}($ )", representada como $\hat{\sigma}_{\left(S: k-N N q<L_{1}(),\left\{I_{c}\right\}, 3>\right)}$ Imagens.

Quando o conjunto de centros de consulta $Q$ possui mais de um objeto, as distâncias de cada centro $s_{q} \in Q$ para um objeto $s_{i} \in S$ devem ser agregadas para fornecer a medida de similaridade $m_{i}$ entre o objeto $s_{i}$ e o conjunto de centros de consulta pertencentes a $Q$ [Papadias et al., 2005]. Essa medida é utilizada pelo operador por similaridade para ordenar os objetos pertencentes a $S$. A princípio existem várias alternativas para gerar essa agregação. A Equação 4.1 apresenta o modo de obtenção dessa medida de agregação proposto no trabalho apresentado nesta tese.

$$
m_{i}=\sqrt[p]{\sum_{s_{q} \in Q} d\left(s_{q}, s_{i}\right)^{p}}
$$

A atribuição de diferentes valores para a potência $p$ leva a diferentes interpretações sobre como a agregação é realizada. Assim, convencionou-se que $p$ corresponde ao "padrão 
de agregação", considerando os casos em que $p$ pode valer 1,2 ou $\infty$. Quando $p=1$, a consulta ordena os objetos para minimizar o somatório das distâncias de cada objeto para os centros de consulta, portanto, diz-se que o padrão corresponde à "minimização da distância total". Quando $p=2$ a consulta resultante corresponde a uma regressão linear, retornando os objetos que minimizam a raiz quadrada da soma dos quadrados das distâncias de cada objeto para os centros de consulta, portanto, diz-se que o padrão corresponde à "minimização da soma dos quadrados das distâncias". Quando $p=\infty$ a resposta da consulta contém os objetos que minimizam as distâncias máximas para os centros de consulta, portanto, diz-se que o padrão corresponde à "minimização da distância máxima".

Para contemplar os casos de seleções por similaridade em que o conjunto de centros de consulta $Q$ possui mais de um objeto, considerando os padrões de agregação descritos acima, foram definidos dois novos tipos de consulta por similaridade: as consultas por abrangência de grupo $(\mathrm{GRq})$ e as consultas aos $k$-Vizinhos mais Próximos de Grupo ( $k$ GNNq). Esses dois novos tipos de seleção por similaridade podem ser representados da maneira descrita a seguir:

- Consulta por Abrangência de Grupo: Dada uma distância máxima de busca $\xi$ como sendo o limite lim, uma função de distância $d()$, um padrão de agregação $p$ e uma coleção de objetos de consulta $Q$, a consulta $G R q$, que recupera todos os objetos $s_{i} \in S$ tal que $m_{i} \leq \xi$, pode ser representada como $\hat{\sigma}_{(S: G R q<d(), Q: p, \xi>} T_{1}$. Exemplos de consultas que podem ser respondidas com a utilização desse tipo de operação seriam:

- Para $p=1$ : "Selecione os restaurantes que estejam localizados a não mais de 5 unidades de distância, considerando a função de distância $L_{2}()$, de minha casa (c), meu trabalho (t) e minha academia (a), para minimizar a distância total percorrida", que é representada como $\hat{\sigma}_{\left(S: G R q<L_{2}(),\{c, t, a\}: 1,5>\right)}$ Restaurantes;

- Para $p=2$ : "Selecione os restaurantes que estejam localizados a não mais de 5 unidades de distância, considerando a função de distância $L_{2}()$, entre minha casa (c), meu trabalho (t) e minha academia (a), para minimizar a distância para todos os destinos", que é representada como $\hat{\sigma}_{\left(S: G R q<L_{2}(),\{c, t, a\}: 2,5>\right)}$ Restaurantes;

- Para $p=\infty$ : "Selecione os restaurantes que estejam localizados a não mais de 5 unidades de distância, considerando a função de distância $L_{2}()$, de minha casa (c), meu trabalho (t) e minha academia (a), para minimizar as distâncias máximas que teriam que ser percorridas ", que é representada como $\hat{\sigma}_{\left(S: G R q<L_{2}(),\{c, t, a\}: \infty, 5>\right)}$ Restaurantes. 
- Consulta aos k-Vizinhos mais Próximos de Grupo: Dado um número inteiro $k \geq 1$ como sendo o limite $\lim$, a consulta $k-G N N q$, que recupera os $k$ objetos mais próximos da coleção de objetos de consulta $Q$ em $S$ de acordo com uma função de distância $d()$ e um padrão de agregação $p$, pode ser representada como $\hat{\sigma}_{(S: k-G N N q<d(), Q: p, k>)} T_{1}$. Exemplos de consultas que podem ser respondidas com a utilização desse tipo de operação seriam:

- Para $p=1$ : "Selecione os 3 restaurantes que estejam próximos, considerando a função de distância $L_{2}($ ), de minha casa (c), meu trabalho (t) e minha academia (a), para minimizar a distância total", que é representada como $\hat{\sigma}_{\left(S: k-G N N q<L_{2}(),\{c, t, a\}: 1,3>\right)}$ Restaurantes;

- Para $p=2$ : "Selecione os 3 restaurantes que estejam próximos, considerando a função de distância $L_{2}()$, entre minha casa (c), meu trabalho (t) e minha academia (a), para minimizar a distância para todos os destinos", que é representada como $\hat{\sigma}_{\left(S: k-G N N q<L_{2}(),\{c, t, a\}: 2,3>\right)}$ Restaurantes;

- Para $p=\infty$ : "Selecione os 3 restaurantes que estejam próximos, considerando a função de distância $L_{2}()$, de minha casa (c), meu trabalho (t) e minha academia (a), para minimizar as distâncias máximas que teriam que ser percorridas ", que é representada como $\hat{\sigma}_{\left(S: k-G N N q<L_{2}(),\{c, t, a\}: \infty, 3>\right)}$ Restaurantes.

A Figura 4.1 ilustra os três padrões de agregação, considerando uma consulta $k$-GNNq com $k=1$, três objetos de consulta e a função de distância Euclidiana. Nessa figura, os círculos representam os objetos de um conjunto de dados $S$, as estrelas representam os centros de consulta pertencentes a $Q$ e o objeto ligado aos centros de consulta corresponde à resposta da consulta.

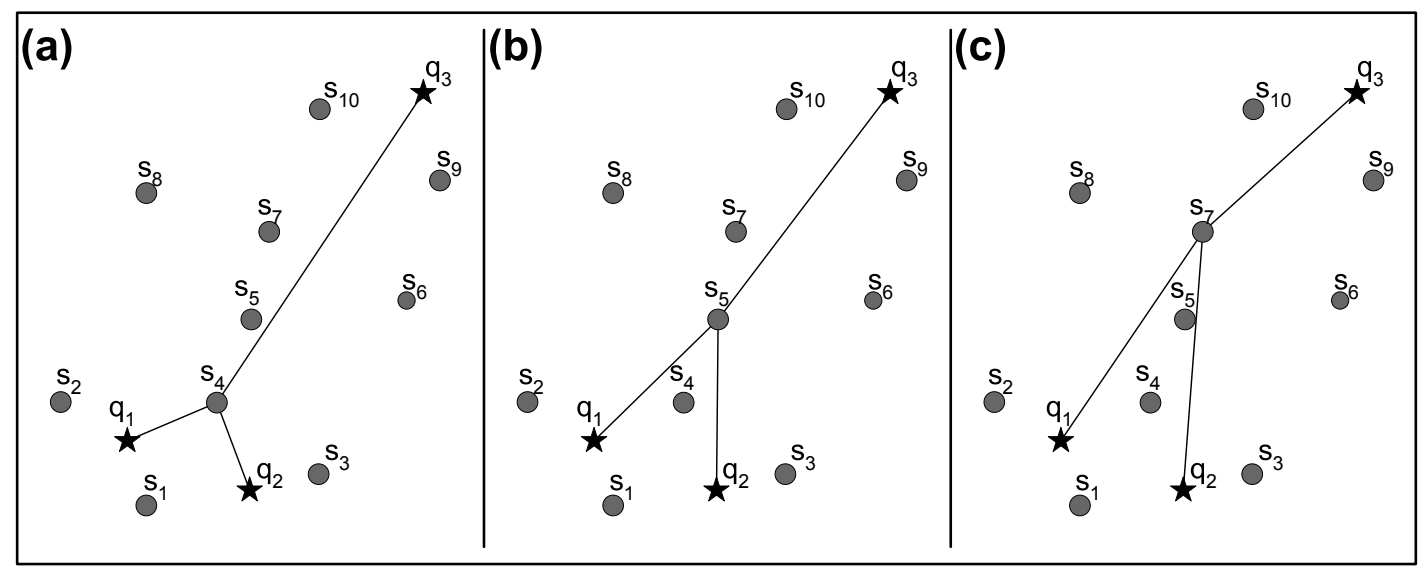

Figura 4.1: Exemplos de consultas $k$-GNNq com $k=1$ e 3 centros de consulta. Ilustração da aplicação da função de distância Euclidiana na Equação 4.1 considerando $p=1$ (a), $p=2(\mathrm{~b})$ e $p=\infty$ (c). 
Os predicados binários correspondem às junções por similaridade. Uma operação de junção por similaridade sobre o atributo $S$ de uma relação $T_{1}$ e o atributo $R$ de uma relação $T_{2}$ pode ser representada como $T_{1} \stackrel{S, R: P<d(), \lim >}{\bowtie} T_{2}$. A resposta de uma operação de junção por similaridade retorna a concatenação de objetos $s_{i} \in S$ e $r_{j} \in R$ que satisfazem a condição expressa no predicado de junção. Os três tipos de junções por similaridade descritos na Seção 2.1.2 do Capítulo 2 também podem ser limitados por um dado limiar lim, como descrito a seguir.

- Junção por Abrangência: Dada uma distância máxima de busca $\xi$ como sendo o limite lim e uma função de distância $d()$, a junção $\stackrel{R q}{\bowtie}$, que recupera os pares de objetos $\left\langle s_{i}, r_{i}>\right| s_{i} \in S, r_{i} \in R, d\left(s_{i}, r_{j}\right) \leq \xi$, pode ser representada como $T_{1} \stackrel{S, R: R q<d(), \xi>}{\bowtie} T_{2}$. Um exemplo de consulta que pode ser respondida com a utilização desse tipo de operação seria: "Selecione as paisagens européias que diferem das paisagens brasileiras até no máximo 5 unidades de distância, considerando a função de distância $L_{2}$ ", representada como PaisagemEuropeia $\stackrel{R q<L_{2}(), 5>}{\bowtie}$ PaisagemBrasileira.

- Junção pelos $k$-Vizinhos mais Próximos: Dado um número inteiro $k \geq 1$ como sendo o limite lim, a junção $\stackrel{k-N N q}{\bowtie}$, que recupera os pares de objetos $<s_{i}, r_{i}>\mid s_{i} \in S, r_{i} \in R$ de maneira que existam $k$ pares para cada objeto pertencente a $S$ juntamente com os objetos de $R$ mais próximos, pode ser representada como $T_{1} \stackrel{S, R: k-N N q<d(), k>}{\bowtie} T_{2}$. Um exemplo de consulta que pode ser respondida com a utilização desse tipo de operação seria: "Selecione as 10 paisagens européias mais similares a cada paisagem brasileira, considerando a função de distância $L_{2}$ ", representada como PaisagemEuropeia ${ }^{k-N N q<L_{2}(), 10>}$ PaisagemBrasileira.

- Junção dos $k$-Pares de Vizinhos mais Próximos: Dado um número inteiro $k \geq 1$ como sendo o limite $\lim$, a junção ${ }_{\bowtie}^{k-C N q}$, que recupera os $k$ pares de objetos $<s_{i}, r_{i}>\mid s_{i} \in S, r_{i} \in R$ mais próximos entre si, pode ser representada como $T_{1} \stackrel{S, R: k-C N q<d(), k>}{\bowtie} T_{2}$. Um exemplo de consulta que pode ser respondida com a utilização desse tipo de operação seria: "Selecione os 20 pares de paisagens européias e brasileiras mais similares, considerando a função de distância $L_{2}$ ", representada como PaisagemEuropeia $\underset{\bowtie}{k-C N q<L_{2}(), 20>}$ PaisagemBrasileira.

Uma última classe de operadores de consulta por similaridade foi ainda abordada nesta tese, visando a contemplar o tratamento de operações de detecção de agrupamentos de dados. Essa classe de operadores não foi originalmente tratada pela álgebra relacional e nem pelos SGBD e suas respectivas linguagens de consulta, tal como a SQL. No entanto, os operadores que realizam operações de análise/mineração de dados têm despertado muito interesse recentemente, devido à necessidade de analisar e minerar as grandes massas de 
dados que vêm sendo coletadas por diversas aplicações. Como visto no Capítulo 3, existem vários trabalhos recentes sobre essa classe de operadores, embora voltados para a análise de dados tradicionais. Assim, considerou-se importante também abordar os operadores para análise de dados complexos por similaridade nesta proposta, definindo uma última operação de consulta por similaridade, para cuidar da operação de "agrupamento por similaridade" sobre um conjunto de objetos complexos, da maneira descrita a seguir. Vale lembrar que outras operações de análise podem vir a ser estudadas e incorporadas usando técnicas equivalentes.

A operação de agrupamento por similaridade em dados complexos foi definida como um processo que recebe um conjunto de objetos $s_{i} \in S$, e gera um conjunto de agrupamentos $c_{j} \in C$ e um conjunto $D$ de pares ordenados $\left\langle s_{i}, c_{j}\right\rangle$. O conjunto de pares ordenados associa cada objeto do conjunto de dados ao seu respectivo agrupamento. Assim, o predicado que define o agrupamento por similaridade sobre o atributo $S$ de um domínio complexo $\mathbb{S}$ por uma determinada função de distância $d()$ em um dado número $k$ de agrupamentos é representado como $M<d(), \mathbb{S}, k>$, o qual pode ser utilizado para gerar dois operadores, um que obtém o conjunto $C$ de agrupamentos, gerado no conjunto de dados, e outro que obtém o conjunto $D$ de pares ordenados. O conjunto de agrupamentos $C$ deve incluir todas as informações pertinentes a cada agrupamento, o que inclui:

- o número de objetos no agrupamento;

- o objeto medóide do agrupamento.

O conjunto de pares ordenados $D$ deve incluir todas as informações referentes à associação, o que inclui:

- a distância do objeto ao medóide de seu agrupamento.

Esses dois operadores de agrupamento por similaridade podem ser representados da maneira descrita a seguir:

- Obtenção do conjunto de agrupamentos em um conjunto de dados: Dado um número de agrupamentos $k$, a ser obtido sobre o atributo $S$ por uma função de distância $\mathrm{d}()$, o operador que obtém os agrupamentos é representado como $\hat{\mu}_{(S: \text { Cluster }<d(), k>))} T_{1}$. Um exemplo de consulta utilizando esse operador é: "Obtenha as informações sobre cada um dos três agrupamentos de flores do gênero Iris, usando a métrica $L_{2}$ ". Essa consulta pode ser representada como $\hat{\mu}_{\left.\left(S: \text { Cluster }<L_{2}(), 3>\right)\right)}$ Iris.

- Obtenção do conjunto de pares ordenados: Dado um número de agrupamentos $k$, a ser obtido sobre o atributo $S$ por uma função de distância d(), o operador que associa cada objeto a seu agrupamento é representado como $\hat{\mu}_{(S \text { :Clustering }<d(), k>))} T_{1}$. 
Um exemplo de consulta utilizando esse operador é: "Determine a qual dos 3 agrupamentos das flores do gênero Iris cada flor pertence, usando a métrica $L_{2}$ ". Essa consulta pode ser representada como $\hat{\mu}_{\left.\left(S: \text { Clustering }<L_{2}(), 3>\right)\right)}$ Iris.

A Tabela 4.1 sintetiza o conjunto de predicados por similaridade tratados nesta tese.

\begin{tabular}{|c|c|c|}
\hline Predicado & Operação & Representação \\
\hline \multirow{2}{*}{$\begin{array}{c}\text { Seleção por similaridade } \\
(\hat{\sigma})\end{array}$} & Abrangência & $\hat{\sigma}_{\left(S: R q<d(),\left\{s_{q}\right\}, \xi>\right)} T_{1}$ \\
\hline & $k$-Vizinhos mais próximos & $\hat{\sigma}_{\left(S: k-N N q<d(),\left\{s_{q}\right\}, k>\right)} T_{1}$ \\
\hline \multirow{3}{*}{$\begin{array}{c}\text { Junção por similaridade } \\
\qquad(\bowtie)\end{array}$} & Abrangência & $T_{1} \stackrel{S, R: R q<d(), \xi>}{\bowtie} T_{2}$ \\
\hline & $k$-Vizinhos mais próximos & $T_{1} \stackrel{S, R: k-N N q<d(), k>}{\bowtie} T_{2}$ \\
\hline & $k$-Pares de vizinhos mais próximos & $T_{1} \stackrel{S, R: k-C N q<d(), k>}{\bowtie} T_{2}$ \\
\hline \multirow{2}{*}{$\begin{array}{c}\text { Seleção por similaridade } \\
\text { de grupo }(\hat{\sigma})\end{array}$} & Abrangência & $\left.\hat{\sigma}_{(S: G R q<d(), Q: p, \xi>}\right)^{T_{1}}$ \\
\hline & $k$-Vizinhos mais próximos & $\left.\hat{\sigma}_{(S: k-G N N q<d(), Q: p, k>}\right)^{T_{1}}$ \\
\hline \multirow{2}{*}{$\begin{array}{c}\text { Análise de agrupamento } \\
\text { por similaridade }(\hat{\mu})\end{array}$} & Agrupamentos & $\left.\hat{\mu}_{(S: C l u s t e r<d(), k>)}\right)^{T_{1}}$ \\
\hline & Vínculo a agrupamentos & $\left.\hat{\mu}_{(S: C l u s t e r i n g<d(), k>)}\right) T_{1}$ \\
\hline
\end{tabular}

Tabela 4.1: Descrição dos predicados por similaridade tratados nesta tese.

\subsection{Extensão da Linguagem SQL}

Para permitir a introdução de consultas por similaridade em SQL, existem algumas questões importantes que devem ser abordadas. A primeira questão está relacionada a como permitir a representação de consultas por similaridade sobre domínios de dados complexos. Isso pode ser feito definindo cada domínio no qual a similaridade será mensurada como um novo tipo de dados.

Para isso, nesta tese é feita a separação dos tipos de objetos complexos em duas classes: uma que considera aqueles objetos que são armazenados como um conjunto de atributos tradicionais (ex.: informações relativas a posições geográficas, séries temporais, etc.) e outra para considerar aqueles armazenados como um único objeto binário BLOB (ex.: imagens, áudio, etc.). Para contemplar esses dois tipos de objetos complexos foram definidos os domínios PARTICULATE e MONOLITHIC, respectivamente. Assim, em resposta à questão mencionada anteriormente, três novos tipos de dados foram definidos: PARTICULATE, STILLIMAGE e AUDIO, sendo que cada um dos dois últimos tipos de dados corresponde a especializações do domínio MONOLITHIC específicas para o armazenamento de imagens e áudio, respectivamente. O termo PARTICULATE foi utilizado para indicar que o objeto complexo é na realidade composto por uma coleção de atributos tradicionais, em que os valores armazenados nos atributos tradicionais são utilizados para calcular a distância entre cada par de objetos complexos. O termo MONOLITHIC 
foi utilizado para indicar a situação oposta, em que o atributo é indivisível para efeito de seu reconhecimento no SGBD. Para poder comparar atributos monolíticos é necessário aplicar algoritmos de extração de características sobre eles. As características devem ser armazenadas de alguma maneira junto com o objeto complexo em si, mas o usuário não deve precisar se preocupar com isso. É importante notar que, embora o domínio MONOLITHIC tenha sido representado no trabalho apresentado nesta tese apenas pelos tipos de dados STILLIMAGE e AUDIO, outros tipos de dados pertencentes a esse domínio, como vídeo, podem ser manipulados utilizando a mesma estratégia adotada para aqueles mencionados anteriormente.

Outras questões importantes para a realização de consultas por similaridade em SQL incluem:

- Como permitir a definição de medidas de similaridade (métricas)?

- Como expressar a associação dessas medidas com atributos de tipos complexos?

- Como expressar predicados por similaridade em uma consulta?

A estratégia adotada para tratar todas essas questões por meio da extensão da sintaxe de comandos DDL e DML do SQL é abordada nas próximas seções. Para definir essa extensão da linguagem SQL é necessário especificar a descrição da aparência dos novos construtores (a sintaxe da linguagem) e o significado dos mesmos (a semântica da linguagem). Para especificar a sintaxe da extensão proposta utilizou-se BNF (Forma de Backus-Naur), uma notação amplamente aceita para a especificação de linguagens de programação (veja Apêndice A). Já para a especificação da semântica dos novos construtores são utilizadas descrições informais e exemplos sugestivos.

\subsubsection{Extensão dos Comandos da DDL}

Um dos pontos fundamentais para a inclusão de consultas por similaridade em SQL está relacionado à definição de medidas de similaridade (métricas). Como não existe nenhum conceito que se assemelhe à definição de operadores de comparação por similaridade em SQL, é necessário criar novos comandos para tratar essa questão. As funções de distância são armazenadas no catálogo da base de dados; assim, os comandos de manipulação dessas funções devem seguir o estilo dos comandos da DDL. Desse modo, são necessários três comandos para manipular funções de distância: CREATE METRIC, ALTER METRIC e DROP METRIC. Como todos esses comandos apresentam construções semelhantes, apenas o comando CREATE METRIC será detalhado nesta tese. É importante notar que esses são os únicos novos comandos necessários para suportar a realização de consultas por similaridade em SQL, já que as outras modificações necessárias restringem-se a extensões de comandos já existentes. 


\section{O Comando CREATE METRIC}

Os objetos particulados podem ser comparados por similaridade usando uma métrica que utilize uma determinada função de distância para comparar os atributos que os compõem. Por exemplo, objetos geo-referenciados podem utilizar a função de distância Euclidiana para comparar os atributos que armazenam as suas coordenadas geográficas. Já os objetos monolíticos requerem a especificação de um conjunto pré-definido de características que devem ser extraídas dos objetos e que são utilizadas no lugar dos objetos propriamente ditos no cálculo da métrica. Dados como imagens, por exemplo, podem ser comparados pela similaridade da distribuição de suas cores ou pela similaridade de suas texturas por meio da utilização de algoritmos específicos de extração de características - para a obtenção de seus histogramas de cor e textura, dos contornos dos objetos presentes em uma imagem, etc. - que podem então ser utilizadas na definição das métricas correspondentes.

Desse modo, existem duas variações para o comando CREATE METRIC, uma para o tipo de dados PARTICULATE, e outra para os tipos de dados STILLIMAGE e AUDIO. Como a sintaxe da extensão do SQL proposta para os tipos de dados STILLIMAGE e AUDIO é a mesma, os exemplos apresentados nesta tese consideram apenas o primeiro tipo de dados (a sintaxe completa da extensão proposta é apresentada no Apêndice A). A sintaxe de um CREATE METRIC para um tipo de dados PARTICULATE é a seguinte:

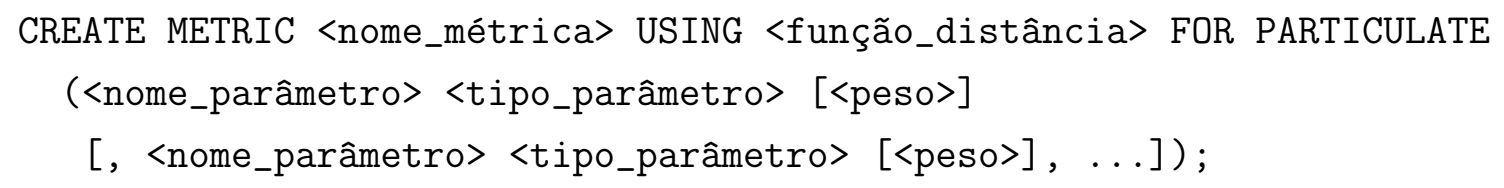

Esse comando pode ser utilizado, por exemplo, para definir uma métrica que avalie a distância entre dois pontos geográficos, representados pelas suas latitude e longitude, da seguinte maneira:

\section{CREATE METRIC Euclidiana2D USING LP2 FOR PARTICULATE}

(Latitude FLOAT, Longitude FLOAT);

O comando acima define que a métrica Euclidiana2D utiliza a função de distância $L_{2}$ (LP2) para comparar um objeto complexo composto por duas coordenadas de tipo FLOAT. Quando uma certa métrica é associada com um tipo de dados PARTICULATE, cada parâmetro da métrica deve ser associado com o atributo de mesmo tipo que compõe o tipo de dados PARTICULATE. A associação de métricas com objetos complexos é explicada mais adiante nesta seção.

Para o domínio de dados MONOLITHIC é necessário utilizar extratores de características para definir os parâmetros utilizados na definição das métricas. Os extratores de características são definidos como procedimentos armazenados (stored procedures) que recebem um objeto complexo, como um argumento, e retornam qualquer número de características que sejam significativas para a comparação dos dados complexos. A sintaxe de um CREATE METRIC para um tipo de dados STILLIMAGE é a seguinte: 
CREATE METRIC <nome_métrica> USING <função_distância> FOR STILLIMAGE (<nome_extrator $>$ (<nome_parâmetro> AS <alias_parâmetro> [<peso $], \ldots$...)

[, <nome_extrator $>$ (<nome_parâmetro> AS <alias_parâmetro> [<peso $], \ldots$...), ...]);

Essa sintaxe permite que uma imagem possa ser comparada por similaridade, considerando mais de um tipo de características. Para ilustrar, nos exemplos a seguir considera-se que os procedimentos armazenados de extração de características HistogramaEXT - que retorna uma estrutura composta por 256 valores inteiros representando o histograma de cor de uma imagem; e MaiorObjetoEXT - que retorna características como área (em número de pixels) e a posição do pixel central da maior área contínua que apresente a mesma cor na imagem - estejam definidos no SGBD. Se for necessário definir uma métrica que avalie a similaridade de duas imagens, considerando seus histogramas de cor e a posição central da maior área contínua (e não a suas áreas), sendo que as características do histograma de cor valem duas vezes mais que a posição central, o seguinte comando pode ser utilizado.

CREATE METRIC Histograma\&Centro USING LP1 FOR STILLIMAGE

(HistogramaEXT (HistogramaC AS Histo 2),

MaiorObjetoEXT (XCentro AS XMaiorObjeto,

YCentro AS YMaiorObjeto));

\section{Associando Métricas com Tipos de Dados Complexos}

Uma vez que as métricas tenham sido criadas elas podem ser associadas com objetos complexos definidos como atributos em qualquer relação. A definição do modo de comparação entre pares de valores de tipos complexos é expressa como uma restrição para o atributo, seguindo as duas maneiras usuais de definição de restrições em um comando CREATE TABLE ou ALTER TABLE: como uma restrição de coluna ou uma restrição de tabela. Além disso, já que as métricas permitem a criação de índices para acelerar a execução de consultas, elas também podem ser especificadas em um comando CREATE INDEX.

Como mencionado anteriormente, o trabalho apresentado nesta tese considera a existência de dois tipos de domínios de objetos complexos, MONOLITHIC e PARTICULATE. Desse modo, a definição da sintaxe para a associação de métricas com tipos de dados complexos levou em consideração as particularidades de cada um desses domínios de dados.

Cada objeto monolítico é armazenado como o valor de um atributo de um tipo monolítico, como o caso do tipo de dados STILLIMAGE. Assim, para associar uma métrica com um atributo de um tipo STILLIMAGE, por exemplo, basta especificar o nome da métrica como uma restrição para o atributo no comando CREATE TABLE. Por exemplo, na relação Paisagem apresentada a seguir o atributo Foto armazena imagens; assim, os objetos que ele armazena podem ser comparados por meio da utilização da métrica Histograma\&Centro, 
definida anteriormente, ou por qualquer outra métrica definida para avaliar a similaridade de duas imagens. A associação entre a métrica Histograma\&Centro e o atributo Foto pode ser definida como uma restrição de coluna da seguinte maneira:

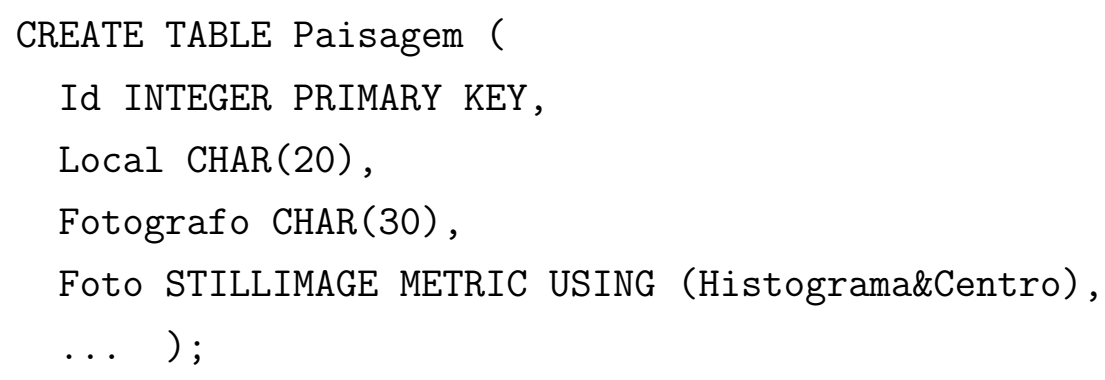

Alternativamente, essa associação também pode ser definida como uma restrição de tabela:

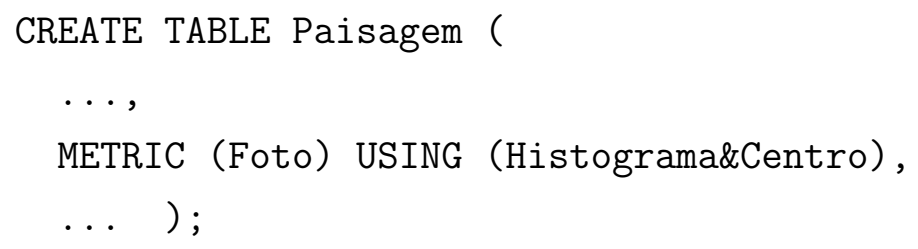

É importante notar que a comparação de duas fotos de paisagens, por meio da utilização da métrica Histograma\&Centro, pode não resultar naquelas mais similares de acordo com os padrões de percepção humano - melhores extratores de características devem ser utilizados/desenvolvidos, mas isso foge ao escopo do trabalho apresentado nesta tese. Assim, o restante dos exemplos apresentados neste capítulo, para o tipo de dados STILLIMAGE, considera a utilização dessa métrica, já que o propósito aqui é apenas ilustrar a sintaxe da linguagem proposta.

Diferentemente dos objetos monolíticos, cada objeto particulado é armazenado como um conjunto de atributos tradicionais (convencionais) em uma relação. Portanto, para associar uma certa métrica a um atributo de tipo PARTICULATE, é necessário definir quais atributos tradicionais serão utilizados, escolhidos entre os que compõem o atributo complexo. Por exemplo, para utilizar a métrica Euclidiana2D para comparar os objetos do conjunto de dados CidadeBR descrito na Seção B.1, pode-se utilizar a restrição de tabela apresentada no comando a seguir:

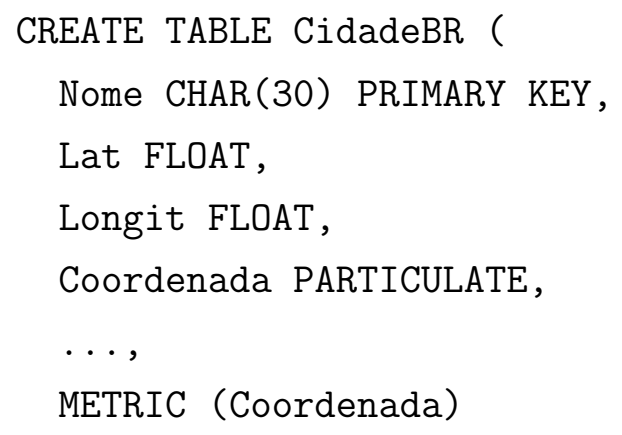




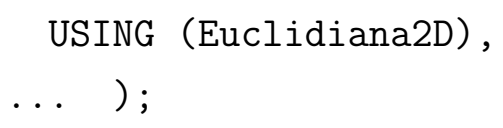

É importante ressaltar que uma restrição de coluna equivalente poderia ser utilizada, desde que os atributos que compõem o atributo complexo tenham sido definidos antes do atributo particulado no comando CREATE TABLE. A cláusula REFERENCES, utilizada para a definição da métrica nas restrições de tabela e coluna para atributos do tipo PARTICULATE, associa cada atributo que compõe o objeto particulado com um dos parâmetros especificados na métrica. Os domínios monolíticos não necessitam dessa cláusula, já que os objetos monolíticos são armazenados como um único objeto BLOB.

Freqüentemente, pode ser necessário oferecer várias opções de comparação por similaridade para objetos de tipos complexos em uma aplicação. Por exemplo, um determinado usuário de um sistema pode estar interessado em paisagens que apresentem distribuições similares de cor; por outro lado, um outro usuário pode estar mais interessado nas paisagens que apresentem texturas semelhantes. Para situações como essa, a sintaxe proposta prevê a possibilidade de associar várias métricas a um mesmo atributo complexo. Quando esse for o caso, deve-se definir uma métrica padrão, adicionando a palavra reservada DEFAULT após um dos nomes das métricas especificadas no comando CREATE TABLE.

\section{Criando Índices para Dados de Tipos Complexos}

Embora consultas por similaridade possam ser realizadas por meio de uma busca seqüencial na base de dados, elas podem ser realizadas mais rapidamente se forem criados índices sobre os atributos complexos. A declaração de índices sobre atributos complexos permite que o SGBD utilize métodos de acesso métrico (MAM) a fim de criar um índice para cada métrica associada a um atributo complexo. Outro ponto importante está relacionado ao fato de que, uma vez que seja necessário definir uma nova métrica que utilize um novo extrator de características, essa métrica pode ser associada com qualquer atributo complexo de uma relação já populada por meio da utilização do comando CREATE INDEX. Considerando as relações CidadeBR e Paisagem, por exemplo, é possível especificar a criação de índices para os seus atributos complexos por meio da utilização dos seguintes comandos:

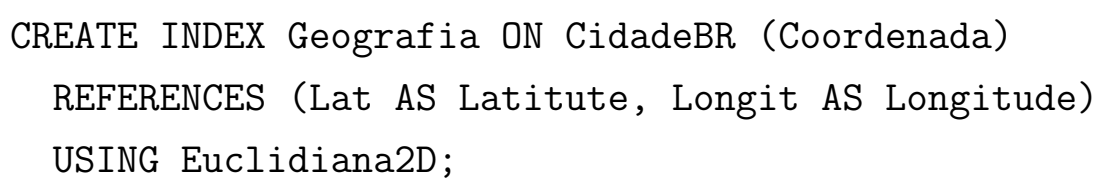

CREATE INDEX FotoPaisagem ON Paisagem (Foto)

USING Histograma\&Centro; 


\subsubsection{Extensão dos Comandos da DML}

Para permitir a utilização de predicados por similaridade em comandos da DML foi necessário adicionar novas construções a sintaxe dos comandos SELECT, UPDATE e DELETE. Nesta tese são apresentadas as novas construções apenas para o comando SELECT, já que as construções definidas para os demais comandos são equivalentes. Para a sintaxe do comando INSERT não foi necessário nenhuma alteração.

O comando SELECT permite uma nova construção para predicados por similaridade na cláusula WHERE, e outra para a especificação de junções por similaridade na cláusula FROM. As próximas subseções detalham cada uma dessas construções.

\section{Predicados por Similaridade na Cláusula WHERE}

A nova construção na cláusula WHERE permite expressar todos os predicados por similaridade descritos na Seção 4.1, a menos dos comandos para as operações de agrupamento, ou seja, consultas que envolvam seleção por similaridade, similaridade de grupo e junção por similaridade.

$\underline{\text { Seleção }}$

A maneira mais simples de expressar um predicado tradicional compara um atributo com um valor constante da seguinte forma: atributo $\theta$ valor, a qual expressa uma seleção. Para expressar um predicado por similaridade, o atributo deve ser de um tipo complexo e deve estar associado a uma métrica, o valor constante valor deve ser um objeto do domínio complexo correspondente, e o operador $\theta$ deve ser um operador por similaridade que utilize a métrica definida sobre o atributo. A sintaxe básica para expressar uma seleção por similaridade é a seguinte:

$<$ atributo> NEAR <valor $>$ [STOP AFTER $<k>$ ] [RANGE $<\xi>$ ]

Se o atributo é do tipo STILLIMAGE, a constante imagem pode ser expressa como um caminho no sistema de arquivos no qual a imagem está armazenada. Considerando a relação Paisagem, por exemplo, para selecionar as cinco paisagens mais similares a uma dada foto, o seguinte comando pode ser utilizado:

\section{SELECT * FROM Paisagem}

WHERE Foto NEAR 'c: \img09.jpg' STOP AFTER 5;

Se o atributo é do tipo PARTICULATE, o valor constante pode ser expresso por uma lista de associações no formato <valor_atributo> AS <nome_parâmetro>. Por exemplo, para selecionar as cidades da relação CidadeBR que estejam próximas até 2 unidades de distância de uma dada coordenada, o seguinte comando pode ser utilizado: 


\section{SELECT * FROM CidadeBR \\ WHERE Coordenada NEAR (-22.02 AS Latitude, \\ 47.89 AS Longitude) RANGE 2;}

Alternativamente, valores constantes também podem ser obtidos a partir da base de dados tanto para atributos de tipos pertencentes ao domínio MONOLITHIC, quanto para atributos do tipo PARTICULATE. Assim, para responder à mesma consulta descrita anteriormente para o tipo de dados STILLIMAGE, considerando agora uma paisagem armazenada na base de dados, o seguinte comando poderia ser utilizado para expressar uma operação de seleção por similaridade.

\section{SELECT * FROM Paisagem \\ WHERE Foto NEAR (SELECT Foto FROM Paisagem \\ WHERE Id = 123) STOP AFTER 5;}

Para ilustrar essa alternativa no caso de atributos do tipo PARTICULATE considere, por exemplo, que se queira retornar as 5 cidades brasileiras mais próximas da cidade com nome = 'São Carlos-SP'. É possível responder a esse tipo de consulta utilizando o comando apresentado abaixo. A Figura 4.2 apresenta uma ilustração da resposta obtida com a execução desse comando pelo protótipo SIREN descrito no Capítulo 5.

\section{SELECT Nome FROM CidadeBR}

WHERE Coordenada NEAR (SELECT Lat AS Latitude, Longit AS Longitude FROM CidadeBR WHERE Nome = 'São Carlos-SP') STOP AFTER 5;

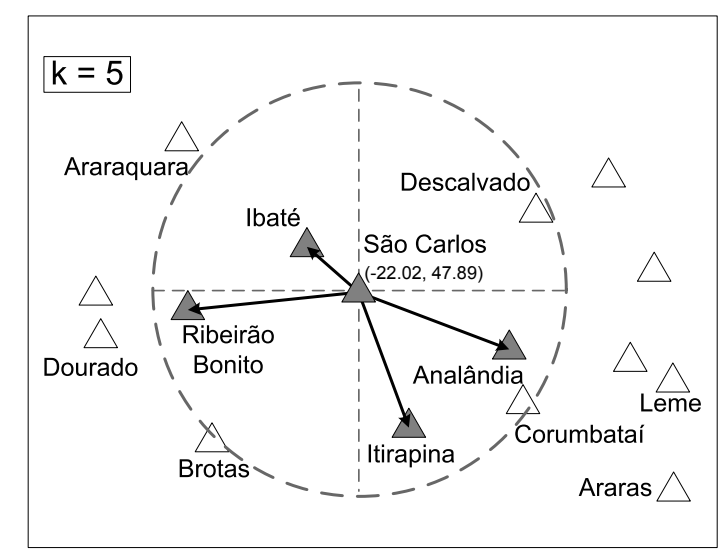

Figura 4.2: Exemplo de consulta por similaridade. Ilustração do resultado de uma consulta $k$-NNq das 5 cidades mais próximas de São Carlos-SP.

Analisando o comando anterior, é possível notar que o comando SELECT interno pode retornar mais de uma tupla se o atributo Nome não for chave. Nesse caso, a execução do SELECT interno fornece não apenas um, mas potencialmente um conjunto com diversos 
centros para o predicado por similaridade, portanto um método de agregação deve ser escolhido, de acordo com a Equação 4.1, apresentada na Seção 4.1. Uma palavra chave inserida após o operador NEAR fornece essa opção: SUM para $p=1$, ALL para $p=2$ e MAX para $p=\infty$. Caso nenhuma dessas palavras chaves seja especificada, o método padrão assumido é SUM.

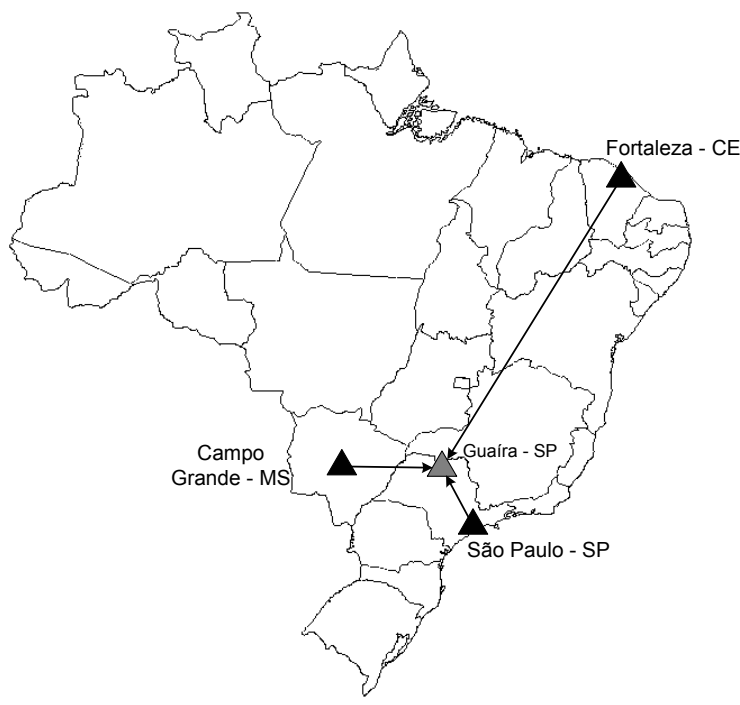

(a)

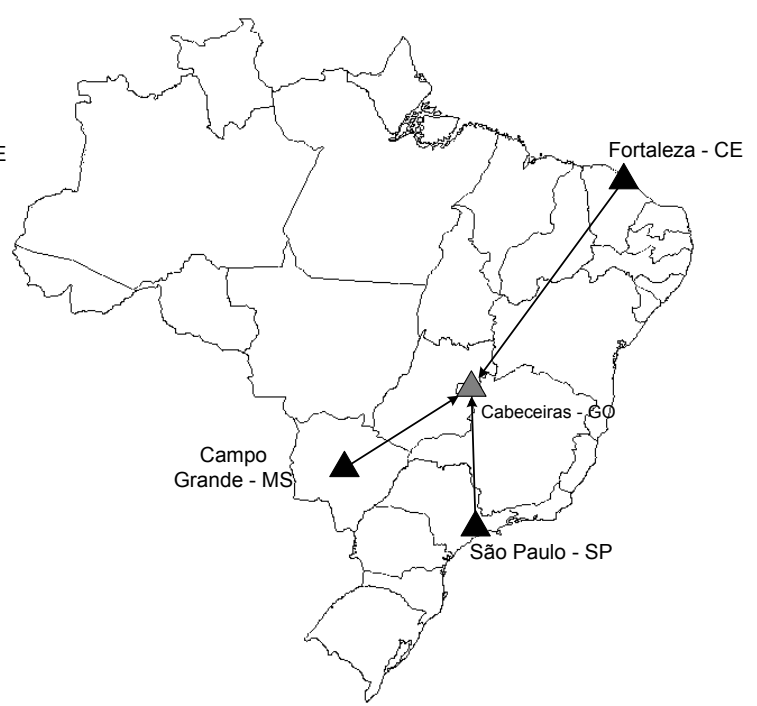

(b)

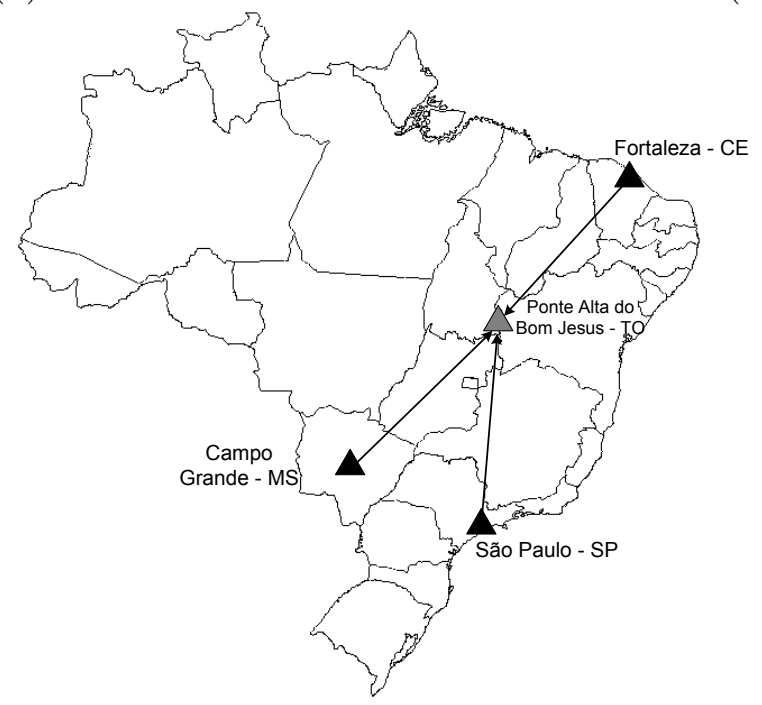

(c)

Figura 4.3: Exemplos de consultas por similaridade de grupo. (a) Com o método de agregação SUM. (b) Com o método de agregação ALL. (c) Com o método de agregação MAX.

Exemplos de aplicações que se beneficiam da utilização de consultas desse tipo incluem as aplicações que lidam com alocação de recursos. Como um exemplo desse tipo de aplicação, considere uma rede de supermercados - com filiais em São Paulo-SP, Campo Grande-MS e Fortaleza-CE - que deseje selecionar uma cidade brasileira para a construção de um novo depósito. Para tomar essa decisão, essa rede de supermercados deseja analisar três situações distintas: qual o local que minimizaria a soma das distâncias para as filiais 
abastecidas por ele; qual seria o local que minimizaria a distância para todas as filiais; e qual o local que minimizaria as distâncias máximas que teriam que ser percorridas para abastecer qualquer uma das filiais. Para responder a essas questões, é possível especificar comandos SQL utilizando respectivamente os métodos de agregação SUM, ALL e MAX. O comando a seguir exemplifica como pode ser respondida a primeira questão mencionada anteriormente. A Figura 4.3 apresenta uma ilustração das respostas obtidas com a execução desse comando pelo protótipo SIREN (veja Capítulo 5), considerando os três métodos de agregação mencionados anteriormente.

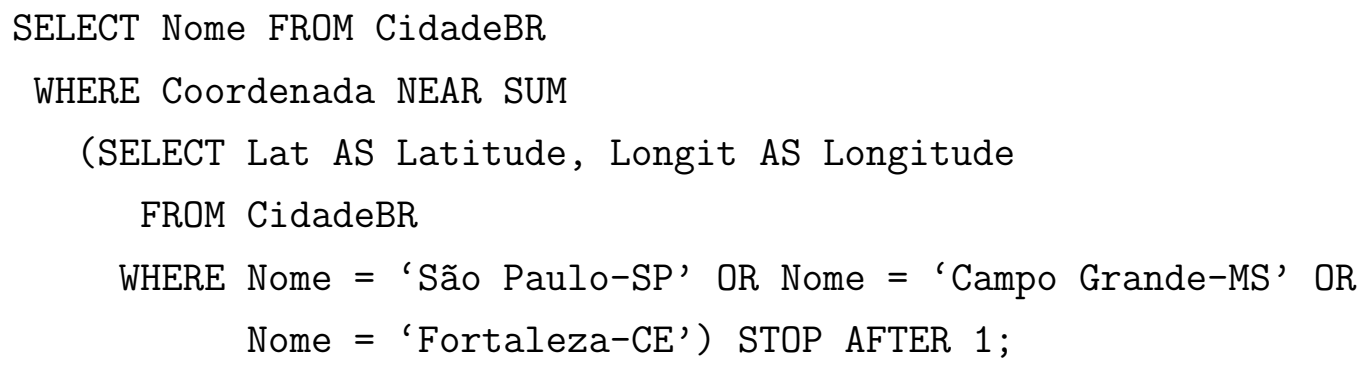

Junção

A construção usual para expressar uma operação de junção na cláusula WHERE compara um atributo de uma tabela com um atributo de outra tabela, no formato $T_{1} \cdot a t r_{1} \theta T_{2} \cdot a t r_{2}$. Junções por similaridade podem ser expressas utilizando o mesmo formato, desde que ambos atributos pertençam ao mesmo domínio complexo e tenham sido associados com a mesma métrica. A construção $T_{1} \cdot a t r_{1}$ NEAR $T_{2} \cdot a t r_{2}$ RANGE $\xi$ expressa uma junção por abrangência; a construção $T_{1}$.atr $r_{1}$ NEAR $T_{2}$.atr $r_{2}$ STOP AFTER $k$ expressa uma junção pelos $k$-vizinhos mais próximos; a construção $T_{1}$.atr $r_{1}$ NEAR ANY $T_{2} . a t r_{2}$ STOP AFTER $k$ expressa uma junção dos $k$-pares de vizinhos mais próximos. Para exemplificar essa sintaxe, considere o seguinte comando que pode ser utilizado para recuperar as cidades que estejam a até 0.9 unidades de distância de cada capital dos estados da Região Sudeste brasileira. A Figura 4.4 apresenta uma ilustração da resposta obtida com a execução desse comando.

SELECT * FROM CapitalSE, CidadeBR

WHERE CapitalSE. Coordenada NEAR CidadeBR.Coordenada RANGE 0.9;

\section{Variações na Consulta por Similaridade}

Variações na sintaxe básica dos comandos apresentados anteriormente podem ser expressas por meio da utilização de modificadores nos comandos. Se for necessário, por exemplo, recuperar os objetos mais dissimilares ao invés dos mais similares, a palavra reservada NEAR deve ser trocada por FAR. Para ilustrar a utilização dessa construção, considere o seguinte comando que pode ser empregado para recuperar as 5 cidades brasileiras que estejam mais distantes de 'São Carlos-SP'. 


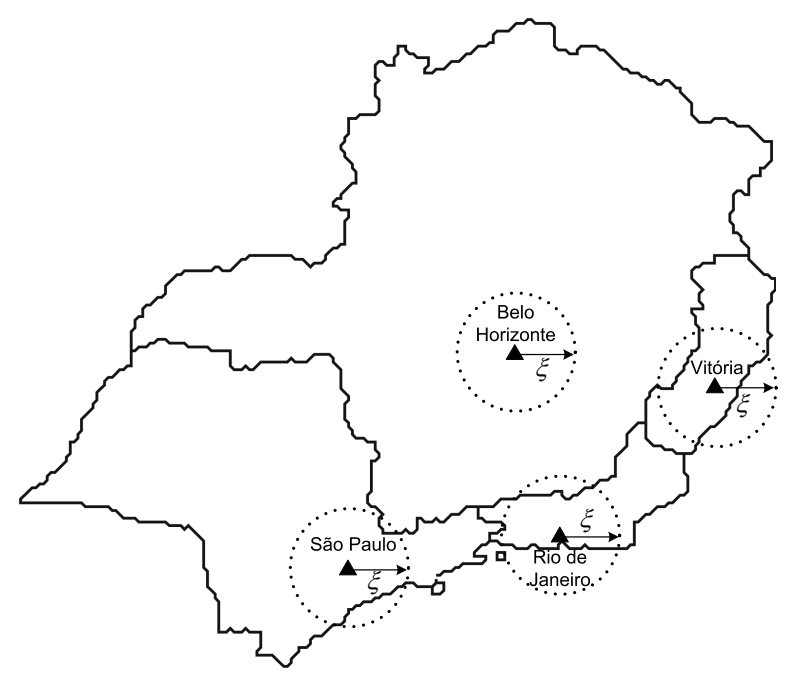

Figura 4.4: Exemplo de consulta por similaridade. Ilustração do resultado de uma junção por abrangência entre as capitais da Região Sudeste com as cidades brasileiras.

SELECT Nome FROM CidadeBR

WHERE Coordenada FAR (SELECT Lat AS Latitude, Longit AS Longitude FROM CidadeBR

WHERE Nome $=$ 'São Carlos-SP')

STOP AFTER 5;

Se mais de uma métrica for definida, a métrica padrão é utilizada, a menos que a cláusula BY <nome_métrica> seja especificada. Por exemplo, considerando o caso em que outra métrica, chamada Textura, também tenha sido associada com o atributo Foto da relação Paisagem, para selecionar até 5 paisagens cujas fotos sejam as mais similares a uma dada foto, considerando ambas as métricas Histograma\&Centro e Textura, o seguinte comando pode ser utilizado:

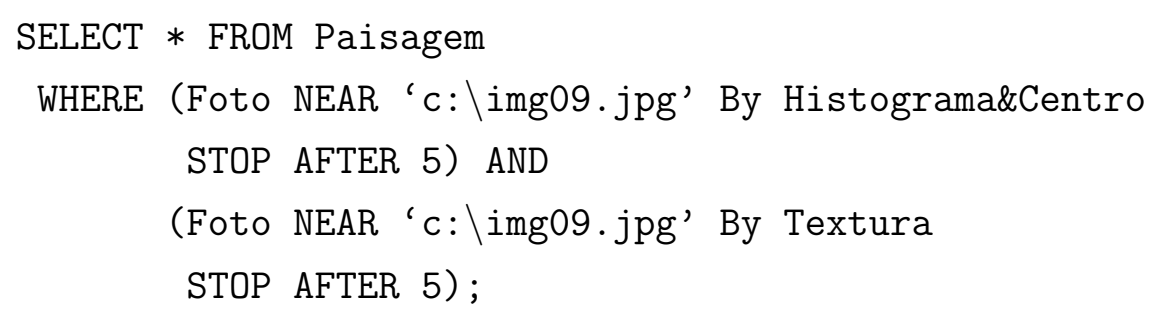

Consultas limitadas por $k$ vizinhos (tanto em seleções quanto em junções) podem levar em consideração a ocorrência de empates, ou seja, a resposta desse tipo de consulta pode conter muitos objetos encontrados à distância máxima. O comportamento padrão de uma consulta limitada por $k$ vizinhos consiste na recuperação de $k$ objetos sem empate, retornando qualquer combinação dos $k_{i}$ objetos empatados à distância máxima. Para recuperar todos os objetos que possam ter empatado com o objeto mais distante em uma consulta, é possível adicionar a cláusula WITH TIE LIST após a especificação da cláusula 
STOP AFTER. Se ocorrerem empates, a consulta que utilizar essa construção pode retornar mais de $k$ objetos.

Ambas cláusulas STOP AFTER e RANGE podem ser especificadas em uma mesma consulta. Nesse caso, a resposta deve conter no máximo $k$ objetos não mais distantes (ou próximos) do que uma distância $\xi$ do centro de consulta. Por exemplo, o comando

SELECT * FROM Paisagem

WHERE Foto NEAR 'c:\img09.jpg' STOP AFTER 5 RANGE 0.03;

recupera no máximo 5 paisagens não distantes mais do que 0.03 unidades de distância da foto de consulta dada.

\section{Junções por Similaridade na Cláusula FROM}

Junções por similaridade também podem ser expressas na cláusula FROM de comandos SELECT. Essa sintaxe segue a representação tradicional de junções nessa cláusula por meio da utilização de uma sintaxe equivalente à utilizada na cláusula WHERE, que pode ser expressa da seguinte maneira:

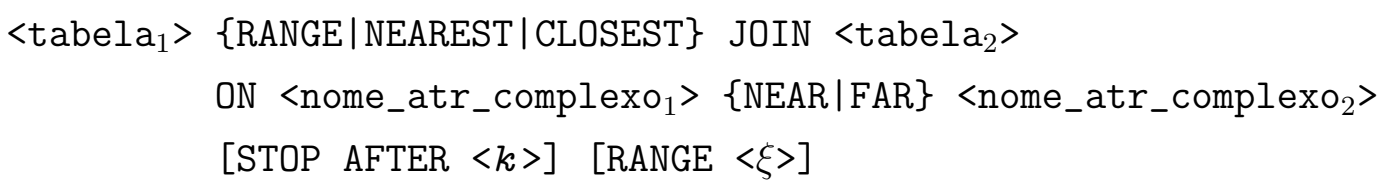

\subsubsection{Extensão de Comandos SQL para a Especificação de Ope- rações de Detecção de Agrupamentos de Dados}

Para permitir a inclusão do suporte a especificação de operações de detecção de agrupamentos de dados na sintaxe da linguagem apresentada neste capítulo, a abordagem adotada considera as seguintes facilidades presentes no padrão SQL:2003 - a possibilidade de especificar funções na cláusula FROM, as quais retornam os seus resultados no formato de tabelas (table functions) [Eisenberg et al., 2003]; e a utilização de construções sintáticas como as empregadas em comandos SET, utilizados na inicialização dos parâmetros de uma sessão, para a inicialização dos parâmetros necessários à realização de uma sessão de detecção de agrupamentos sobre um determinado atributo complexo.

\section{Conceitos e Sintaxe}

Para a realização de um processo de detecção de agrupamentos de dados sobre um atributo $A_{i}$ de uma relação $R$, é necessário que $A_{i}$ seja um atributo de tipo complexo que admita busca por similaridade segundo uma métrica previamente associada a ele. Como resultado desse processo, são obtidas duas relações: a relação de agrupamentos encontrados $C\left(A_{i}\right)$ e uma relação $C I\left(A_{i}\right)$ que associa cada valor de $A_{i}$ a um agrupamento em 
$C\left(A_{i}\right)$. Portanto, sempre que o usuário quiser se referir a um processo de detecção de agrupamentos, deve se referir a pelo menos uma dessas relações em uma cláusula FROM de um comando SELECT. Essas relações são obtidas respectivamente pela execução das funções Cluster e Clustering.

Cada tabela resultante da aplicação das funções Cluster e Clustering refere-se a um atributo $A_{i}$ de uma tabela $R$, a qual, sendo uma tabela definida pelo sistema, tem uma estrutura pré-definida. Além disso, é necessário definir os parâmetros do processo de detecção de agrupamentos a que cada uma corresponde. Assim, define-se:

1. Como se referir ao atributo?

2. Como se referir à estrutura das tabelas?

3. Como parametrizar o processo de detecção de agrupamento?

$\underline{\text { Referência ao Atributo }}$

Para se referir a um atributo de tipo complexo, que possua ao menos uma métrica associada a ele, utiliza-se a sintaxe '('<nome_tabela $>$. $\left.\langle\text { nome_atributo }\rangle^{6}\right)$ ' tal como exemplificado no comando a seguir:

SELECT *

FROM Clustering(Paisagem. Foto);

O comando apresentado acima poderia ser empregado para mostrar os agrupamentos de cada instância do atributo Foto da tabela Paisagem. Para mostrar todas os agrupamentos de um atributo Foto poderia ser utilizado o seguinte comando:

\section{SELECT *}

FROM Cluster (Paisagem.Foto);

\section{Estrutura das Tabelas}

A estrutura de cada tabela associada a um processo de detecção de agrupamentos é prédefinida, e é independente de qual seja o algoritmo de detecção de agrupamentos usado, o que significa que, dependendo do algoritmo usado, alguns atributos podem ficar indefinidos (nulos). A tabela resultante da aplicação da função Cluster contém todas as informações sobre cada agrupamento, e é definida como:

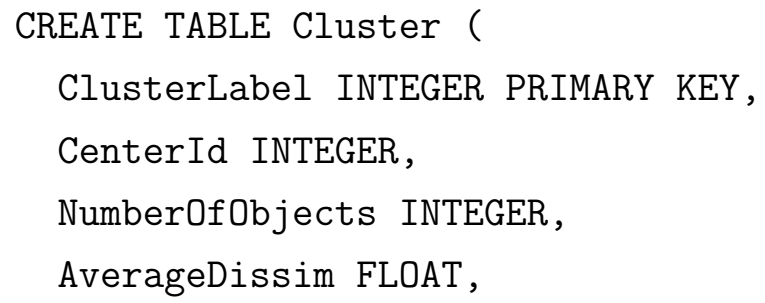




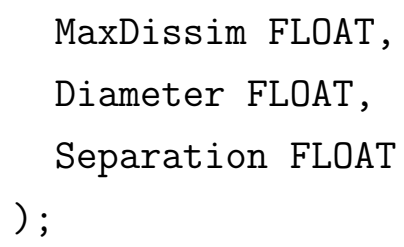

ClusterLabel: identifica o agrupamento;

CenterId: corresponde a uma referência ao objeto central (medóide);

NumberOfObjects: é o número de objetos pertencentes ao agrupamento;

AverageDissim: armazena a dissimilaridade média dos objetos ao objeto central;

MaxDissim: armazena a dissimilaridade máxima de qualquer objeto ao objeto central;

Diameter: armazena o diâmetro do agrupamento;

Separation: armazena a separação entre os agrupamentos.

Já a tabela resultante da aplicação da função Clustering armazena as informações relativas a associação de cada objeto do conjunto de dados ao agrupamento a que ele pertence da maneira descrita a seguir:

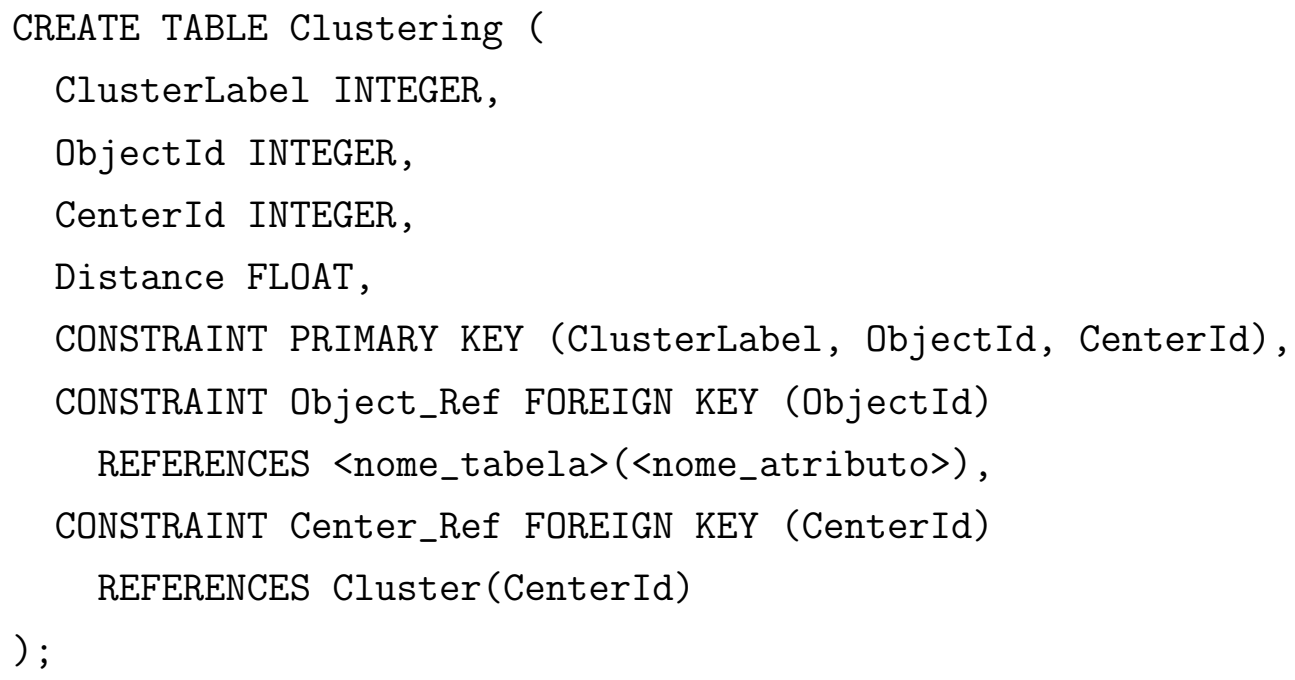

Para os algoritmos de detecção de agrupamentos baseados no método $k$-medoid, que correspondem ao tipo de algoritmos de detecção de agrupamentos abordados no trabalho apresentado nesta tese, é necessário definir pelo menos três parâmetros para cada atributo pertencente aos domínios PARTICULATE e MONOLITHIC: 
1. A métrica que deve ser utilizada;

2. O número de agrupamentos $k$;

3. Qual algoritmo de detecção de agrupamentos utilizar.

Para tanto foi definida a seguinte construção sintática:

SET

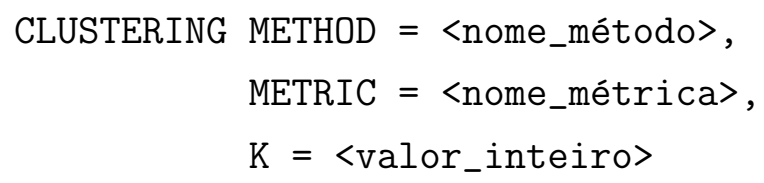

que deve ser especificada antes da realização de comandos SQL que façam referência ao resultado do processo de detecção de agrupamentos definido sobre um atributo complexo.

Para ilustrar a utilização dessa construção sintática, são apresentados a seguir alguns exemplos de consultas que incluem comandos de agrupamento. Para a especificação desses comandos, são consideradas a métrica e a tabela definidas abaixo para o conjunto de dados Autos descrito na Seção B.2:

CREATE METRIC CustoBeneficio

FOR PARTICULATE (Cavalos INTEGER, Volume INTEGER 0.5, km_l INTEGER 10);

CREATE TABLE Autos (Nome CHAR(60) NOT NULL PRIMARY KEY,

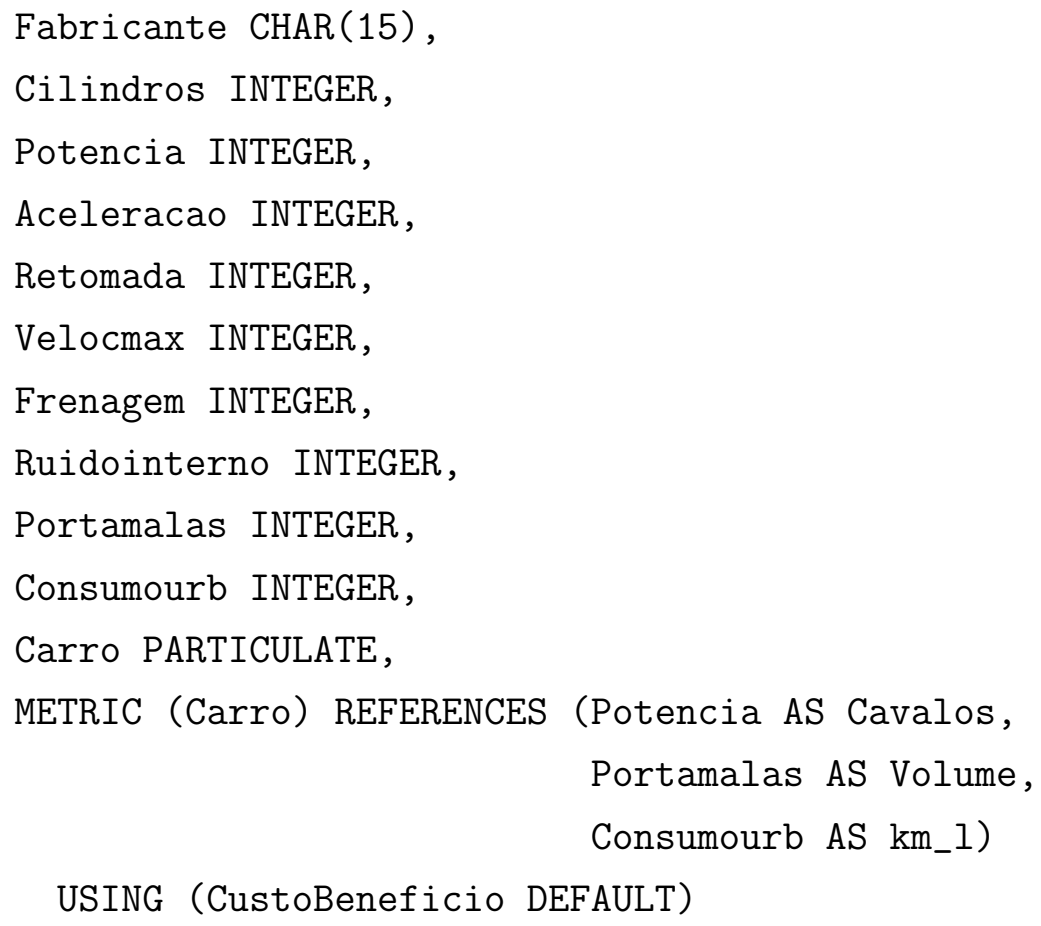


Exemplo1. Obter quais carros pertencem a cada uma das 5 classes de carros, segundo o critério de CustoBeneficio.

SET CLUSTERING METHOD = 'Clarans', METRIC = 'CustoBeneficio',

$$
\mathrm{K}=5 \text { ON Autos.Carro; }
$$

SELECT Autos.Nome, AutoClustering.ClusterLabel

FROM Autos, Clustering(Autos.Carro) AutoClustering

WHERE Autos.Carro = AutoClustering.ObjectId;

Exemplo2: Obter os carros mais representativos de cada uma das 5 classes de carros.

SELECT Autos.Nome, AutoCluster.ClusterLabel

FROM Autos, Cluster(Autos.Carro) AutoCluster

WHERE Autos.Carro = AutoCluster. CenterId;

Exemplo3: Para cada carro, indicar a qual de cada uma das 5 classes ele pertence, qual o carro mais representativo de sua classe, e a distância entre ambos.

SELECT A.Nome, AutoClustering.ClusterLabel, ACentro.Nome, AutoClustering.Distance

FROM Autos A, Autos ACentro, Clustering(Autos.Carro) AutoClustering

WHERE A.Carro = AutoClustering.ObjectId AND

ACentro.Carro = AutoClustering. CenterId;

Exemplo4: Listar todos os carros que estão na mesma classe de CustoBeneficio e de Motorizacao do carro 'FiatPalio' dado que também existe a métrica Motorizacao e o atributo MotorSimilar definidos como:

CREATE METRIC Motorizacao USING LP2

FOR PARTICULATE (NrO INTEGER 5.0, km_h INTEGER);

\section{ALTER TABLE Autos}

ADD MotorSimilar PARTICULATE METRIC

REFERENCES (Cilindros AS Nro, Aceleracao AS km_h) USING (Motorizacao);

SET CLUSTERING METHOD = 'Clarans', METRIC = 'Motorizacao', $\mathrm{K}=5$ ON Autos.MotorSimilar; 


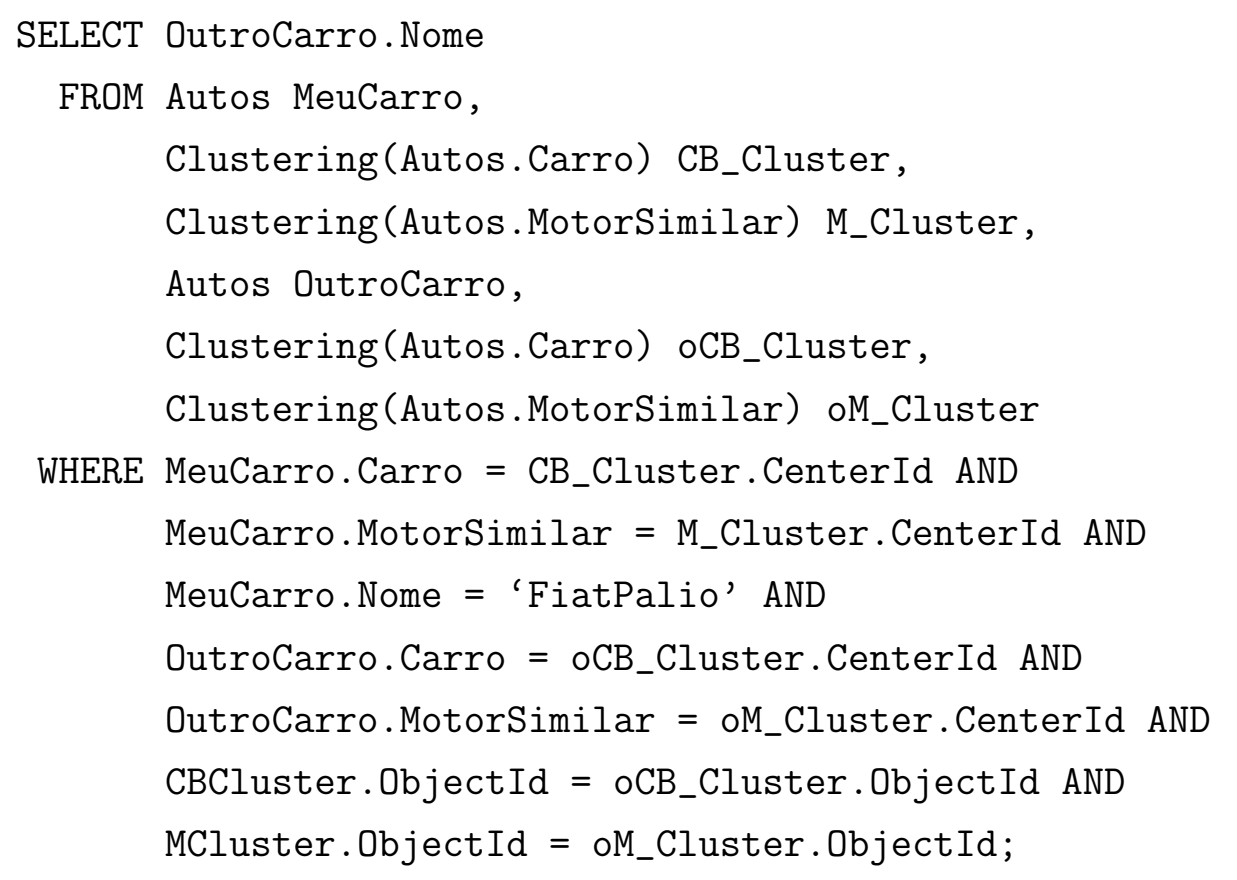

\subsubsection{Outras Construções para a Recuperação dos Valores de Atributos das Métricas}

Existe ainda uma última construção sintática que permite a utilização dos componentes de uma métrica em comandos SQL. Um dos componentes úteis para seleções por similaridade é o valor da distância retornado pela métrica. A construção sintática empregada para recuperar esse valor expressa o nome da métrica como uma função. Por exemplo, o seguinte comando seleciona os nomes dos cinco fotógrafos cujas paisagens fotografadas sejam as mais similares a uma foto dada, além de informar a distância de cada paisagem ao centro de consulta, que é calculada pela métrica Histograma\&Centro:

\section{SELECT Fotografo, Histograma\&Centro() FROM Paisagem WHERE Foto NEAR 'c: \img09.jpg' STOP AFTER 5;}

É importante notar que a distância retornada pela métrica Histograma\&Centro não é um atributo do objeto Foto, mas sim uma propriedade do objeto relativa a um predicado específico. Assim, essa construção só pode ser utilizada em comandos compostos por apenas um predicado por similaridade. Para os casos em que os comandos possuam vários centros de consulta, essa construção retorna a distância agregada empregada na escolha de cada tupla. E em consultas que necessitem da realização de junções por similaridade, essa construção retorna a distância entre cada objeto do par retornado em uma tupla.

Os componentes dos objetos particulados empregados nos cálculos de similaridade podem ser acessados diretamente, uma vez que correspondem a atributos tradicionais em uma relação; assim, não existe necessidade de nenhuma construção especial para recuperá-los. Por outro lado, os domínios monolíticos utilizam características que não 
são disponibilizadas diretamente para os usuários. Dessa maneira, é necessário utilizar a seguinte construção para recuperar os valores dessas características:

$[<$ tabela>'.']<atributo>'. '<extrator>' . '<parâmetro>

Exemplificando essa construção, o seguinte comando poderia ser utilizado para recuperar a coordenada XCentro do pixel central do maior objeto presente nas paisagens.

SELECT Fotografo, Foto.MaiorObjetoEXT.XMaiorObjeto

FROM Paisagem WHERE Foto NEAR 'c: \img09.jpg' STOP AFTER 5;

\subsubsection{Precedência dos Operadores por Similaridade}

Os predicados por similaridade limitados por $\xi$ apresentam a propriedade de comutatividade, tanto com os predicados limitados por $\xi$ quanto com os predicados tradicionais. Por outro lado, os predicados por similaridade limitados por $k$ não apresentam essa propriedade com qualquer tipo de predicado. Na verdade, é possível verificar diretamente que a expressão

$$
\sigma_{(\text {atributo } \theta \text { valor })}\left(\hat{\sigma}_{\left(S: k-N N q\left(d(), s_{q}, k\right)\right.} T_{1}\right) \subseteq \hat{\sigma}_{\left(S: k-N N q\left(d(), s_{q}, k\right)\right)}\left(\sigma_{(\text {atributo } \theta \text { valor })} T_{1}\right)
$$

é verdadeira, como ilustrado nas Figuras 4.5 e 4.6 que exibem os resultados da execução de seleções considerando a tabela CidadeBR e os Predicados P4.1 e P4.2 apresentados na Tabela 4.2. Nessas figuras, os triângulos brancos representam as cidades que não fazem parte das respostas e os triângulos de cor cinza representam as que fazem.

\begin{tabular}{|c|lr|c|}
\hline Identificação & \multicolumn{2}{|c|}{ Predicado } & Tipo \\
\hline \hline P4.1 & Coordenada & NEAR $(-22.02$ as Latitude, & \\
& & 47.89 as Longitude) & por similaridade \\
& & STOP AFTER 5 & tradicional \\
\hline P4.2 & Lat $<-22.02$ & & \\
\hline
\end{tabular}

Tabela 4.2: Descrição dos predicados utilizados na realização de seleções sobre a tabela CidadeBR.

A Figura 4.5 (a) ilustra o resultado obtido com a execução de uma seleção por similaridade sobre a tabela CidadeBR considerando o predicado P4.1; e a Figura 4.5 (b) ilustra a resposta retornada pela execução de uma seleção sobre o resultado exibido em (a), considerando o predicado P4.2, que contém 3 cidades \{'Analândia-SP' , 'Ribeirão Bonito-SP', 'Itirapina-SP'\}. Já a Figura 4.6 ilustra o resultado obtido pela execução dessas mesmas seleções na ordem inversa. Dessa forma, a Figura 4.6 (a) ilustra o resultado obtido com a execução de uma seleção sobre a tabela CidadeBR considerando o 


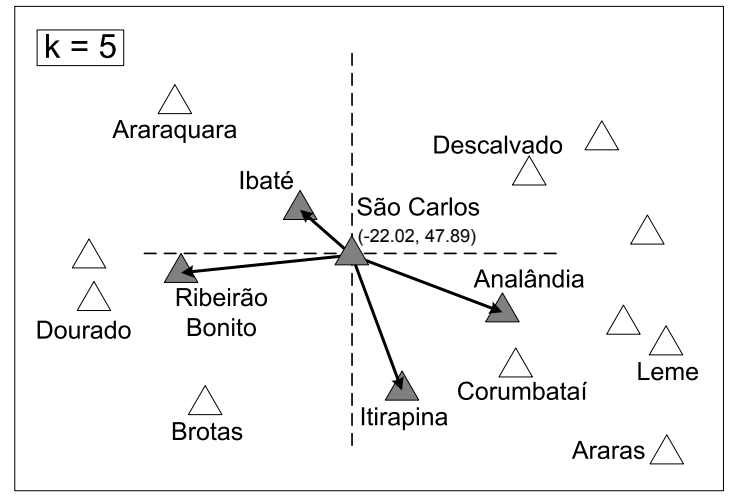

(a)

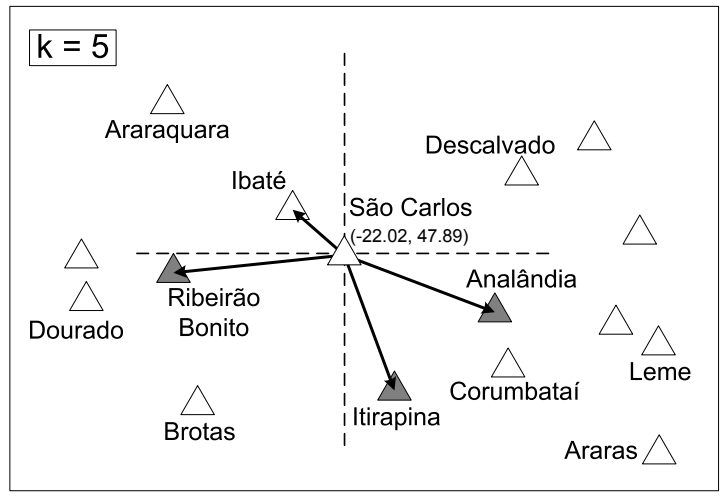

(b)

Figura 4.5: Ilustração da execução de seleções considerando a tabela CidadeBR e os Predicados P4.1 e P4.2 apresentados na Tabela 4.2. (a) Resultado parcial após a execução do predicado P4.1 sobre a tabela CidadeBR. (b) Resposta final após a execução do predicado P4.2 sobre o resultado exibido em (a).

predicado P4.2 e a Figura 4.6 (b) apresenta a resposta retornada pela execução de uma seleção sobre o resultado ilustrado em (a), considerando o predicado por similaridade P4.1, que contém 5 cidades: \{'Analândia-SP', 'Ribeirão Bonito-SP', 'Itirapina-SP', 'Corumbataí-SP', 'Brotas-SP'\}.

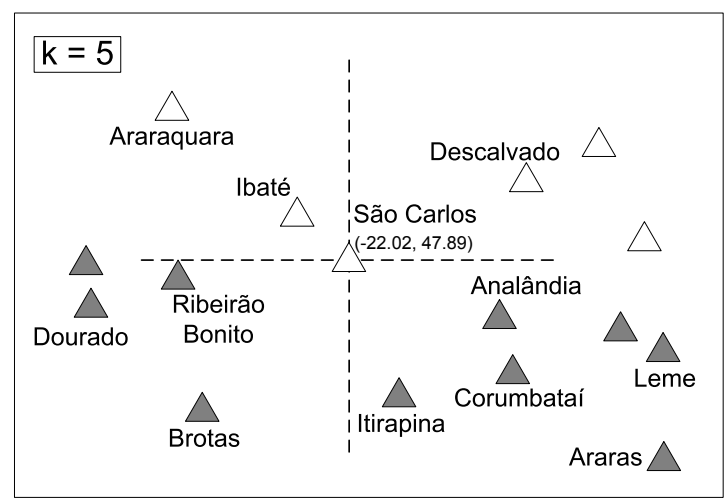

(a)

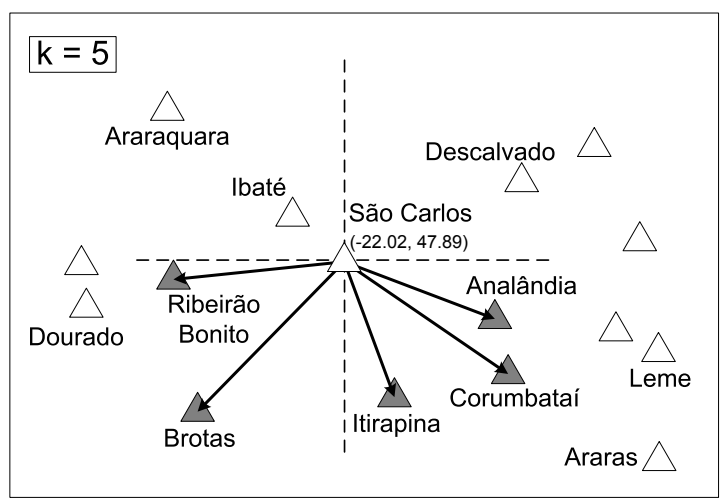

(b)

Figura 4.6: Ilustração da execução de seleções considerando a tabela CidadeBR e os Predicados P4.1 e P4.2 apresentados na Tabela 4.2. (a) Resultado parcial após a execução do predicado P4.2 sobre a tabela CidadeBR. (b) Resposta final após a execução do predicado P4.1 sobre o resultado exibido em (a).

A não comutatividade dos predicados por similaridade limitados por $k$ impede a equivalência de seqüências de predicados para conjunções de predicados e para intersecções dos conjuntos de resultados individuais. Esse é um efeito indesejável, já que os comandos SQL sempre usaram o conector AND para representar seqüências de predicados. Para evitar ambigüidade na avaliação de predicados por similaridade, foram estabelecidas as seguintes regras: 1) os predicados por similaridade expressos na cláusula WHERE devem ser sempre executados antes de qualquer predicado tradicional; 2) os predicados por si- 
milaridade limitados por $k$ devem ser executados antes dos predicados por similaridade limitados por $\xi$; e 3) dois ou mais predicados por similaridade limitados por $k$ devem ser executados independentemente sobre a tabela base devendo ser realizada a intersecção de seus resultados (se conectados por AND) ou a união (se conectados por OR). Dessa maneira, os dois comandos apresentados a seguir,

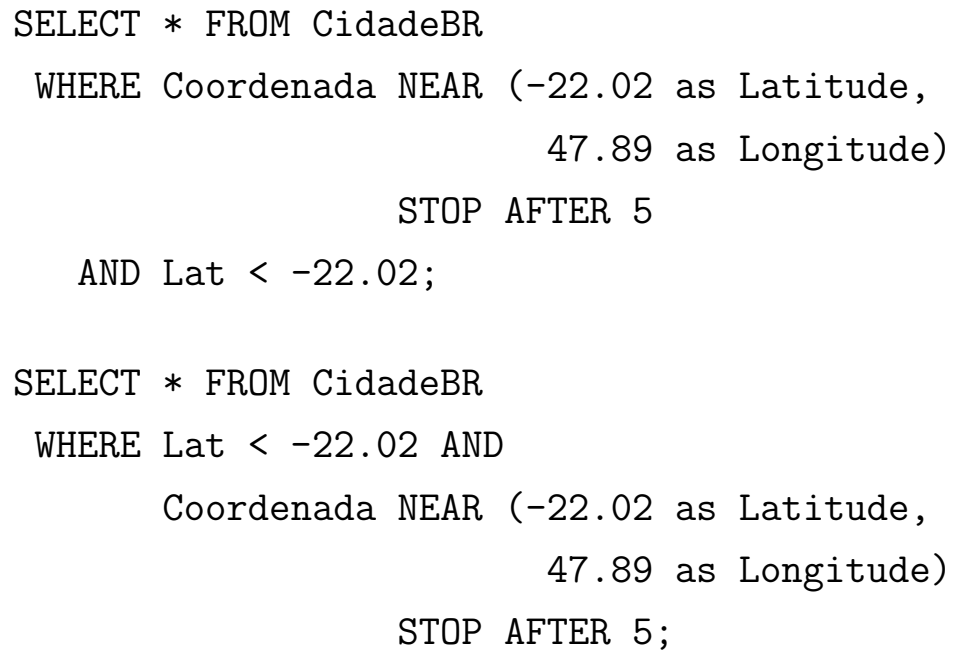

são traduzidos para a mesma expressão algébrica:

$$
\begin{gathered}
\sigma_{(\text {Lat }<-22.02)}(\hat{\sigma} \\
(\text { Coordenada: } k-N N q(\text { Euclidiana } 2 D(),(-22.02 \text { as Latitude, } 47.89 \text { as Longitude }), 5)) \\
\text { CidadeB } R) .
\end{gathered}
$$

A imposição dessas regras aumenta a utilização de estruturas de indexação na realização de buscas por similaridade, o que é um efeito desejável, já que operações de busca por similaridade são normalmente mais caras que as operações de busca tradicionais. Ela também permite que qualquer predicado não limitado por $k$ seja tratado normalmente (da maneira usual) após o processamento dos predicados limitados por $k$. Entretanto, uma consulta que necessite da seqüência oposta não pode ser expressa por meio de um único comando SQL utilizando apenas a cláusula WHERE. Contudo, ela pode ser expressa por meio da preparação das tabelas, utilizando a facilidade presente no SQL:1999, que permite a utilização de tabelas aninhadas na cláusula FROM. Desse modo, uma consulta que corresponda à seguinte expressão algébrica:

$$
\begin{aligned}
& \left.\hat{\sigma}_{(\text {Coordenada:k-NNq(Euclidiana2D }(),(-22.02 \text { as Latitude, } 47.89 \text { as Longitude }), 5)}\right)\left(\sigma_{(\text {HomeLat }<-22.02)}\right. \\
& \text { BRCities), }
\end{aligned}
$$

pode ser representada como:

\section{SELECT *}


WHERE Lat $<-22.02)$

WHERE Coordenada NEAR ( -22.02 as Latitude,

47.89 as Longitude)

STOP AFTER 5;

Essas regras se aplicam tanto para seleções por similaridade quanto para as similaridade por grupo e junções por similaridade.

\subsection{Considerações Finais}

Com o aumento da quantidade de dados de domínios complexos (como imagens, áudio, vídeo, séries temporais, etc.) sendo armazenados em bases de dados, a disponibilização de suporte para a realização de consultas por similaridade em SGBD têm recebido grande atenção. Entretanto, o padrão atual da linguagem comumente utilizada para realizar consultas em bases de dados, a linguagem SQL, não prevê a especificação dessas consultas. O trabalho apresentado neste capítulo teve como objetivo suprir essa necessidade por meio da definição de uma extensão na linguagem SQL para a realização de consultas por similaridade, considerando a existência de dois domínios de dados complexos - PARTICULATE e MONOLITHIC. A extensão definida neste capítulo atende aos seguintes requisitos:

- Permite representar consultas por similaridade de maneira flexível e que, ainda assim, apresenta um baixo impacto sobre a sintaxe padrão do SQL;

- Permite a realização de consultas por similaridade tanto em domínios MONOLITHIC quanto em domínios PARTICULATE por meio da utilização de construções sintáticas equivalentes;

- Permite a definição de métricas sobre domínios complexos de modo que qualquer atributo definido nesses domínios possa utilizar essas métricas;

- Permite a possibilidade de otimização de consultas por similaridade, seguindo o mesmo processo de otimização utilizado para as consultas tradicionais expressas em SQL;

- Permite a especificação de consultas sobre o resultado de processos de detecção de agrupamentos de dados baseados no método $k$-medoid.

Para validar o trabalho apresentado neste capítulo, foi desenvolvido o protótipo de uma ferramenta que implementa um mecanismo para a realização de consultas por similaridade em um SGBD relacional, utilizando a extensão da linguagem SQL descrita neste capítulo. Os conceitos envolvidos na implementação desse protótipo são apresentados no Capítulo 5 . 


\section{Capítulo \\ 5 \\ SIREN - Um Mecanismo para
Consultas por Similaridade}

Este capítulo descreve um protótipo de ferramenta, denominado SIREN (SImilarity Retrieval ENgine), que implementa um mecanismo para realizar consultas por similaridade, usando a extensão da linguagem SQL apresentada no Capítulo 4 em um SGBD relacional. O protótipo permite demonstrar todos os aspectos da extensão, incluindo os comandos da DDL e DML, além de utilizar um método de acesso métrico para acelerar as consultas.

\subsection{Arquitetura do SIREN}

O SIREN foi implementado para validar a adequação da proposta de extensão da linguagem SQL padrão que permite a realização de consultas por similaridade (veja Capítulo 4). Esse protótipo implementa um serviço entre um SGBD convencional e os programas de aplicação, que intercepta todo comando SQL enviado por uma aplicação, tratando as construções sintáticas relacionadas às operações por similaridade. O protótipo SIREN é constituído basicamente por três componentes (veja Figura 5.1):

- Um componente responsável pela interpretação da especificação de uma extensão da sintaxe SQL para a definição e manipulação de objetos complexos, considerando aspectos relacionados à realização de consultas por similaridade;

- Um componente responsável pela extração de características que são utilizadas para a representação e indexação de objetos complexos, como imagens e áudio; 
- Um componente responsável pela utilização de estruturas de indexação apropriadas para responder às consultas por similaridade.

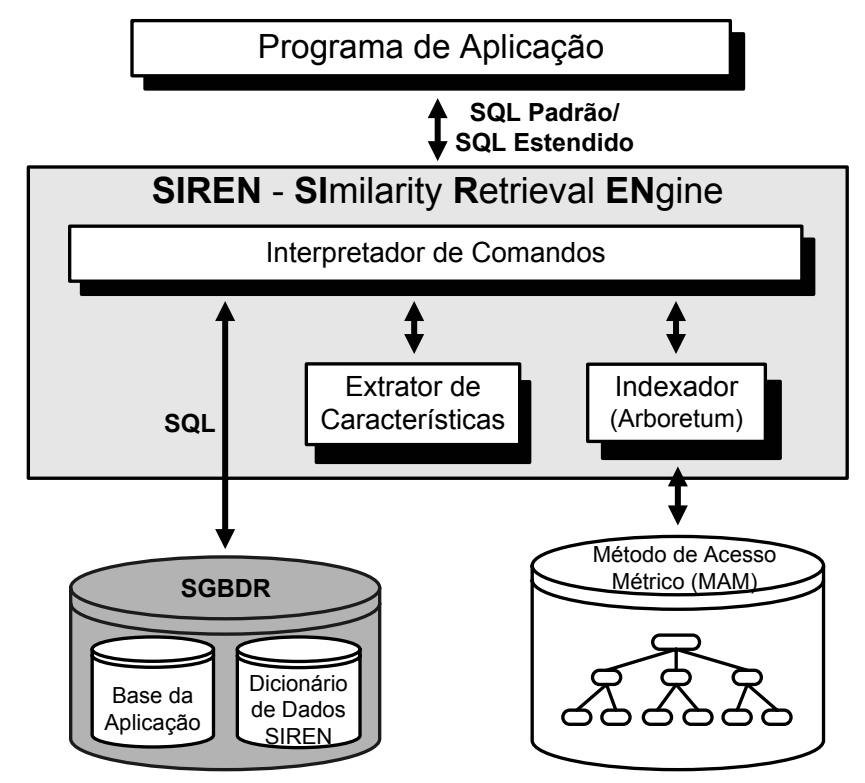

Figura 5.1: Arquitetura do SIREN.

Nas próximas seções são abordados os principais aspectos relacionados a cada um desses componentes.

\subsubsection{Interpretação dos Comandos}

O interpretador de comandos é o principal componente do SIREN, pois são as análises, sintáticas e semânticas realizadas por ele que determinam: quais e como os dados complexos devem ser consultados ou adicionados, tanto nas bases de dados das aplicações quanto no dicionário de dados; quando e quais extratores de características devem ser utilizados; quando e como os atributos complexos devem ser indexados por um MAM; quais e como as operações por similaridade devem ser realizadas. Todos os comandos SQL enviados pelas aplicações são interceptados pelo SIREN e analisados pelo interpretador. Caso o comando não possua nenhuma cláusula que envolva construções que representem operações por similaridade e nenhuma referência a um objeto complexo, ele é enviado para o SGBD e a resposta retornada pelo SGBD é repassada de volta para a aplicação. Assim, quando uma aplicação envia apenas comandos em SQL padrão, estes são executados de maneira transparente. Por outro lado, caso o comando possua alguma cláusula que envolva construções por similaridade ou alguma referência a um objeto complexo definido pela extensão da linguagem, o comando é re-escrito e as operações por similaridade são executadas internamente, utilizando o SGBD em questão para executar as operações sobre os dados tradicionais. 
Para permitir a manipulação de objetos complexos dos tipos PARTICULATE, STILLIMAGE e AUDIO por meio de comandos SQL em um SGBD relacional, foi necessário estender o dicionário de dados do SGBD com uma base de meta-dados para armazenar a estrutura de como esses objetos são utilizados pelas aplicações (veja Apêndice C). A definição de dados complexos é utilizada pelo SIREN para manipular dados como: quais extratores de características são utilizados nas métricas definidas para os tipos de dados STILLIMAGE e AUDIO; quais atributos tradicionais compõem cada atributo PARTICULATE; quais métricas estão disponíveis para cada domínio complexo; quais são os atributos de domínios complexos armazenados em cada relação; quais métricas estão associadas a cada atributo complexo. Os dados que compõem a base de meta-dados do SIREN são obtidos no momento da interpretação de comandos SQL que definem a criação de métricas, índices e tabelas que façam referência ou contenham atributos pertencentes aos domínios complexos suportados pelo SIREN.

Sempre que um comando CREATE TABLE é interceptado, o SIREN o analisa e armazena as informações referentes aos atributos complexos nas tabelas do sistema. Quanto ao armazenamento dos dados de tipos complexos, os dados do tipo PARTICULATE são armazenados pelos atributos que os compõem e assim, não apresentam nenhum requisito especial de armazenamento além dos já disponíveis nos SGBD. Por outro lado, o armazenamento de dados dos tipos STILLIMAGE e AUDIO precisa considerar as características associadas a eles. Embora esses tipos de dados sejam armazenados em atributos do tipo BLOB, é preciso armazenar as características extraídas deles. A extração de características é uma tarefa geralmente custosa e deve ser executada somente uma vez, quando um objeto é armazenado na base de dados. As características são armazenadas como atributos textuais ou numéricos, associados ao objeto complexo. Como o usuário não especifica atributos nas suas relações para armazenar as características extraídas, o sistema deve criar o local para armazenar essas características e suas associações com os respectivos objetos complexos de modo transparente ao usuário.

Para objetos dos tipos STILLIMAGE e AUDIO isso é feito seguindo uma abordagem semelhante à utilizada pelo CIRCE, ou seja, modificando a estrutura das tabelas definidas pelo usuário, que contenham esses tipos de atributos, da seguinte maneira: cada atributo STILLIMAGE/AUDIO é substituído por uma referência a uma tabela controlada pelo sistema (denominada IPV\$nometabela_nomeatributo no caso de atributos STILLIMAGE e APV\$nometabela_nomeatributo no caso de atributos AUDIO), que possui como atributos um identificador, o atributo BLOB que armazena a imagem/trilha de áudio e o conjunto de atributos que armazenam as características extraídas pelos extratores utilizados em cada métrica associada ao atributo STILLIMAGE/AUDIO. Assim, uma nova tabela é criada para cada atributo STILLIMAGE/AUDIO. Toda vez que uma nova imagem/trilha de áudio é armazenada na relação, o SIREN intercepta o comando INSERT, armazena os atributos tradicionais na tabela definida pelo usuário e as imagens/trilhas de áudio nas respectivas 
(a)

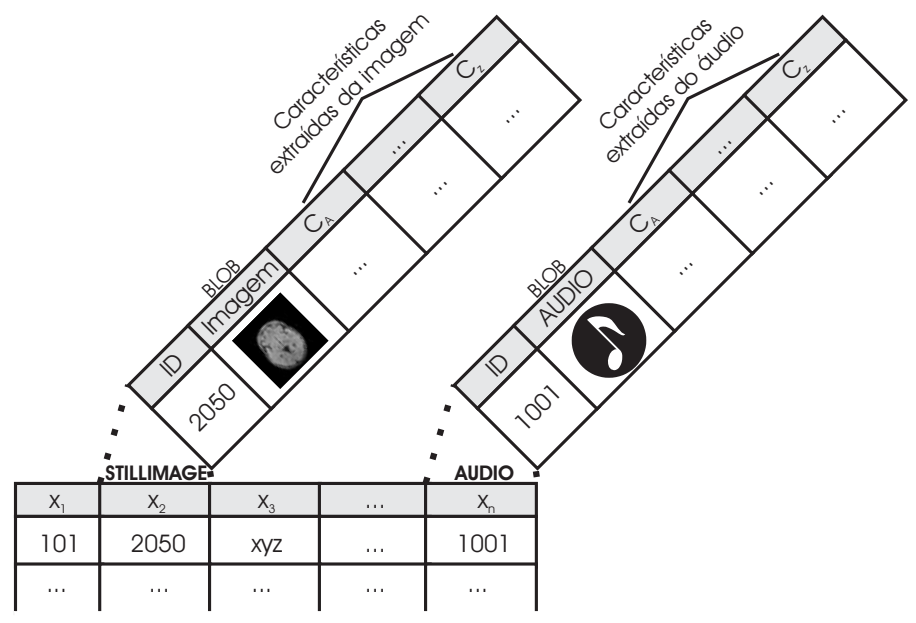

(b)

PARTICULATE
\begin{tabular}{|c|c|c|c|c|c|c|}
\hline $\mathrm{y}_{1}$ & $\mathrm{y}_{2}$ & $\mathrm{y}_{3}$ & $\mathrm{y}_{4}$ & $\mathrm{y}_{5}$ & $\ldots$ & \multicolumn{1}{c|}{$\mathrm{y}_{\mathrm{m}}$} \\
\hline 22 & 125 & 50.5 & 75 & 33 & $\ldots$ & 12.8 \\
\hline$\ldots$ & $\ldots$ & $\ldots$ & $\ldots$ & $\ldots$ & $\ldots$ & $\ldots$ \\
\hline
\end{tabular}

Figura 5.2: Esquema de armazenamento dos novos tipos de dados complexos. (a) STILLIMAGE e AUDIO. (b) PARTICULATE.

tabelas do sistema e também insere os objetos complexos em um MAM. Em seguida, o SIREN realiza chamadas para os extratores de características e armazena a saída desses extratores nas tabelas correspondentes do sistema. A Figura 5.2 apresenta uma ilustração do esquema de armazenamento desses novos tipos de dados complexos.

Toda vez que um usuário solicita dados de suas tabelas por meio da especificação de comandos SELECT, o SIREN realiza uma junção entre as tabelas do sistema e as tabelas do usuário e remove os atributos que armazenam as características, de maneira que o usuário não vê a tabela dividida nem suas características. Quando um usuário envia consultas que envolvem predicados por similaridade, o SIREN utiliza as características extraídas dos objetos do tipo STILLIMAGE/AUDIO ou o conjunto de atributos que compõem o objeto PARTICULATE para executar as operações por similaridade.

\subsubsection{Outros Aspectos Relacionados à Implementação}

O protótipo SIREN foi desenvolvido em $\mathrm{C}++$ para ambiente Windows e utiliza o protocolo ODBC para conexão com o SGBD Oracle 10g. A versão atual do protótipo conta com quatro tipos de extratores de características, sendo três deles específicos para dados do tipo STILLIMAGE: um extrator de textura (TEXTUREEXT) [Felipe \& Traina, 2002], um extrator de forma baseado em momentos de Zernike (ZERNIKEEXT) [Kamila et al., 2005] e um extrator de cor baseado no histograma normalizado de cores (HISTOGRAMEXT) [Swain \& Ballard, 1991]. Para dados do tipo AUDIO, o SIREN disponibiliza um extrator de textura do som (SOUNDTEXTUREEXT) que possui dois conjuntos de características, sendo um deles baseado em STFT (Short Time Fourier Transform) e o outro em MFCC 
(Mel-Frequency Cepstral Coefficients) [Tzanetakis, 2001, Hu et al., 2003].

Para responder as consultas que envolvam predicados por similaridade, como os descritos na Seção 4.1, o SIREN conta com onze operadores por similaridade. Dois operadores realizam seleção por similaridade, que são os dois tipos tradicionais de busca por similaridade: consulta por abrangência $(\mathrm{Rq})$ e consulta aos $k$-vizinhos mais próximos $(k-\mathrm{NNq})$. Seis operadores contemplam a realização de seleções por similaridade de grupo GRq e $k$-GNNq, considerando os padrões de agregação por similaridade SUM, MAX e ALL. Os outros três operadores correspondem à realização das junções por similaridade (junção por abrangência, junção pelos $k$-vizinhos mais próximos e junção dos $k$-pares de vizinhos mais próximos).

O método de acesso métrico (MAM) utilizado pelo SIREN, para indexar os atributos PARTICULATE, STILLIMAGE e AUDIO, é o MAM Slim-tree [Traina-Jr. et al., 2002] disponibilizado pela biblioteca de código livre Arboretum [GBDI-ICMC-USP, 2006a]. Nessa implementação da Slim-tree já existem procedimentos para a execução de Rq e $k$-NNq. Entretanto ainda não há procedimentos publicados para a execução dos demais operadores por similaridade, nem na Slim-tree nem em qualquer outro MAM. Dessa maneira, se um atributo complexo é associado a um índice, o SIREN executa a seleção por similaridade utilizando a Slim-tree. Porém, tanto as seleções por similaridade de grupo quanto as junções por similaridade são realizadas por meio de busca seqüencial. A implementação desses operadores por similaridade na Arboretum é abordada no Capítulo 6.

\subsubsection{Processamento de Consultas por Similaridade}

Para ilustrar o processamento de um comando SELECT que envolva um predicado por similaridade no SIREN, considere o Comando C5.1 apresentado abaixo:

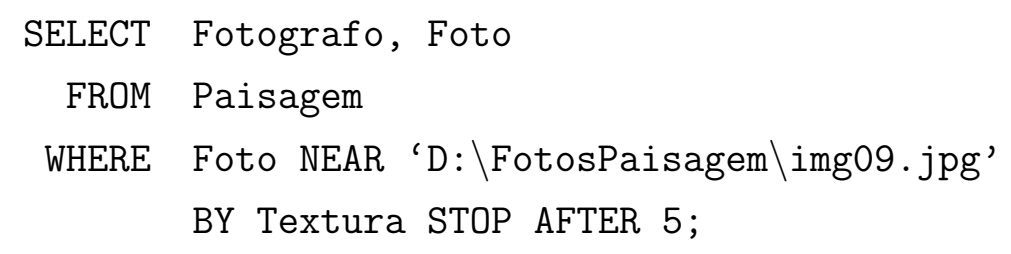

Esse comando é analisado e reescrito pelo SIREN conforme os passos observados na Figura 5.3 e descritos a seguir:

1. O programa de aplicação envia um comando SQL que contém um predicado por similaridade, indicando uma imagem de consulta que não está armazenada no SGBD;

2. O interpretador de comandos analisa o comando original, identificando o tipo de operação por similaridade a ser executada e os parâmetros que devem ser empregados para a sua realização. Além disso, ele consulta o dicionário de dados do SIREN para obter as seguintes informações: quais extratores de características são empregados 
pela métrica especificada no comando, qual é a função de distância a ser utilizada e qual é o nome do arquivo que contém o índice a ser utilizado na execução do comando;

3. As informações solicitadas no passo anterior são retornadas;

4. A imagem de consulta é enviada a um ou mais extratores de características de acordo com a métrica especificada na consulta;

5. O vetor de características é retornado pelo(s) extrator(es) de características;

6. Para a realização da operação por similaridade especificada no predicado por similaridade do comando original, o SIREN informa ao indexador os seguintes parâmetros: o vetor de características da imagem de consulta, a operação por similaridade a ser executada (ex.: Rq, $k$-NNq, etc) juntamente com os respectivos parâmetros requeridos por ela (ex.: $k$, raio de abrangência, etc) e o nome do arquivo de índice que contém a estrutura a ser utilizada na execução do comando;

7. O indexador retorna os identificadores das imagens que irão compor o resultado final da execução do comando;

8. O interpretador de comandos utiliza esses identificadores na reconstrução do comando original enviado pelo programa de aplicação. O comando reescrito é enviado ao SGBD;

9. O SGBD responde ao comando reescrito, retornando as imagens solicitadas juntamente com os demais dados dos atributos tradicionais requisitados;

10. A resposta retornada pelo SGBD é enviada ao programa de aplicação.

O comando resultante do processamento do Comando C5.1 pelo SIREN é apresentado abaixo:

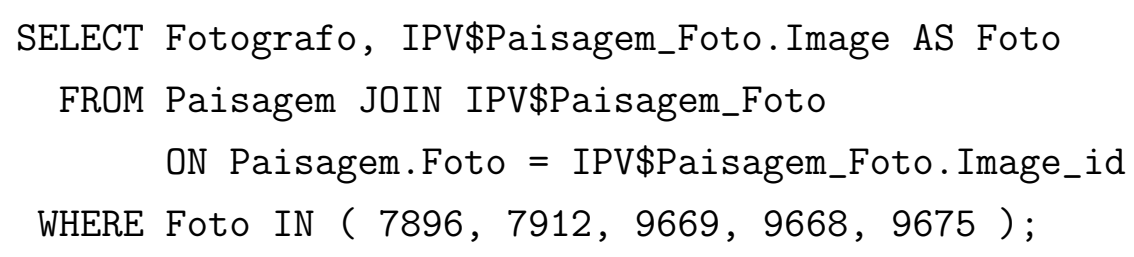

Se o Comando C5.1 enviado pelo programa de aplicação especificasse uma imagem de consulta que já estivesse armazenada no SGBD, seria desnecessário enviá-la ao extrator de características. Nesse caso, os passos 4 e 5 do processamento do comando são substituídos por um outro passo que realiza consultas ao SGBD para a obtenção do vetor de características da imagem de consulta. 


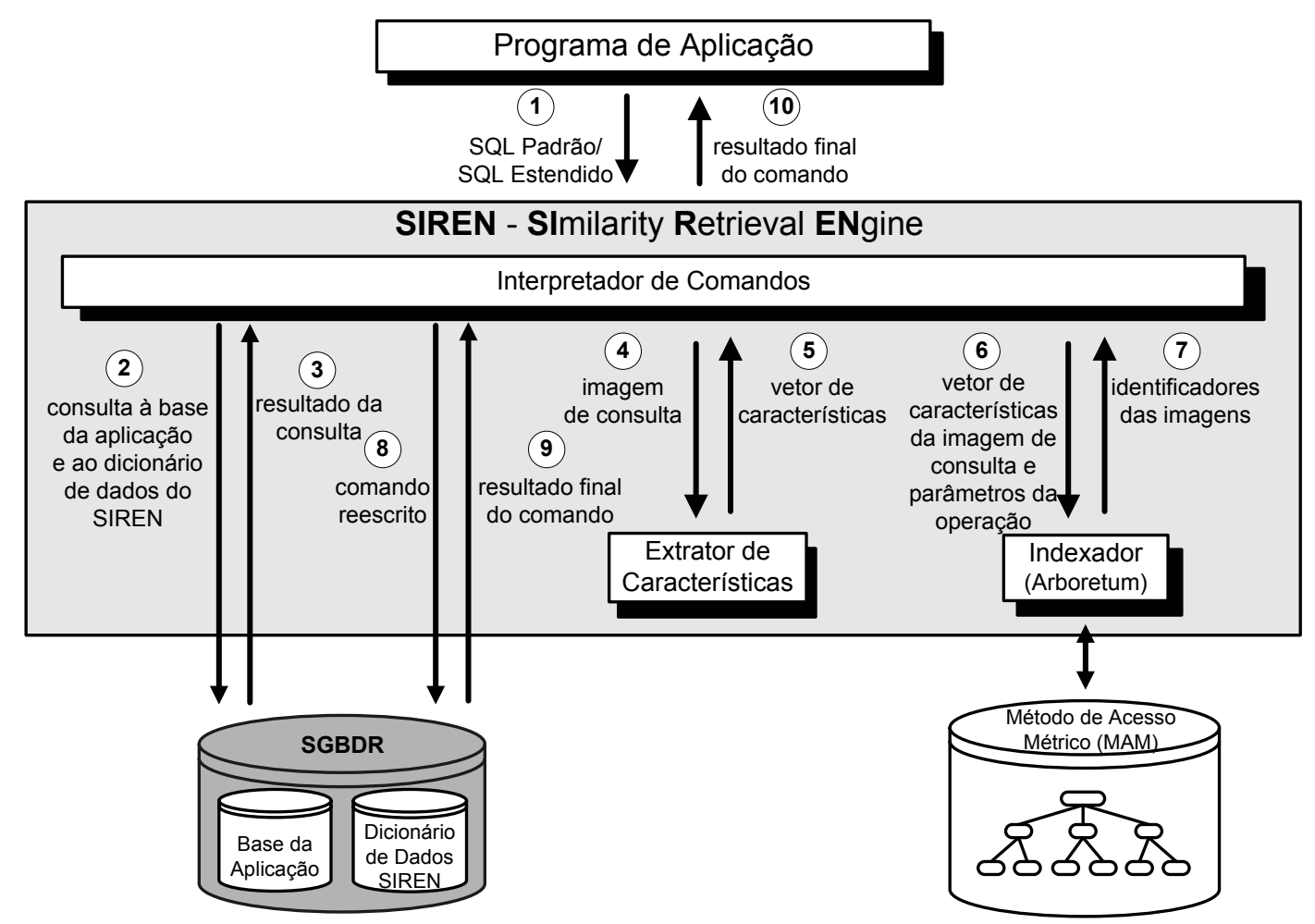

Figura 5.3: Ilustração do processo de execução do Comando [C5.1].

\subsection{Exemplos de Utilização}

Para a validação do protótipo SIREN foi implementada uma aplicação web (cgi) em $\mathrm{C}++$ que fornece um ambiente para a execução de comandos em SQL [GBDI-ICMC-USP, 2006b]. Nessa seção são apresentados diversos exemplos de execuções de consultas por similaridade que foram realizadas por meio da utilização dessa aplicação. A descrição dos vários conjuntos de dados utilizados pelos comandos-exemplo a seguir, é apresentada no Apêndice B.

Exemplo 1. O primeiro conjunto de exemplos de consulta utiliza o conjunto de dados Exame descrito na Seção B.3. Para consultar esse conjunto de dados foram definidas duas métricas: uma que utiliza o extrator HISTOGRAMEXT e outra que usa o extrator TEXTUREEXT. Os comandos utilizados para a criação dessas métricas e da tabela referente ao conjunto Exame são os seguintes.

CREATE METRIC Histograma

FOR STILLIMAGE (HistogramExt (histogram AS histo))

CREATE METRIC Textura

FOR STILLIMAGE (TextureExt (texture AS text)) 
Idexame INTEGER PRIMARY KEY,

Imagem STILLIMAGE METRIC USING (Histograma DEFAULT, Textura),

Corte CHAR(20))

Exemplos de comandos SELECT que utilizam cada uma dessas métricas são apresentados na Figura 5.4. A Figura 5.4 (a) apresenta um exemplo de consulta por abrangência que especifica o caminho de uma imagem de consulta em disco. Já a Figura 5.4 (b) apresenta um exemplo de consulta aos $k$-vizinhos mais próximos que utiliza uma imagem já armazenada na base de dados como sendo a imagem de consulta.

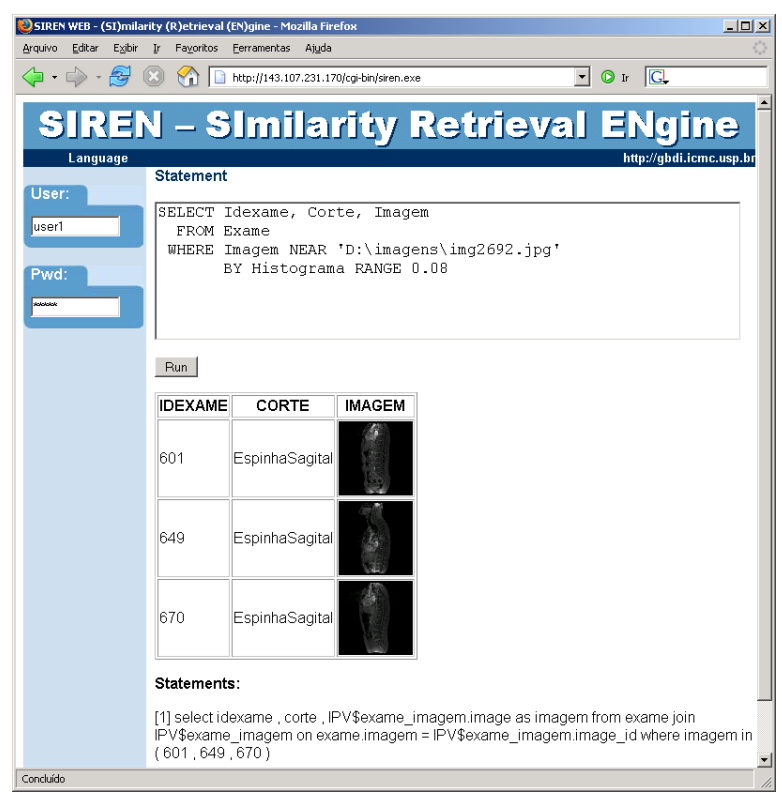

(a)

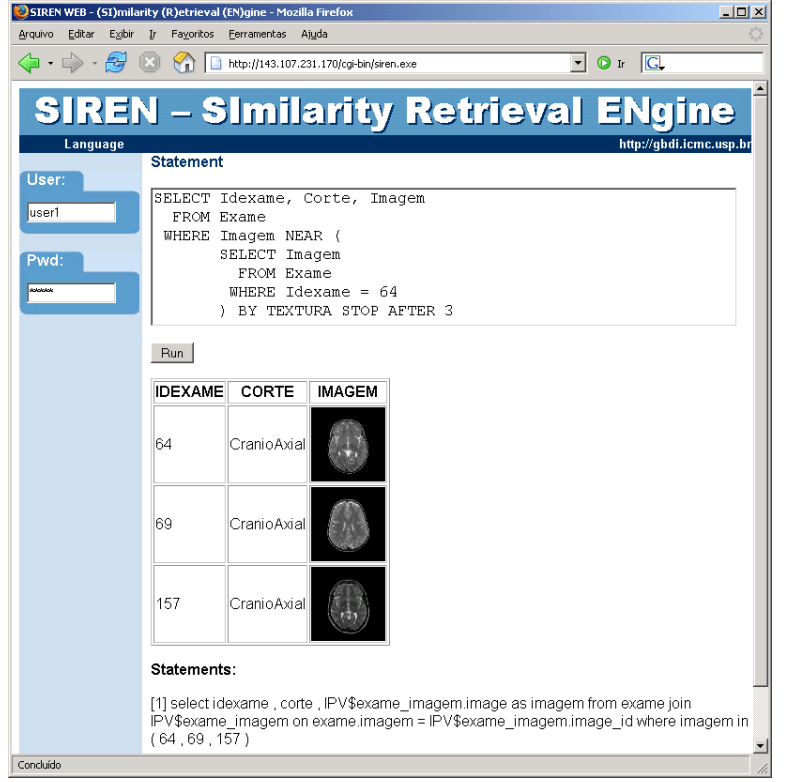

(b)

Figura 5.4: Exemplos de consultas por similaridade sobre a tabela Exame. (a) Rq usando a métrica Histograma. (b) $k$-NNq usando a métrica Textura.

Exemplo 2. O segundo conjunto de exemplos utiliza o conjunto de dados Autos apresentado na Seção B.2. Os comandos que definem a tabela e a métrica empregada na realização de consultas por similaridade sobre esse conjunto são apresentados a seguir.

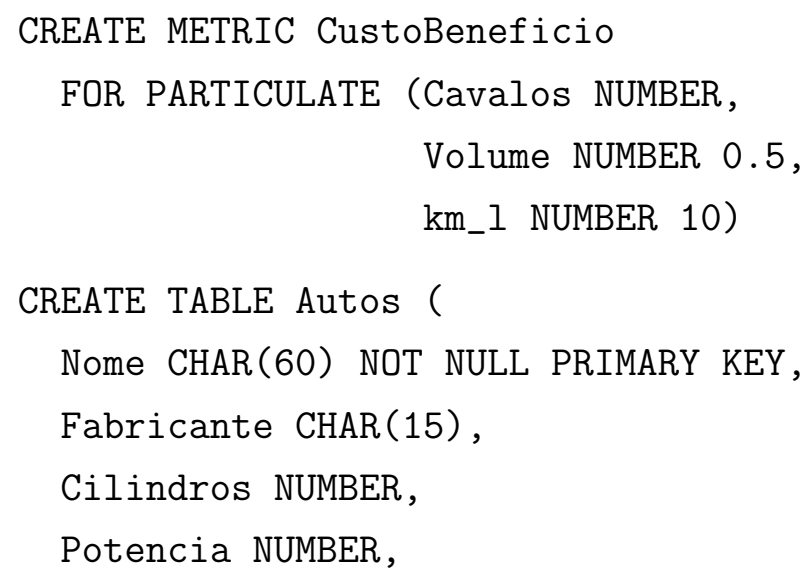




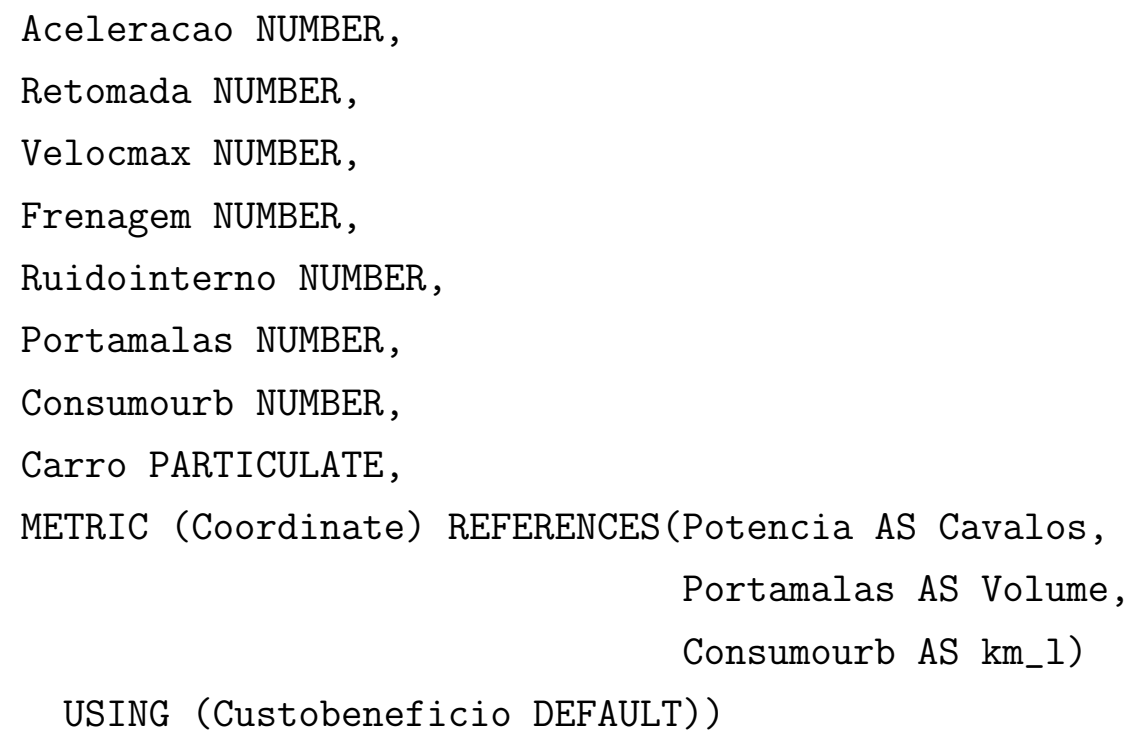

Considerando a métrica criada para analisar o conjunto de dados Autos, é possível fazer consultas do tipo - "Quais são os 5 carros que apresentam as características mais próximas de um carro popular com 70 cavalos de potência, $250 \mathrm{l}$ de volume de porta malas e $13 \mathrm{~km} / 1$ de consumo urbano?"; ou ainda: "Retorne os 5 carros mais próximos de um determinado carro que não sejam do mesmo fabricante deste". Os resultados obtidos com a execução dos comandos empregados para responder essas consultas - que correspondem a consultas aos $k$-vizinhos mais próximos - no SIREN são apresentados na Figura 5.5.

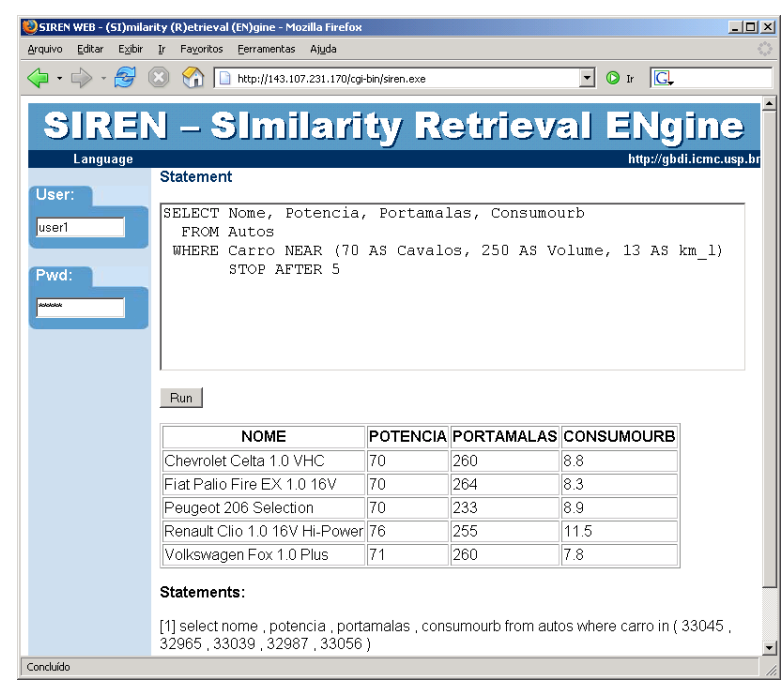

(a)

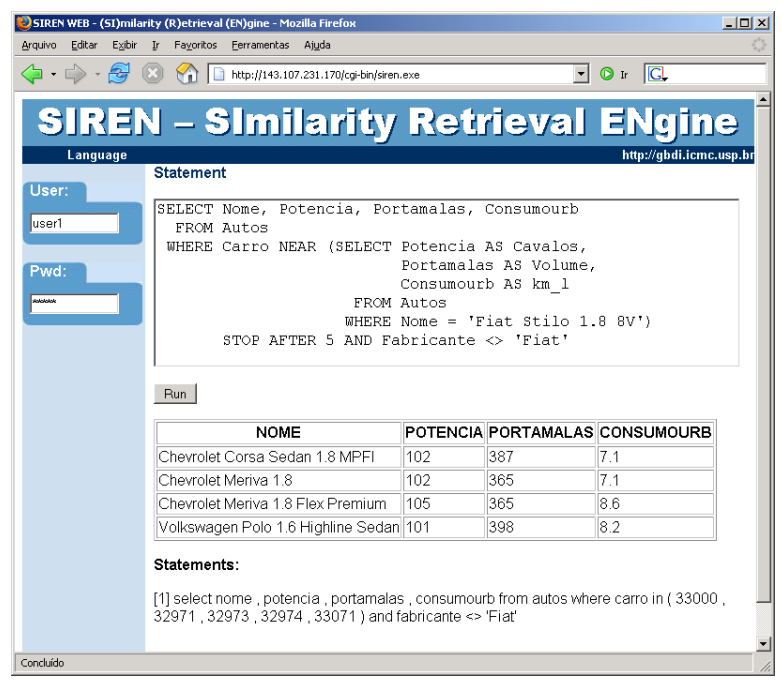

(b)

Figura 5.5: Exemplos de consultas por similaridade sobre a tabela Autos. (a) "Quais são os 5 carros que apresentam as características mais próximas de $70 \mathrm{cv}$ de potência, $250 \mathrm{l}$ de volume de porta malas e $13 \mathrm{~km} / \mathrm{l}$ de consumo urbano?". (b) "Retorne os 5 carros mais próximos de um determinado carro e que não sejam do mesmo fabricante deste".

Outra questão interessante para ser verificada nesse conjunto de dados é saber quais carros se aproximam mais de uma mistura das características de 3 carros em que se está 
interessado. Por exemplo, o comando - que corresponde a uma consulta por abrangência de grupo - apresentado na Figura 5.6 pode ser utilizado para responder a essa questão.

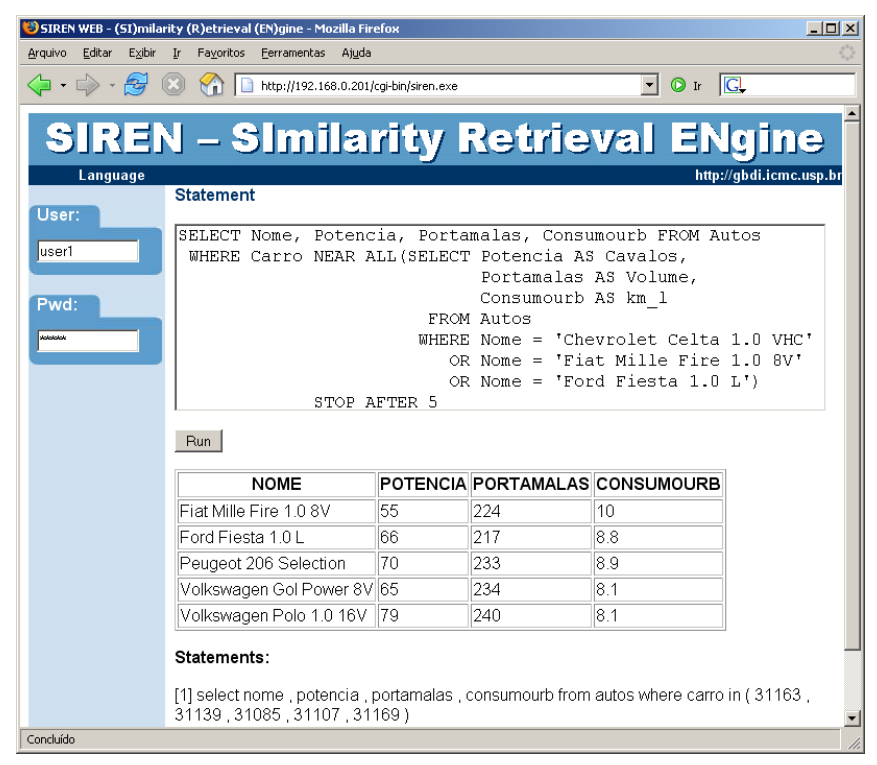

Figura 5.6: Exemplo de consulta por similaridade sobre a tabela Autos: "Quais são os 5 carros que possuem as características mais parecidas com as de 3 carros de interesse?".

Exemplo 3. Outros conjuntos de dados que podem ser explorados por meio da realização de consultas por similaridade são os conjuntos, BRPolitico e OrientacaoPartido, descritos na Seção B.4. Os comandos utilizados para a criação das tabelas que armazenam cada um desses conjuntos de dados e para a criação da métrica empregada para o cálculo de similaridade são os seguintes.

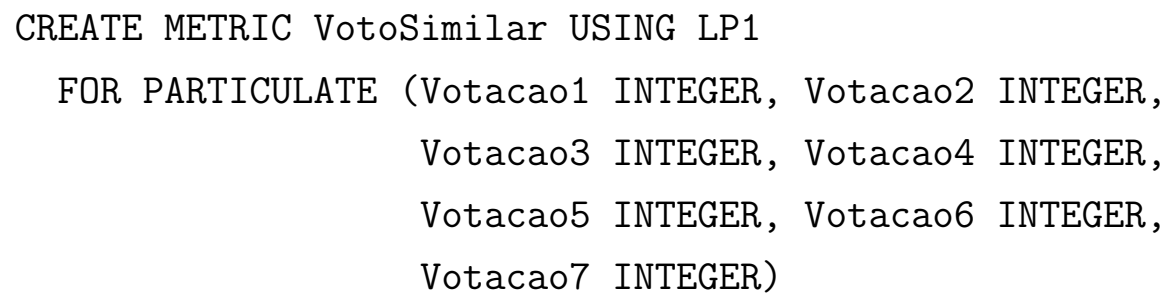




\section{V7 AS Votacao7)}

USING (VotoSimilar DEFAULT))

\section{CREATE TABLE OrientacaoPartido (}

Partido CHAR(10) PRIMARY KEY,

V1 INTEGER NOT NULL, V2 INTEGER NOT NULL,

V3 INTEGER NOT NULL, V4 INTEGER NOT NULL,

V5 INTEGER NOT NULL, V6 INTEGER NOT NULL,

V7 INTEGER NOT NULL,

Votacoes PARTICULATE METRIC

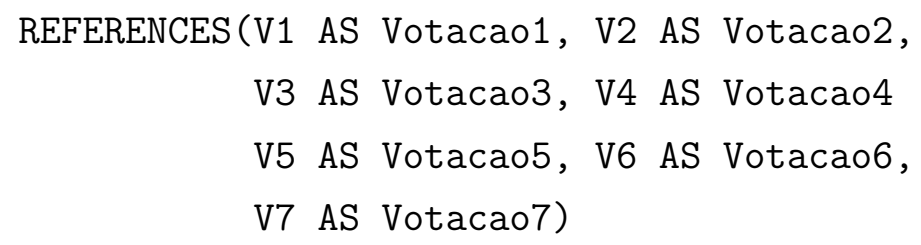

Uma das questões que pode ser analisada nesse conjunto de dados está relacionada à afinidade política existente entre deputados de diferentes partidos políticos. Por exemplo, é possível considerar um determinado deputado e então verificar os deputados que tenham votado de maneira mais similar a ele, excluindo aqueles de seu partido, como é mostrado na Figura 5.7, que exibe uma consulta aos $k$-vizinhos mais próximos.

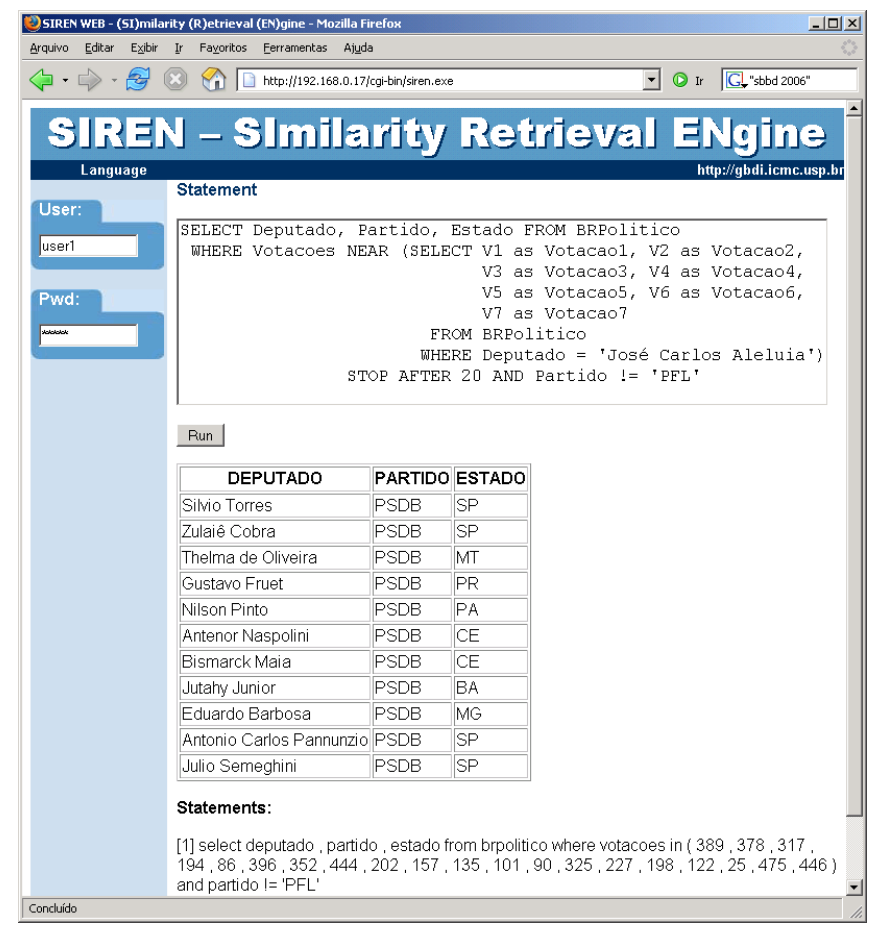

Figura 5.7: Exemplo de consulta por similaridade sobre a tabela BRPolitico. $k$-NNq utilizando o Deputado 'José Carlos Aleluia' como objeto de consulta.

Outra questão que pode ser verificada é a coesão partidária. Para responder a essa 
questão, basta considerar uma certa orientação partidária e então verificar se os votos mais similares pertencem ou não aos deputados desse partido. Por exemplo, para selecionar todos os deputados que tenham votado de acordo com as cinco votações mais parecidas com a orientação do Partido PT, o comando apresentado na Figura 5.8 (a) que corresponde a uma consulta aos $k$-vizinhos mais próximos - foi enviado ao SIREN. Essa figura apresenta apenas 18 das 24 tuplas retornadas como resposta. Observando o resultado obtido com a execução desse comando, é possível notar que existem deputados de outros partidos (ex.: PFL) que votaram de maneira mais parecida com a orientação do Partido PT do que outros membros do próprio PT.

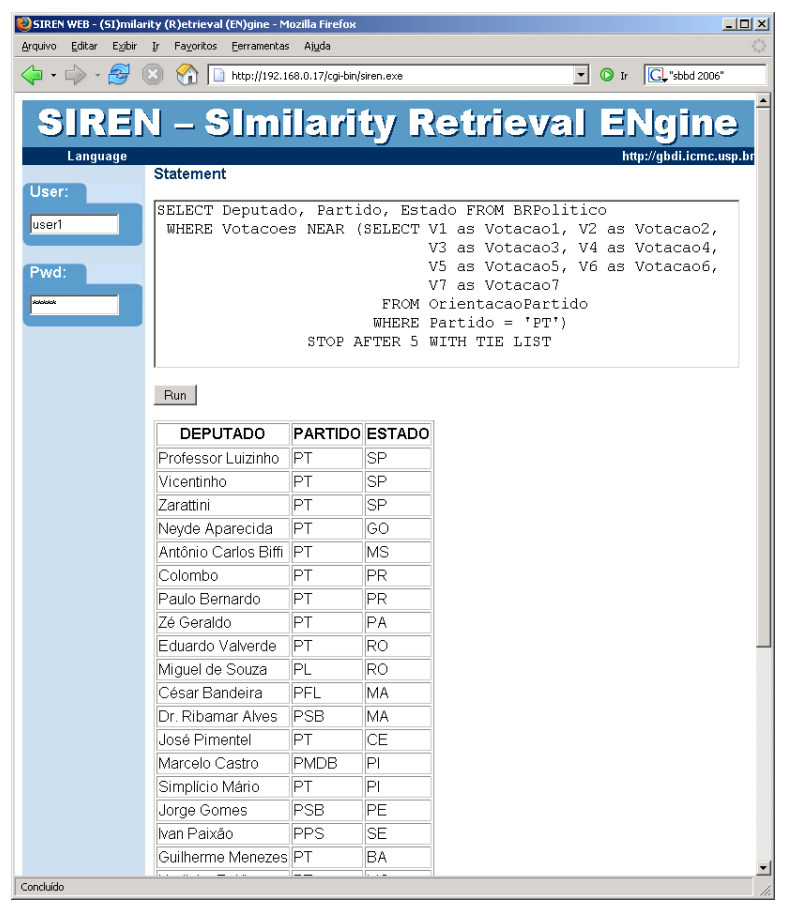

(a)

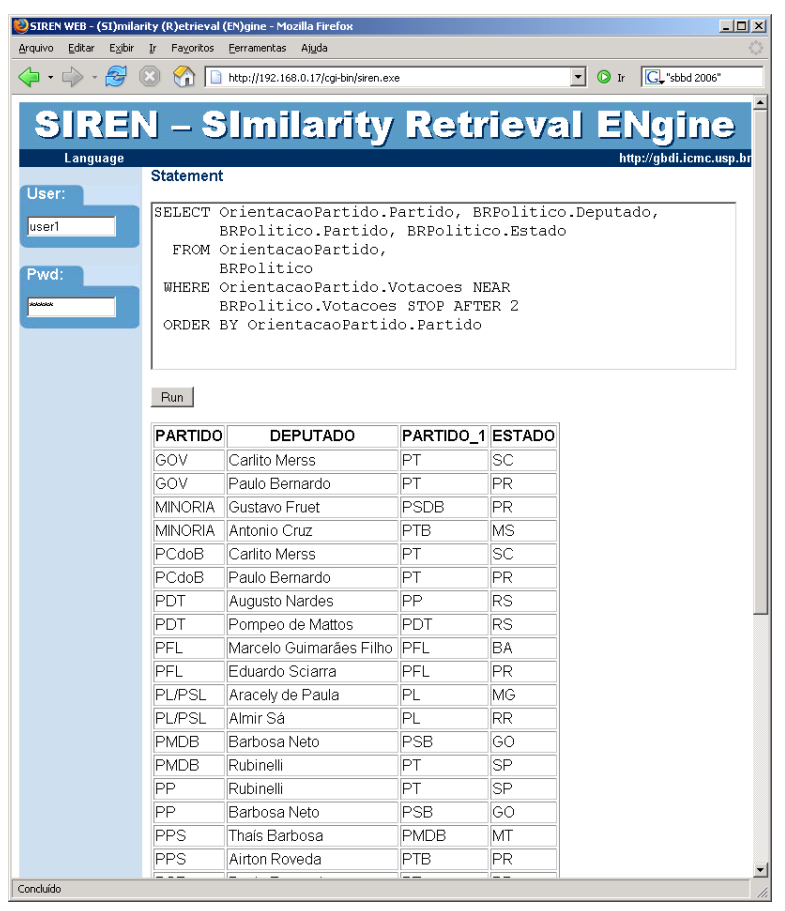

(b)

Figura 5.8: Exemplos de consultas por similaridade sobre as tabelas BRPolitico e OrientacaoPartido. (a) $k$-NNq utilizando a orientação do Partido PT como objeto de consulta. (b) Exemplo da execução de uma junção pelos $k$-vizinhos mais próximos.

Como um outro exemplo, também é possível responder a questões como, "Quem são os dois deputados que votaram de modo mais parecido com a orientação de cada partido político?". Para responder a essa questão, o comando apresentado na Figura 5.8 (b), que utiliza um predicado que expressa a realização de uma junção pelos $k$-vizinhos mais próximos, foi enviado ao SIREN. Essa figura também mostra as primeiras 18 das 30 tuplas retornadas como resposta.

Outra possibilidade de análise interessante corresponde a verificação de estatísticas sobre as votações realizadas. Por exemplo, para obter o número de deputados que votaram de acordo com a orientação de cada partido político em todas as votações o comando - que corresponde a uma junção por abrangência com raio zero - apresentado na Figura 5.9 pode ser utilizado. 


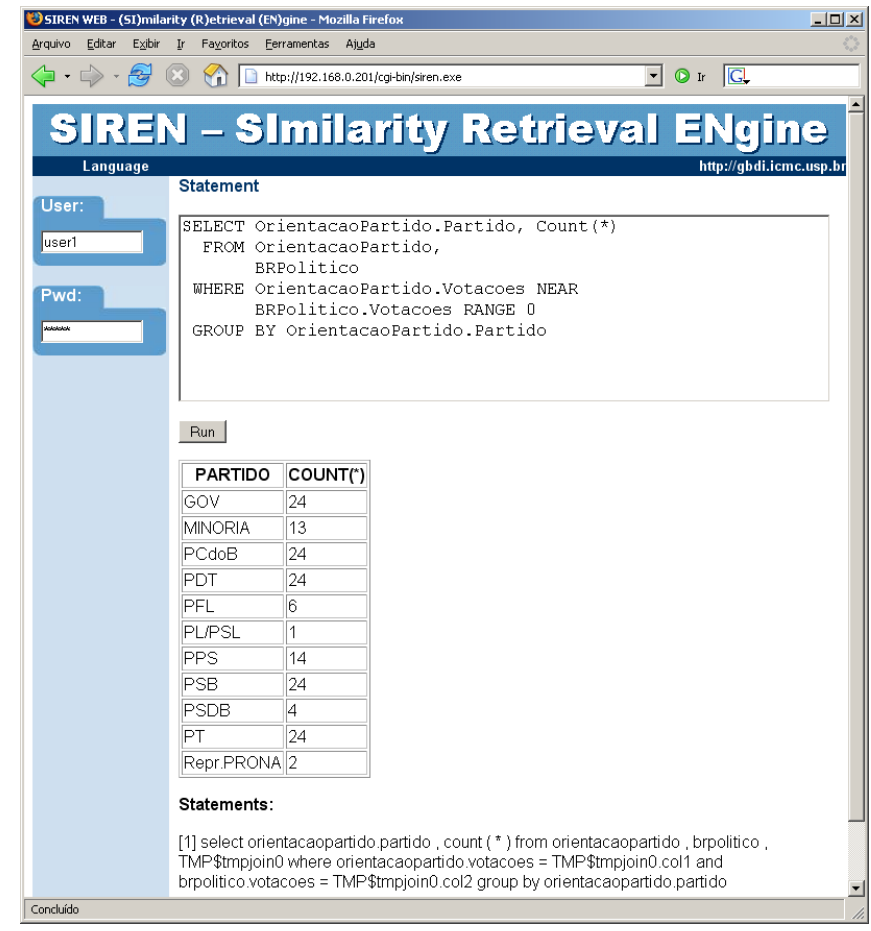

Figura 5.9: Exemplo de consulta por similaridade que envolve a realização de uma junção por abrangência entre as tabelas OrientacaoPartido e BRPolitico.

Exemplo 4. Esse conjunto de exemplos utiliza o conjunto de dados Musica descrito na Seção B.5. Os comandos que definem as métricas utilizadas nas consultas por similaridade e a tabela que armazena esse conjunto de dados são apresentados a seguir.

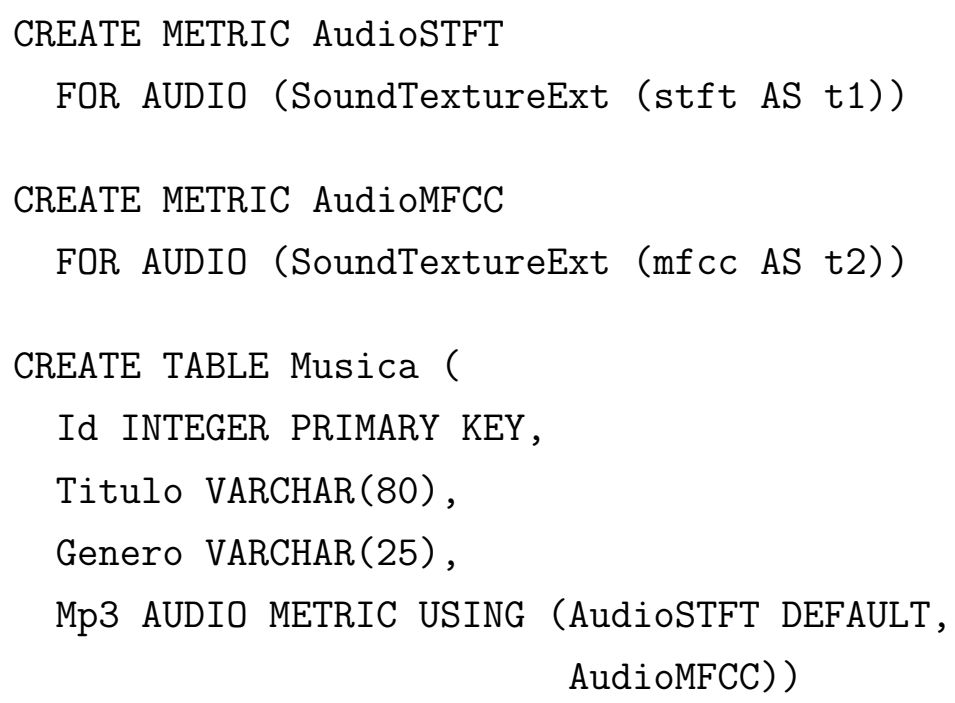

Exemplos de comandos SELECT que utilizam cada uma dessas métricas na especificação de consultas aos $k$-vizinhos mais próximos são apresentados nas Figuras 5.10 e 5.11. Os comandos mostrados nessas figuras empregam músicas de diferentes gêneros musicais 
como objeto de consulta.

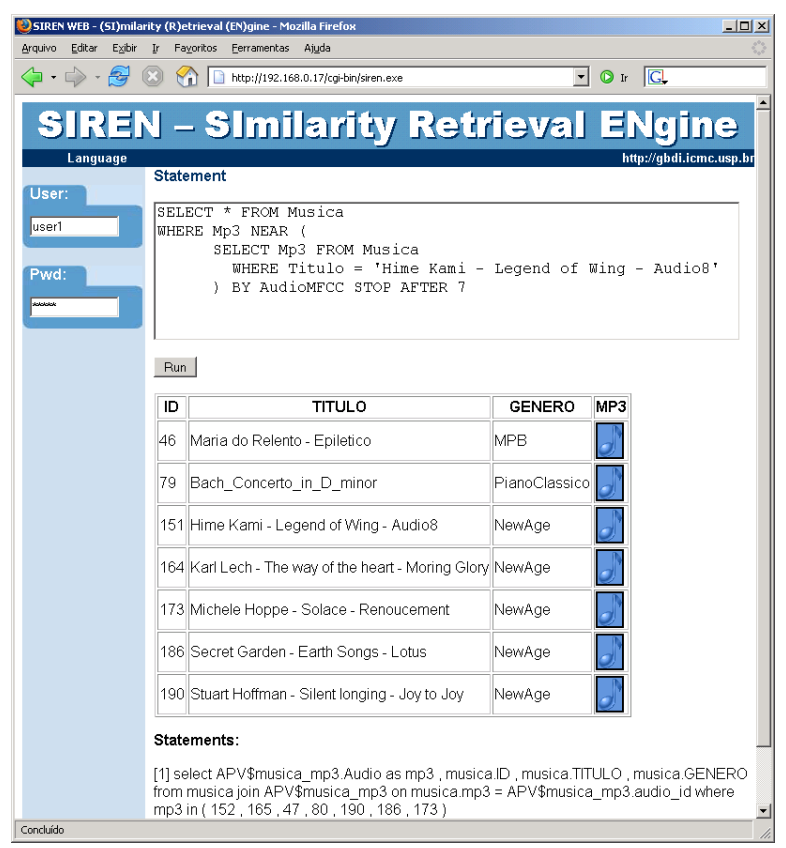

(a)

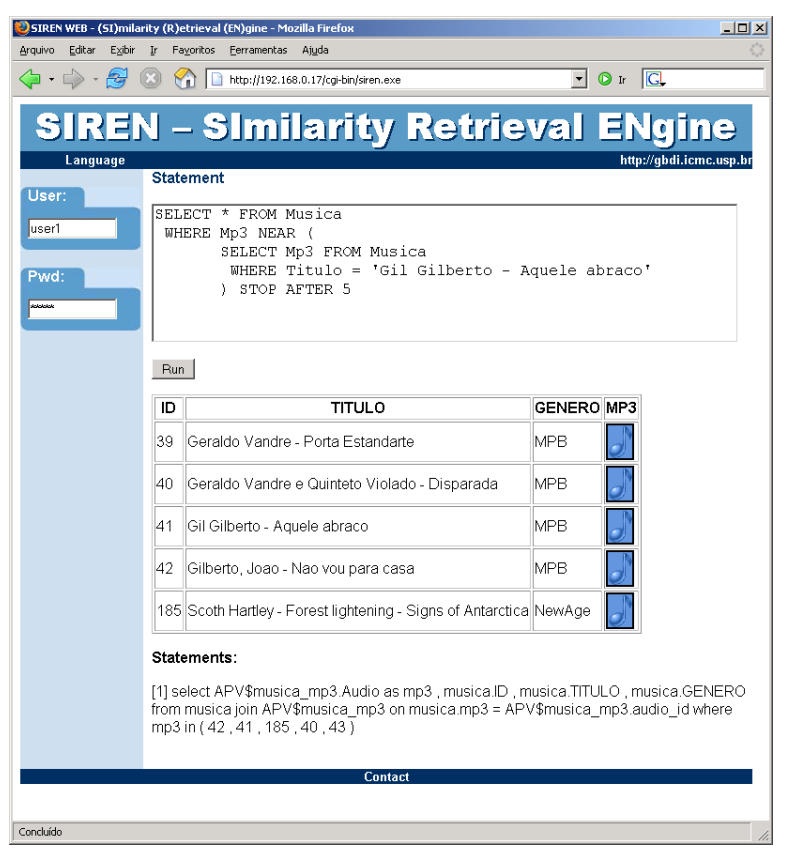

(b)

Figura 5.10: Exemplos de consultas por similaridade sobre a tabela Musica. (a) $k$-NNq utilizando uma música do gênero NewAge como objeto de consulta e a métrica AudioMFCC. (b) $k$-NNq utilizando uma música do gênero MPB como objeto de consulta e a métrica padrão definida na criação da tabela (AudioSTFT).

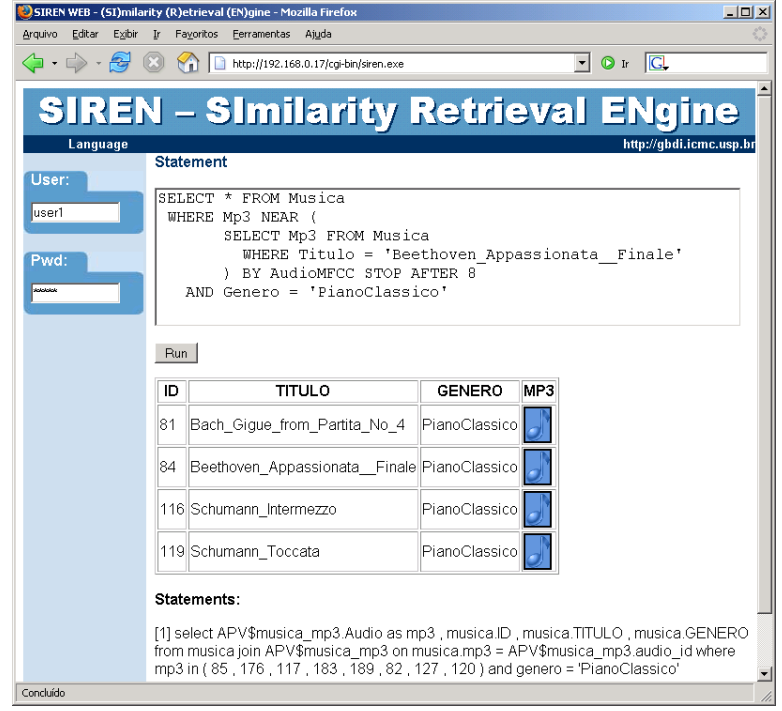

(a)

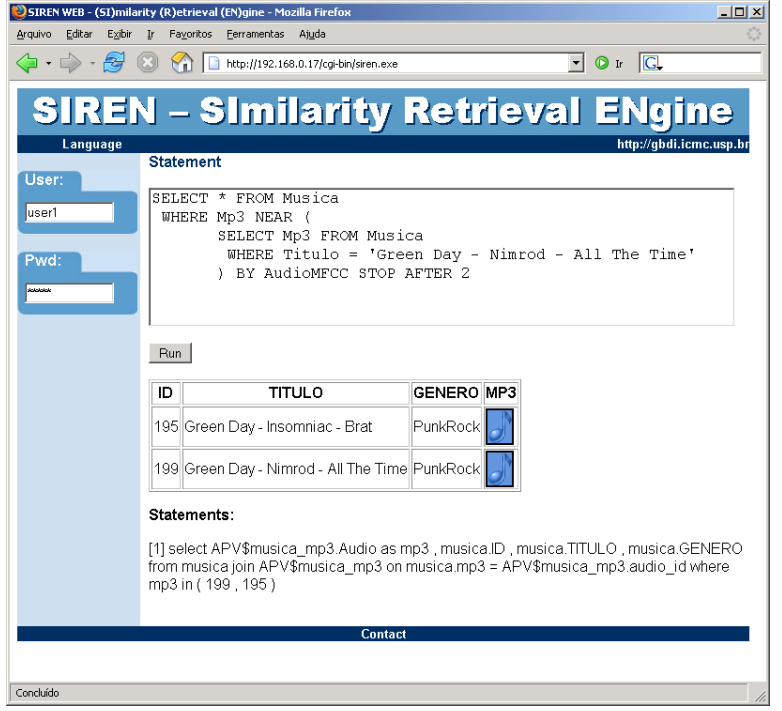

(b)

Figura 5.11: Exemplos de consultas por similaridade sobre a tabela Musica. (a) $k$-NNq utilizando uma música do gênero PianoClassico como objeto de consulta e a métrica $\mathrm{Au}-$ dioMFCC. (b) $k$-NNq utilizando uma música do gênero PunkRock como objeto de consulta e a métrica AudioMFCC. 
Para a execução de comandos SELECT que envolvam predicados por similaridade, como os empregados nos exemplos apresentados nesta seção, o tempo total gasto pelo SIREN depende, basicamente, do tempo gasto na análise do comando (feita pelo interpretador de comandos) e do tempo gasto na execução das operações especificadas nos predicados por similaridade, sendo este último maior ou menor de acordo com o operador utilizado (as seleções por similaridade são executadas utilizando o MAM Slim-tree, enquanto as seleções por similaridade de grupo e as junções por similaridade, por meio de métodos que realizam busca seqüêncial). Para as operações por similaridade que empregam a Slim-tree, o tempo de busca no MAM depende de fatores tais como: tamanho dos vetores de características ou número de atributos indexados; número de objetos complexos indexados; tempo de leitura de um bloco no disco rígido. Assim, para obter informações detalhadas sobre o desempenho da Slim-tree veja [Traina et al., 2000].

\begin{tabular}{|l|c|c|c|c|}
\hline Operador & Parâmetros & MAM & $\begin{array}{c}\mathrm{N}^{o} \text { de tuplas } \\
\text { retornadas }\end{array}$ & $\begin{array}{c}\text { Tempo total } \\
\text { (em segundos) }\end{array}$ \\
\hline \hline $\mathrm{Rq}$ & $\xi=0,2, N^{\circ}$ Objs_c $=1$ & Slim-tree & 3 & 0,31 \\
$k$-NNq & $k=10, N^{\circ}$ Objs_c $=1$ & Slim-tree & 10 & 0,44 \\
$\mathrm{GRq}$ & $\xi=2, N^{\circ}$ Objs_c $=3, p=1$ & Acesso seqüêncial & 148 & 0,99 \\
$k$-GNNq & $k=10, N^{o}$ Objs_c $=3, p=1$ & Acesso seqüêncial & 10 & 0,90 \\
$k-C N q$ & $k=10$ & Acesso seqüêncial & 10 & 122,53 \\
\hline
\end{tabular}

Tabela 5.1: Tempo para o processamento de comandos que utilizam operadores por similaridade no SIREN.

Como referência, a Tabela 5.1 apresenta o tempo necessário para a execução de comandos SELECT que empregam alguns dos operadores por similaridade suportados pelo SIREN, sendo eles: os dois tipos básicos de seleções por similaridade Rq e $k$-NNq; duas seleções por similaridade de grupo, GRq e $k$-GNNq, utilizando o padrão de agregação SUM como exemplos representativos das seleções por similaridade de grupo; e, para exemplificar as operações de junção por similaridade, a junção dos $k$-pares de vizinhos mais próximos ${ }_{\bowtie}^{k-C N q}$. É importante ressaltar que todos os tipos de dados complexos suportados pelo SIREN (STILLIMAGE, AUDIO e PARTICULATE) são baseados em valores armazenados como atributos numéricos em uma tabela; assim, não existe diferença algorítmica nos métodos de consulta por similaridade empregados para tratar qualquer um desses tipos de dados. Na Tabela 5.1 também são apresentados o método de indexação utilizado (MAM), o número médio de tuplas retornadas pelos comandos, juntamente com todos os parâmetros empregados para a execução de cada uma das operações mencionadas acima, ou seja, o número de objetos a serem retornados $(k)$ ou o raio máximo de busca $(\xi)$, o padrão de agregação utilizado $(p)$, e o número de objetos de consulta $\left(N^{\circ}\right.$ Objs_c).

Os tempos mostrados na Tabela 5.1 correspondem ao tempo total (incluindo a análise e a execução) necessário para a realização de comandos SELECT sobre uma tabela $S$ com 40.000 imagens indexadas pelo resultado do extrator HISTOGRAMEXT e a função de distância $L_{1}$. Os tempos gastos na análise realizada pelo interpretador de comandos do SIREN 
não ultrapassaram 0,10 $\mathrm{s}$ em todos os comandos testados. Todas as medidas de tempo foram realizadas em um PC equipado com um processador Athlon XP 3.200 de 2,2 GHz, 1 GB RAM e disco rígido de 80 GB. Os tempos obtidos para os comandos que utilizam os operadores Rq, $k$-NNq, GRq e $k$-GNNq correspondem à média de 400 execuções. Todos os objetos de consulta empregados na execução desses comandos foram selecionados aleatoriamente a partir do conjunto de imagens. Para testar o operador $\stackrel{k-C N q}{\bowtie}$ foram selecionadas aleatoriamente 400 imagens de $S$ para compor a tabela $R$ utilizada no lado esquerdo da junção $(R \stackrel{k-C N q}{\bowtie} S)$.

Analisando os tempos apresentados na Tabela 5.1, é possível observar que, embora os comandos que tenham requerido o maior processamento não tenham sido realizados considerando a utilização de estruturas de índice, os resultados foram obtidos dentro de um tempo aceitável. À medida que forem disponibilizados métodos mais eficientes para a realização das operações de consulta por similaridade de grupo e das junções por similaridade, esses métodos poderão ser facilmente adicionados ao SIREN, acelerando a execução de comandos que demandem a utilização dessas operações.

\subsection{Considerações Finais}

Este capítulo apresentou a ferramenta SIREN, um interpretador para uma extensão à linguagem SQL, que permite a representação e execução de consultas por similaridade sobre dados complexos armazenados em SGBD relacionais. A ferramenta permite executar operações, tanto de seleção quanto de junção, baseadas na similaridade entre objetos de um tipo complexo. Estão definidos três tipos de dados complexos: imagens, áudio e atributos descritos por um subconjunto dos atributos convencionais que formam cada tabela. A ferramenta permite executar tanto consultas simples quanto qualquer combinação das operações desenvolvidas entre si e entre as operações de seleção e junção tradicionais, provendo um meio poderoso para a realização de consultas por similaridade em bases de dados complexos. No próximo capítulo são apresentados os algoritmos utilizados para a implementação dos métodos de consulta por similaridade não suportados pela Slim-tree, i.e., para a realização de consultas por similaridade de grupo e de junções por similaridade. 


\section{Capítulo \\ 6 \\ Algoritmos Desenvolvidos}

Vários algoritmos foram implementados com o objetivo de fornecer meios para a validação dos conceitos desenvolvidos. Dentre eles, algoritmos para a realização de operações de junção por similaridade (Seção 6.2) e algoritmos para o cálculo da agregação de distâncias para suportar a realização de consultas por similaridade de grupo, que envolvem múltiplos centros (Seção 6.1). Além disso, com o intuito de tornar exeqüível a realização de operações de detecção de agrupamentos em SGBD, também foi explorado o desenvolvimento de uma abordagem para a otimização da eficiência computacional dos algoritmos de detecção de agrupamentos baseados no método $k$-medoid (Seção 6.3). Este capítulo aborda os aspectos relacionados às implementações dos algoritmos e da abordagem mencionados acima. Todos os algoritmos descritos neste capítulo foram implementados dentro da mesma plataforma, utilizando a linguagem $\mathrm{C}++$ em uma biblioteca que implementa vários métodos de acesso métrico (MAM), a Arboretum [GBDI-ICMC-USP, 2006a].

Além de diversos métodos de acesso métrico (como a Slim-tree [Traina et al., 2000], DBM-tree [Vieira et al., 2004], DF-tree [Traina et al., 2002b], M-tree [Ciaccia et al., 1997], VP-tree [Yianilos, 1993] e GH-tree [Uhlmann, 1991]), com o objetivo de suportar comparações, a Arboretum fornece um método de acesso seqüencial que possui a mesma interface externa e comportamento de um MAM. Esse recurso foi utilizado na implementação de alguns dos algoritmos apresentados neste capítulo. Na realidade, o acesso seqüencial é o básico, utilizado sempre que algum outro método mais elaborado não está disponível. A Tabela 6.1 mostra os métodos de acesso que foram usados para implementar as operações de consulta por similaridade necessárias ao suporte dos conceitos propostos nesta tese (veja Tabela 4.1). Nessa tabela são indicadas 
as operações que já existiam na biblioteca Arboretum e as que foram desenvolvidas para atender às necessidades do SIREN. Essa tabela mostra também quais operações estão disponíveis nos métodos de acesso seqüencial e quais estão disponíveis na Slim-tree.

\begin{tabular}{|c|c|c|c|}
\hline Predicado & Operação & $\begin{array}{c}\text { Acesso } \\
\text { Seqüencial }\end{array}$ & Slim-tree \\
\hline \multirow{2}{*}{$\begin{array}{l}\text { Seleção por similaridade } \\
\qquad(\hat{\sigma})\end{array}$} & Abrangência & $*$ & $*$ \\
\hline & $k$-Vizinhos mais próximos & $*$ & $*$ \\
\hline \multirow{3}{*}{$\begin{array}{l}\text { Junção por similaridade } \\
\qquad(\bowtie)\end{array}$} & Abrangência & $\#$ & - \\
\hline & $k$-Vizinhos mais próximos & $\#$ & - \\
\hline & $k$-Pares de vizinhos mais próximos & $\#$ & - \\
\hline \multirow{6}{*}{$\begin{array}{c}\text { Seleção por similaridade } \\
\text { de grupo }(\hat{\sigma})\end{array}$} & Abrangência SUM & $\#$ & - \\
\hline & Abrangência ALL & $\#$ & - \\
\hline & Abrangência ALL & $\#$ & - \\
\hline & $k$-Vizinhos mais próximos SUM & $\#$ & - \\
\hline & $k$-Vizinhos mais próximos MAX & $\#$ & - \\
\hline & $k$-Vizinhos mais próximos ALL & $\#$ & - \\
\hline \multirow{2}{*}{$\begin{array}{l}\text { Análise de agrupamento } \\
\text { por similaridade }(\hat{\mu})\end{array}$} & Agrupamentos & $\#$ & $\#$ \\
\hline & Vínculo a agrupamentos & $\#$ & $\#$ \\
\hline
\end{tabular}

Tabela 6.1: Operações implementadas nos métodos de acesso seqüencial e Slim-tree. (*) Previamente existente. (\#) Implementada neste trabalho. (-) Não disponível ainda.

\subsection{Operações por Similaridade de Grupo}

A estratégia adotada para a implementação dos algoritmos de consulta por similaridade de grupo, utilizados para responder às consultas de múltiplos centros, segue a mesma estratégia adotada na Arboretum para a implementação dos algoritmos básicos de consulta por similaridade ( $\mathrm{Rq}$ e $k-\mathrm{NNq}$ ), no método de acesso seqüencial. Essa estratégia utiliza uma lista de páginas em disco para armazenar os objetos de um conjunto de dados.

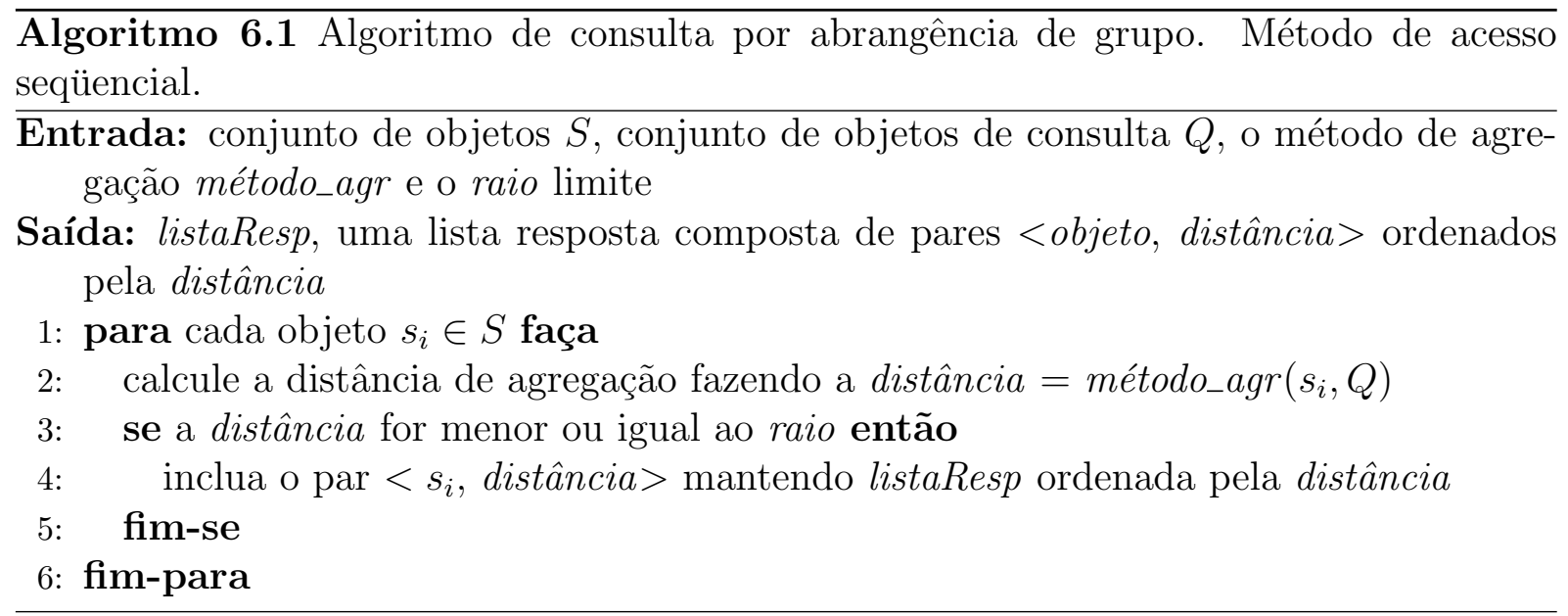




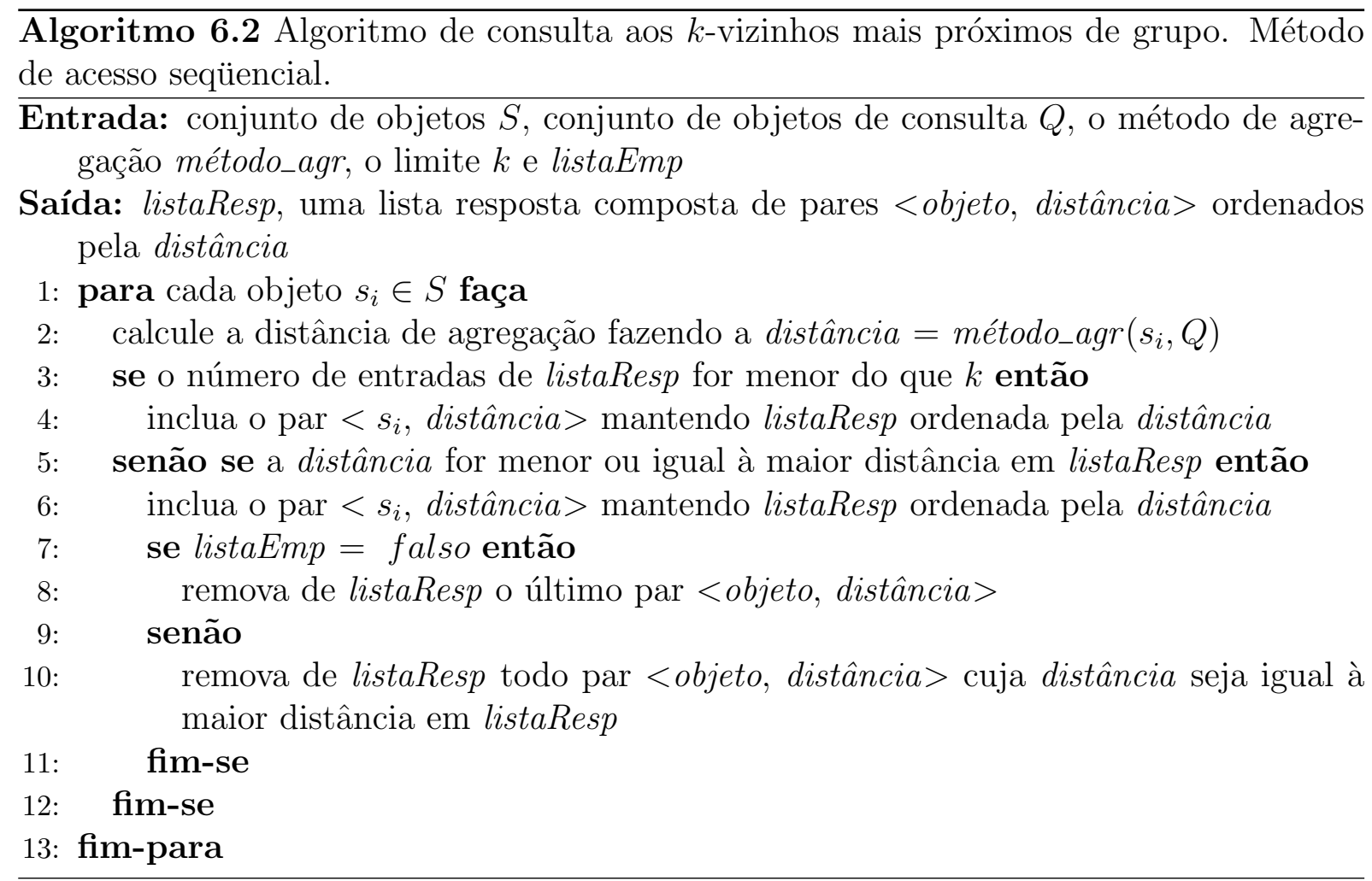

Assumindo que um conjunto de dados $S \subseteq \mathbb{S}$ esteja indexado pelo método de acesso seqüencial, e que o conjunto de objetos de consulta $Q \subseteq \mathbb{S}$ contenha apenas um objeto, a estratégia adotada pela Arboretum percorre a lista de páginas que armazenam os objetos de $S$ seqüencialmente. Começando pelo início da lista, o algoritmo verifica todos os objetos $s_{i} \in S$ armazenados em cada página. Para cada objeto $s_{i}$, ele calcula a distância de $s_{i}$ ao objeto de consulta $s_{q} \in Q$, atribuindo $s_{i}$ ao conjunto resposta, caso ele satisfaça a uma condição que é determinada pelo tipo de consulta por similaridade a ser executada. No caso de consultas por abrangência, essa condição determina que a distância entre $s_{i}$ e $s_{q}$ não deve ser maior do que uma distância máxima de busca (ou raio). Para o caso de consultas pelos $k$-vizinhos mais próximos, essa condição determina que $s_{i}$ só deve ser adicionado ao conjunto resposta caso o número de entradas desse conjunto não tenha ultrapassado o número $k$ de respostas solicitadas, ou caso a distância entre $s_{i}$ e $s_{q}$ seja menor ou igual à maior distância apresentada pelos objetos já adicionados ao conjunto resposta. É importante ressaltar que, caso a consulta $k$-NNq admita a existência de empates, o conjunto resposta pode retornar mais de $k$ objetos de $S$.

Para utilizar essa estratégia na implementação das variações das consultas Rq e $k$-NNq que consideram a existência de múltiplos objetos de consulta, foi necessário fornecer métodos de agregação para o cálculo da distância entre um objeto do conjunto de dados e os centros de consulta (veja Seção 4.1). A descrição dos principais passos empregados na realização de consultas GRq e $k$-GNNq com múltiplos centros é apresentada nos Algoritmos 6.1 e 6.2 . 
Para gerar a agregação das distâncias utilizadas na execução dessas consultas foram implementados os três métodos de agregação descritos na Seção 4.2.2, ou seja, SUM, ALL e MAX. Os Algoritmos 6.3, 6.4 e 6.5 apresentam o pseudocódigo específico de cada um desses métodos de agregação.
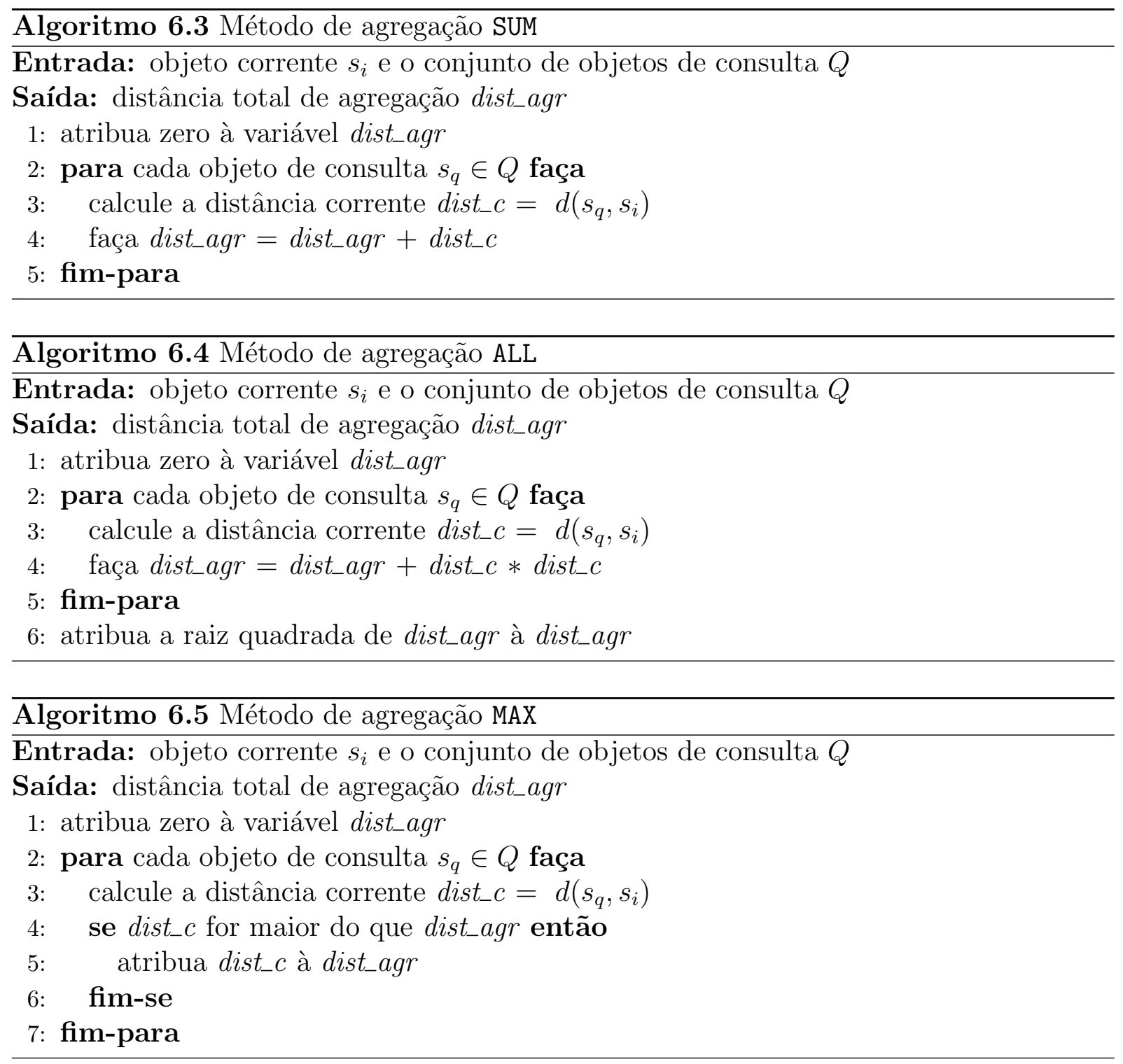

A Figura 6.1 apresenta uma ilustração dos cálculos de distância realizados em uma consulta por similaridade de grupo $k$-GNNq - considerando o conjunto de pontos $P=$ $\left\{p_{10}, p_{11}, p_{12}\right\}$, com $k=1, Q=\left\{q_{1}, q_{2}, q_{3}\right\}$ e a função de distância $d()$ Euclidiana $\left(L_{2}\right)$ para os métodos de agregação SUM, ALL e MAX. Empregando qualquer um dos métodos de agregação no Algoritmo 6.2, a execução dessa consulta verifica cada ponto de $P$, utilizando o resultado do cálculo da distância $L_{2}($ dist_c) de um ponto a todos os objetos de consulta no cálculo da distância agregada, que é então usada para decidir a inclusão ou não de um ponto na lista de resposta (listaResp). Para a situação ilustrada na Figura 6.1, os pontos obtidos como resposta, considerando os métodos de agregação SUM, ALL e MAX são os pontos $p_{10}, p_{12}$ e $p_{11}$, respectivamente. 


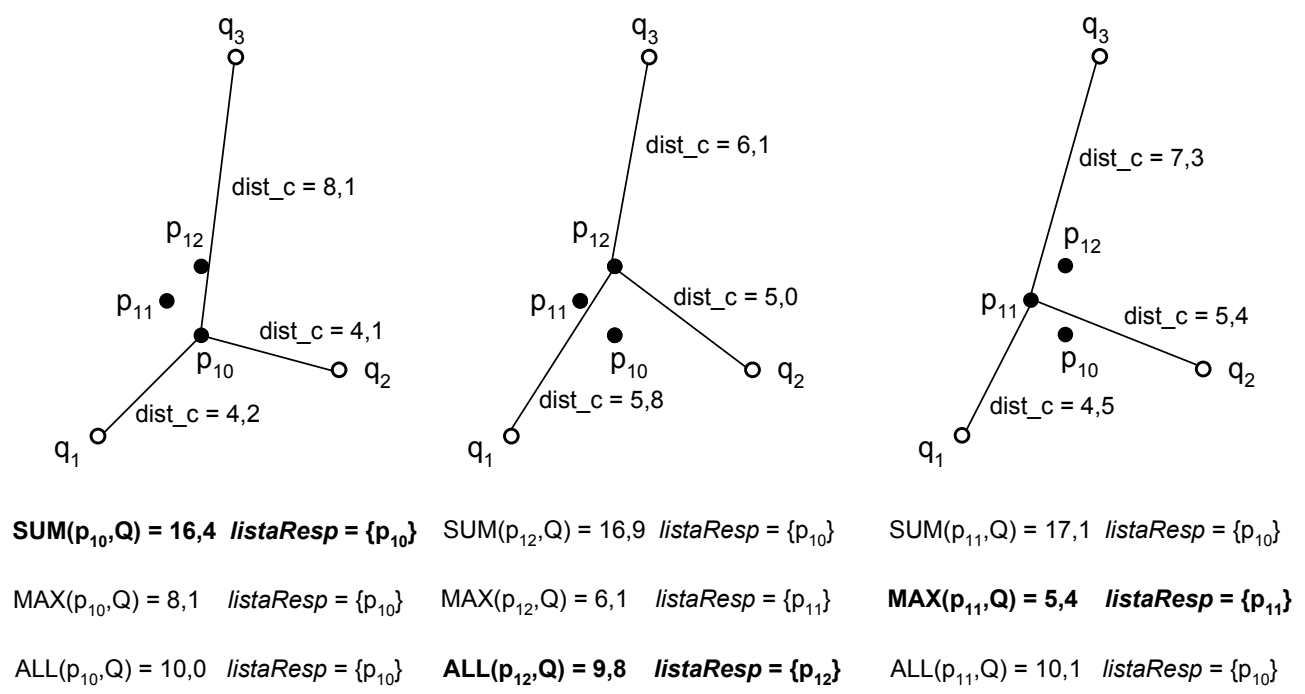

Figura 6.1: Exemplo da execução de uma consulta $k$-NNq considerando 3 centros de consulta e os métodos de agregação SUM, ALL e MAX.

\subsection{Operações de Junção por Similaridade}

Para a implementação das operações de junção por similaridade descritas na Seção 2.1.2 também foi utilizado o mesmo recurso da Arboretum descrito na seção anterior, i.e., o método de acesso seqüencial. Como o propósito da implementação desses algoritmos consistia apenas em fornecer métodos de junção por similaridade - que correspondessem aos predicados binários definidos na extensão da linguagem SQL desenvolvida durante a realização do trabalho apresentado nesta tese - para deixar o protótipo SIREN funcional, ela não abordou nenhum aspecto relacionado à otimização da complexidade computacional dos mesmos. Esses aspectos foram o escopo de outro trabalho de doutorado que foi desenvolvido paralelamente a este [Seraphim, 2005].

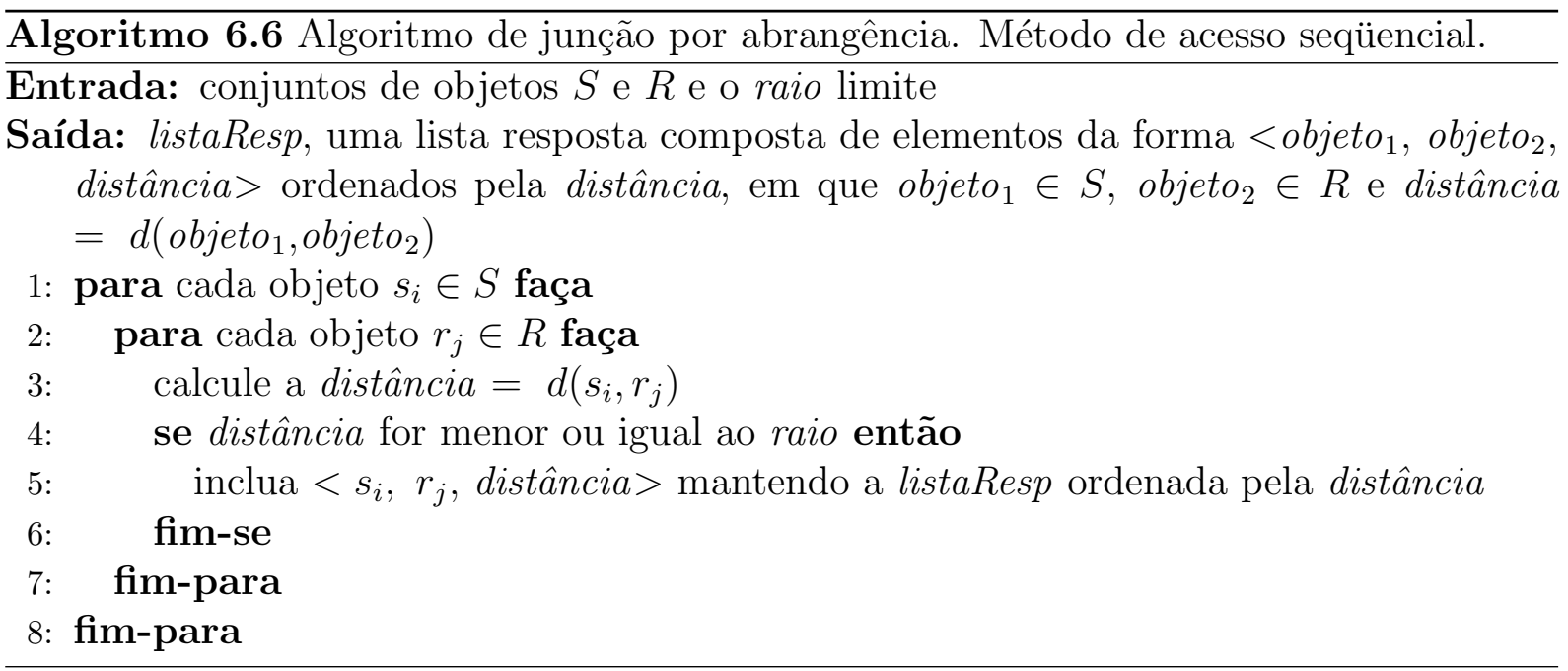

Assumindo a existência de dois conjuntos de dados $S=\left\{s_{1}, s_{2}, s_{3}\right\}$ e $R=\left\{r_{1}, r_{2}, \ldots, r_{6}\right\}$ $\subseteq \mathbb{S}$, a execução das operações de junção por similaridade retorna o conjunto de todos 


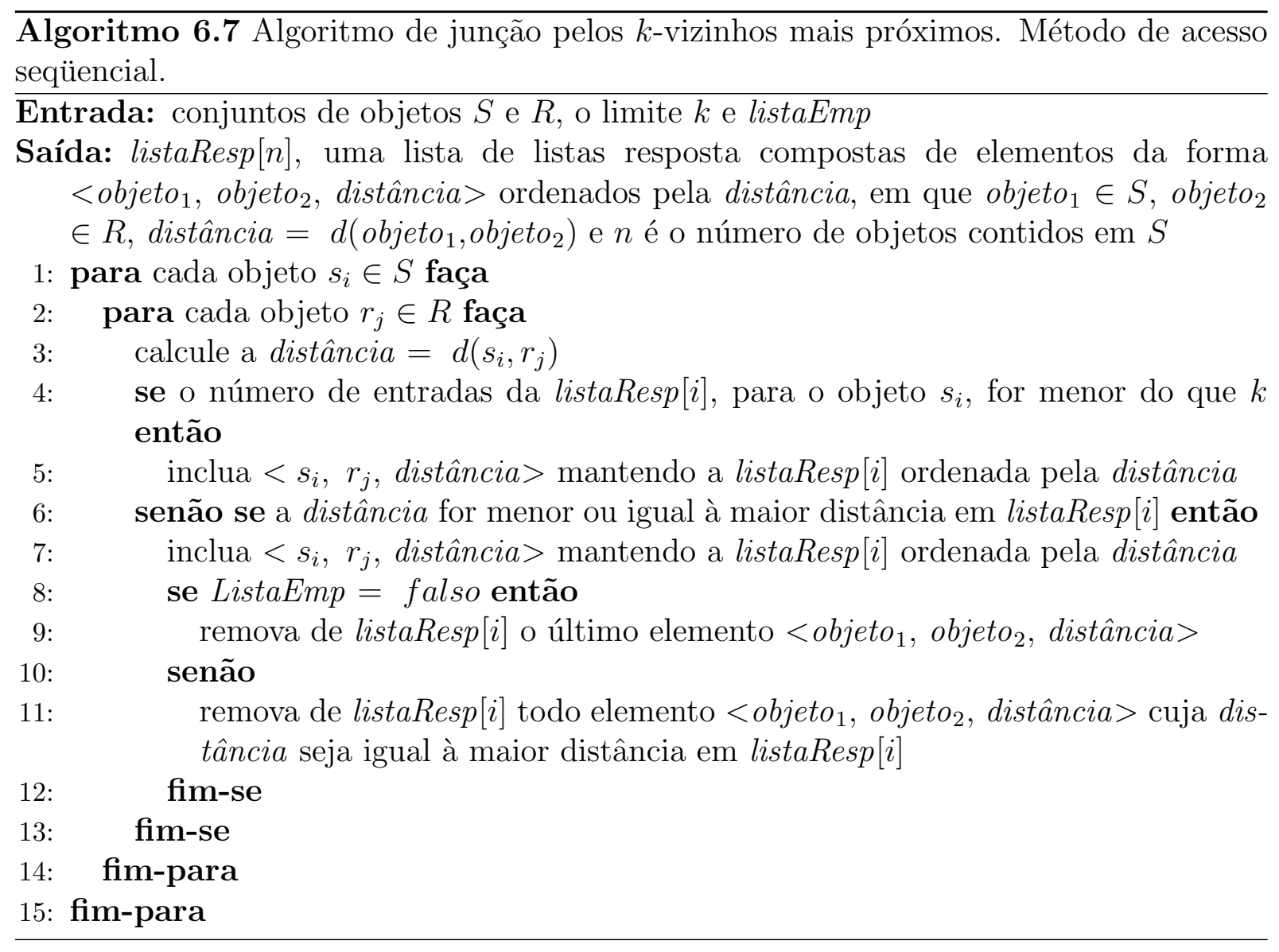

os pares de objetos $\left\langle s_{i}, r_{j}>\right.$ de $S \times R$ que satisfaçam a uma condição específica, de acordo com o tipo de junção por similaridade. Para a junção por abrangência, assim como na consulta Rq, essa condição determina que as distâncias entre os objetos de cada par retornado como resposta não podem ser maiores do que uma distância máxima de busca (ou raio). Já para a junção pelos $k$-vizinhos mais próximos e para a junção dos $k$-pares de vizinhos mais próximos, assim como na consulta $k$-NNq, a condição que limita a quantidade de pares de objetos de $R$ e $S$ na resposta é determinada por um número inteiro $k$, especificado pelo usuário. Na junção pelos $k$-vizinhos mais próximos entre $S$ e $R$, o $k$ é utilizado para limitar o número de vizinhos $R$ mais próximos, que devem ser recuperados juntamente com cada objeto de $S$. Por exemplo, se $k=2$, o conjunto resposta dessa junção retorna 6 pares de objetos. Já na junção dos $k$-pares de vizinhos mais próximos entre $S$ e $R$, o $k$ é utilizado para limitar o número dos pares de objetos mais similares entre si. Nesse caso, o conjunto resposta resultante da junção de $S$ e $R$, considerando o $k=2$, será composto por dois pares de objetos.

Os pseudocódigos específicos de cada um desses métodos de junção por similaridade são apresentados nos Algoritmos 6.6, 6.7 e 6.8. A definição desses algoritmos seguiu basicamente a mesma seqüência de passos adotada na definição dos algoritmos de consulta por similaridade $\mathrm{Rq}$ e $k$-NNq utilizados no método de acesso seqüencial da Arboretum. A principal diferença se deve à adição de um laço a mais, englobando todos os passos 


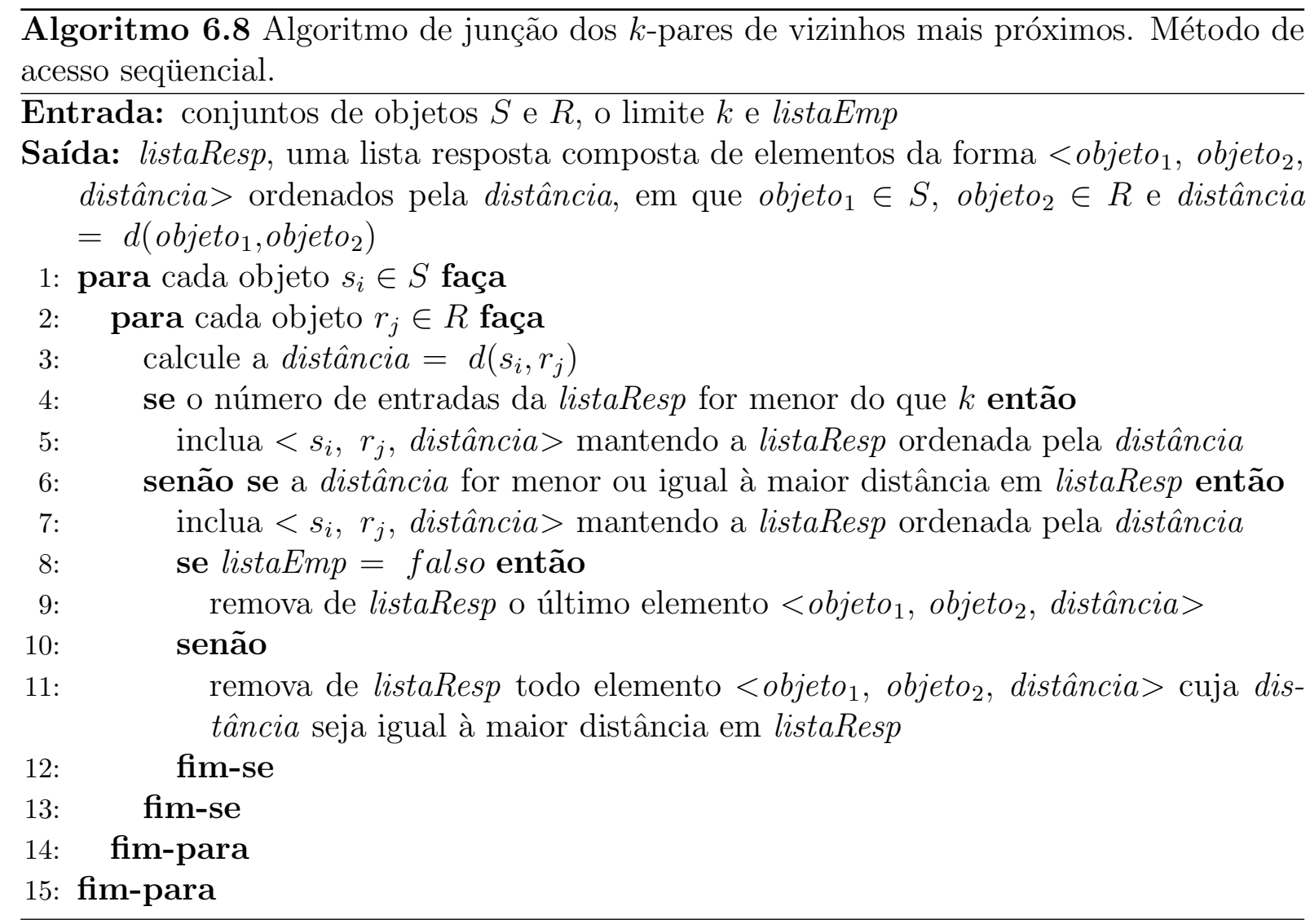

utilizados na computação das consultas por similaridade tradicionais. Isso faz com que, considerando os conjuntos de dados $S$ e $R$, a execução de uma junção por abrangência entre $S$ e $R$, por exemplo, realize uma consulta $\operatorname{Rq}$ em $R$ para cada objeto de $S$.

\subsection{Operações de Detecção de Agrupamentos}

Dentre os vários algoritmos de detecção de agrupamentos existentes, os algoritmos baseados no método $k$-medoid foram escolhidos como base para o trabalho apresentado nesta seção pelas seguintes razões: a qualidade dos agrupamentos obtidos por métodos de detecção de agrupamentos baseados em partição tende a ser melhor do que a dos métodos hierárquicos; eles são menos sensíveis à presença de outliers; não apresentam limitações quanto aos tipos dos atributos (a aplicação do $k$-means, por exemplo, restringe-se a conjuntos de dados multi-dimensionais contínuos); e também porque o agrupamento obtido com a aplicação desses algoritmos não depende da ordem de entrada do conjunto de dados. Além disso, eles são invariantes quanto a translações e transformações ortogonais dos objetos [Ng \& Han, 2002, Kaufman \& Rousseeuw, 2005].

Apesar das vantagens mencionadas, os algoritmos de detecção de agrupamentos baseados no método $k$-medoid são muito caros do ponto de vista do volume de processamento que eles requerem, em geral de ordem quadrática, ou pior, sobre o número de instâncias na base de dados. Para que a operação de detecção de agrupamento possa ser suportada 
por um SGBD, é importante que as boas características dos algoritmos que implementam o método $k$-medoid sejam mantidas, mas é fundamental conseguir um ganho de desempenho significativo, pois as respostas dadas por um SGBD têm que ser obtidas muito mais rapidamente do que os algoritmos tradicionais conseguem responder.

Nesta seção apresenta-se uma abordagem de otimização de algoritmos de detecção de agrupamentos baseados no método $k$-medoid desenvolvido neste trabalho de doutorado especificamente para atender a esses requisitos. Essa abordagem utiliza métodos de acesso métrico para selecionar um conjunto representativo de objetos do conjunto de dados para a aplicação desses algoritmos. Essa nova abordagem tem como objetivo reduzir a complexidade dos algoritmos de detecção de agrupamentos baseados no método $k$-medoid, tentando preservar a qualidade dos agrupamentos gerados, o que permite a obtenção de técnicas de agrupamento escaláveis para tratar volumes de dados muito grandes (da ordem de dezenas ou centenas de milhares de instâncias); no caso desta tese, grandes bases de dados complexos.

\subsubsection{Abordagem do Problema}

O trabalho apresentado nesta seção parte da seguinte suposição: "um método de indexação métrico tal como a Slim-tree deve naturalmente, por construção, agrupar em um mesmo nó instâncias semelhantes. Assim, o conjunto de representantes dos nós em um determinado nivel da hierarquia deve compreender um conjunto apropriado de centros de agrupamentos, ou seja, de medóides".

Embora conceitualmente, qualquer MAM dinâmico pudesse ter sido utilizado na realização do trabalho apresentado nesta seção, este trabalho considerou particularmente o MAM Slim-tree. Por definição, uma Slim-tree divide o espaço métrico no qual os dados estão, indiretamente, em um número de agrupamentos que depende do tamanho das instâncias e da capacidade de armazenamento do nó. Assim, o conjunto de representantes distorce o que seria um conjunto de medóides, pois o critério empregado para a geração dos agrupamentos (dos nós índice) não tem por prioridade a identificação dos mesmos. Além disso, o número de agrupamentos não é um parâmetro fornecido pelo usuário, o que faz com que os MAM e, em particular a Slim-tree, não possam realizar todo o processo de agrupamento dos dados. Por outro lado, os objetos representantes armazenados em algum nível da árvore, como nós índice, tendem a ser centros de agrupamentos adequados para compor o conjunto de amostras a ser utilizado por um algoritmo de detecção de agrupamentos.

\subsubsection{Descrição do Algoritmo}

A complexidade computacional dos algoritmos de agrupamento baseados no método $k$ medoid apresentados na Seção 3.4.2 depende do número de objetos do conjunto de dados 
$n$, e do número de agrupamentos $k$. Para reduzir essa complexidade, uma estratégia comumente utilizada consiste em reduzir o número total de objetos que são empregados na execução desses algoritmos por meio da realização de uma amostragem do conjunto de dados original. Nessa estratégia, a qualidade do agrupamento resultante está diretamente relacionada à qualidade da amostragem realizada sobre o conjunto de dados.

O algoritmo desenvolvido visa otimizar a eficiência computacional desses algoritmos realizando operações de amostragem baseadas em características da Slim-tree. Por construção, cada nível de uma Slim-tree representa uma divisão no espaço de dados com uma certa granularidade que cresce a partir da raiz para as folhas, que armazenam todos os objetos de um conjunto de dados. Assim, uma questão importante que precisou ser respondida para o desenvolvimento da estratégia apresentada nesta seção foi: "Qual nível da árvore contém informações suficientes sobre a distribuição dos dados que podem gerar agrupamentos com um baixo custo computacional e ao mesmo tempo manter uma qualidade razoável?".

Analisando a estrutura hierárquica gerada pelas Slim-trees, é possível observar que os níveis superiores da árvore (próximos ao nível da raiz) não contém muita informação sobre a distribuição dos dados porque os dados são agrupados a partir de um pequeno número de representantes. Por outro lado, os níveis inferiores (próximos ao nível das folhas) tendem a conter muita informação, o que pode reduzir a eficiência computacional dos algoritmos de deteç̧ão de agrupamentos. Intuitivamente, conclui-se que os níveis próximos à metade da altura da árvore devem conter informações suficientes sobre a distribuição dos dados para a geração de agrupamentos apropriados. Os experimentos que foram realizados indicaram que o nível correspondente à metade da altura da árvore realmente é uma escolha adequada.

Embora a estratégia proposta também possa ser aplicada a outros algoritmos de detecção de agrupamentos baseados no método $k$-medoid, o trabalho apresentado nesta seção considerou apenas o algoritmo PAM, já que dentre os algoritmos de detecção de agrupamentos considerados nesta tese ele é o algoritmo que identifica agrupamentos de melhor qualidade. O algoritmo de amostragem que utiliza a Slim-tree aplicada ao PAM foi denominado PAM-SLIM.

O algoritmo PAM-SLIM é composto por três fases principais: uma fase inicial de préprocessamento; uma fase de inicialização, na qual a amostragem dos dados é obtida; e a fase final de agrupamento dos dados. A primeira fase é responsável pela construção da Slim-tree. Essa fase permite a especificação de alguns dos parâmetros necessários à construção da árvore, como a política de escolha de subárvore (ChooseSubtree) e o tamanho de página do nó. Como mencionado na Seção 2.1.3, Slim-trees construídas com diferentes opções de políticas de escolha de subárvore tendem a apresentar diferentes graus de sobreposição entre os seus nós. Assim, a possibilidade de determinar qual política de escolha de subárvore utilizar, na fase de pré-processamento, permite avaliar os resultados 
obtidos pelo algoritmo PAM-SLIM, considerando diferentes configurações na construção da Slim-tree. Outro parâmetro que merece atenção na construção de uma Slim-tree é o tamanho da página do nó. Como o algoritmo PAM-SLIM escolhe os seus medóides de acordo com os nós representantes, o tamanho do nó afeta o comportamento do algoritmo. Assim, esse parâmetro deve ser inicializado de acordo com o conjunto de dados a ser analisado.

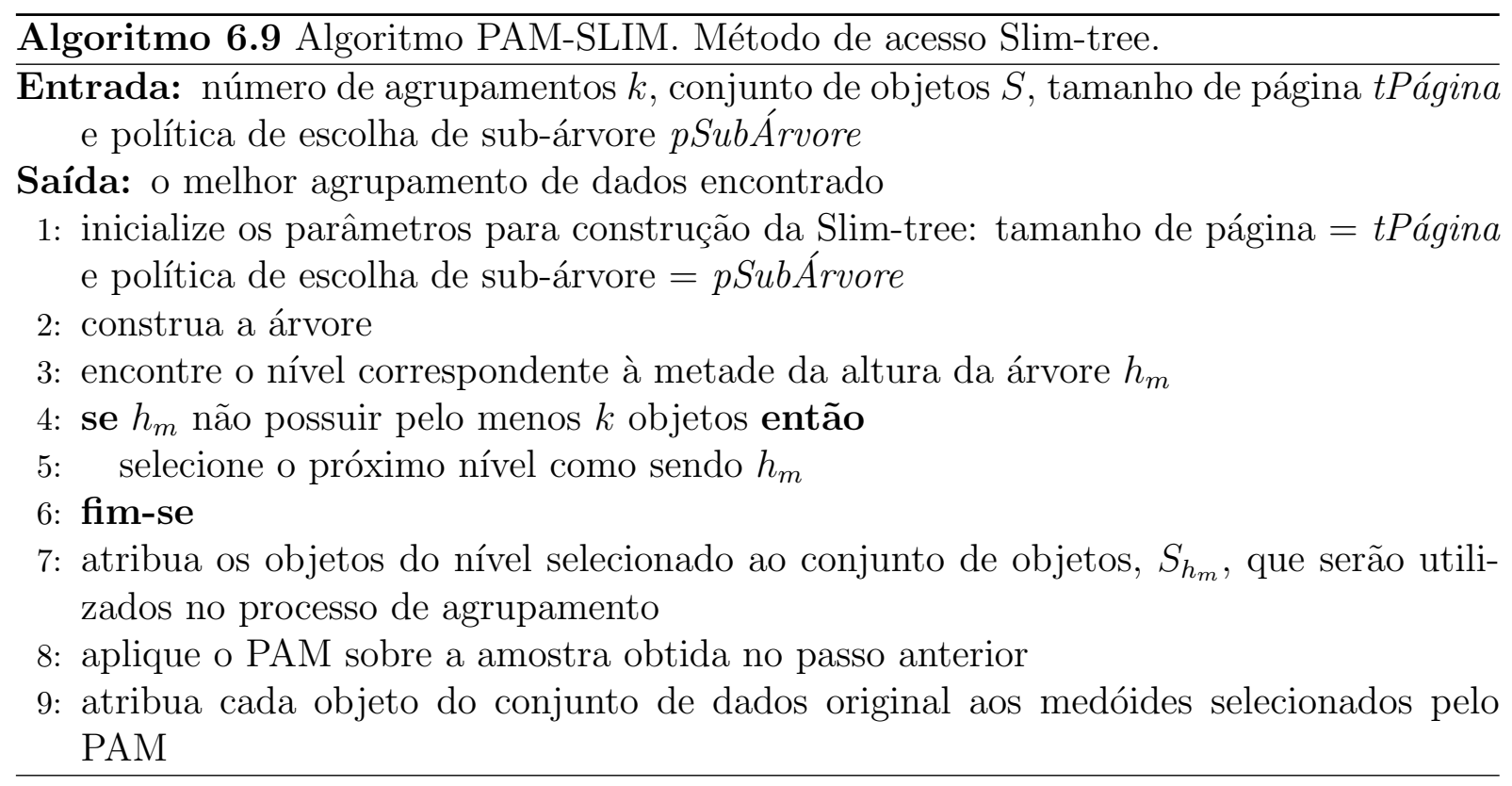

Uma vez que a Slim-tree tenha sido construída, o subconjunto de objetos que deve ser enviado ao PAM é selecionado na segunda fase. Esse subconjunto de objetos é composto pelos nós representantes armazenados no nível correspondente à metade da altura da árvore. A última fase aplica o algoritmo PAM sobre os objetos selecionados na fase anterior e atribui cada objeto do conjunto de dados original ao conjunto de medóides retornados pelo PAM. Todos os passos necessários para a execução das três fases do algoritmo PAM-SLIM descritas acima são apresentados no Algoritmo 6.9.

\subsubsection{Experimentos}

Com o objetivo de mostrar a eficiência computacional e a qualidade dos agrupamentos obtidos com a utilização da estratégia desenvolvida, esta seção apresenta três conjuntos de experimentos. Para avaliar a qualidade dos agrupamentos obtidos pelas técnicas analisadas (qualidade de agrupamento, por simplicidade), foi utilizado o cálculo da distância média dos agrupamentos resultantes, i.e., a distância média entre todos os objetos e seus medóides (menores valores para a distância média indicam agrupamentos melhores). Essa é a medida padrão utilizada na literatura para avaliar a qualidade dos agrupamentos obtidos por algoritmos de detecção de agrupamentos baseados no método $k$-medoid. A eficiência computacional (eficiência, por simplicidade) foi medida pelo nú- 
mero de cálculos de distância que precisam ser executados pelos algoritmos.

O objetivo do primeiro conjunto de experimentos foi comparar a estratégia adotada pelo PAM-SLIM com os algoritmos tradicionais de detecção de agrupamentos baseados no método $k$-medoid - PAM, CLARA e CLARANS. Como o algoritmo PAM não é adequado para o processamento de grandes conjuntos de dados devido a sua complexidade computacional (como descrito na Seção 3.4.2), ele foi considerado apenas no primeiro conjunto de experimentos. No segundo conjunto de experimentos foi avaliada a escalabilidade da abordagem desenvolvida quando o tamanho do conjunto de dados aumenta. E o terceiro conjunto de experimentos teve como objetivo mostrar a performance do algoritmo desenvolvido por meio da utilização de um grande conjunto de dados real. É importante notar que, em todos os experimentos, os gráficos de eficiência são apresentados em escala logarítmica para o eixo que corresponde ao número de cálculos de distância, devido à grande diferença existente entre os resultados obtidos para os algoritmos testados.

Em todos os conjuntos de experimentos, foram consideradas duas configurações para a abordagem adotada pelo PAM-SLIM: PAM-SLIM-MD, que utiliza a política de escolha de sub-árvore minDist; e PAM-SLIM-MO, que utiliza a política minOccup. Com isso, foi possível analisar as diferenças nos resultados dos agrupamentos obtidos pela realização de amostragens de objetos selecionados a partir de árvores com diferentes configurações.

Para encontrar o tamanho de página ideal para cada conjunto de dados testado, os experimentos foram executados, variando-se o tamanho de página para os métodos que utilizam a Slim-tree. Os tamanhos de página do nó foram escolhidos de acordo com o tamanho dos objetos de cada conjunto de dados. É importante notar que os algoritmos PAM, CLARA e CLARANS são executados apenas em memória principal e, assim, não são influenciados pelo tamanho de página.

Para obter uma comparação justa, todos os cinco algoritmos de detecção de agrupamentos utilizados nos testes - PAM, CLARA, CLARANS, PAM-SLIM-MD e PAM-SLIM$\mathrm{MO}$ - foram implementados dentro da mesma plataforma, utilizando a linguagem $\mathrm{C}++$ na biblioteca de MAM Arboretum [GBDI-ICMC-USP, 2006a]. A Arboretum fornece o método de acesso seqüencial que possui a mesma interface externa e comportamento dos demais MAM que ela implementa. Esse recurso foi novamente utilizado na implementação dos algoritmos PAM, CLARA e CLARANS descritos na Seção 3.4.2, sendo que os parâmetros dos algoritmos CLARA e CLARANS foram inicializados considerando as melhores configurações recomendadas, i.e., 5 amostras contendo $50+2 k$ objetos do conjunto de dados original para o algoritmo CLARA e numLocal $=2$ e maxVizinhos $=\max (250,1.25 \%$ de $k *(n-k))$ para o algoritmo CLARANS, sendo $k$ o número de agrupamentos solicitado e $n$ o número de objetos do conjunto de dados.

É importante ressaltar que os algoritmos PAM e PAM-SLIM realizam o agrupamento de maneira determinística, de modo que qualquer execução sempre apresenta o mesmo resultado. Por outro lado, os algoritmos CLARANS e CLARA são baseados em amos- 
tragem aleatória, assim, os resultados de todos os conjuntos de experimentos sobre esses algoritmos são apresentados considerando a média de dez execuções. Os experimentos foram realizados em um PC equipado com um processador Intel Pentium IV de 2,4 GHz, 1 GB RAM e disco rígido de 60 GB.

\section{Conjuntos de Dados}

\begin{tabular}{|c|c|c|c|c|c|c|}
\hline Nome & $N^{o} \mathrm{Obj}$. & $\begin{array}{c}\text { Tamanho do } \\
\text { objeto (Bytes) }\end{array}$ & $k$ & $D$ & $d()$ & Descrição \\
\hline Sint10_5k & 10.000 & 24 & 5 & 5 & $L_{2}$ & \multirow{4}{*}{$\begin{array}{l}\text { Dados vetorias sintéticos com distri- } \\
\text { buição Gaussiana em um hipercubo } \\
\text { com } 5 \text { dimensões. }\end{array}$} \\
\hline Sint10_10k & 10.000 & 24 & 10 & 5 & $L_{2}$ & \\
\hline Sint10_15k & 10.000 & 24 & 15 & 5 & $L_{2}$ & \\
\hline Sint10_20k & 10.000 & 24 & 20 & 5 & $L_{2}$ & \\
\hline Sint30_10k & 30.000 & 44 & 10 & 10 & $L_{1}$ & \multirow{4}{*}{$\begin{array}{l}\text { Dados vetorias sintéticos com distri- } \\
\text { buição Gaussiana em um hipercubo } \\
\text { com } 10 \text { dimensões. }\end{array}$} \\
\hline Sint60_10k & 60.000 & 44 & 10 & 10 & $L_{1}$ & \\
\hline Sint90_10k & 90.000 & 44 & 10 & 10 & $L_{1}$ & \\
\hline Sint120_10k & 120.000 & 44 & 10 & 10 & $L_{1}$ & \\
\hline MedHisto & 40.000 & $\begin{array}{c}44-380 \\
\text { (média de } 280 \text { ) }\end{array}$ & - & - & $L_{M}$ & $\begin{array}{l}\text { Histogramas métricos de imagens mé- } \\
\text { dicas em tons de cinza. Esse conjun- } \\
\text { to de dados é adimensional e foi ge- } \\
\text { rado pelo GBDI-ICMC-USP. Para } \\
\text { maiores detalhes sobre esse conjunto } \\
\text { de dados e a função de distância uti- } \\
\text { lizada, veja [Traina et al., 2002a]. }\end{array}$ \\
\hline
\end{tabular}

Tabela 6.2: Descrição dos conjuntos de dados, sintéticos e reais, utilizados nos experimentos.

Nove conjuntos de dados foram utilizados para a realização dos testes apresentados nessa seção. Oito deles foram gerados a partir de dados sintéticos ${ }^{1}$ com o objetivo de permitir uma avaliação apropriada dos algoritmos. O nono conjunto de dados foi composto a partir de dados adimensionais reais e foi utilizado com o objetivo de analisar o comportamento do algoritmo proposto no mundo real. A descrição dos conjuntos de dados é apresentada na Tabela 6.2 juntamente com seus nome, número total de objetos $\left(N^{o}\right.$ Objs.), tamanho do objeto em bytes, número de agrupamentos ( $k$ ) utilizado para gerar o conjunto, número de dimensões dos objetos que compõem o conjunto de dados $(D)$ e a função de distância utilizada $(d())$.

\section{Experimento 1: PAM-SLIM vs. Algoritmos de Detecção de Agrupamentos Tradicionais}

O primeiro conjunto de experimentos foi realizado com o objetivo de comparar as duas configurações do método PAM-SLIM, PAM-SLIM-MD e PAM-SLIM-MO, com os algoritmos baseados no método $k$-medoid PAM, CLARA e CLARANS.

\footnotetext{
${ }^{1} \mathrm{O}$ processo para a geração desses conjuntos de dados é descrito em [Ciaccia et al., 1997]
} 
A Figura 6.2 mostra a comparação em termos de eficiência computacional ((a), (b), (c) e (d)) e qualidade dos agrupamentos obtidos ((e), (f), (g) e (h)) entre os métodos PAM, CLARA, CLARANS, PAM-SLIM-MD e PAM-SLIM-MO para os conjuntos de dados Sint10_5k, Sint10_10k, Sint10_15k e Sint10_20k, nos quais 5, 10, 15 e 20 medóides foram selecionados, respectivamente. Como os algoritmos de detecção de agrupamentos tradicionais - PAM, CLARANS e CLARA - são executados em memória principal, os resultados obtidos com a execução desses algoritmos são apresentados nos gráficos apenas como as três primeiras barras, sem legenda para o tamanho de página. Os algoritmos PAM-SLIM-MD e PAM-SLIM-MO foram executados utilizando disco, empregando tamanhos de página de 1.024, 2.048 e 4.096 bytes.

Considerando os tamanhos de página empregados nos testes para ambas configurações do algoritmo PAM-SLIM, o tamanho de página de 4.096 bytes foi o que apresentou o melhor custo-benefício entre eficiência computacional e qualidade de agrupamento. Se forem considerados apenas os gráficos relativos à qualidade de agrupamento (Figuras 6.2 (e), (f), (g) e (h)), é possível verificar que, de maneira geral, a qualidade de agrupamento obtido para as duas configurações do algoritmo PAM-SLIM, considerando o tamanho de página de 1.024 bytes, é melhor do que as qualidades de agrupamentos obtidas considerando os tamanhos de página de 2.048 e 4.096 bytes. Entretanto, se os gráficos correspondentes de eficiência forem observados (Figura 6.2(a), (b), (c) e (d)), é possível verificar que as execuções dos algoritmos PAM-SLIM, com tamanho de página de 4.096 bytes, foram as que apresentaram os menores números de cálculos de distância quando comparadas com as execuções dos mesmos algoritmos, considerando os demais tamanhos de página utilizados nesse conjunto de testes. Assim, foi possível concluir que o tamanho de página de 4.096 bytes foi o que apresentou o melhor resultado geral, apesar dessa configuração ter resultado em um pequeno decréscimo na qualidade de agrupamento, quando comparada com a configuração que utiliza o tamanho de página de 1.024 bytes.

Em particular, para o PAM-SLIM-MO, foram observados aumentos de eficiência, variando de 70 a 137 vezes, quando comparado com o CLARANS, enquanto a perda de qualidade variou apenas entre 2,1\% e 5,6\%. Quando comparado com o PAM, a eficiência foi melhorada por um fator de 3.577 a 6.695 vezes (mais de três mil vezes mais rápido), embora se tenha observado uma diminuição da qualidade do agrupamento que variou entre $7,4 \%$ e $11,8 \%$. Quando comparado com o CLARA, a melhoria de qualidade obtida com o algoritmo PAM-SLIM-MO variou entre 9,7\% e 26\%, obtendo ainda uma melhoria de eficiência entre $11 \%$ e $33 \%$.

A Tabela 6.3 apresenta o tempo (medido como horas:minutos:segundos) gasto na execução dos algoritmos de detecção de agrupamentos sobre os conjuntos de dados utilizados pelos testes apresentados nesta seção. A comparação de tempo entre os algoritmos PAM, CLARANS, CLARA, PAM-SLIM-MD e PAM-SLIM-MO considera o tamanho de página que apresentou a melhor relação custo-benefício para os algoritmos PAM-SLIM (tamanho 
(a) Sint10_5k

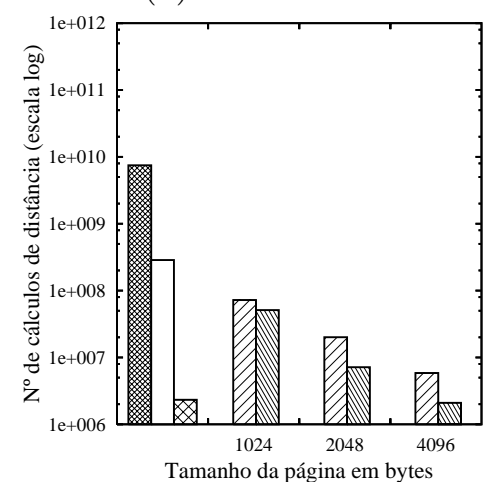

(b) Sint10_10k

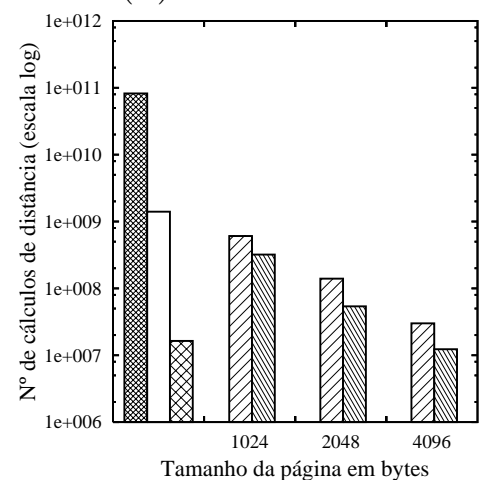

(c) Sint10_15k

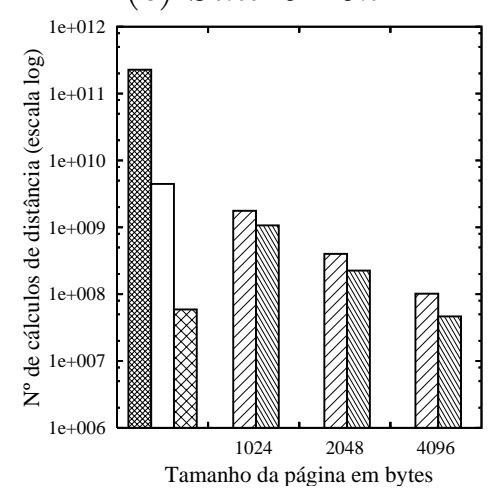

(d) Sint10_20k

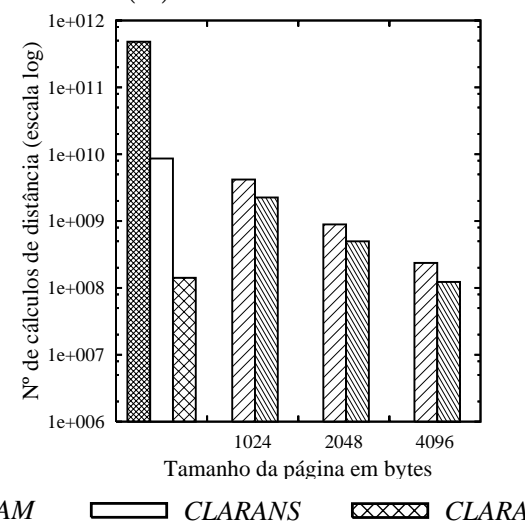

(e) Sint10_5k

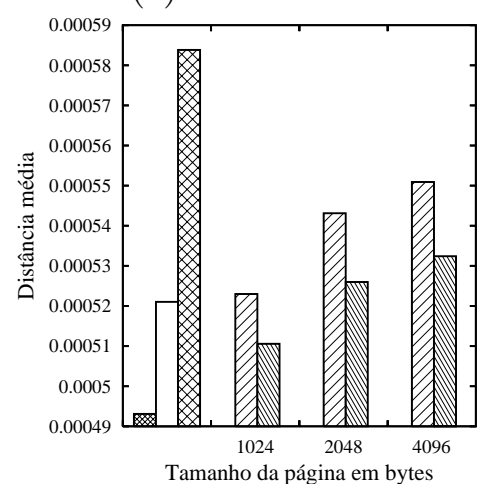

(f) Sint10_10k

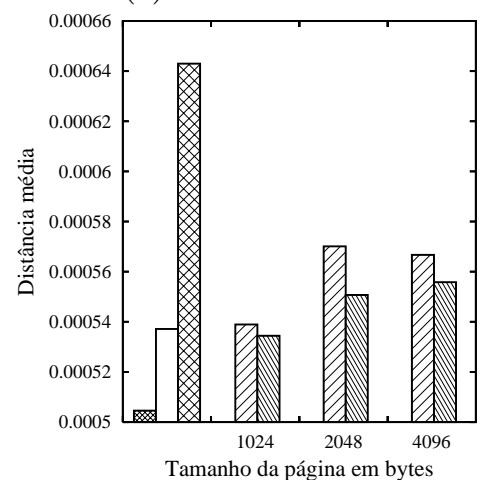

(g) Sint10_15k

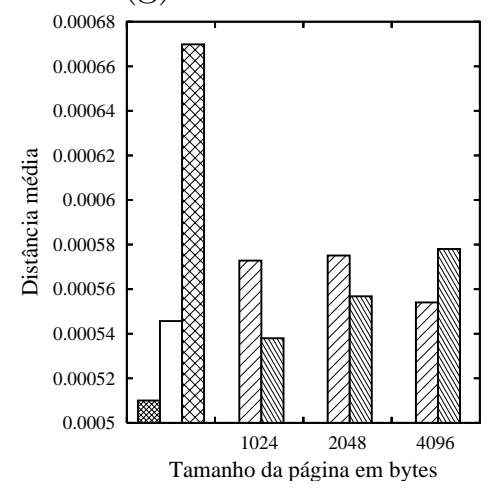

(h) Sint10_20k

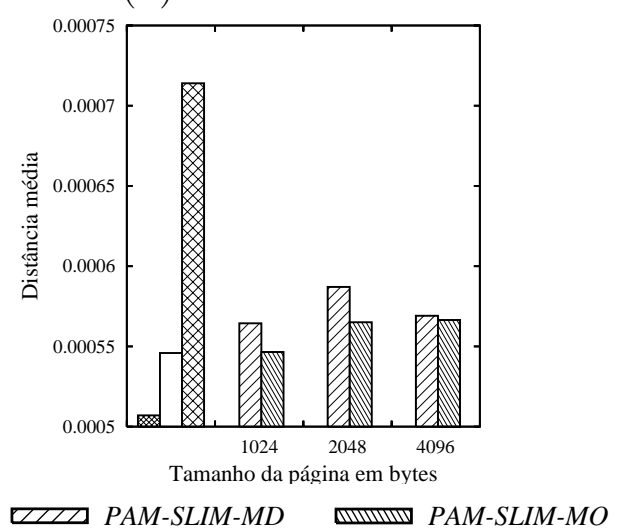

Figura 6.2: Comparação de eficiência computacional ((a), (b), (c) e (d)) e qualidade de agrupamento ((e), (f), (g) e (h)) entre PAM, CLARANS, CLARA, PAM-SLIMMD e PAM-SLIM-MO para os conjuntos de dados Synt10_5k, Sint10_10k, Sint10_15k e Sint10_20k. 
de página de 4.096 bytes).

\begin{tabular}{|c|c|c|c|c|c|}
\hline $\begin{array}{c}\text { Conjunto } \\
\text { de dados }\end{array}$ & PAM & CLARANS & CLARA & $\begin{array}{c}\text { PAM-SLIM- } \\
\text { MD }\end{array}$ & $\begin{array}{c}\text { PAM-SLIM- } \\
\text { MO }\end{array}$ \\
\hline \hline Sint10_5k & $00: 42: 48$ & $00: 01: 31$ & $00: 00: 01$ & $00: 00: 04$ & $00: 00: 02$ \\
Sint10_10k & $07: 49: 42$ & $00: 07: 18$ & $00: 00: 06$ & $00: 00: 10$ & $00: 00: 05$ \\
Sint10_15k & $21: 27: 41$ & $00: 23: 03$ & $00: 00: 20$ & $00: 00: 33$ & $00: 00: 15$ \\
Sint10_20k & $43: 44: 47$ & $00: 44: 10$ & $00: 00: 47$ & $00: 01: 14$ & $00: 00: 39$ \\
\hline
\end{tabular}

Tabela 6.3: Comparação de tempo entre os algoritmos PAM, CLARANS, PAM-SLIMMD e PAM-SLIM-MO para os conjuntos de dados Synt10_5k, Synt10_10k, Synt10_15k e Synt10_20k. Considerando a execução dos algoritmos PAM-SLIM-MD e PAM-SLIM-MO com tamanho de página de 2.048 bytes. Tempo medido em horas:minutos:segundos.

Após a análise da tabela e dos gráficos apresentados, é possível concluir que o algoritmo PAM-SLIM-MO foi o que apresentou a melhor relação custo-benefício entre eficiência computacional e qualidade de agrupamento para os conjuntos de dados utilizados nos testes apresentados nesta seção. Como os experimentos mostraram, o algoritmo PAM-SLIM foi mais de três mil vezes mais rápido que o PAM produzindo, ainda assim, agrupamentos de qualidade comparável. No próximo conjunto de experimentos, o algoritmo PAM não foi considerado devido a seu custo computacional proibitivo.

\section{Experimento 2: Avaliação da Escalabilidade dos Algoritmos PAM-SLIM}

Os conjuntos de dados Sint30_10k, Sint60_10k, Sint90_10k e Sint120_10k foram utilizados no segundo conjunto de experimentos com o objetivo de avaliar a escalabilidade dos algoritmos PAM-SLIM à medida que o número de objetos do conjunto de dados aumenta (veja a Tabela 6.2). Nesse conjunto de experimentos foram solicitados aos algoritmos de detecção de agrupamentos 10 medóides para cada conjunto de dados. A Figura 6.3 exibe a comparação de eficiência computacional e qualidade de agrupamento para os algoritmos CLARANS, CLARA, PAM-SLIM-MD e PAM-SLIM-MO. Os tamanhos de página empregados nesses experimentos para os algoritmos PAM-SLIM-MD e PAM-SLIM-MO variaram de 2.048 a 8.192 bytes.

Analisando os gráficos de qualidade de agrupamento (Figuras 6.3 (e), (f), (g) e (h)) gerados pela execução dos testes do segundo conjunto de experimentos, é possível verificar que não houve uma grande variação entre os resultados obtidos para os algoritmos PAMSLIM, considerando os diversos tamanhos de página empregados nesses experimentos (a diferença observada entre os resultados de qualidade obtidos para esses algoritmos foi de 0,0033). Por outro lado, se forem analisados os gráficos de eficiência (Figuras 6.3 (a), (b), (c) e (d)), é possível verificar que, para o algoritmo PAM-SLIM-MO, o número de cálculos de distância necessários para a sua execução diminui à medida que tamanhos de página maiores foram considerados. 
(a) Sint30_10k

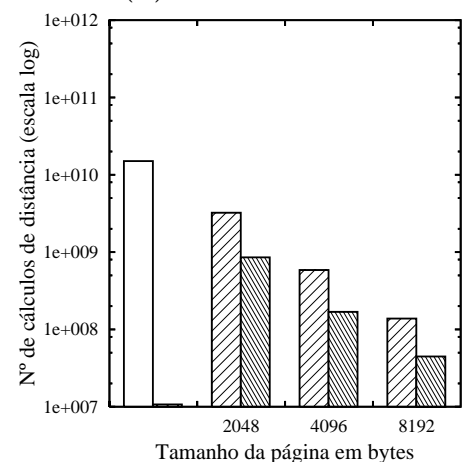

(b) Sint60_10k

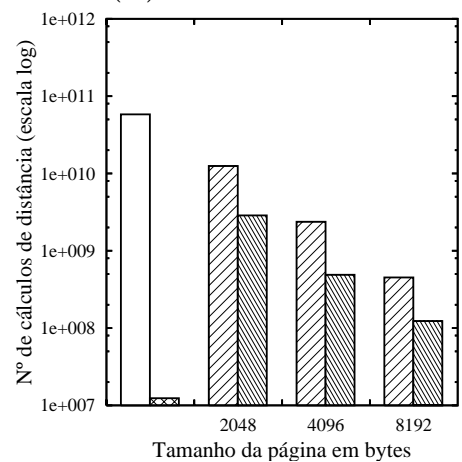

(c) Sint90_10k

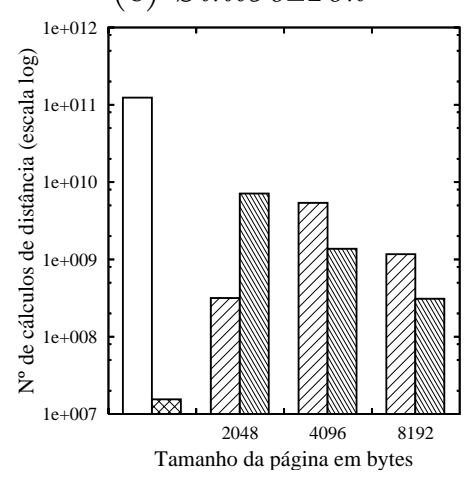

(d) Sint120_10k

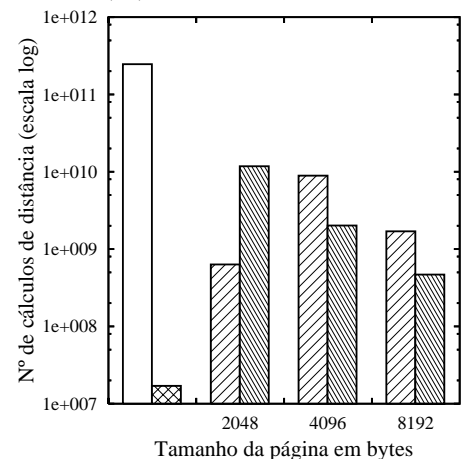

(e) Sint30_10k

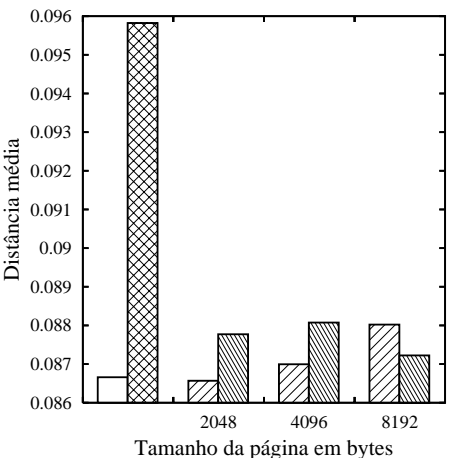

(f) Sint60_10k

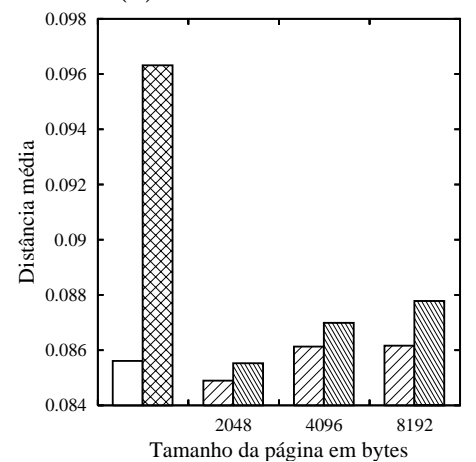

(g) Sint90_10k

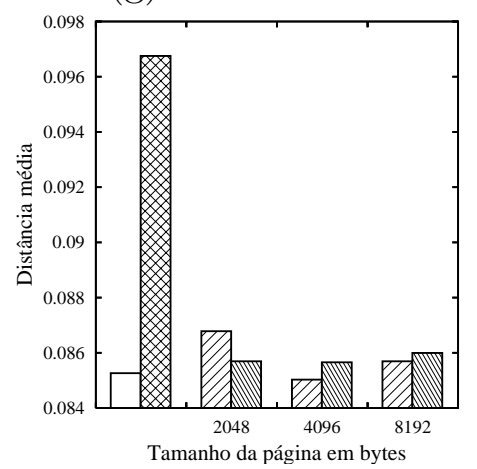

(h) Sint120_10k

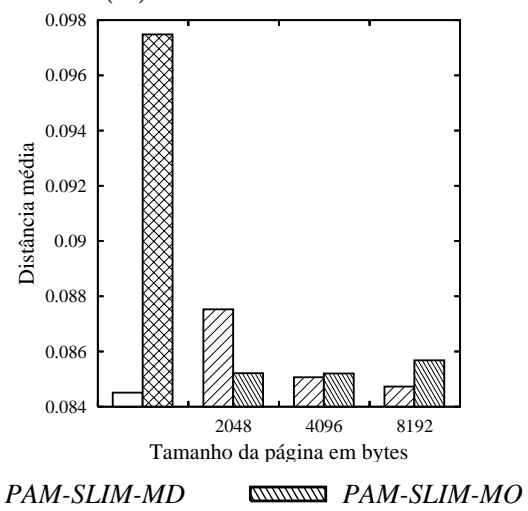

Figura 6.3: Comparação de eficiência computacional ((a), (b), (c) e (d)) e qualidade de agrupamento ((e), (f), (g) e (h)) entre PAM, CLARANS, CLARA, PAM-SLIMMD e PAM-SLIM-MO para os conjuntos de dados Sint30_10k, Sint60_10k, Sint90_10k e Sint120_10k. 
Desse modo, é possível concluir que, de maneira geral, a configuração que resultou na melhor relação custo-benefício entre eficiência computacional e qualidade de agrupamento foi a que considera a utilização do tamanho de página de 8.192 bytes para o algoritmo PAM-SLIM-MO. Levando em consideração esse tamanho de página, é possível observar que o algoritmo PAM-SLIM-MO obteve melhoria de eficiência, variando de 337 a 527 vezes, quando comparado com o CLARANS (o algoritmo de detecção de agrupamentos que apresentou a melhor qualidade de agrupamento nesse segundo conjunto de experimentos), enquanto a perda de qualidade de agrupamento variou apenas entre 0,6\% e 2,5\%.

Embora o algoritmo CLARA, inicializado com a melhor configuração recomendada, tenha apresentado a melhor eficiência computacional (em termos de número de cálculos de distância) em todos os testes realizados no segundo conjunto de experimentos, sua perda de qualidade de agrupamento foi de até 13,3\% quando comparado com o CLARANS, e de até 12,1\% quando comparado com a melhor configuração do PAM-SLIM-MO. Para melhorar a qualidade dos agrupamentos obtidos pelo CLARA, é necessário aumentar o número de amostras e/ou o número de objetos que compõem as amostras, o que causaria grande redução de sua eficiência.

\section{Experimento 3: Exploração de um Conjunto de Dados Real}

O último conjunto de experimentos utilizou um conjunto de dados adimensional do mundo real, MedHisto, com o objetivo de observar o comportamento do algoritmo PAM-SLIM em uma situação real. Nesses experimentos, foram solicitados 5, 10 e 15 medóides a partir dos 40.000 objetos do conjunto de dados MedHisto. Os tamanhos de página empregados para os algoritmos PAM-SLIM variaram de 8.192 a 32.768 bytes.

A Figura 6.4 apresenta a comparação de eficiência computacional ((a), (b) e (c)) e qualidade de agrupamento ((d), (e) e (f)) entre os algoritmos CLARANS, CLARA, PAM-SLIM-MD e PAM-SLIM-MO para esse conjunto de dados. A melhor qualidade de agrupamento obtida para o PAM-SLIM-MO foi quando se empregou o tamanho de página de 8.192 bytes, enquanto que para o PAM-SLIM-MD as melhores qualidades de agrupamento foram conseguidas considerando as configurações de tamanho de página de 16.384 e 32.768 bytes. Observando a melhor configuração para o PAM-SLIM-MO, a melhoria de eficiência variou de 7 a 13 vezes quando comparado com o CLARANS, enquanto a perda de qualidade de agrupamento variou de 2,8\% a 7,5\%. Para o PAMSLIM-MD, considerando dentre as configurações que obtiveram as melhores qualidades de agrupamento, aquela que resultou no menor número de cálculos de distância (tamanho de página de 32.768 bytes), a melhoria de eficiência computacional variou de 75 a 200 vezes quando comparado com o CLARANS, enquanto a perda de qualidade de agrupamento variou de $2,2 \%$ a $7,6 \%$.

É importante ressaltar que, a perda de qualidade de agrupamento apresentada pelos algoritmos PAM-SLIM nesse conjunto de experimentos, foi muito menor que a apresentada 
pelo algoritmo CLARA quando comparados com o CLARANS. A perda de qualidade de agrupamento apresentada pelo CLARA foi superior a 43,4\% quando comparado com o CLARANS e superior a 41,7\% quando comparado com a melhor configuração do PAMSLIM-MD.

(a) MedHisto - $5 k$

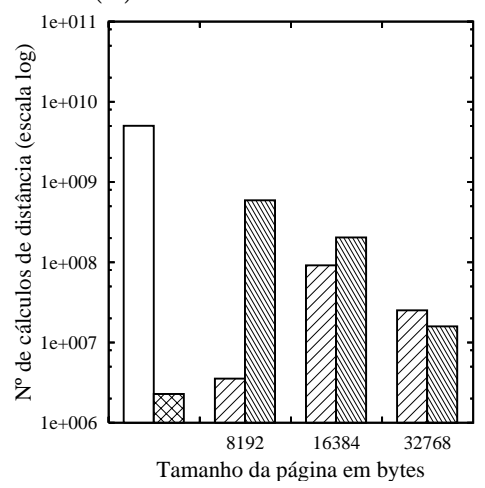

(d) MedHisto - $5 \mathrm{k}$

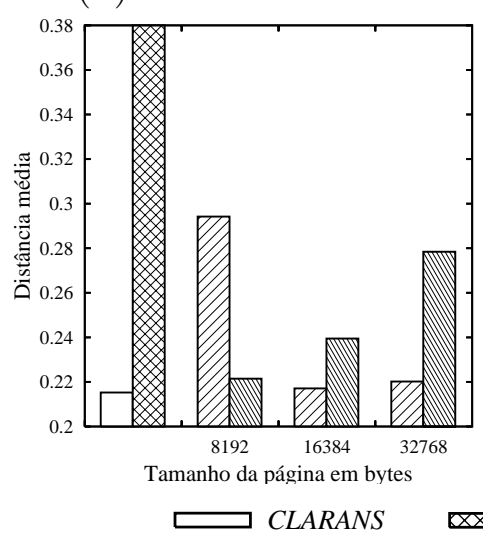

(b) MedHisto - $10 k$

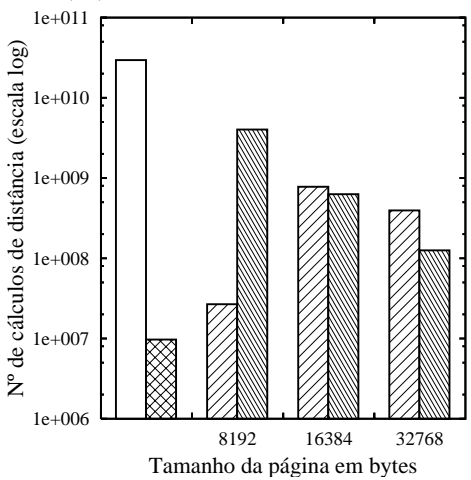

(e) MedHisto - $10 k$

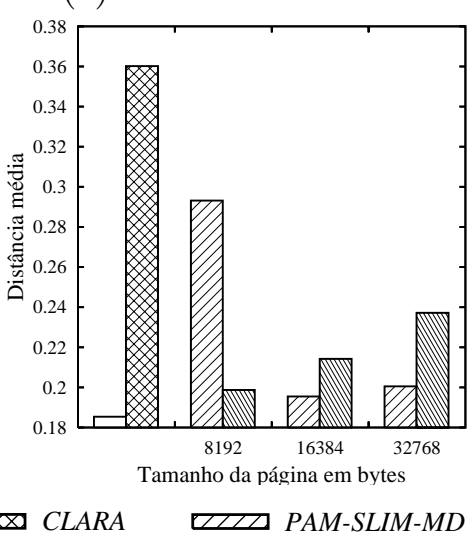

(c) MedHisto - $15 k$

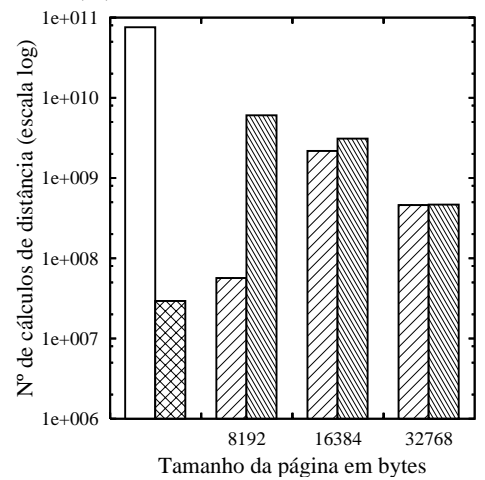

(f) MedHisto - $15 k$

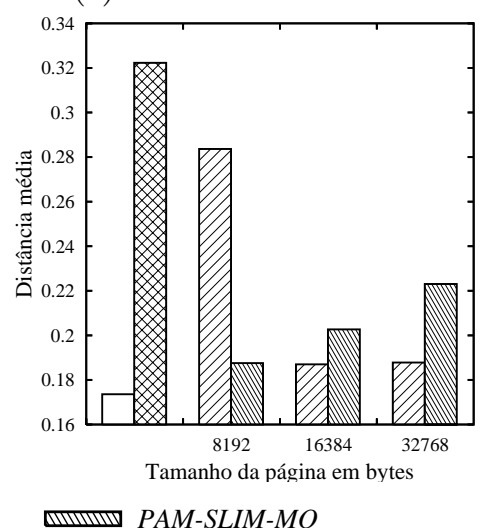

Figura 6.4: Comparação de eficiência computacional ((a), (b) e (c)) e qualidade de agrupamento ((d), (e) e (f)) entre PAM, CLARANS, CLARA, PAM-SLIM-MD e PAM-SLIM-MO para o conjunto de dados MedHisto.

\subsection{Considerações Finais}

Este capítulo apresentou todos os algoritmos desenvolvidos durante a realização do trabalho apresentado nesta tese, dando especial ênfase ao algoritmo PAM-SLIM que utiliza uma abordagem que emprega métodos de acesso métricos para otimizar os algoritmos de agrupamento baseados no método $k$-medoid. A qualidade de agrupamento produzida pelos algoritmos baseados no método $k$-medoid tradicionais depende da seleção inicial dos medóides. O algoritmo apresentado neste capítulo assume que árvores métricas tendem a escolher naturalmente medóides apropriados para compor seus nós representantes. Os experimentos realizados confirmam que essa suposição é realmente verdadeira. A estratégia adotada por esse algoritmo pode ser eficientemente aplicada para agrupar tanto conjuntos de dados multi-dimensionais quanto adimensionais. 
Os experimentos realizados mostraram que o algoritmo PAM-SLIM apresentou resultados adequados para várias configurações da Slim-tree, utilizando diferentes tamanhos de página e políticas de escolha de sub-árvore. Quando comparado com os algoritmos PAM e CLARANS, os algoritmos PAM-SLIM apresentaram qualidade de agrupamento comparáveis, oferecendo uma notável relação de custo-benefício entre eficiência computacional e qualidade de agrupamento. Quando comparado com o CLARA, o novo algoritmo também apresentou uma qualidade de agrupamento superior para todos os conjuntos de dados utilizados nos testes apresentados neste capítulo. Além disso, é importante notar que o algoritmo PAM-SLIM é executado sobre conjuntos de dados armazenados em disco, enquanto os outros algoritmos testados são executados apenas em memória principal. Dessa forma, a eficiência computacional apresentada pelo algoritmo PAM-SLIM permite a execução de algoritmos de detecção de agrupamentos em SGBD.

Com isso, existem algoritmos disponíveis para executar todas as operações de busca por similaridade em bases de dados, incluindo seleções por similaridade, seleções por similaridade de grupo, junções por similaridade e um algoritmo para busca de agrupamentos por similaridade, como um exemplo de algoritmo para a análise de dados baseada em similaridade. 


\section{Capítulo \\ 7 \\ Conclusão}

\subsection{Considerações Finais}

A realização de consultas por similaridade em grandes conjuntos de dados complexos tem atraído muita atenção de pesquisadores em diversas áreas, como Gerenciamento de Bases de Dados, Recuperação de Informação e Aprendizado de Máquina. Entretanto, embora os trabalhos realizados até o momento tenham focalizado tópicos específicos relacionados ao conceito geral de similaridade, não existe ainda uma linha de desenvolvimento capaz de unir esses vários esforços dispersos. A criação de um suporte para a realização de consultas por similaridade em SQL, permitindo a completa integração das consultas por similaridade com os demais recursos da linguagem, é uma forte razão para ser considerada uma linha mestra. O trabalho apresentado nesta tese contribui para o fornecimento desse suporte.

O suporte desenvolvido para consultas por similaridade é poderoso o suficiente para permitir muitas variações, incluindo seleções e junções por similaridade, assim como comparações por similaridade envolvendo grupos de objetos complexos e operações de análise e mineração de dados. Todos os tipos de consulta por similaridade podem ser aplicados sobre qualquer conjunto de objetos complexos para o qual seja possível definir uma medida de similaridade, incluindo grandes objetos monolíticos armazenados em atributos de tipo BLOB e objetos armazenados por um conjunto particulado de atributos.

Esse suporte também permite a especificação de extratores de características de objetos complexos na definição de métricas, o que torna possível a realização de operações de recuperação baseada em conteúdo. Nesta tese, foi apresentado, especificamente, como 
realizar a recuperação de imagens e áudio por conteúdo como exemplos representativos de objetos monolíticos. Também foram apresentados os resultados da utilização de um protótipo que implementa consultas por similaridade sobre imagens, áudio e dados particulados por meio da utilização do SGBD Oracle $10 \mathrm{~g}$.

Como linha de desenvolvimento para reunir diversas atividades de pesquisa, a solução para a representação de consultas por similaridade apresentada nesta tese também possui várias características interessantes. Primeiramente, permite a representação de consultas por similaridade como um novo tipo de predicado, levando à integração da similaridade como mais uma das operações da álgebra relacional. Essa característica irá possibilitar a extensão dos otimizadores dos SGBD relacionais, permitindo o tratamento e a otimização de consultas por similaridade.

Em segundo lugar, a solução apresentada nesta tese também pode se beneficiar de melhorias realizadas sobre técnicas de recuperação que tenham como meta a recuperação baseada em similaridade, como é o caso do desenvolvimento de estruturas de indexação para suportar a realização de consultas por similaridade. Essa característica pode também guiar o desenvolvimento de tais estruturas, já que ela determina os tipos de operações de recuperação que valem a pena otimizar.

Em terceiro e último lugar, a solução apresentada pode agir como um elemento de integração para o desenvolvimento de algoritmos que necessitem da realização de operações por similaridade, amplamente empregados em processos de análise de dados (i.e., técnicas de mineração de dados). Como um passo inicial nessa direção, o presente trabalho explora a otimização de algoritmos de detecção de agrupamentos de dados baseados no método $k$ medoid, integrando a realização desses algoritmos em SGBD por meio da definição de uma extensão da linguagem SQL que permite a especificação de consultas sobre o resultado de processos de detecção de agrupamentos.

\subsection{Principais Contribuições}

As contribuições proporcionadas por este trabalho de doutorado foram obtidas em duas vertentes principais: o fornecimento do suporte para a especificação de consultas por similaridade em SGBDR e o desenvolvimento de uma abordagem que explora a integração de técnicas de detecção de agrupamentos de dados em SGBD. Considerando essas duas vertentes, as principais contribuições do trabalho de doutorado apresentado nesta tese são sintetizadas nos itens apresentados a seguir.

1. Incorporação de consultas por similaridade na linguagem SQL:

- Definição dos predicados por similaridade correspondentes aos principais tipos de consultas por similaridade requeridas pelas aplicações que manipulam dados complexos, i.e., predicados que envolvem seleção por similari- 
dade, similaridade de grupo e junção por similaridade [Barioni et al., 2005b, Barioni et al., 2006b];

- Especificação da ordem de precedência dos operadores por similaridade [Barioni et al., 2005b];

- Criação do suporte para a incorporação de consultas por similaridade na linguagem SQL[Barioni et al., 2005b, Barioni et al., 2006b]:

- Definição de dois domínios de dados complexos, PARTICULATE e MONOLITHIC, para tratar a manipulação de conjuntos de dados com características distintas;

- Definição de construções sintáticas equivalentes para a realização de consultas por similaridade sobre objetos complexos pertencentes tanto ao domínio PARTICULATE quanto ao domínio MONOLITHIC;

- Criação de novos comandos para a definição de medidas de similaridade em SQL, permitindo que qualquer atributo definido nesses domínios possa utilizar essas métricas;

- Incorporação dos conceitos desenvolvidos neste trabalho na implementação da ferramenta SIREN [Barioni et al., 2005a, Barioni et al., 2006c]:

- Com o objetivo de fornecer meios para a validação dos diversos tipos de consultas por similaridade definidas na extensão da linguagem SQL proposta nesta tese, foi necessário implementar alguns métodos de consulta por similaridade não suportados pela Slim-tree, o MAM empregado na implementação do SIREN. Foram implementados, no método de acesso seqüencial disponível na Arboretum, métodos para a realização dos três tipos de operações de junção por similaridade e dos tipos de consulta por similaridade de grupo, considerando os padrões de agregação por similaridade SUM, MAX e ALL.

2. Incorporação de processos de detecção de agrupamentos de dados em SGBD:

- Desenvolvimento do algoritmo PAM-SLIM [Barioni et al., 2006a]. Para desenvolver novos algoritmos, em qualquer área, é importante primeiro entender, implementar, comparar e melhorar os algoritmos existentes. Assim, várias técnicas de agrupamento, baseadas no algoritmo $k$-medoid (i.e., os algoritmos PAM, CLARA e CLARANS), foram implementadas na biblioteca $\mathrm{C}++$ Arboretum e foi desenvolvida uma nova estratégia para otimizar o algoritmo PAM. Resultados experimentais, obtidos com a comparação da execução dos algoritmos implementados, demonstraram a viabilidade da utilização de MAM na otimização de processos de detecção de agrupamentos de dados baseados no 
método $k$-medoid. Os resultados obtidos pela execução do algoritmo PAMSLIM apresentaram um significativo aumento da eficiência computacional e uma notável relação custo benefício entre eficiência computacional e qualidade de agrupamento, tornando possível a execução desse tipo de algoritmos em SGBD.

- Definição de uma extensão da linguagem SQL para a especificação de consultas sobre o resultado de processos de detecção de agrupamentos de dados baseados no método $k$-medoid.

\subsection{Propostas para Trabalhos Futuros}

O trabalho apresentado nesta tese de doutorado abre a perspectiva de que novas pesquisas possam vir a ser desenvolvidas. Dentre elas é possível mencionar:

- Desenvolvimento de algoritmos para a realização de operações por similaridade de grupo em MAM;

- Análise do processamento necessário nos SGBD para a incorporação da extensão da linguagem SQL, definida para a realização de consultas sobre o resultado de processos de detecção de agrupamentos de dados, implementando-a no protótipo SIREN;

- Exploração da abordagem adotada nesta tese, para a otimização de algoritmos de detecção de agrupamentos de dados baseados no método $k$-medoid, na otimização de outros tipos de algoritmos de detecção de agrupamentos;

- Exploração de outros tipos de técnicas de mineração de dados cujas operações básicas estejam relacionadas à realização de cálculos de medidas de similaridade;

- Exploração de métodos de representação de documentos textuais e de funções de distância utilizadas para a realização de comparações por similaridade entre documentos visando à incorporação dessas técnicas tanto na linguagem, quanto no protótipo apresentado nesta tese;

- Exploração de métodos de representação e de funções de distância para outros tipos de objetos complexos tanto em domínios genéricos (como vídeo, data streams, dados multi-dimensionais, etc.) quanto específicos (como faces humanas, impressões digitais, seqüências genéticas, etc.);

- Definição de uma interface de plugins para a incorporação de novos extratores de características e de novas funções de distância; 
- Utilização dos conceitos e da extensão da linguagem SQL, definidos nesta tese, para o desenvolvimento de estratégias para a incorporação de realimentação de relevância em SGBD;

- Incorporação de estratégias, que permitam a otimização de consultas que considerem a utilização dos operadores de seleção e junção por similaridade, no módulo de otimização de consultas dos SGBDR;

- Incorporação dos conceitos abordados nesta tese em um SGBDR;

- Integração da funcionalidade de busca por similaridade em dados multimídia, proposta nesta tese, com a proposta de padronização de operações sobre dados multimídia SQL/MM. 


\section{Apêndice \\ $A$ \\ Extensão da Linguagem SQL}

Este apêndice apresenta em detalhes a sintaxe da extensão desenvolvida neste trabalho para suportar consultas por similaridade em SQL. Para a apresentação dessa sintaxe utiliza-se a notação BNF, na qual [ ] significa uma escolha entre termos opcionais, e \{ \} significa a escolha obrigatória de um dos termos. Os tipos de dados complexos podem ser PARTICULATE ou um dos tipos pertencentes ao domínio MONOLITHIC. Neste apêndice são considerados apenas os tipos de dados STILLIMAGE e AUDIO, como exemplos representativos do domínio MONOLITHIC, pois a utilização desses tipos de dados já foi explorada na implementação do protótipo SIREN. Entretanto, outros tipos de dados pertencentes a esse domínio podem compartilhar a mesma sintaxe. Com relação aos comandos da DDL, apenas a sintaxe para os comandos CREATE é apresentada, já que as construções correspondentes para os comandos ALTER e DROP seguem a mesma estrutura.

\section{A.1 O Comando CREATE METRIC}

A sintaxe para a definição de uma métrica (i.e., uma medida de similaridade) é a seguinte:

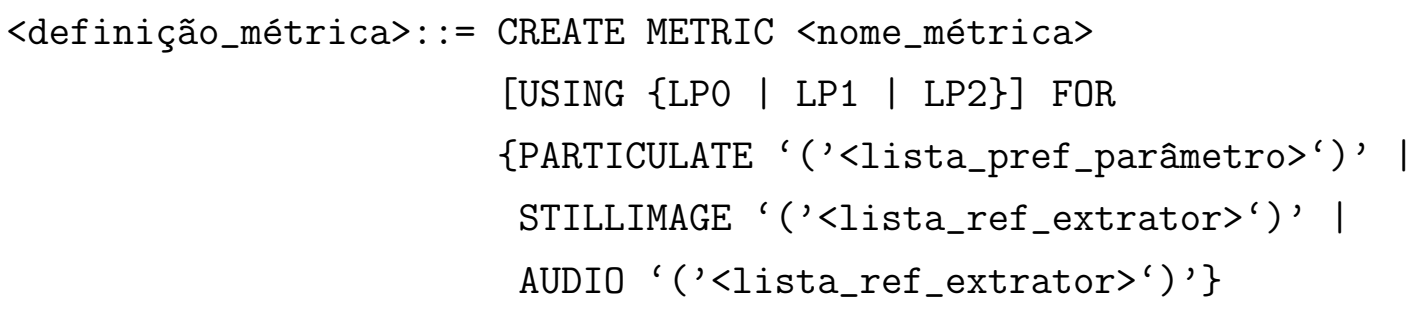




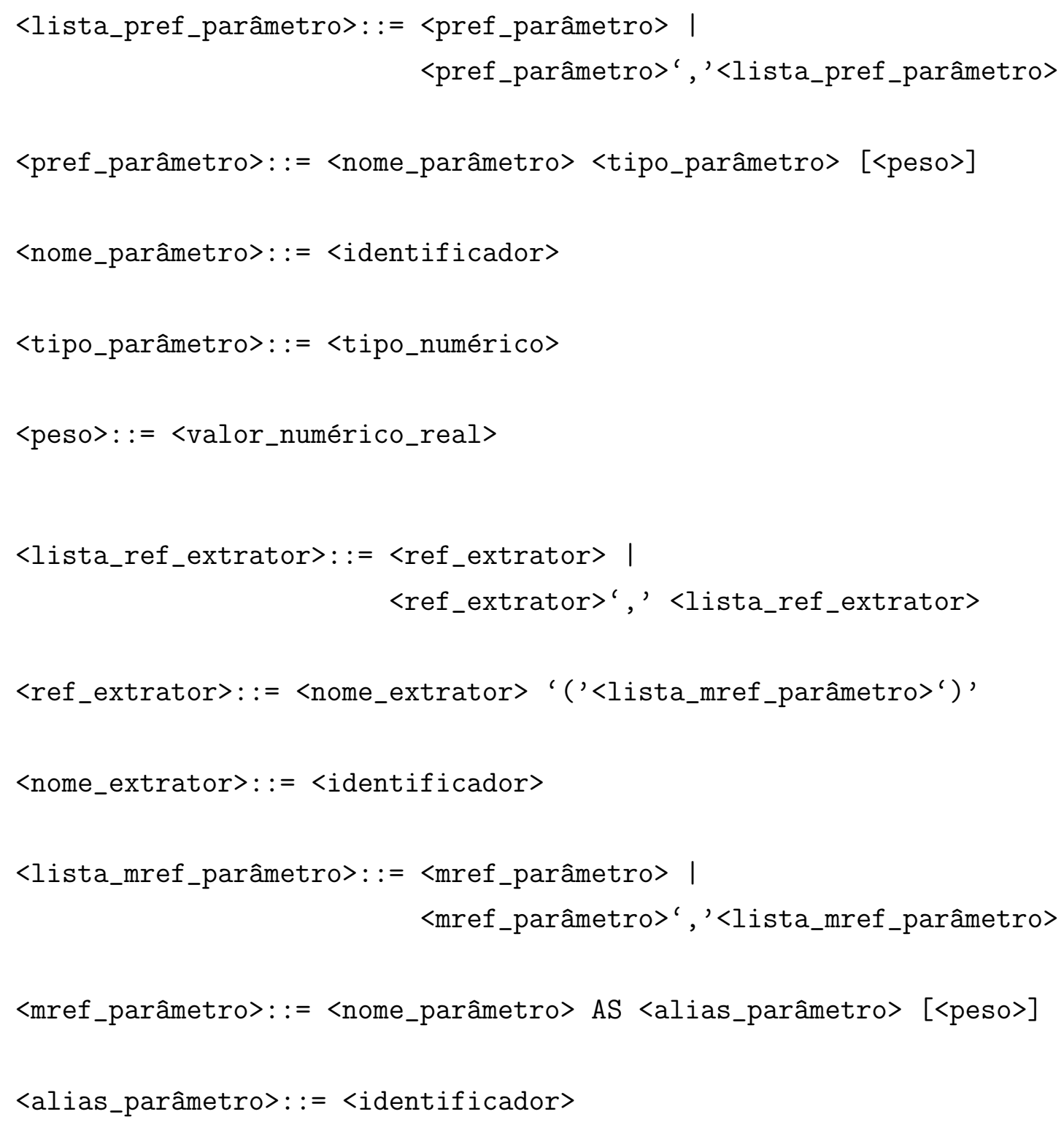

\section{A.1.1 Especificando Métricas como Restrições de Coluna no Co- mando CREATE TABLE}

A restrição METRIC pode ser associada tanto com atributos pertencentes ao domínio MONOLITHIC, representados no trabalho apresentado nesta tese pelos tipos de dados STILLIMAGE e AUDIO, quanto com atributos pertencentes ao domínio PARTICULATE. A sintaxe utilizada para especificar essa restrição como uma restrição de coluna é a seguinte:

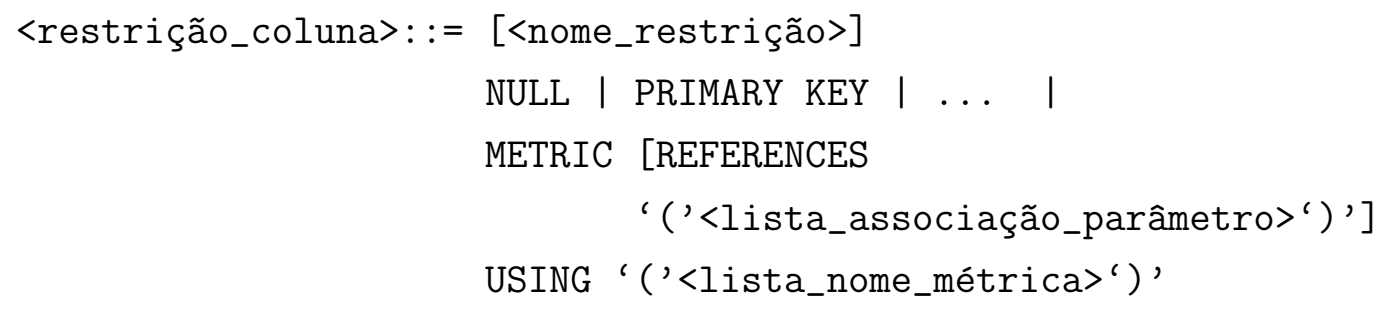




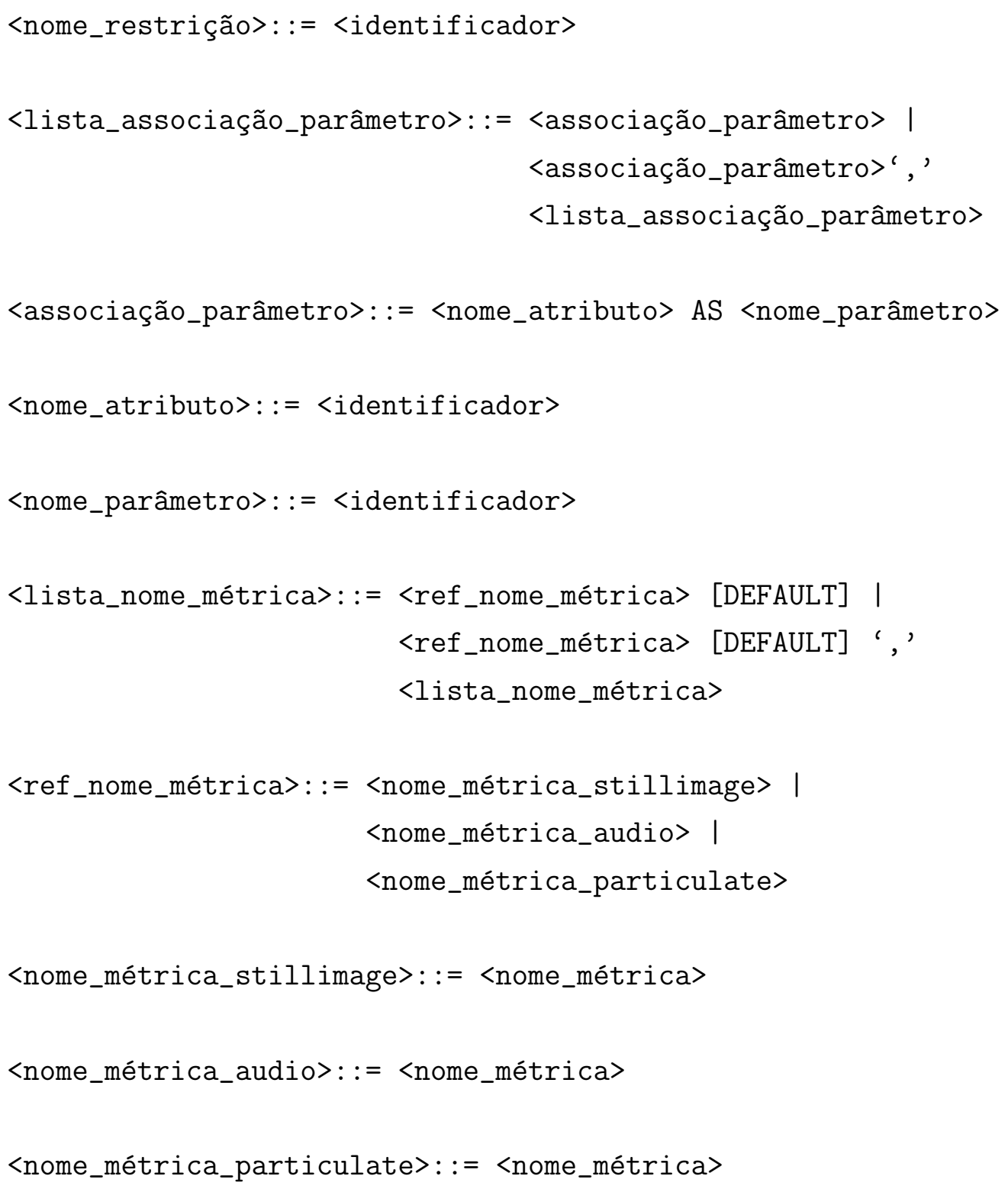

A cláusula opcional REFERENCES '('<lista_associação_parâmetro>') é utilizada na definição de restrições de coluna somente para atributos do tipo PARTICULATE. Os atributos de tipos complexos que não forem associados a uma métrica não podem ser utilizados em predicados por similaridade. Se um atributo de tipo complexo for associado a duas ou mais métricas, então é necessário especificar uma métrica padrão, utilizando a palavra reservada DEFAULT. Uma métrica pode ser associada a qualquer número de atributos complexos desde que ambos, atributo e métrica, sejam definidos sobre o mesmo domínio de dados complexos, ou seja, STILLIMAGE, AUDIO ou PARTICULATE.

\section{A.1.2 Especificando Métricas como Restrições de Tabela no Co- mando CREATE TABLE}

A sintaxe empregada para associar uma métrica com um atributo de tipo complexo como uma restrição de tabela é a seguinte: 


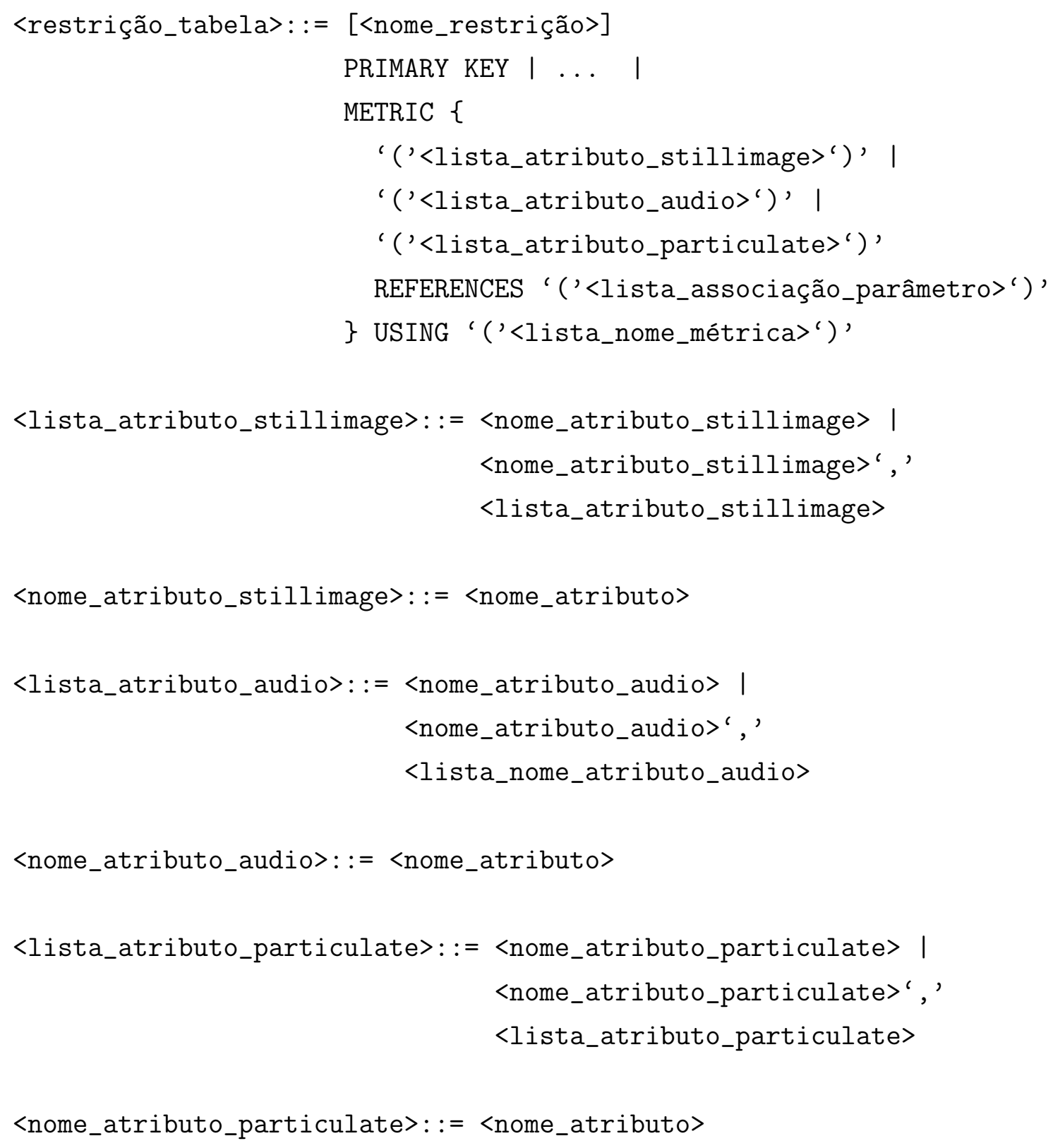

\section{A.2 CREATE INDEX para Dados Complexos}

As construções sintáticas empregadas no comando CREATE INDEX para a especificação de índices sobre atributos de domínios complexos são apresentadas a seguir:

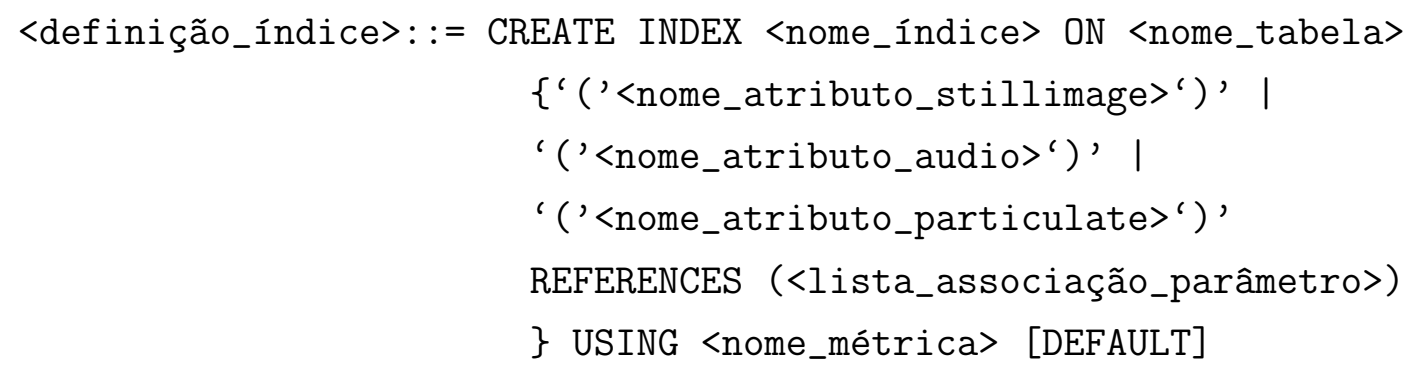


$\langle$ nome_indice $>:$ : $<$ identificador $>$

$\langle$ nome_tabela $>:=\langle$ identificador $>$

\section{A.3 Especificando Consultas por Similaridade no Co- mando SELECT}

O comando SELECT foi estendido com uma nova construção para a especificação de predicados por similaridade na cláusula WHERE e outra para a especificação de junções por similaridade na cláusula FROM.

\section{A.3.1 Predicados por Similaridade na Cláusula WHERE}

As seleções por similaridade são expressas como predicados na cláusula WHERE. Já as junções por similaridade podem ser expressas tanto como predicados na cláusula WHERE quanto na cláusula FROM.

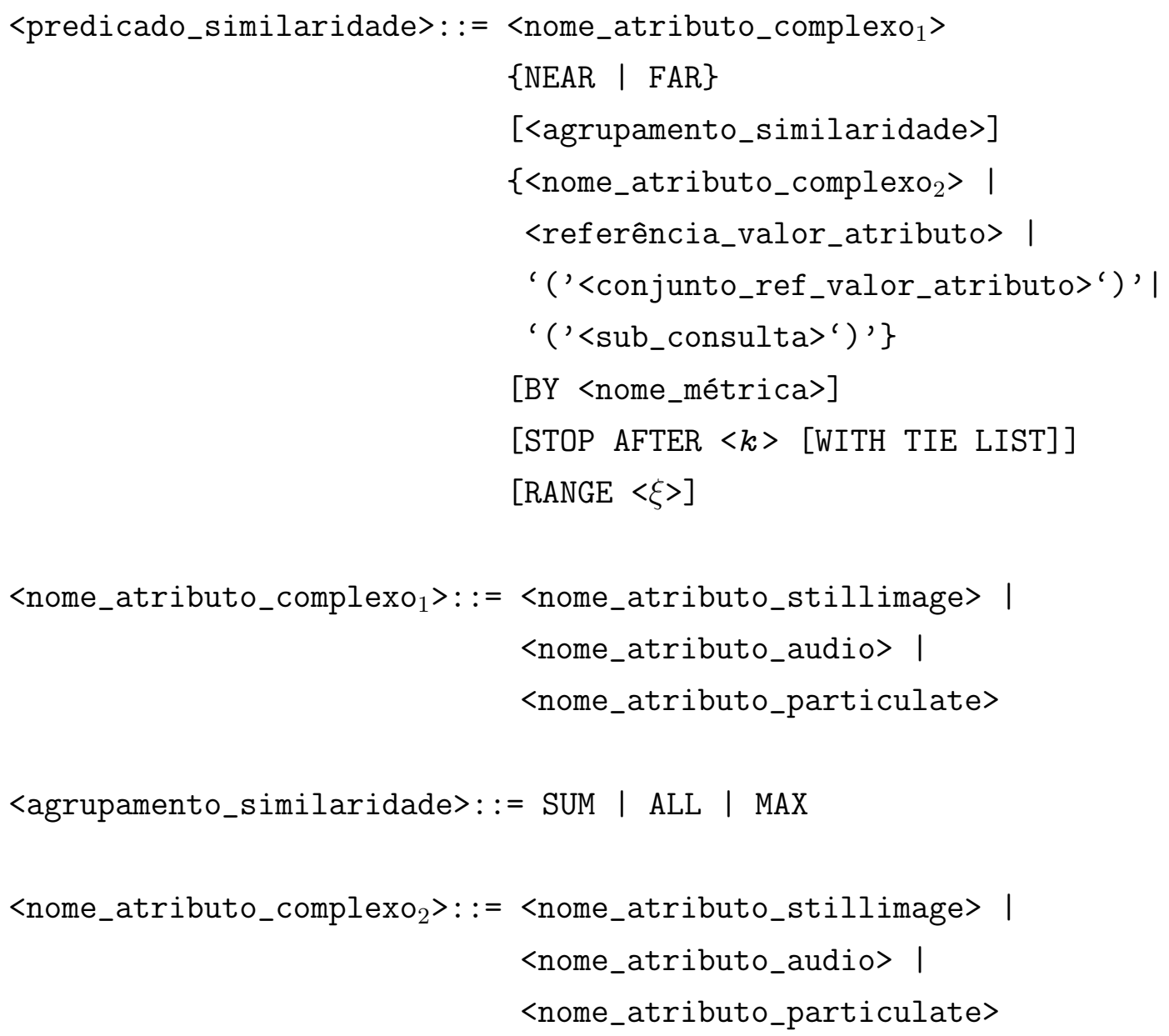




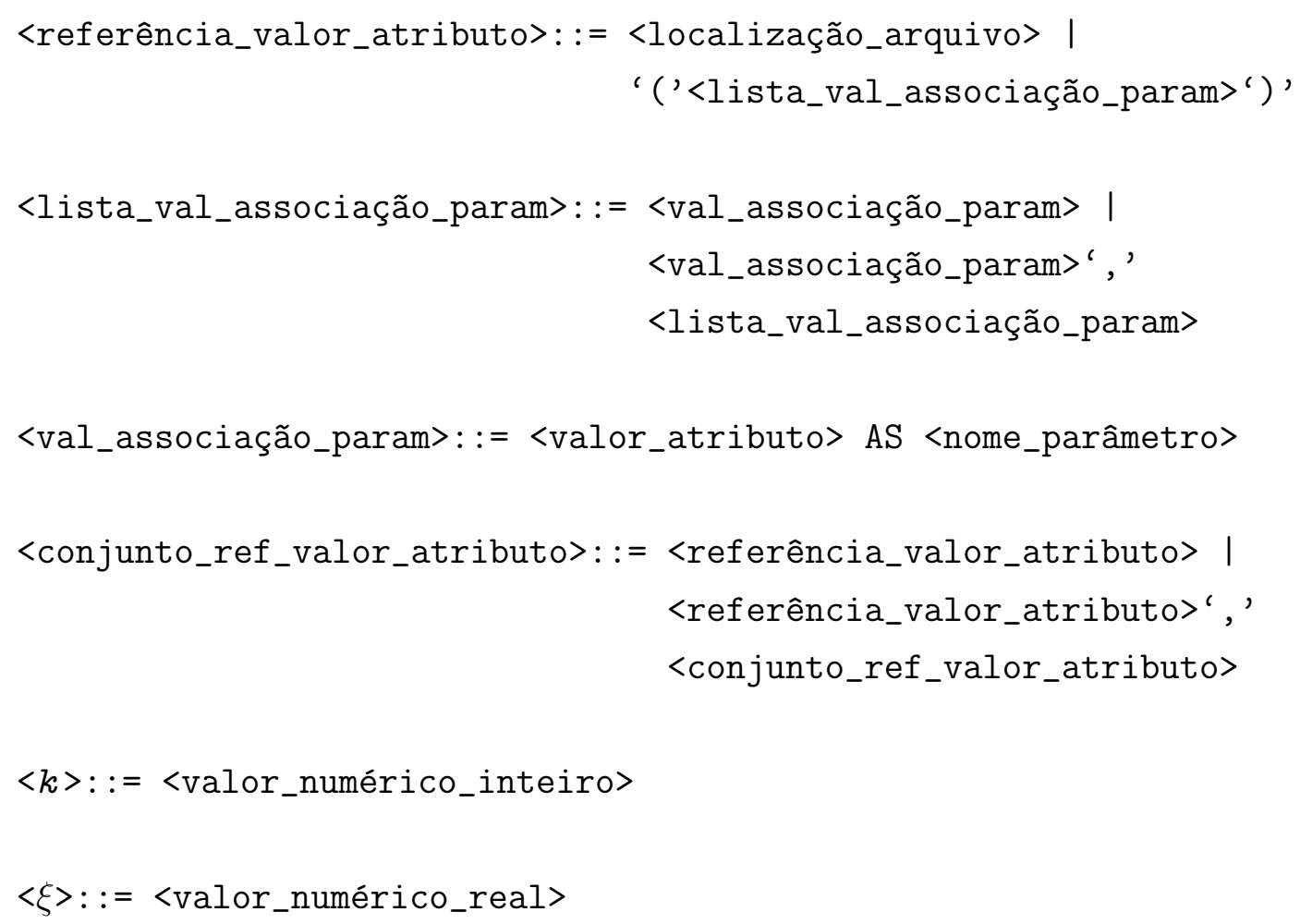

$\mathrm{O}<$ nome_atributo_complexo $_{1}$ > especifica o atributo a ser pesquisado nos predicados de comparação por similaridade. Ele pode ser comparado com:

- Um valor constante especificado pela <referência_valor_atributo>;

- Um conjunto de valores constantes especificados pelo '('<conjunto_ref_valor_atributo>')';

- Um ou mais valores constantes retornados por uma subconsulta;

- Outro atributo de qualquer tabela da base de dados.

Se o atributo <nome_atributo_complexo $>$ > é do tipo STILLIMAGE/AUDIO e for comparado com um valor constante, a constante corresponde a uma imagem/trilha de áudio expressa como um caminho no sistema de arquivos no qual a imagem/áudio está armazenada(o) como, por exemplo 'c:/imagens/img.jpg'. Se o atributo <nome_atributo_complexo $>$ é do tipo PARTICULATE, a constante é expressa pela lista '('<lista_val_associação_param >')'.

A comparação do atributo <nome_atributo_complexo $>$ com uma constante ou com um conjunto de constantes representa operações de seleção por similaridade, em que:

- A construção <nome_atributo_complexo $>$ > NEAR|FAR <referência_valor_atributo> pode representar tanto uma consulta por abrangência quanto uma consulta aos $k$-vizinhos mais próximos; 
- A construção <nome_atributo_complexo ${ }_{1}>$ NEAR|FAR '('<conjunto_ref_valor_atributo>')' representa uma consulta por similaridade de grupo.

Já a comparação do atributo com outro atributo pertencente ao mesmo domínio representa operações de junção por similaridade, em que:

- A construção <nome_atributo_complexo $>$ > NEAR|FAR <nome_atributo_com$\mathrm{plexo}_{2}>$ STOP AFTER $k$ representa uma junção pelos $k$-vizinhos mais próximos;

- A construção <nome_atributo_complexo $>$ > NEAR|FAR ANY <nome_atributo_complexo $2>$ STOP AFTER $k$ representa uma junção dos $k$-pares de vizinhos mais próximos;

- A construção <nome_atributo_complexo $>$ > NEAR|FAR <nome_atributo_complexo ${ }_{2}>\operatorname{RANGE} \xi$ representa uma junção por abrangência.

Considerando as construções sintáticas apresentadas nesta seção, foram definidas diretrizes para algumas situações específicas:

- A especificação de ambas cláusulas STOP AFTER e RANGE requer a consideração de ambos limites, $k$ e $\xi$, na execução do comando. Caso contrário, se nenhuma dessas cláusulas for especificada, considera-se a realização de RANGE 0 ;

- Se a cláusula <agrupamento_similaridade> for omitida em uma consulta por similaridade que especifique mais de um objeto de consulta, considera-se a utilização do método de agregação SuM;

- Se a cláusula BY for omitida, considera-se a utilização da métrica padrão;

- Se a opção WITH TIE LIST for omitida na cláusula STOP AFTER, nenhuma lista de empate é considerada.

\section{A.3.2 Junções por Similaridade na Cláusula FROM}

A sintaxe empregada para expressar junções por similaridade na cláusula FROM é a seguinte:

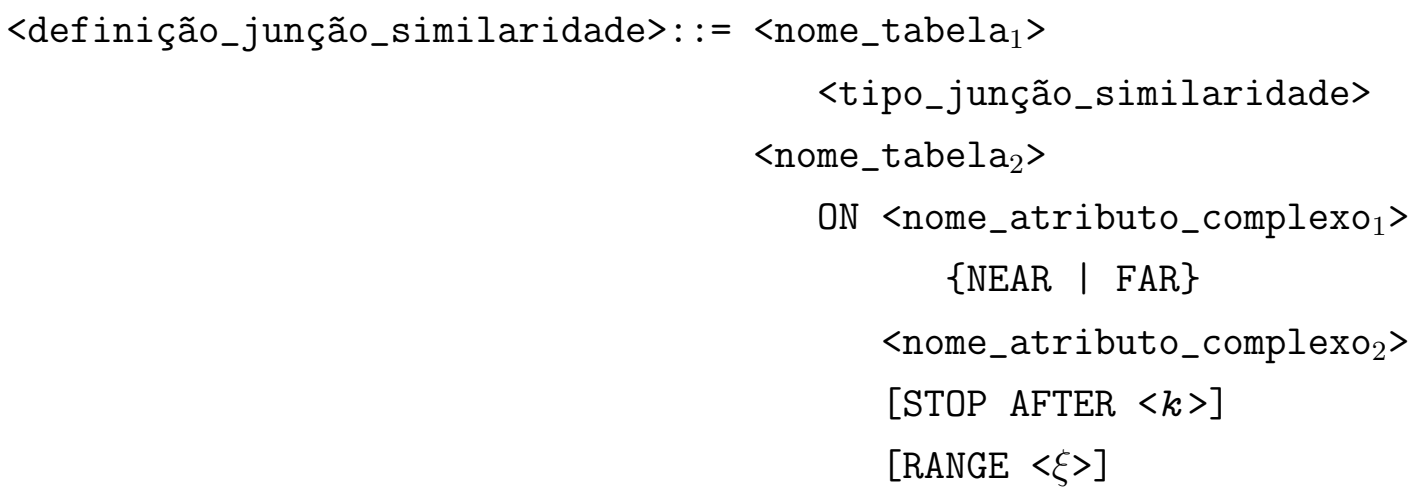


<tipo_junção_similaridade>: := \{CLOSEST | NEAREST | RANGE\} JOIN

Se as junções CLOSEST JOIN ou NEAREST JOIN forem especificadas e a cláusula STOP AFTER for omitida, então considera-se $k=1$. Se a junção RANGE JOIN for especificada e a cláusula RANGE for omitida, então considera-se $\xi=0$, retornando os objetos que ocorrem nas duas tabelas.

\section{A.4 Especificando Operações de Detecção de Agru- pamentos de Dados em SQL}

Para a parametrização do processo de detecção de agrupamentos de dados foi definida a seguinte construção sintática:

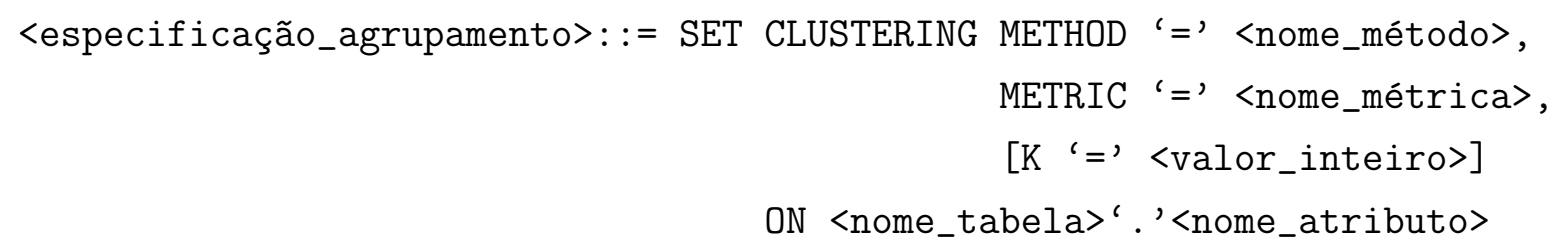

$\langle$ nome_método $>:$ : <identificador $>$

Nessa construção, os parâmetros METHOD '=' <nome_método> e METRIC '=' <nome_métrica> são obrigatórios para qualquer tipo de processo de agrupamento, enquanto o parâmetro K '=' <valor_inteiro> é obrigatório para os processos de detecção de agrupamentos baseados em métodos de particionamento (como os métodos PAM, CLARA, CLARANS e PAM-SLIM). Para se referir aos resultados de processos de detecção de agrupamentos de dados, sobre um determinado atributo complexo, em comandos SELECT foram definidas as seguintes construções sintáticas:

CLUSTERING '('<nome_tabela> '. '<nome_atributo>')'

CLUSTER '( '<nome_tabela>' . '<nome_atributo>')'

Essas construções são utilizadas como referências a tabelas na cláusula FROM de comandos SELECT e correspondem à especificação de table functions [Eisenberg et al., 2003]. A primeira construção foi definida para permitir o acesso às informações de cada agrupamento resultante. Já a segunda, foi definida para permitir o acesso às informações relativas a associação de cada objeto do conjunto de dados ao agrupamento a que ele pertence. 


\section{A.5 Outras Construções}

As características extraídas dos dados pertencentes ao domínio MONOLITHIC podem ser utilizadas em comandos SQL, em qualquer construção sintática em que seja possível fazer uma referência a um atributo, por meio da utilização da seguinte sintaxe:

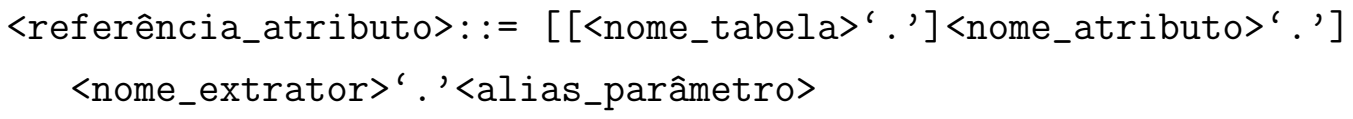

A distância entre o objeto de consulta e o objeto da resposta da consulta pode ser retornada em comandos que envolvam seleções por similaridade, desde que exista apenas um predicado por similaridade no comando. Esse valor pode ser requisitado em comandos SQL, sempre que for possível fazer uma referência a uma atributo, utilizando a seguinte sintaxe:

<referência_atributo>: := <nome_extrator>()

Para as seleções por similaridade que envolvam mais de um objeto de consulta, essa construção retorna a distância agregada utilizada para selecionar cada tupla, i.e.: a soma das distâncias do objeto ao conjunto de objetos de consulta para o SUM; a raiz quadrada da soma dos quadrados das distâncias para o ALL; e a menor das maiores distâncias obtidas entre o objeto e os objetos de consulta para o MAX. Para as junções por similaridade, essa construção retorna a distância entre cada objeto do par retornado.

Também existem construções definidas para permitir: listar extratores, métricas e índices disponíveis para dados complexos; e descrever tabelas, métricas e índices que sejam definidos para ou armazem dados complexos. A sintaxe de cada uma dessas construções é apresentada abaixo:

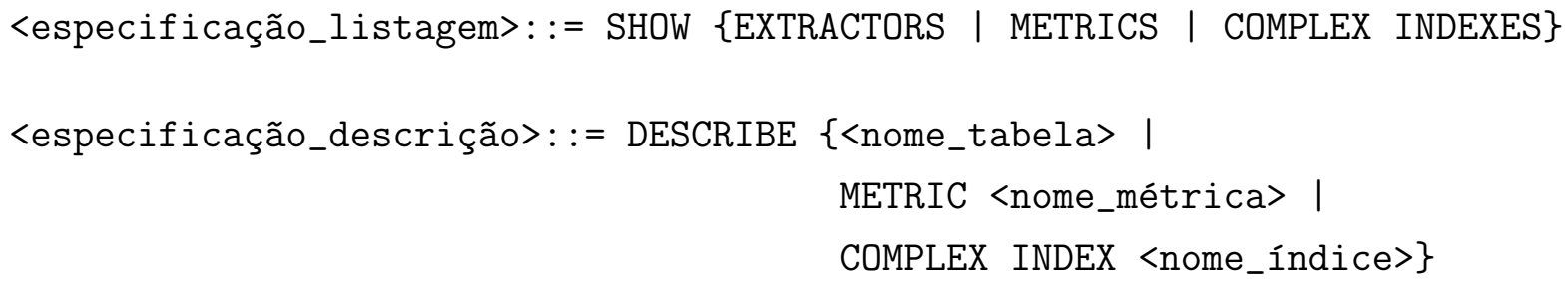




\section{Apêndice \\ $B$ \\ Conjuntos de Dados}

Este apêndice descreve os conjuntos de dados reais utilizados nos comandos SQL empregados na ilustração das construções sintáticas apresentadas nesta tese.

\section{B.1 CidadeBR}

O conjunto de dados CidadeBR contém 5.507 tuplas contendo informações a respeito das posições geográficas das cidades brasileiras [IBGE, 2006]. A Tabela B.1 apresenta os atributos que compõem cada tupla desse conjunto. A medida de similaridade empregada na realização de consultas sobre esse conjunto de dados é a distância entre as cidades, calculada a partir da aplicação da função de distância Euclidiana $\left(L_{2}\right)$ sobre suas coordenadas.

\begin{tabular}{lll}
\hline \hline Atributo & Tipo & Descrição \\
\hline \hline Nome & Cadeia de caracteres & Nome da cidade-UF \\
Lat & Numérico & Latitude \\
Longit & Numérico & Longitude \\
Coordenada & Complexo & Posição geográfica da cidade \\
\hline
\end{tabular}

Tabela B.1: Descrição dos atributos do conjunto de dados CidadeBR.

\section{B.2 Autos}

O conjunto de dados Autos é formado pelo resumo dos testes realizados pela revista Quatro Rodas, entre maio de 2001 e junho de 2005, com 140 carros de vários fabricantes 
[Revista Quatro Rodas, 2005]. Cada tupla desse conjunto possui o resultado da avaliação de vários ítens. A Tabela B.2 apresenta a lista dos ítens avaliados. Consultas por similaridade podem ser empregadas para explorar esse conjunto de dados em diversas questões como, por exemplo, a relação custo/benefício, considerando itens como potência, volume do porta malas e consumo urbano.

\begin{tabular}{lll}
\hline \hline Atributo & Tipo & Descrição \\
\hline \hline Nome & Cadeia de caracteres & Nome do modelo do carro \\
Fabricante & Cadeia de caracteres & Nome do fabricante do carro \\
Cilindros & Numérico & Número de cilindros \\
Potência & Numérico & Potência em cavalos \\
Aceleração & Numérico & Aceleração de 0 a $100 \mathrm{~km} / \mathrm{h} \mathrm{em} \mathrm{segundos}$ \\
Retomada & Numérico & Retomada de 40 a $80 \mathrm{~km} / \mathrm{h}$ em segundos \\
Velocmax & Numérico & Velocidade máxima em km $/ \mathrm{h}$ \\
Frenagem & Numérico & Frenagem de 80 a $0 \mathrm{~km} / \mathrm{h} \mathrm{em} \mathrm{metros}$ \\
Ruidointerno & Numérico & Ruído interno em dB \\
Portamalas & Numérico & Volume do porta malas em litros \\
Consumourb & Numérico & Consumo urbano em km/l \\
Carro & Complexo & Identifica um automóvel \\
\hline
\end{tabular}

Tabela B.2: Descrição dos atributos do conjunto de dados Autos.

\section{B.3 Exame}

O conjunto de dados Exame é formado por 800 imagens de exames de tomografia computadorizada (CT) divididas em quatro classes com 200 imagens cada: crânio axial, crânio coronal, crânio sagital e espinha sagital. Essas imagens podem ser consultadas de várias maneiras. Elas podem ser comparadas, por exemplo, pela similaridade da distribuição de suas cores ou de suas texturas. Os atributos desse conjunto são apresentados na Tabela B.3.

\begin{tabular}{lll}
\hline \hline Atributo & Tipo & Descrição \\
\hline \hline Idexame & Numérico & Identificador da imagem \\
Imagem & Complexo & Imagem do exame \\
Corte & Cadeia de caracteres & Classe da imagem \\
\hline
\end{tabular}

Tabela B.3: Descrição dos atributos do conjunto de dados Exame.

\section{B.4 BRPolitico e OrientacaoPartido}

O conjunto de dados BRPolitico é composto pelos votos de deputados federais brasileiros em questões discutidas na Câmara dos Deputados. Cada tupla desse conjunto corresponde 
aos votos de um dos 509 deputados que estavam presentes em sete votações, sendo que os atributos que representam cada uma das questões votadas possuem valor igual a 10 (favorável), 1 (obstrução), zero (abstenção), -1 (ausente) ou -10 (contrário). Já o conjunto de dados OrientacaoPartido é composto por 15 tuplas que representam o voto que cada partido político requisitou de seus membros em cada questão votada. Esses dois conjuntos de dados foram obtidos a partir dos resultados de votações realizadas por deputados federais brasileiros entre fevereiro e março de 2005 e disponíveis no web-site da Câmara dos Deputados [Câmara dos Deputados, 2006]. Para esses conjuntos de dados, a medida de similaridade entre os sete atributos de votação pode ser obtida por meio de uma métrica que empregue a função de distância $L_{1}$ (Manhattan). Os atributos que compõem cada um desses conjuntos são apresentados nas Tabelas B.4 e B.5.

\begin{tabular}{lll}
\hline \hline Atributo & Tipo & Descrição \\
\hline \hline Deputado & Cadeia de caracteres & Nome do deputado \\
Partido & Cadeia de caracteres & Nome do partido político \\
V1 & Numérico & Votação 1 \\
V2 & Numérico & Votação 2 \\
V3 & Numérico & Votação 3 \\
V4 & Numérico & Votação 4 \\
V5 & Numérico & Votação 5 \\
V6 & Numérico & Votação 6 \\
V7 & Numérico & Votação 7 \\
Votacoes & Complexo & Várias votações \\
\hline
\end{tabular}

Tabela B.4: Descrição dos atributos do conjunto de dados BRPolitico.

\begin{tabular}{lll}
\hline \hline Atributo & Tipo & Descrição \\
\hline \hline Partido & Cadeia de caracteres & Nome do partido político \\
V1 & Numérico & Orientação para a votação 1 \\
V2 & Numérico & Orientação para a votação 2 \\
V3 & Numérico & Orientação para a votação 3 \\
V4 & Numérico & Orientação para a votação 4 \\
V5 & Numérico & Orientação para a votação 5 \\
V6 & Numérico & Orientação para a votação 6 \\
V7 & Numérico & Orientação para a votação 7 \\
Votacoes & Complexo & Várias votações \\
\hline
\end{tabular}

Tabela B.5: Descrição dos atributos do conjunto de dados OrientacaoPartido.

\section{B.5 Musica}

O conjunto de dados Musica corresponde a uma coleção de 196 arquivos MP3 de diversos gêneros musicais divididos em seis classes: (19) "PopRockBrasileiro", (52) "MPB", (50) 
"PianoClassico", (65) "NewAge" e (10) "PunkRock". Os atributos desse conjunto de dados são descritos na Tabela B.6. As medidas de similaridade utilizadas para consultar esse conjunto de dados são baseadas nos dois tipos de características de textura do som disponíveis no SIREN.

\begin{tabular}{lll}
\hline \hline Atributo & Tipo & Descrição \\
\hline \hline Id & Numérico & Identificador do arquivo Mp3 \\
Titulo & Cadeia de caracteres & Título da música \\
Genero & Cadeia de caracteres & Gênero musical \\
Mp3 & Complexo & Arquivo Mp3 \\
\hline
\end{tabular}

Tabela B.6: Descrição dos atributos do conjunto de dados Musica. 


\section{Apêndice

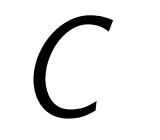 \\ Dicionário de Dados do SIREN}

Este apêndice descreve a estrutura do dicionário de dados do SIREN. A Seção C.1 apresenta o diagrama Entidade-Relacionamento do dicionário de dados e a Seção C.2 apresenta o Modelo Relacional correspondente.

\section{C.1 Diagrama Entidade-Relacionamento}

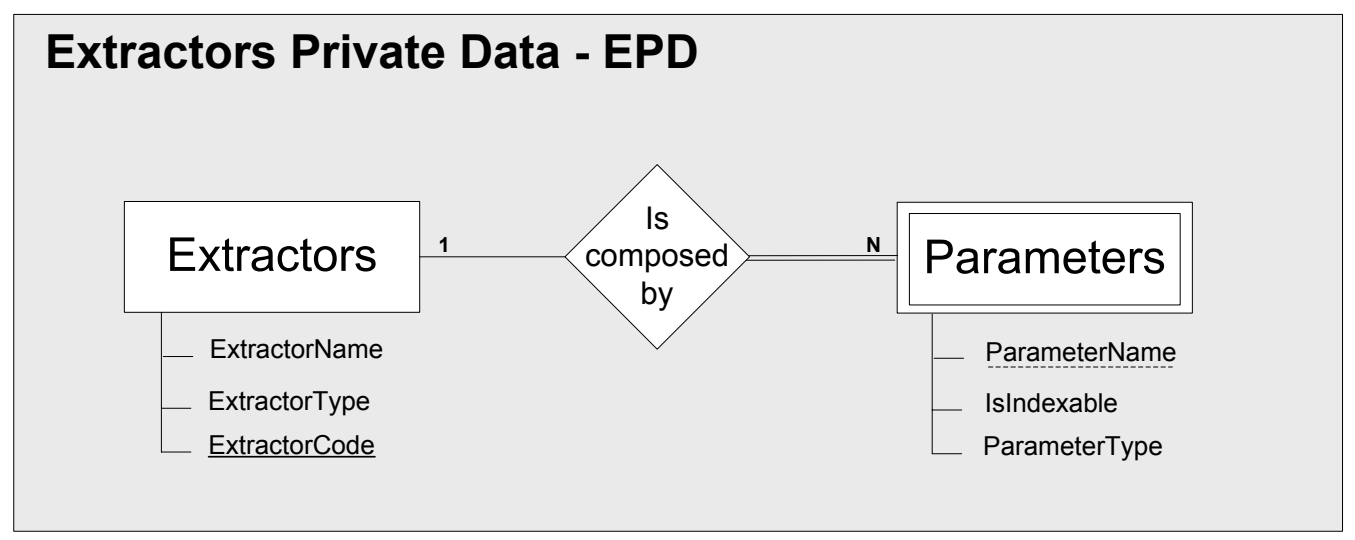

Figura C.1: Diagrama Entidade-Relacionamento dos extratores de características disponíveis no SIREN.

O dicionário de dados do SIREN armazena informações referentes aos extratores de características disponíveis (Extractors Private Data - EPD) e a definição da estrutura de como os dados complexos são manipulados pelas aplicações (Complex Data Definition CDD). A Figura C.1 apresenta o modelo que representa a estrutura de como as informações 
relacionadas aos extratores de características são armazenadas pelo SIREN. Esse modelo de dados informa que um extrator de características pode disponibilizar $n$ parâmetros, indexáveis ou não.

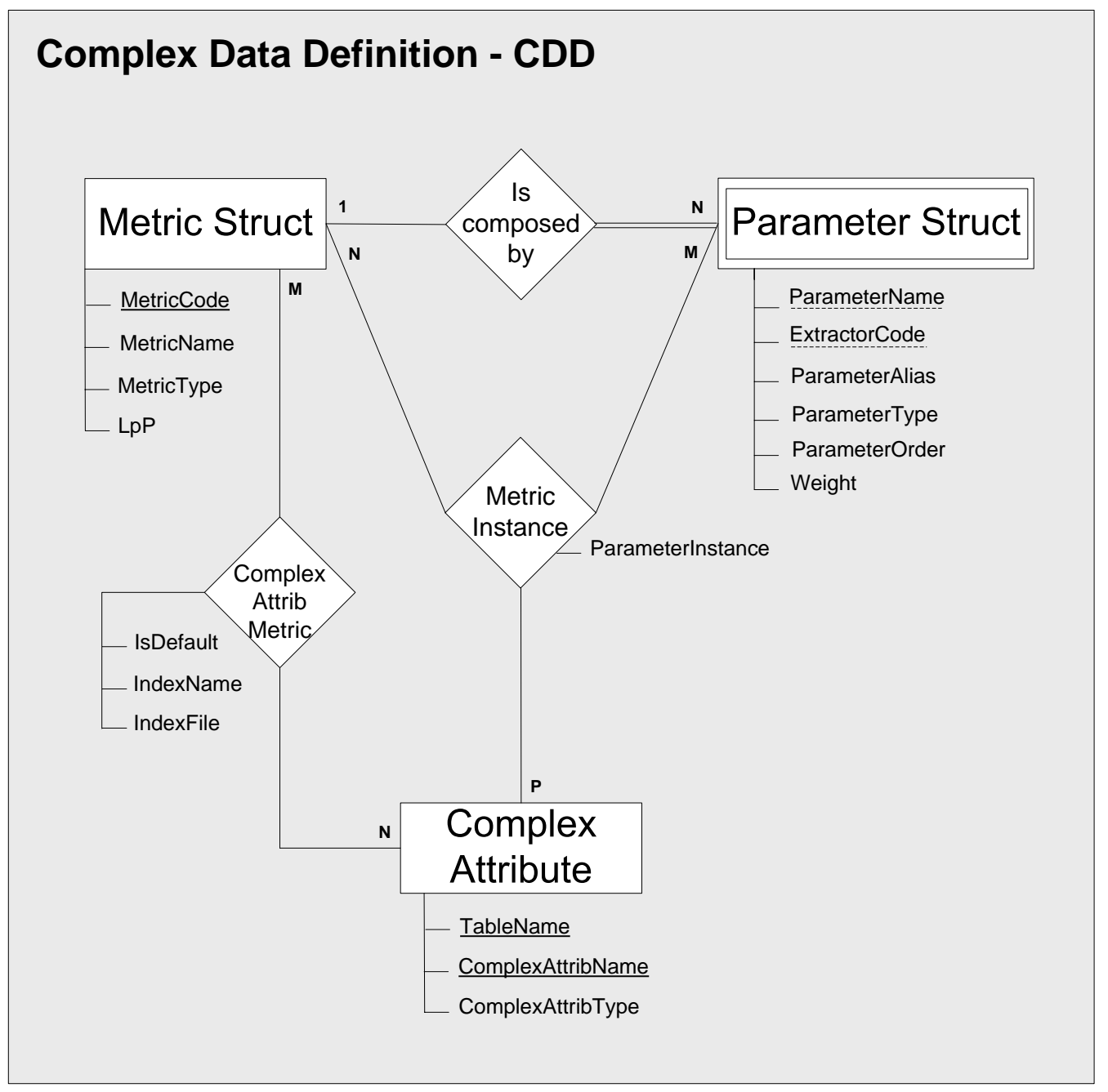

Figura C.2: Diagrama Entidade-Relacionamento da definição dos dados complexos no SIREN.

Já a Figura C.2 apresenta o diagrama do Modelo Entidade-Relacionamento que representa a definição dos dados complexos no SIREN. Nesse modelo, a entidade MetricStruct representa as métricas definidas pelos usuários, a entidade ParameterStruct representa os parâmetros disponíveis em uma métrica e a entidade ComplexAttribute representa os atributos complexos (PARTICULATE, AUDIO ou STILLIMAGE) definidos pelos usuários. O relacionamento ComplexAttribMetric representa a associação de uma métrica a um atributo complexo e o relacionamento MetricInstance representa cada instância de uma métrica. 


\section{C.2 Modelo Relacional}

A Figura C.3 apresenta a transformação dos Modelos Entidade-Relacionamento apresentados na seção anterior para o Modelo Relacional de dados.

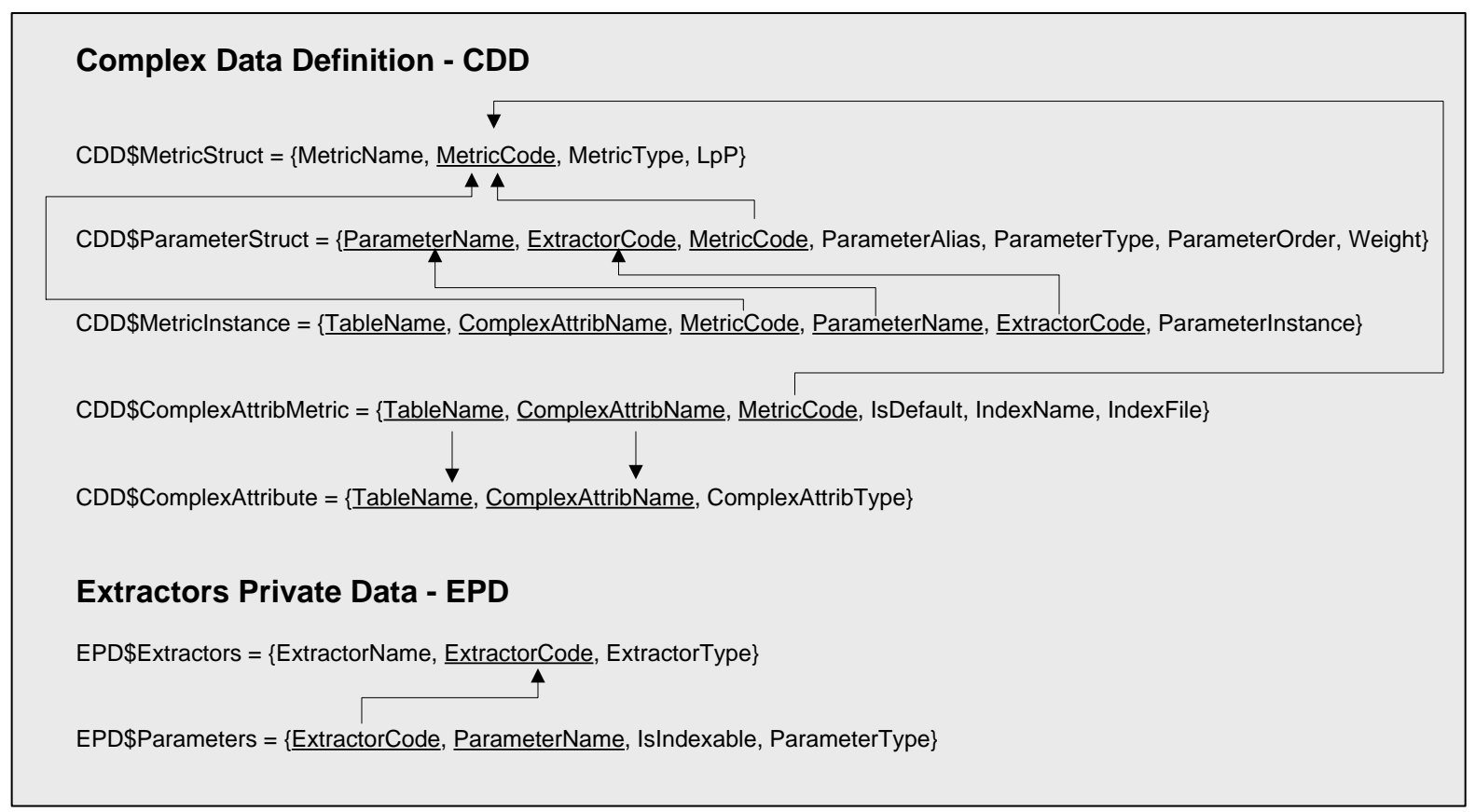

Figura C.3: Modelo Relacional do dicionário de dados do SIREN.

Os comandos para a criação das tabelas do dicionário de dados e as informações referentes aos atributos dessas tabelas são apresentados a seguir:

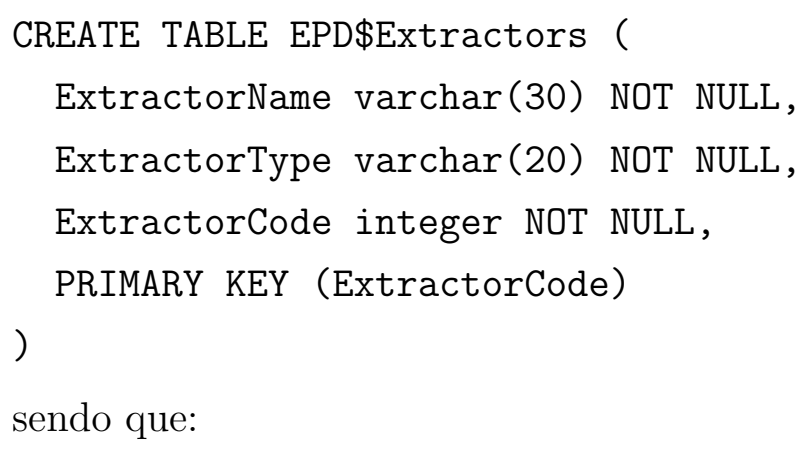

ExtractorName: armazena o nome do extrator de características;

ExtractorType: especifica o tipo de dados suportado pelo extrator de características (STILLIMAGE ou AUDIO);

ExtractorCode: identifica o extrator de características.

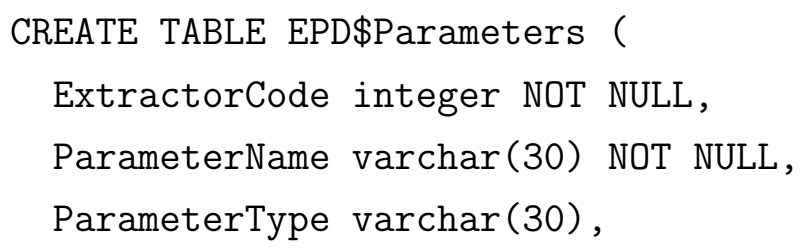




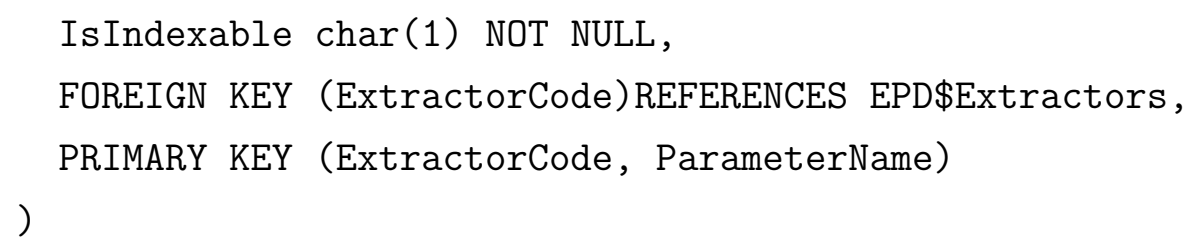


ParameterAlias: armazena o apelido dado ao parâmetro do extrator de características em uma métrica;

ParameterType: especifica o tipo de dados do parâmetro;

ParameterOrder: indica a ordem do parâmetro na métrica;

Weight: armazena o peso do parâmetro no cálculo da distância.

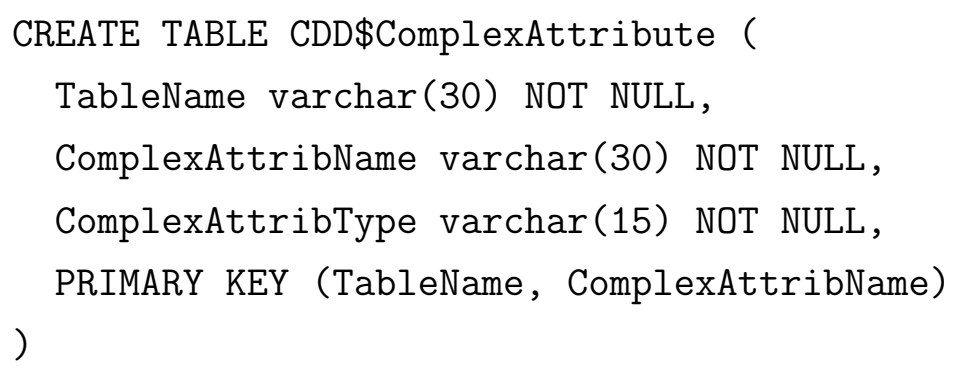

sendo que:

TableName: armazena o nome da tabela do usuário que contém o atributo complexo;

ComplexAttribName: armazena o nome do atributo complexo;

ComplexAttribType: armazena o tipo do atributo complexo (PARTICULATE, STILLIMAGE ou AUDIO).

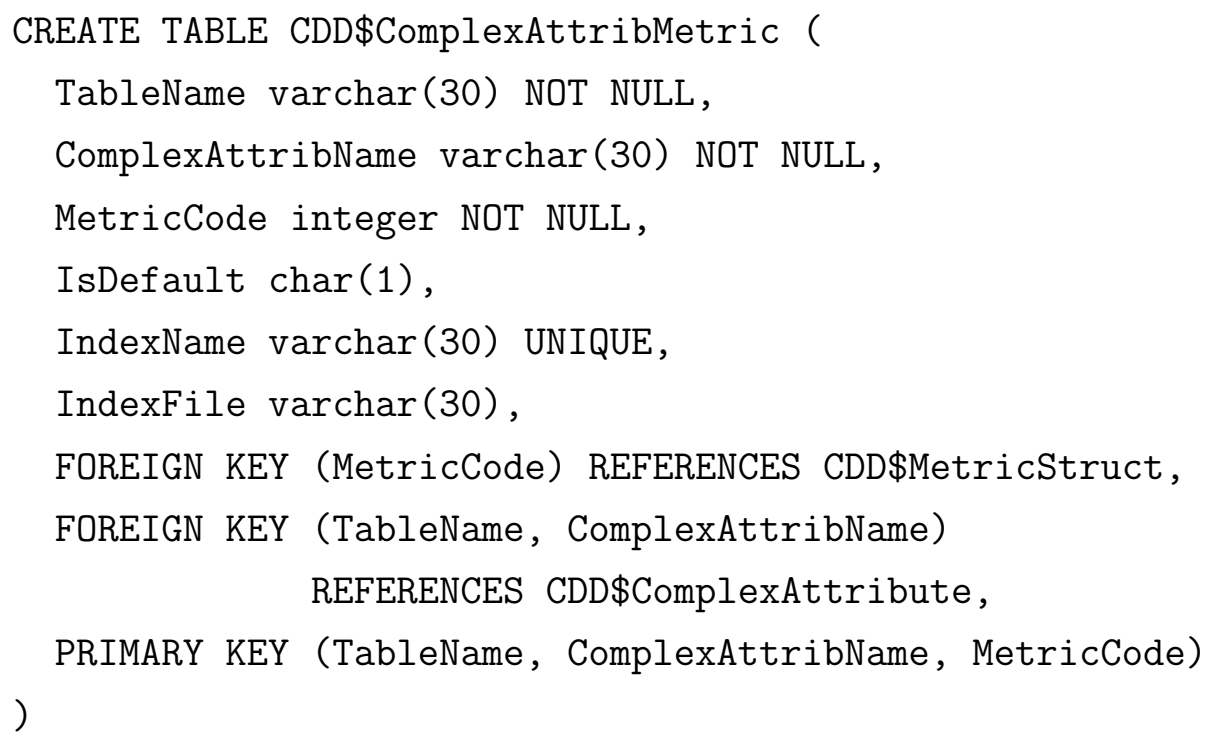

sendo que:

TableName: armazena o nome da tabela que contém o atributo complexo;

ComplexAttribName: armazena o nome do atributo complexo;

MetricCode: identifica a métrica utilizada para a indexação;

IsDefault: especifica se a métrica foi definida como padrão para um determinado atributo complexo;

IndexName: armazena o nome do índice;

IndexFile: armazena o nome do arquivo físico que contém o índice. 


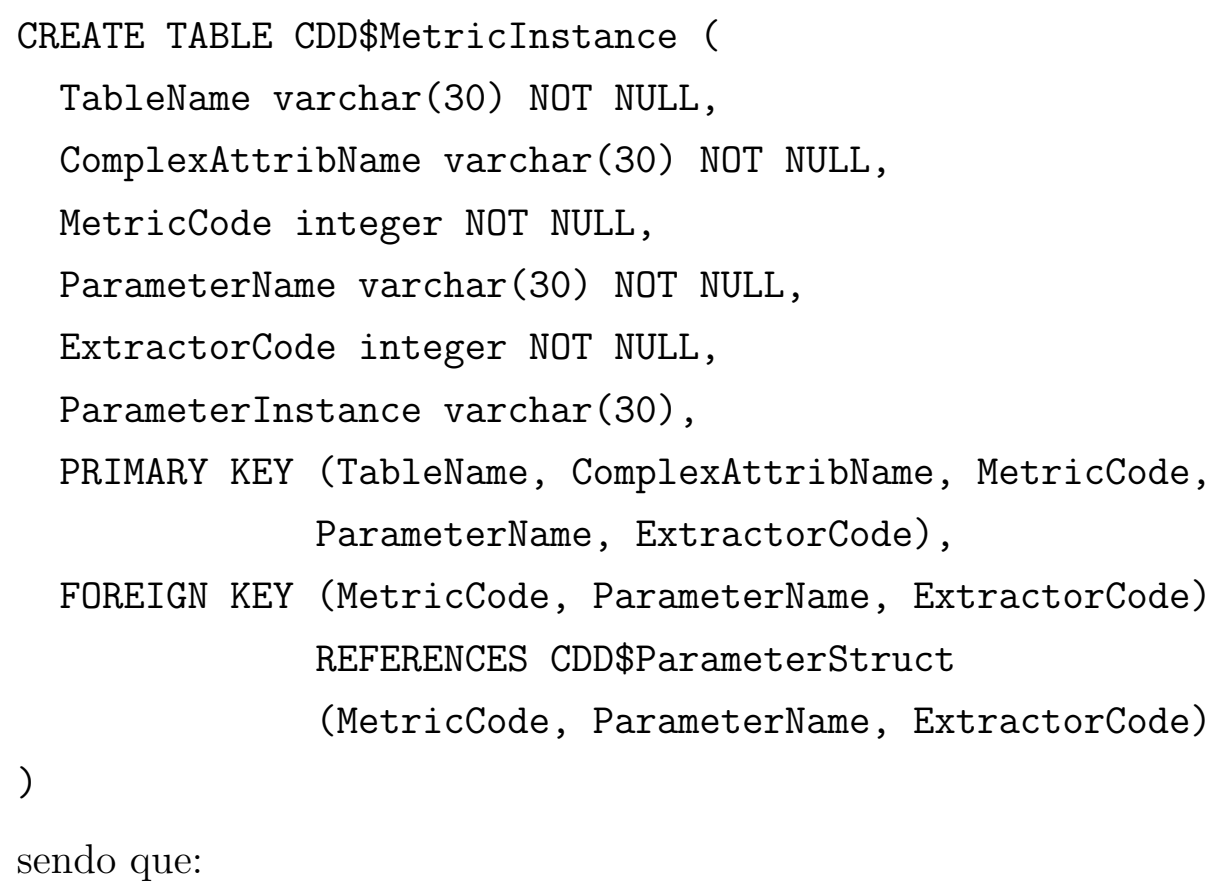

TableName: armazena o nome da tabela que contém o atributo complexo;

ComplexAttribName: armazena o nome do atributo complexo;

MetricCode: identifica a métrica utilizada para a indexação;

ParameterName: armazena o nome do parâmetro (PARTICULATE) ou o nome do parâmetro do extrator de características;

ExtractorCode: identifica o extrator de características;

ParameterInstance: armazena o nome do atributo da tabela TableName relacionado com o parâmetro ParameterName da métrica de código MetricCode (usado apenas para atributos PARTICULATE). 


\section{Referências Bibliográficas}

[Aggarwal et al., 2001] Aggarwal, C. C., Hinneburg, A., e Keim, D. A. (2001). On the surprising behavior of distance metrics in high dimensional space. In 8th International Conference on Database Theory (ICDT), p. 420-434, London, UK.

[Araújo, 2003] Araújo, M. R. B. (2003). Incorporação de suporte à recuperação de imagens baseada em conteúdo em sistemas gerenciadores de banco de dados relacionais. Tese de Doutorado, ICMC/USP, São Carlos, 134 p.

[Aslandogan \& Yu, 1999] Aslandogan, Y. A. e Yu, C. T. (1999). Techniques and systems for image and video retrieval. IEEE Transactions on Knowledge and Data Engineering (TKDE), 11(1):56-63.

[Bach et al., 1996] Bach, J. R., Fuller, C., Gupta, A., Hampapur, A., Horowitz, B., Humphrey, R., Jain, R., e Shu, C. f. (1996). The virage image search engine: An open framework for image management. In 4 th Storage and Retrieval for Image and Video Databases (SPIE), p. 76-87, San Jose, CA, USA.

[Baeza-Yates \& Ribeiro-Neto, 1999] Baeza-Yates, R. e Ribeiro-Neto, B. A. (1999). Modern information retrieval. Addison-Wesley.

[Barioni et al., 2006a] Barioni, M. C. N., Razente, H., Traina, A. J. M., e Traina-Jr, C. (2006a). An efficient approach to scale up k-medoid based algorithms in large databases. In $21^{\circ}$ Simpósio Brasileiro de Banco de Dados (SBBD). A ser publicado, 15 p.

[Barioni et al., 2006b] Barioni, M. C. N., Razente, H., Traina, A. J. M., e Traina-Jr, C. (2006b). Seamlessly integrating similarity queries in SQL. Relatório técnico, ISSN 0103-2569, nro 277, ICMC/USP, São Carlos. 17 p.

[Barioni et al., 2006c] Barioni, M. C. N., Razente, H., Traina, A. J. M., e Traina-Jr, C. (2006c). SIREN: A similarity retrieval engine for complex data. In Demonstration 
Session of the 32nd International Conference on Very Large Data Bases (VLDB). A ser publicado, $4 \mathrm{p}$.

[Barioni et al., 2005a] Barioni, M. C. N., Razente, H., Traina-Jr, C., e Traina, A. J. M. (2005a). Incluindo consultas por similaridade em SQL. In $2^{a}$ Sessão de Demos do $20^{\circ}$ Simpósio Brasileiro de Banco de Dados (SBBD), p. 13-18, Uberlândia, MG, Brasil. SBC.

[Barioni et al., 2005b] Barioni, M. C. N., Razente, H., Traina-Jr, C., e Traina, A. J. M. (2005b). Querying complex objects by similarity in SQL. In $20^{\circ}$ Simpósio Brasileiro de Banco de Dados (SBBD), p. 130-144, Uberlândia, MG, Brasil. SBC.

[Beckmann et al., 1990] Beckmann, N., Kriegel, H.-P., Schneider, R., e Seeger, B. (1990). The $\mathrm{R}^{*}$-Tree: An efficient and robust access method for points and rectangles. In 16th ACM International Conference on Management of Data (SIGMOD), p. 322-331, Atlantic City, USA. ACM Press.

[Berkhin, 2002] Berkhin, P. (2002). Survey of clustering data mining techniques. Technical report, Accrue Software, San Jose, CA, USA. 56 p.

[Böhm et al., 2001] Böhm, C., Berchtold, S., e Keim, D. A. (2001). Searching in highdimensional spaces - index structures for improving the performance of multimedia databases. ACM Computing Surveys, 33(3):322-373.

[Böhm \& Krebs, 2002] Böhm, C. e Krebs, F. (2002). High performance data mining using the nearest neighbor join. In 2nd IEEE International Conference on Data Mining (ICDM), p. 43-50, Maebashi City, Japan. IEEE Computer Society.

[Bozkaya \& Ozsoyoglu, 1999] Bozkaya, T. e Ozsoyoglu, Z. M. (1999). Indexing large metric spaces for similarity search queries. ACM Transactions On Database Systems, 24(3):361-404.

[Bozkaya \& Özsoyoglu, 1997] Bozkaya, T. e Özsoyoglu, M. (1997). Distance-based indexing for high-dimensional metric spaces. In 23rd ACM International Conference on Management of Data (SIGMOD), p. 357-368, Tucson, USA.

[Bradley et al., 1998] Bradley, P. S., Fayyad, U. M., e Reina, C. (1998). Scaling clustering algorithms to large databases. In 4th International Conference on Knowlege Discovery and Data Mining (KDD), p. 9-15, New York City, NY, USA. AAAI Press.

[Breunig et al., 2001] Breunig, M. M., Kriegel, H.-P., Kröger, P., e Sander, J. (2001). Data bubbles: quality preserving performance boosting for hierarchical clustering. SIGMOD Record (ACM Special Interest Group on Management of Data), 30(2):79-90. 
[Brin, 1995] Brin, S. (1995). Near neighbor search in large metric spaces. In 21st International Conference on Very Large Data Bases (VLDB), p. 574-584, Zurich, Switzerland. Morgan Kaufmann.

[Bueno, 2001] Bueno, J. M. (2001). Suporte à recuperação de imagens médicas baseada em conteúdo através de histogramas métricos. Tese de Doutorado, ICMC/USP, São Carlos, 96 p.

[Carey \& Kossmann, 1997] Carey, M. e Kossmann, D. (1997). On saying "enough already!" in SQL. In 23rd ACM International Conference on Management of Data (SIGMOD), p. 219-230, Tucson, USA.

[Carey \& Kossmann, 1998] Carey, M. e Kossmann, D. (1998). Reducing the braking distance of an SQL query engine. In 24th International Conference on Very Large Data Bases (VLDB), p. 158-169, New York City, NY, USA. Morgan Kaufmann.

[Chu et al., 2002] Chu, S.-C., Roddick, J. F., e Pan, J. S. (2002). An efficient k-medoidsbased algorithm using previous medoid index, triangular inequality elimination criteria, and partial distance search. In 4th International Conference on Data Warehousing and Knowledge Discovery (DaWaK), p. 63-72, London, UK. Springer-Verlag.

[Chávez et al., 2001] Chávez, E., Navarro, G., Baeza-Yates, R., e Marroquín, J. L. (2001). Searching in metric spaces. ACM Computing Surveys, 33(3):273-321.

[Ciaccia \& Patella, 2002] Ciaccia, P. e Patella, M. (2002). Searching in metric spaces with user-defined and approximate distances. ACM Transactions on Database Systems, $27(4): 398-437$.

[Ciaccia et al., 1997] Ciaccia, P., Patella, M., e Zezula, P. (1997). M-tree: An efficient access method for similarity search in metric spaces. In 23rd International Conference on Very Large Data Bases (VLDB), p. 426-435, Athens, Greece. Morgan Kaufmann.

[Clear et al., 1999] Clear, J., Dunn, D., Harvey, B., Heytens, M., Lohman, P., Mehta, A., Melton, M., Rohrberg, L., Savasere, A., Wehrmeister, R., e Xu, M. (1999). Nonstop SQL/MX primitives for knowledge discovery. In 5th International Conference on Knowledge Discovery and Data Mining (KDD), p. 425-429, New York City, NY, USA. ACM Press.

[Câmara dos Deputados, 2006] Câmara dos Deputados (2006). Resultado da votação eletrônica e lista de presença. Disponível na url: http://www2.camara .gov.br/plenario/votacao. Em 10/07/2006. 
[Codd, 1970] Codd, E. F. (1970). A relational model of data for large shared data banks. Communications of the ACM, 13(6):377-387. Disponível na url: http://www.acm.org/classics/nov95/toc.html. Em 10/09/2006.

[Datta et al., 2005] Datta, R., Li, J., e Wang, J. Z. (2005). Content-based image retrieval: approaches and trends of the new age. In 7th ACM SIGMM International Workshop on Multimedia Information Retrieval (MIR), p. 253-262, New York City, NY, USA. ACM Press.

[Daubechies, 1990] Daubechies, I. (1990). The wavelet transform, time-frequency localization and signal analysis. IEEE Transactions on Information Theory, 36:961-1005.

[Daugman, 1998] Daugman, J. G. (1998). Complete discrete 2D Gabor transforms by neural networks for image analysis and compression. IEEE Transactions on Acoustics, Speech, and Signal Processing, 36:1169-1179.

[Eisenberg et al., 2003] Eisenberg, A., Melton, J., Kulkarni, K., Michels, J.-E., e Zemke, F. (2003). SQL: 2003 has been published. SIGMOD Record, 33(1):119-126.

[Ester et al., 1995] Ester, M., Kriegel, H.-P., e Xu, X. (1995). Knowledge discovery in large spatial databases: focusing techniques for efficient class identification. In 4th International Symposium on Advances in Spatial Databases, v. 951, p. 67-82, Portland, ME. Springer.

[Fayyad, 1997] Fayyad, U. (1997). Mining databases: Towards algorithms for knowledge discovery. Bulletin of the IEEE Technical committee on Data Engineering, 21:39-48.

[Fayyad et al., 1996] Fayyad, U. M., Piatetsky-Shapiro, G., e Smyth, P. (1996). From data mining to knowledge discovery: An overview. In Advances in Knowledge Discovery and Data Mining, p. 1-34. AAAI/MIT Press.

[Felipe \& Traina, 2002] Felipe, J. C. e Traina, A. J. M. (2002). Utilizando características de textura para identificação de tecidos em imagens médicas. In $2^{\circ}$ Workshop de Informática Médica (WIM), Gramado, RS, Brasil. 4 p. em CDROM.

[Filho et al., 2001] Filho, R. F. S., Traina, A. J. M., Traina-Jr, C., e Faloutsos, C. (2001). Similarity search without tears: The OMNI family of all-purpose access methods. In 17th IEEE International Conference on Data Engineering (ICDE), p. 623-630, Heidelberg, Germany.

[Flickner et al., 1995] Flickner, M., Sawhney, H., Niblack, W., Ashley, J., Huang, Q., Dom, B., Gorkani, M., Hafner, J., Lee, D., Petkovic, D., Steele, D., e P., Y. (1995). Query by image and video content: The QBIC system. IEEE Computer, 28(9):23-32. 
[Foote, 2000] Foote, J. (2000). Arthur: Retrieving orchestral music by long-term structure. In 1st International Symposium on Music Information Retrieval (ISMIR), Plymouth, MA, USA. 6 p.

[Gao et al., 2004] Gao, L., Wang, M., S.W., X., e Padmanabhan, S. (2004). Expressing and optimizing similarity-based queries in SQL. In 23rd International Conference on Conceptual Modeling (ER), v. 3288 of Springer LNCS, p. 464-478, Shanghai, China.

[Garcia-Molina et al., 2002] Garcia-Molina, H., Ullman, J. D., e Widom, J. (2002). Database systems: The complete book. Prentice Hall, Upper Saddle River, New Jersey.

[GBDI-ICMC-USP, 2006a] GBDI-ICMC-USP (2006a). GBDI Arboretum Library. http://gbdi.icmc.usp.br/arboretum/.

[GBDI-ICMC-USP, 2006b] GBDI-ICMC-USP (2006b). Similarity Retrieval Engine - SIREN. http://gbdi.icmc.usp.br/siren/.

[Gehrke et al., 1998] Gehrke, J., Ramakrishnan, R., e Ganti, V. (1998). Rainforest - a framework for fast decision tree construction of large datasets. In 24th International Conference on Very Large Data Bases (VLDB), p. 416-427, New York City, NY, USA.

[Ghias et al., 1995] Ghias, A., Logan, J., Chamberlin, D., e Smith, B. (1995). Query by humming: Musical information retrieval in an audio database. In ACM International Conference on Multimedia, p. 213-236.

[Graefe et al., 1998] Graefe, G., Fayyad, U. M., e Chaudhuri, S. (1998). On the efficient gathering of sufficient statistics for classification from large SQL databases. In 4th International Conference on Knowledge Discovery and Data Mining (KDD), p. 204208, New York City, NY, USA.

[Gudivada \& Raghavan, 1995] Gudivada, V. N. e Raghavan, V. V. (1995). Content-based image retrieval systems. IEEE Computer, 28(9):18-22.

[Han \& Kamber, 2001] Han, J. e Kamber, M. (2001). Data mining: Concepts and techniques. Academic Press, San Diego, USA.

[Hand et al., 2001] Hand, D. J., Mannila, H., e Smyth, P. (2001). Principles of data mining. MIT Press, Cambridge, MA.

[Haralick et al., 1973] Haralick, R. M., Shanmugarn, K., e Dinstein, I. (1973). Texture features for image classification. IEEE Transactions on Systems, Man, and Cybernetics, $3(6): 610-621$. 
[Hu et al., 2003] Hu, N., Dannenberg, R. B., e Tzanetakis, G. (2003). Polyphonic audio matching and alignment for music retrieval. In IEEE Workshop on Applications of Signal Processing to Audio and Acoustics (WASPAA), p. 185-188.

[Huang et al., 1997] Huang, J., Kumar, S. R., Mitra, M., Zhu, W.-J., e Zabih, R. (1997). Image indexing using color correlogram. In IEEE International Conference on Computer Vision and Pattern Recognition, p. 762-768, Puerto Rico.

[Hunt et al., 1980] Hunt, M., Lennig, M., e Mermelstein, P. (1980). Experiments in syllable-based recognition of continuous speech. In IEEE International Conference on Acoustics, Speech, and Signal Processing (ICASSP), v. 5, p. 880-883.

[IBGE, 2006] IBGE (2006). Coordenadas geográficas das cidades brasileiras. http://www.ibge.gov.br, acessado em 07/08/2006.

[IBMCorporation, 2003] IBMCorporation (2003). Image, audio, and video extenders administration and programming guide. DB2 Universal Database Version 8, 550 p. Disponível na url: http://www.ibm.com/db2. Em 07/06/2006.

[Imielinski \& Virmani, 1999] Imielinski, T. e Virmani, A. (1999). MSQL: A query language for database mining. Data Mining and Knowledge Discovery, 3(4):373-408.

[Jain et al., 1999] Jain, A., Murty, M., e Flynn, P. (1999). Data clustering: A review. ACM Computing Surveys, 31(3):264-323.

[Jamil, 2001] Jamil, H. M. (2001). Ad hoc association rule mining as SQL3 queries. In 1st IEEE International Conference on Data Mining (ICDM), p. 609-612, San Jose, CA, USA.

[Kamila et al., 2005] Kamila, N., Mahapatra, S., e Nanda, S. (2005). Invariance image analysis using modified zernike moments. Pattern Recognition Letters, 26(6):747-753.

[Kaufman \& Rousseeuw, 2005] Kaufman, L. e Rousseeuw, P. J. (2005). Finding groups in data: An introduction to cluster analysis. John Wiley and Sons.

[Kruskal, 1956] Kruskal, J. (1956). On the shortest spanning subtree of a graph and the travelling salesman problem. In American Mathematical Society, v. 7, p. 48-50.

[Levenshtein, 1966] Levenshtein, V. (1966). Binary codes capable of correcting deletions, insertions, and reversals. Cybernetics and Control Theory, 10(8):707-710.

[Long et al., 2002] Long, F., Zhang, H., e Feng, D. D. (2002). Fundamentals of contentbased image retrieval. In Multimedia Information Retrieval and Management - Technological Fundamentals and Applications. Springer. 
[Ma \& Manjunath, 1995] Ma, W. Y. e Manjunath, B. S. (1995). A comparison of wavelet transform features for texture image annotation. In 2nd IEEE International Conference on Image Processing (ICIP), v. 2, p. 23-26, Washington, USA.

[Mehrotra et al., 1997] Mehrotra, S., Rui, Y., Chakrabarti, K., Ortega, M., e Thomas, S. H. (1997). Multimedia analysis and retrieval system. In 3rd International Workshop on Information Retrieval Systems, p. 39-45, Italy.

[Melton \& Eisenberg, 2001] Melton, J. e Eisenberg, A. (2001). SQL Multimedia and Application Packages (SQL/MM). SIGMOD Record, 30:97-102.

[Meo et al., 1996] Meo, R., Psaila, G., e Ceri, S. (1996). A new SQL-like operator for mining association rules. In 22nd International Conference on Very Large Data Bases (VLDB), p. 122-133, Bombay, India.

[Meo et al., 1998] Meo, R., Psaila, G., e Ceri, S. (1998). An extension to SQL for mining association rules. Data Mining and Knowledge Discovery, 2(2):195-224.

[Netz et al., 2000] Netz, A., Chaudhuri, S., Bernhardt, J., e Fayyad, U. M. (2000). Integration of data mining with database technology. In 26th International Conference on Very Large Data Bases (VLDB), p. 719-722, Cairo, Egypt. Morgan Kaufmann.

[Netz et al., 2001] Netz, A., Chaudhuri, S., Fayyad, U. M., e Bernhardt, J. (2001). Integrating data mining with SQL databases: Ole db for data mining. In 17 th International Conference on Data Engineering (ICDE), p. 379-387, Heidelberg, Germany. IEEE Computer Society.

[Ng \& Han, 1994] Ng, R. T. e Han, J. (1994). Efficient and effective clustering methods for spatial data mining. In 20th International Conference on Very Large Data Bases (VLDB), p. 144-155, Santiago, Chile. Morgan Kaufmann.

[Ng \& Han, 2002] Ng, R. T. e Han, J. (2002). Clarans: A method for clustering objects for spatial data mining. IEEE Transactions on Knowledge and Data Engineering (TKDE), 14(5):1003-1016.

[Ohanian \& Dubes, 1992] Ohanian, P. P. e Dubes, R. C. (1992). Performance evaluation for four classes of texture features. Pattern Recognition, 25(8):819-833.

[OracleCorporation, 2005] OracleCorporation (2005). Oracle intermedia user's guide. Oracle Database 10g Release 2 Documentation Library, 254 p. Disponível na url: http://www.oracle.com/. Em 07/06/2006.

[Ordonez, 2006] Ordonez, C. (2006). Integrating k-means clustering with a relational dbms using SQL. IEEE Transactions on Knowledge and Data Engineering (TKDE), 18(2):188-201. 
[Ordonez \& Cereghini, 2000] Ordonez, C. e Cereghini, P. (2000). SQLEM: fast clustering in SQL using the EM algorithm. In 26th ACM International Conference on Management of Data (SIGMOD), p. 559-570, Dallas, USA.

[Papadias et al., 2005] Papadias, D., Tao, Y., Mouratidis, K., e Hui, C. K. (2005). Aggregate nearest neighbor queries in spatial databases. ACM Transactions on Database Systems, 30(2):529-576.

[Pass \& Zabith, 1996] Pass, G. e Zabith, R. (1996). Histogram refinement for contentbased image retrieval. In IEEE Workshop on Applications of Computer Vision, p. 96-102.

[Pavlidis, 1978] Pavlidis, T. (1978). A review of algorithms for shape analysis. Computer Graphics and Image Processing, 7:243-258.

[Pentland et al., 1994] Pentland, A., Picard, R., e Sclaroff, S. (1994). Photobook: Tools for content-based manipulation of image databases. In 2nd Storage and Retrieval of Image and Video Databases (SPIE), p. 34-47, San Jose, CA, USA.

[Rabiner \& Schafer, 1978] Rabiner, L. R. e Schafer, R. W. (1978). Digital Processing of Speech Signals. Prentice-Hall, New Jersey.

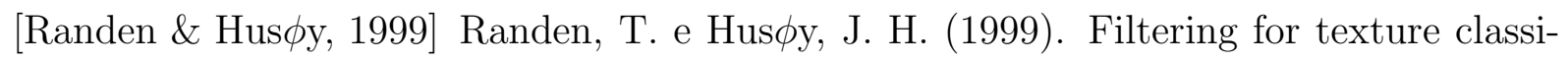
fication: A comparative study. IEEE Transactions on Pattern Analysis and Machine Intelligence, 21(4):291-310.

[Revista Quatro Rodas, 2005] Revista Quatro Rodas (2005). Resumo dos Testes. Editora Abril. http://quatrorodas.abril. com.br/carros/resumo/index.shtml, acessado em $28 / 06 / 2005$.

[Rezende, 2003] Rezende, S. O. (2003). Sistemas inteligentes: Fundamentos e aplicações. Manole, Barueri, SP.

[Rui et al., 1997] Rui, Y., Huang, T. S., e Chang, S.-F. (1997). Image retrieval: Past, present, and future. In International Symposium on Multimedia Information Processing, Taiwan.

[Salton \& McGill, 1983] Salton, G. e McGill, M. J. (1983). Introduction to modern information retrieval. McGraw-Hill Book Company.

[Sarawagi et al., 1998] Sarawagi, S., Thomas, S., e Agrawal, R. (1998). Integrating mining with relational database systems: Alternatives and implications. In 24th ACM International Conference on Management of Data (SIGMOD), p. 343-354, Seattle, USA. ACM Press. 
[Sattler \& Dunemann, 2001] Sattler, K. e Dunemann, O. (2001). SQL database primitives for decision tree classifiers. In 10th ACM International Conference on Information and Knowledge Management (CIKM), p. 379-386, Atlanta, USA.

[Seraphim, 2005] Seraphim, E. (2005). Operadores binários para consulta de similaridade em banco de dados multimídia. Tese de Doutorado, ICMC/USP, São Carlos, 130 p.

[Singh \& Singh, 2002] Singh, M. e Singh, S. (2002). Spatial texture analysis: A comparative study. In 16th International Conference on Pattern Recognition (ICPR), v. 1, Quebec, Canada. IEEE.

[Smeulders et al., 2000] Smeulders, A. W. M., Worring, M., Santini, S., Gupta, A., e Jain, R. (2000). Content-based image retrieval at the end of the early years. IEEE Transactions on Pattern Analysis and Machine Intelligence, 22(12):1349-1380.

[Smith \& Chang, 1996] Smith, J. R. e Chang, S. F. (1996). VisualSEEK: A fully automated content-based image query system. In 4th ACM International Conference on Multimedia, p. 87-98, Boston, MA.

[Sonka et al., 1999] Sonka, M., Hlavac, V., e Boyle, R. (1999). Image processing, analysis and machine vision. PWS publishing, San Francisco.

[Stehling et al., 2003] Stehling, R. O., Nascimento, M. A., e Falcão, A. X. (2003). Cell histograms versus color histograms for image representation and retrieval. Knowledge and Information Systems, 5(3):315-336.

[Swain \& Ballard, 1991] Swain, M. J. e Ballard, D. H. (1991). Color indexing. International Journal of Computer Vision, 7(1):11-32.

[Traina, 2001] Traina, A. J. M. (2001). Suporte à visualização de consultas por similaridade em imagens médicas através de estruturas de indexação métricas. Tese de Livre-Docência em Computação, ICMC/USP, São Carlos, 104 p.

[Traina et al., 2002a] Traina, A. J. M., Traina, Caetano, J., Bueno, J. M., e Marques, P. M. d. A. (2002a). The metric histogram: A new and efficient approach for contentbased image retrieval. In 6th IFIP Working Conference on Visual Database Systems, v. 216, p. 297-311, Brisbane, Australia. Kluwer Academic Publishers.

[Traina \& Traina-Jr., 2003] Traina, A. J. M. e Traina-Jr., C. (2003). Similarity search in multimedia databases. In Handbook of video databases: design and applications, v. 1, p. 711-738. CRC Press.

[Traina et al., 2002b] Traina, Caetano, J., Traina, A. J. M., Santos Filho, R. F., e Faloutsos, C. (2002b). How to improve the pruning ability of dynamic metric access methods. 
In 11st ACM International Conference on Information and Knowledge Management (CIKM), p. 219-226, McLean, USA.

[Traina et al., 2000] Traina, Caetano, J., Traina, A. J. M., Seeger, B., e Faloutsos, C. (2000). Slim-Trees: High performance metric trees minimizing overlap between nodes. In 7th IEEE International Conference on Extending Database Technology (EDBT), p. 51-65, Konstanz, Germany.

[Traina-Jr. et al., 2002] Traina-Jr., C., Traina, A. J. M., Faloutsos, C., e Seeger, B. (2002). Fast indexing and visualization of metric datasets using Slim-trees. IEEE Transactions on Knowledge and Data Engineering (TKDE), 14(2):244-260.

[Tuceryan \& Jain, 1998] Tuceryan, M. e Jain, A. (1998). Texture analysis. In HPRCV: Handbook of Pattern Recognition and Computer Vision, p. 235-276, Singapore. World Scientific.

[Typke et al., 2005] Typke, R., Wiering, F., e Veltkamp, R. C. (2005). A survey of music information retrieval systems. In 6th International Conference on Music Information Retrieval (ISMIR), p. 153-160, London, UK.

[Tzanetakis, 2001] Tzanetakis, G. (2001). Automatic musical genre classification of audio signals. In 2nd International Symposium on Music Information Retrieval (ISMIR), p. 205-210, Bloomington, Indiana, USA.

[Tzanetakis, 2002] Tzanetakis, G. (2002). Manipulation, analysis and retrieval systems for audio signals. Tese de Doutorado, Faculty of Princeton University, Princeton - NJ USA, 184 p. Disponível na url: http://www.cs.uvic.ca/gtzan/work/publications.html. Em 04/06/2006.

[Tzanetakis \& Cook, 2000] Tzanetakis, G. e Cook, P. (2000). Audio information retrieval (AIR) tools. In 1st International Symposium on Music Information Retrieval (ISMIR), Plymouth, MA, USA. 6 p.

[Tzanetakis et al., 2002] Tzanetakis, G., Ermolinskiy, A., e Cook, P. R. (2002). Pitch histograms in audio and symbolic music information retrieval. In 3rd International Symposium on Music Information Retrieval (ISMIR), p. 31-38, Paris, France.

[Uhlmann, 1991] Uhlmann, J. K. (1991). Satisfying general proximity/similarity queries with metric trees. Information Processing Letters, 40(4):175-179.

[Veltkamp \& Tanase, 2000] Veltkamp, R. C. e Tanase, M. (2000). Content-based image retrieval systems: A survey. Technical Report UU-CS-2000-34, Utrecht University, Department of Computer Science. 
[Vieira et al., 2004] Vieira, M. R., Chino, C. T.-J. F., e Traina, A. J. M. (2004). Dbmtree: A metric access method sensitive to local density data. In $19^{\circ}$ Simpósio Brasileiro de Banco de Dados (SBBD), p. 163-177, Brasília, DF, Brasil. SBC.

[Wang et al., 2003] Wang, H., Zaniolo, C., e Luo, C. R. (2003). Atlas: a small but complete SQL extension for data mining and data streams. In 29th International Conference on Very Large Data Bases (VLDB), p. 1113-1116, Berlin, Germany.

[Wilson \& Martinez, 1997] Wilson, D. R. e Martinez, T. R. (1997). Improved heterogeneous distance functions. Journal of Artificial Intelligence Research, 6:1-34.

[Wold et al., 1996] Wold, E., Blum, T., Keislar, D., e Wheaton, J. (1996). Content-based classification, search and retrieval of audio. IEEE Multimedia, 3(2):27-36.

[Yianilos, 1993] Yianilos, P. N. (1993). Data structures and algorithms for nearest neighbor search in general metric spaces. In 4th ACM-SIAM Symposium on Discrete Algorithms (SODA), p. 311-321, Austin, USA.

[Zhang \& Lu, 2001] Zhang, D. e Lu, G. (2001). Content-based shape retrieval using different shape descriptors: A comparative study. In IEEE International Conference on Multimedia and Expo (ICME), p. 317-320, Tokyo, Japan. IEEE Computer Society.

[Zhang \& Couloigner, 2005] Zhang, Q. e Couloigner, I. (2005). A new and efficient kmedoid algorithm for spatial clustering. In International Conference on Computational Science and Its Applications, v. 3482 of LNCS, p. 181-189, Singapore. Springer-Verlag.

[Zhang et al., 1996] Zhang, T., Ramakrishnan, R., e Livny, M. (1996). Birch: An efficient data clustering method for very large databases. In 22nd ACM International Conference on Management of Data (SIGMOD), p. 103-114, Montreal, Canada. ACM. 